\title{
SNAP REACTOR PROGRAMS
}

PROGRESS REPORT

MAY-JULY 1970

(Title Unclassified)

AEC Research and Development Report
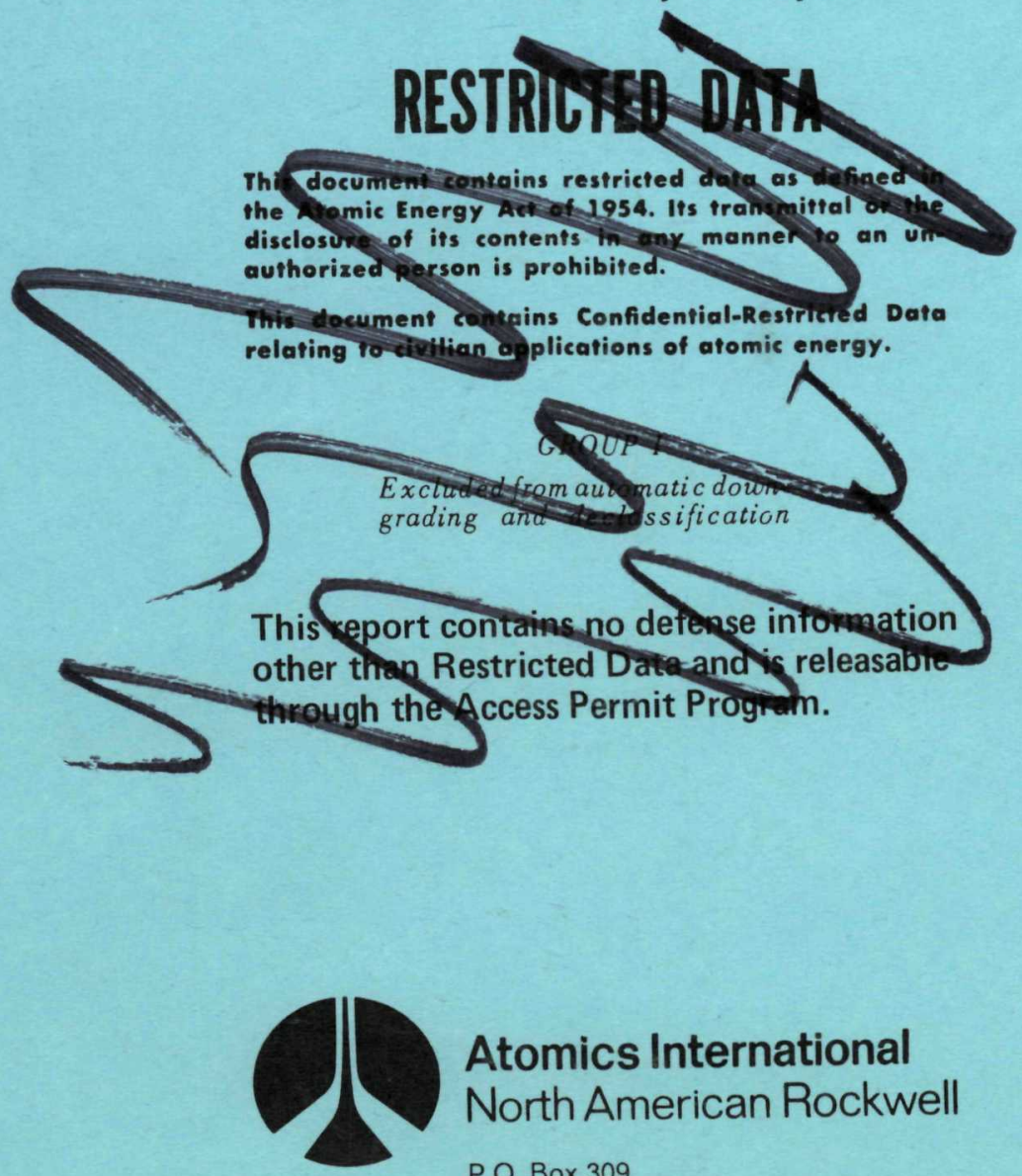

Atomics International

North American Rockwell

P.O. Box 309

Canoga Park, California 91304 


\section{DISCLAIMER}

This report was prepared as an account of work sponsored by an agency of the United States Government. Neither the United States Government nor any agency Thereof, nor any of their employees, makes any warranty, express or implied, or assumes any legal liability or responsibility for the accuracy, completeness, or usefulness of any information, apparatus, product, or process disclosed, or represents that its use would not infringe privately owned rights. Reference herein to any specific commercial product, process, or service by trade name, trademark, manufacturer, or otherwise does not necessarily constitute or imply its endorsement, recommendation, or favoring by the United States Government or any agency thereof. The views and opinions of authors expressed herein do not necessarily state or reflect those of the United States Government or any agency thereof. 


\section{DISCLAIMER}

Portions of this document may be illegible in electronic image products. Images are produced from the best available original document. 


\section{LEGAL NOTICE}

This report was prepared as an account of work sponsored by the United States Government. Neither the United States nor the United States Atomic Energy Commission, nor any of their employees, nor any of their contractors, subcontractors, or their employees, makes any warranty, express or implied, or assumes any legal liability or responsibility for the accuracy, completeness or usefulness of any information, apparatus, product or process disclosed, or represents that its use would not infringe privately owned rights.

U.S. Atomic Energy Commission,

Division of Technical Information Extension,

P. 0. Box 62

Oak Ridge, Tennessee.

Please direct to the same address inquiries covering the procurement of other classified AEC reports. 


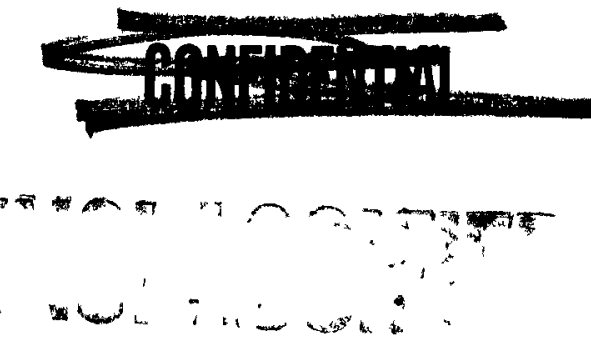

Al-AEC-12975 SNAP REACTOR SNAP PROGRAM M-3679 (63rd Ed.)

\section{SNAP REACTOR PROGRAMS}

PROGRESS REPORT

MAY-JULY 1970

(Title Unclassified)
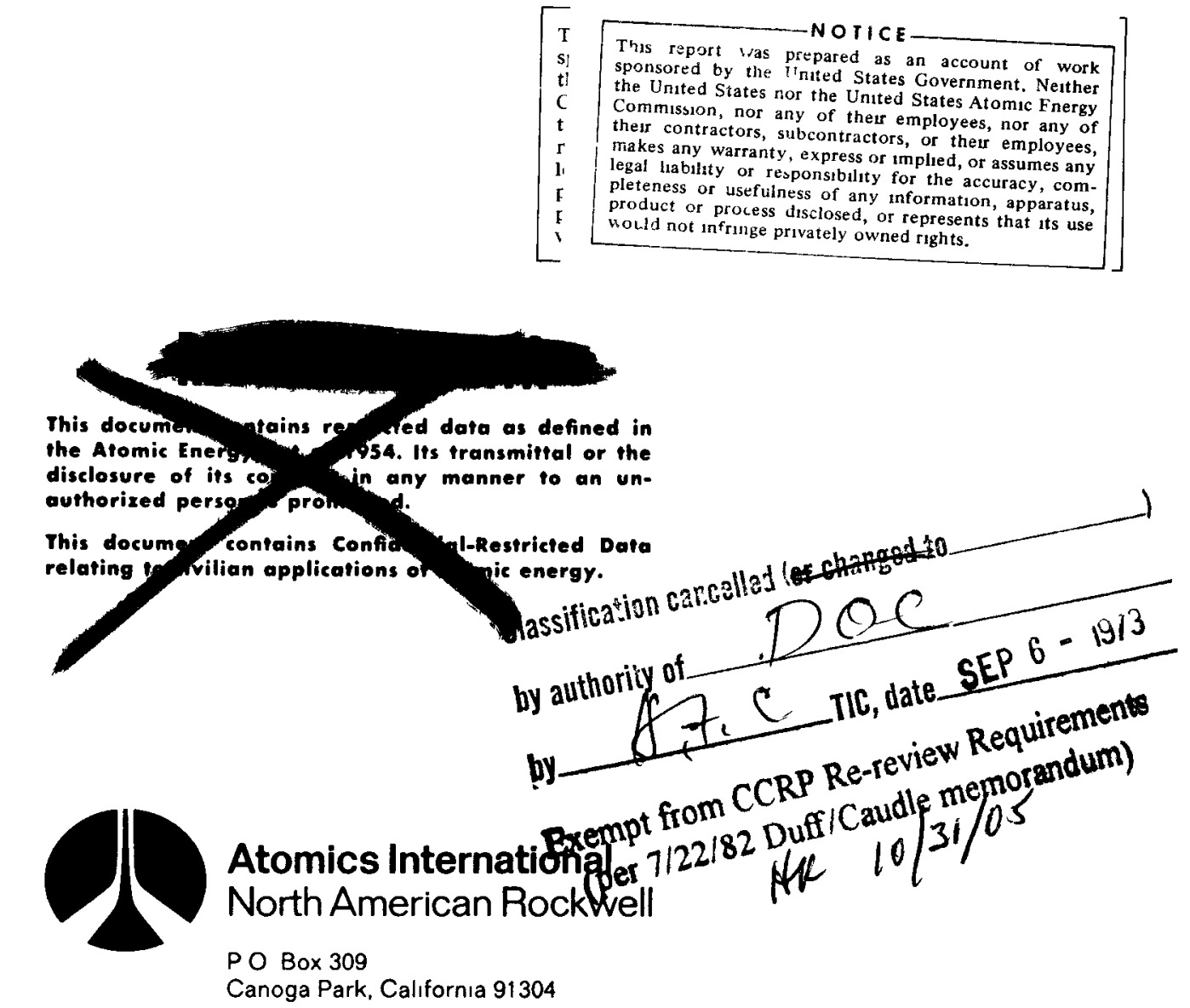


\section{DISTRIBUTION}

\section{SYSTEMS FOR NUCLEAR AUXILIARY POWER (SNAP) REACTOR-SNAP PROGRAM $M-3679$ (63d Ed.)}

No. of

Copies

A EC Albuquerque Operations Office

A EC California Patent Group

A FC Chicago Patent Group

A E:C Library, Washington

A EC New York Operations Office

AFC Patent Office

AFC SNAP Project Office

Aerojet-General Corporation (NASA)

Aerojet-General Corporation,

Sacramento (AEC)

Aerospace Corporation, Los Angeles (AF)

Air Force Air University Library

Air Force Headquarters

Alr Force Strategic Air Command

Air Force Technical Applications

Center

Alr Force Weapons Laboratory

Argonne National Laboratory (AEC)

Army Engineer Reactors Group

Army White Sands Missile Range

ARO, Inc. (AF)

Battelle Memorial Institute (AEC)

Batt:1l(-Northwest (AEC)

Bellcomm, Incorporated (NASA)

Bendix Corporation (NASA)

Brookhaven National Laboratory (AEC)

Central Intelligence Agency

Donald W. Douglas Laboratories (AEC)

DuPont Company, Aiken (AEC)

DuPont Company, Wilmington (AEC)

General Dynamics/Fort Worth (AF)

General Electric Company (AEG) (NASA)

General Electric Company, Cincinnati (AEC)

General Electric Company, MSD (AFC)

General Electric Company, San Jose (A EC)

Gulf General Atomic Incorporated (A EC)

Institute for Defense Analyses (ARPA)

Jet Propulsion Laboratory (NASA)

Lawrence Radiation Laboratory, Livermore (AEC)

Lockheed-Georgia Company (NASA)

Los Alamos Scientific Laboratory (AEC)

Minnesota Mining and Manufacturing

Company (AEC)

Mound Laboratory (AEC)

NASA Goddard Space Flight Center

NASA Langley Research Center

NASA Lewis Research Center

NASA Marshall Space Flight Center

NASA. Washington

National Reactor Te'sting Station (INC) (AEC)

Navy Facilities Engineering Command

Navy Office of the Chief of Naval

Operations

Navy Ordnance Laboratory

Navy Ordnance Systems Command

Navy Research Laboratory

Navy Ship Research \& Dévelopment Lab.

Navy Ship Systems Command

Headquarters

Navy Space Systems Activity

Oak Ridge National Laboratory (AEC)

Radio Corporation of America (AEC)

Rand Corporation (AF)

Sandia Corporation, Albuquerque

(AEC)

Sandia Corporation, ARPIC (AEC)

Weiner Associates. Inc. (Navy)

Westinghouse Electric Corporation, Lima (NASA)

Westinghouse Electric Corporation. WAL (AEC)

A EC Division of Technical Information Extension

No. of

Copies

I Engineering Data (Includes 2 copies to AEC-SNAP Project Office, 2 copies to SAN, 2 copies to C. E. Johnson, l copy to W. L. Kitterman, 1 copy to Joseph Kenney (WAL).

1 copy to George P. Dix, and

1 copy to AEC-WASH 
I. Introduction $\ldots \ldots \ldots \ldots 11$

A. Program Scope and Objectives ................ 11

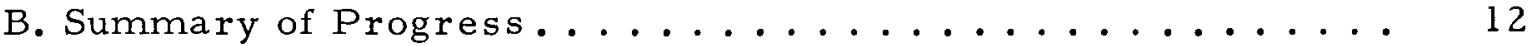

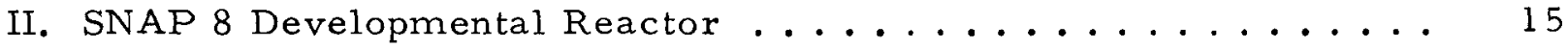

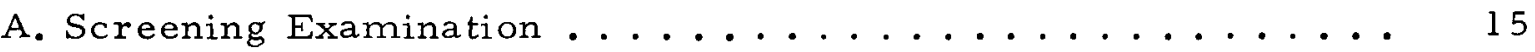

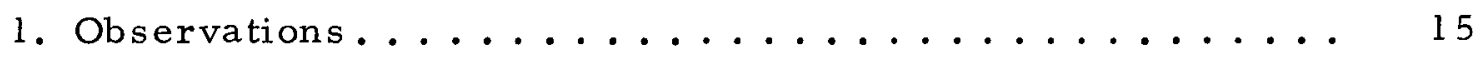

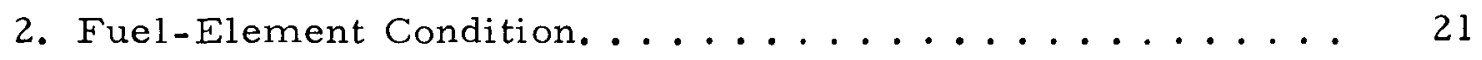

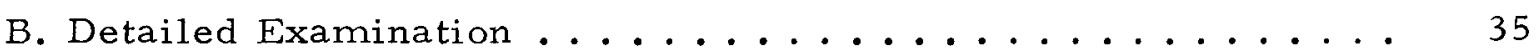

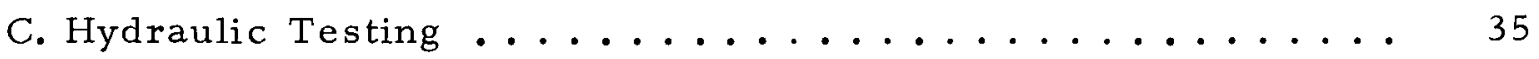

III. Reference Zirconium Hydride Reactor Engineering . . . . . . . 37

A. Introduction and Summary ................. 37

B. Core Thermal/Hydraulic Analysis .............. 37

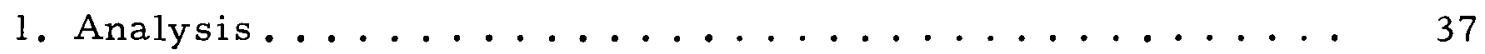

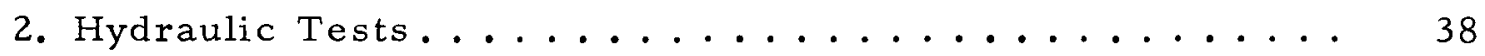

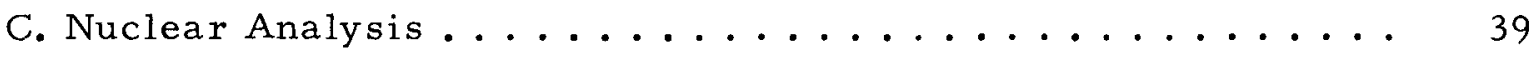

IV. Reactor-Thermoelectric System Engineering . . . . . . . . . 47

V. Thermoelectric Converter Development............. 51

A. Reactor Tubular Power Modules................. 51

1. Performance Data ........................ 51

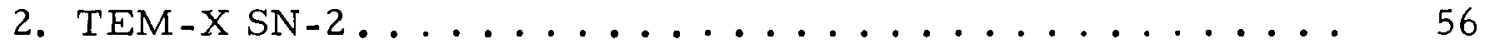

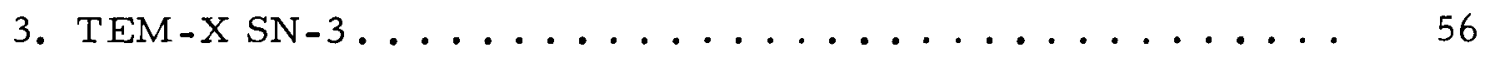

B. Pump Tubular Power Modules ................ 61

1. Performance Summary of Prototype Pump Modules . . . . . 61

C. Supporting Technology Development. .............. 62

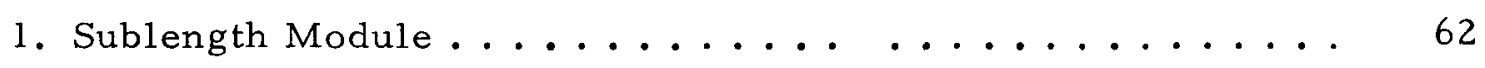

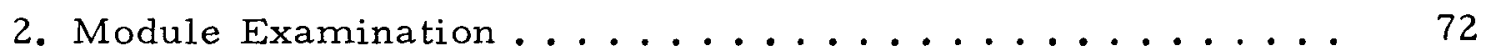

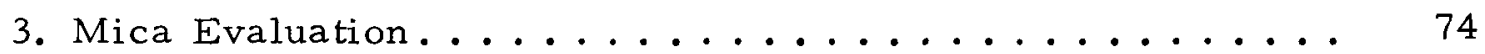

4. Improved Thermoelectric Materials ............. 74

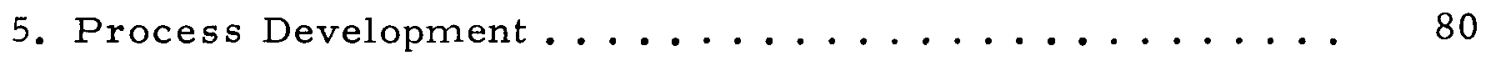

VI. Component Development ..................... 81

A. Introduction and Summary ................. 81

B. Fuel-Element Heat-Transfer Studies . . . . . . . . . . . 82 
C. Fuel-Element and Core Hydraulics ............... 85

1. S8DR Core Hydraulic Studies .................. 85

2. Zirconium Hydride Reactor Core Hydraulic Studies . . . . . 87

D. Control-Drum Actuator................... 93

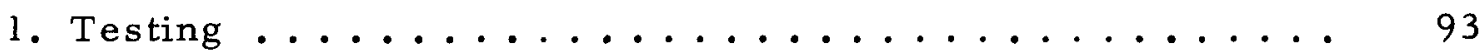

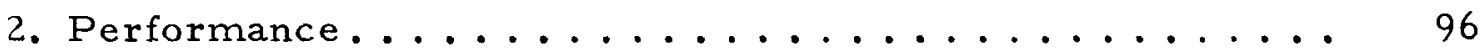

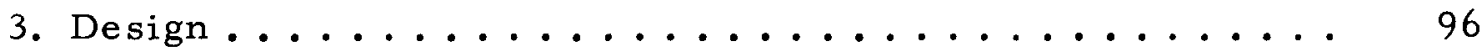

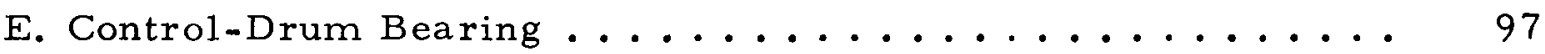

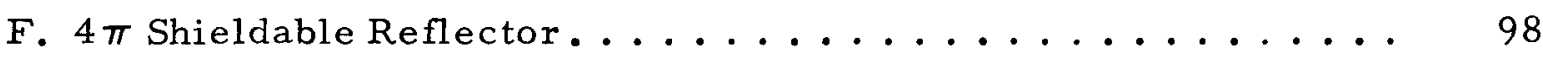

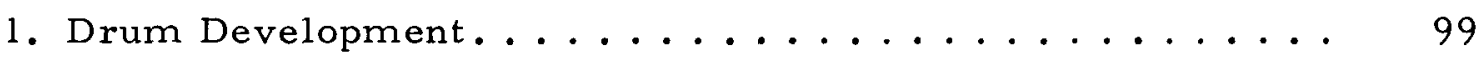

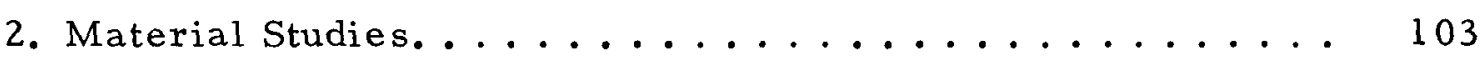

G. Control-Drum Drive System ................ 111

H. Shield Design and Fabrication ................ 114

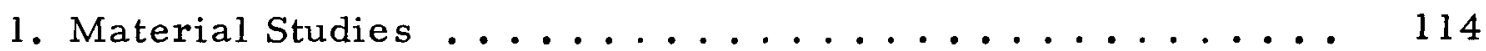

2. Design and Fabrication Development........... 120

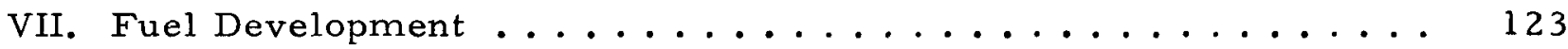

A. Fuel-Element Materials Evaluation.............. 123

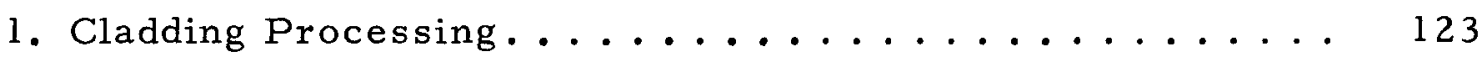

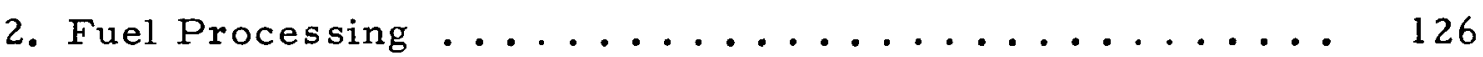

3. Fuel-Element Assembly and Test............. 127

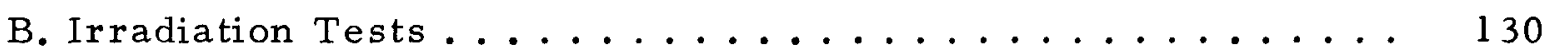

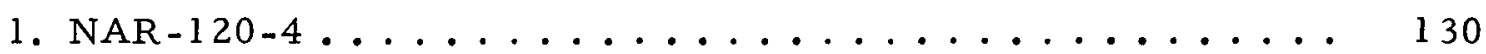

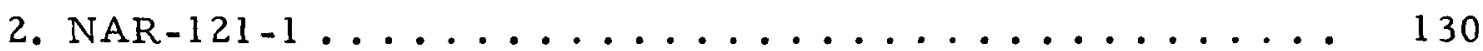

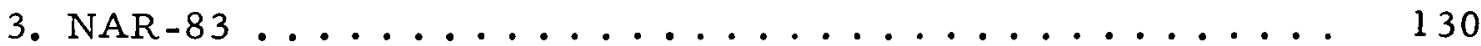

VIII. Aerospace Safety......................... 137

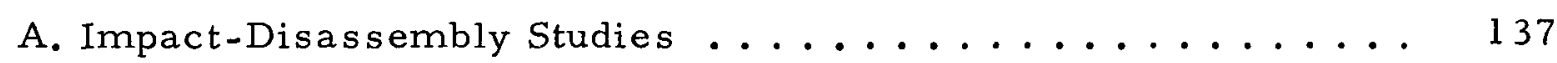

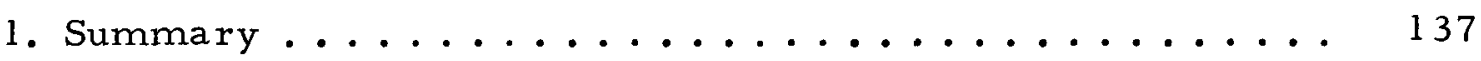

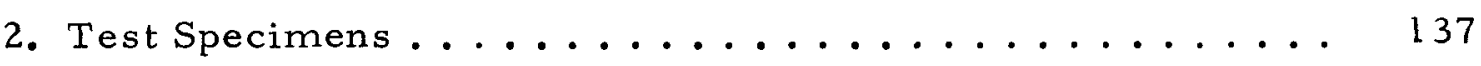

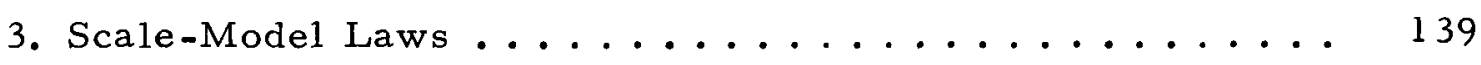

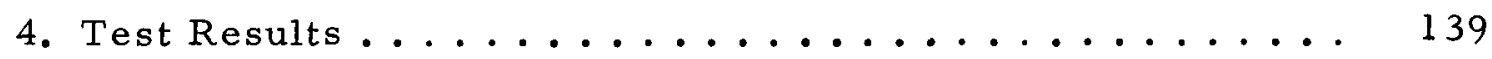

B. Intrinsic Subcriticality ................. 155

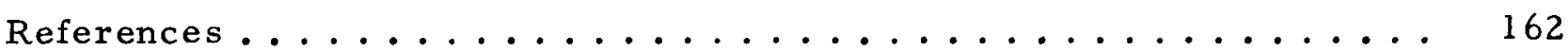


II-1. SNAP 8 Developmental Reactor Screening - Examination

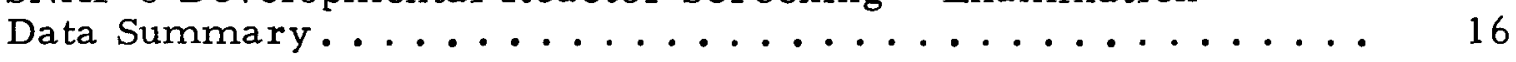

II-2. Film Analysis ....................... 19

IV-1. Reactor-Thermoelectric System NaK Basic Radiator, Organic Supplemental Radiator.................

V-1. Comparison of TEM-15 Module Beginning-of-Life Test Results with Calculated Parameters for $\overline{\mathrm{T}}_{\mathrm{H}}=1125^{\circ} \mathrm{F}$ and

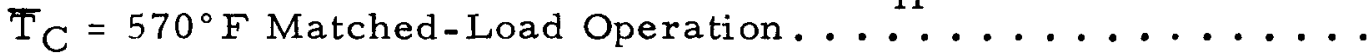

V-2. TEM-15 Performance-Analysis Summary ........... 71

V-3. Excess Tellurium, Sodium Compositions ............ 75

VI-1. Total Normal Emittance of UOX + 0.5 MgO Grade BeO ...... 104

VI-2. Total Normal Emittance of Boron Carbide ........... 105

VI-3. Types of Coating Proof-Test Samples Tested ......... 106

VI-4. Depth of Decarburization of 1020 Carbon Steel ........ 116

VI-5. Depth of Decarburization of Croloy 2-1/4 Steel ........ 118

VII-1. Ingot Chemistry: Three New Heats of Incoloy-800 Double Vacuum-Melted (units in wt $\%$ ) ............. 125

\section{FIGURES}

II-1. SNAP 8 Developmentaí Reactor Screening - Examination

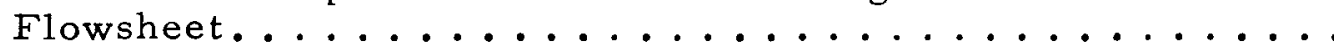

II-2. Inlet-Plenum Components After Removal and Before

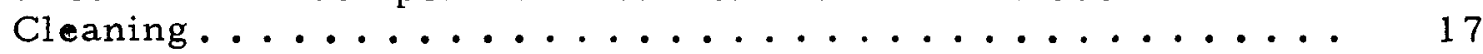

II-3. Inlet-Plenum Components After Cleaning . . . . . . . . 18

II-4. Typical Appearance of Metallic Film Deposit (outlet

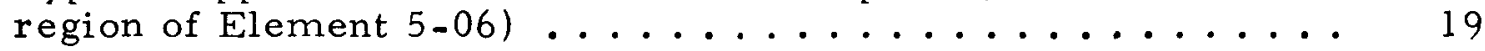

II-5. Distribution of Film Deposits on Fuel Elements ........ 20

II-6. Core Locations of Cracked Elements (as viewed looking down on top of core $\ldots \ldots \ldots \ldots \ldots \ldots$

II-7. Appearance of Some Typical Cracks .............

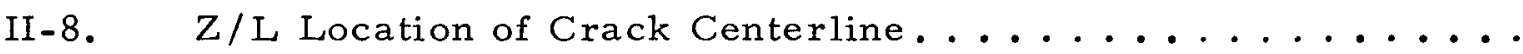

II-9. Orientation of Cracks on Element-to-Element Positioning Basis (degrees) $10^{\circ}$ is on element-to-element line of

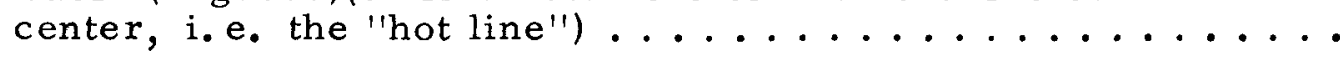

II-10. Azimuthal Orientation of Cladding Cracks (as seen looking

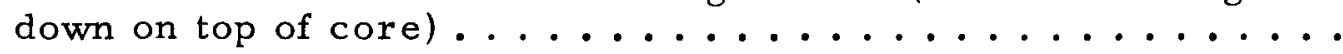


FIGURES

Page

II-11. Cracked/Intact Element Summary (by Ring) . . . . . . . . 26

II-12. Fuel-Element Bow Measurements .............. 27

II-13. Maximum Diametral Cladding Strain Inferred from

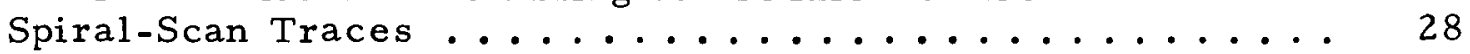

II-14. Apparent Strain Capability of SNAP 8 Developmenta1

Reactor Fuel-Element Cladding ................

II-15. Typical Neutron Radiograph (shot for fuel-rod cracks and

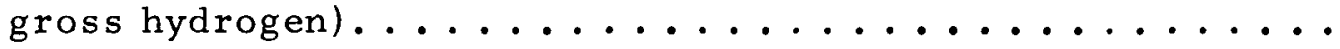

II-16. Location of Fuel Elements Observed (by n-ray) to Have Fuel-Rod Regions Grossly Depleted in Hydrogen Content ....

II-17. Location of Fuel Elements Containing Fuel Rods with Transverse Cracks ....................

II-18. S8DR Fuel-Rod $\triangle D$ Characteristics (by Ring) Based Upon n-Ray Observations: Intact Elements Only (with anomalous

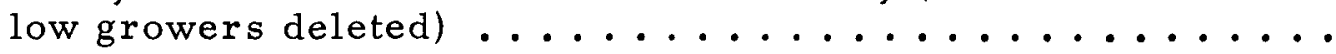

II-19. Relative Radial Power Distribution in S8DR Core ....... 36

III-1. Effect on ZrH Reactor of Temperature, Lifetime, and Tritium Excess and Control Requirements vs Available

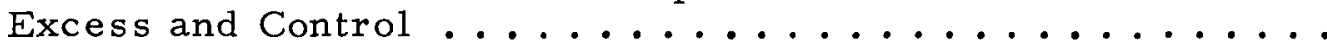

III-2. Pictorial Representation of Reactivity and Control Swing ....

III-3. Reference Zirconium Hydride Reactor Excess-Reactivity Requirements vs Prepois on Loading .............

III-4. Reference Zirconium-Hydride Reactor Control Require-

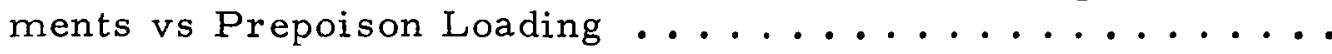

III 5. Required Control Worth with Margins vs Required Excess

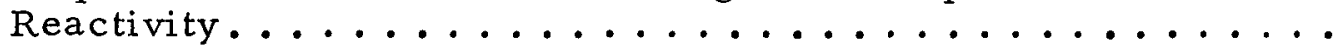

IV-1. Reactor-Thermoelectric System with Supplemental Radiator (Parameters shown for design point at $5 \mathrm{yr}$ )......

V-1. Comparison of TEM-13G SN-12 Open-Circuit Voltage Data with Performance Calculations .............

V-2. Comparison of TEM-13G SN-12 Internal-Resistance Data with Performance Calculations ............

V-3. Comparison of TEM-13G SN-12 Power-Output Data with Performance Calculations...............

V-4. Comparison of TEM-13G SN-12 Overall Efficiency Data with Performance Calculations................

V-5. Relationship Between Voltage-to-Power Ratio and Number of Thermoelectric Couples for a TEM-X-3 Module .......

V-6. Comparison of TEM-13G and TEM-X SN-3 Modules....... 


\section{FIGURES}

Page

V-7. Electrical-Current Data from Three Prototype Pump-

Power Modules ......................

V-8. Power-Output Data from Three Prototype Pump-Power

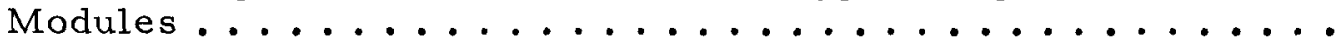

V-9. Comparison of Steady-State Power Output Data from

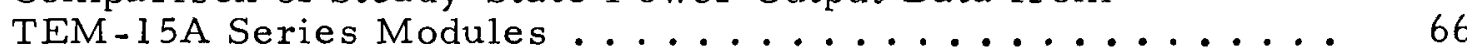

V-10. Comparison of Steady-State Overall Efficiency Data

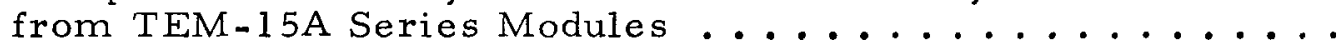

V-11. Electrical-Power Output vs Elapsed Time at Test

Conditions for TEM-15 Modules Fabricated with Diffusion

Barriers in the Mica Insulator ...............

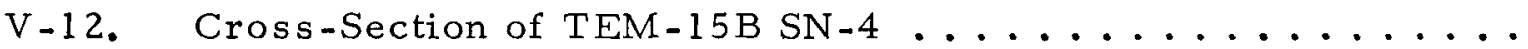

$\mathrm{V}$-13. Electrical Resistivity of P-Type $\mathrm{PbTe}_{0.95} \mathrm{Se}_{0.05}$ Alloys;

$650^{\circ} \mathrm{C} / \mathrm{H}_{2}-$ Treated Specimens, Pressed from $650^{\circ} \mathrm{C} / \mathrm{H}_{2}-$

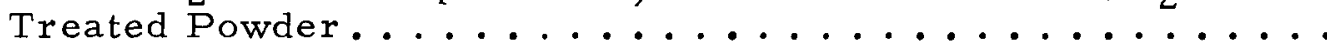

$\mathrm{V}-14$. Seebeck Coefficient of P-Type PbTe $0.95 \mathrm{Se}_{0.05}$ Alloys;

$650^{\circ} \mathrm{C} / \mathrm{H}_{2}-\mathrm{Treated}$ Specimens, Pressed from $650^{\circ} \mathrm{C} / \mathrm{H}_{2}-$

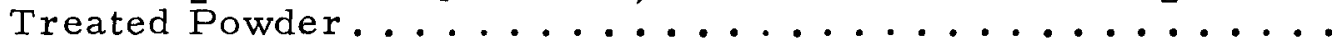

$\mathrm{V}-15$. Seebeck Coefficient of $\mathrm{P}-\mathrm{Type} \mathrm{PbTe}_{0.96} \mathrm{Se}_{0.05} \mathrm{Na} 0.01$

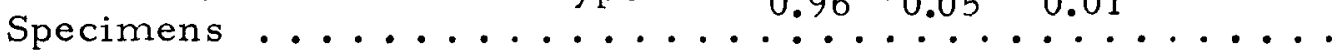

VI-1. Heat-Transfer Test Section for SNAP 8 Developmental

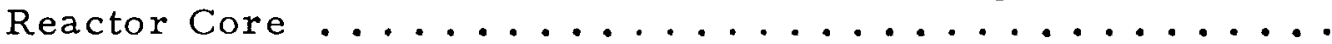

VI-2. Partially Assembled S8DR Core Hydraulic Model . . . . . 86

VI-3. Top View of S8DR Core Model ................ 88

VI-4. S8DR Core Module Instrumented for Inlet Plenum

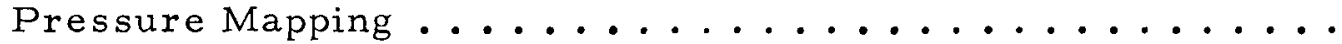

VI-5. Location of Pressure Probes Beneath Lower Gridplate

S8DR Hydraulic Core Model. . . . . . . . . . . . .

VI-6. S8DR Core Model Setup for Initial Bubble Tests

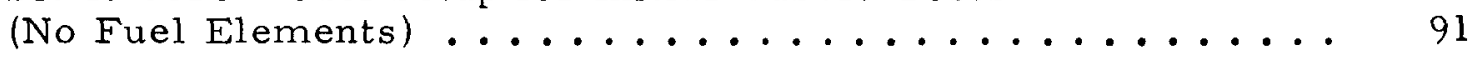

VI-7. View of Plenum Showing Vortex Locations . . . . . . . . . 92

VI-8. Nineteen-Element Zirconium Hydride Mixing Test. . . . . . 94

VI-9. Injector Setup for Zirconium Hydride Mixing Test . . . . . . .

VI-10. Advanced Zirconium Hydride Bearing Simulated Life

Test Friction Torque at $1500^{\circ} \mathrm{F}, 10^{-8}$ torr, $\mathrm{Al}_{2} \mathrm{O}_{3}$

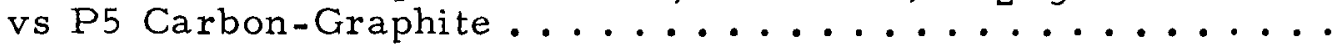

VI-11. Advanced Zirconium Hydride Bearing Material Evaluation

Test Friction Coefficient vs Time at $1500^{\circ} \mathrm{F}, 10^{-8}$ torr,

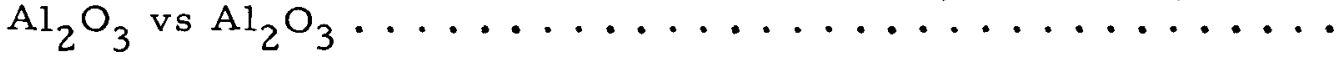




\section{FIGURES}

Page

VI-12. Energy-Absorption Study Configurations ...........

VI-13. Midplane Energy-Absorption Rates, Reference Zirconium Hydride Reactor Poison-Backed Drum in STIR Pool,

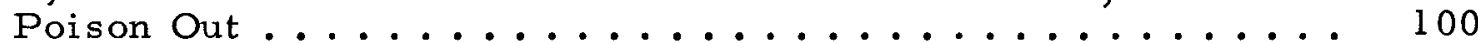

VI-14. Midplane Energy-Absorption Rates, Reference Zirconium Hydride Reactor Poison-Backed Drum in STIR Pool,

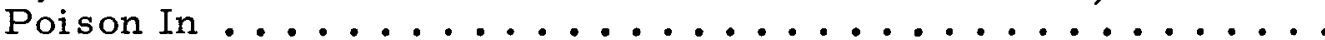

VI-15. View of Test Samples in Test Setup.............

VI-16. Failure of $\mathrm{Fe}_{2} \mathrm{TiO}_{5}$ Emittance Coating (over CVD tungsten undercoat $\ldots \ldots \ldots \ldots \ldots \ldots$

VI-17. Adherent $\mathrm{Fe}_{2} \mathrm{TiO}_{5}$ Emittance Coating (plasma-sprayed

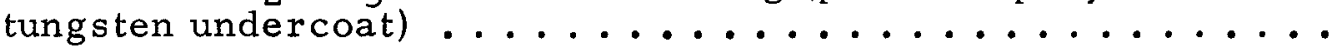

$\mathrm{VI}-18$. Chipped $\mathrm{Fe}_{2} \mathrm{TiO}_{5}$ Emittance Coating (plasma-sprayed

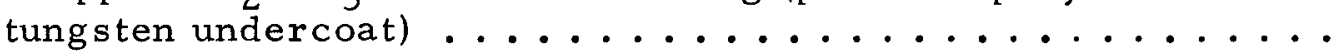

VI-19. Zirconium Hydride Reactor Control-Drum Drive Train ....

VI-20. Zirconium Hydride Reactor Control Drum and Bearings .....

VI-21. Annular Neutron Shield ..................

VII-1. Average Normalized Leakrate of the Seven Incoloy-800-

Clad Developmental Fuel Elements ..............

VII-2. Cumulative Average Hydrogen Loss for the Seven

Incoloy-800-Clad Developmental Fuel Elements ........

VII-3. Average Normalized Leakrate of the Four Enriched Uranium Double-Blind-End Incoloy-800-Clad Develop-

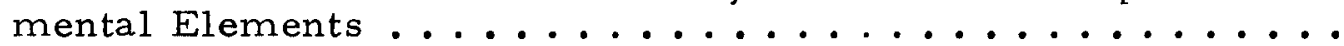

VII-4. Cumulative Average Hydrogen Loss for Four Enriched Uranium Double-Blind-End Incoloy-800-Clad Develop-

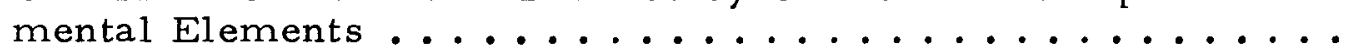

VII-5. $1400^{\circ} \mathrm{F}$ Biaxial Stress-Rupture Tests ............. 131

VII-6. $1400^{\circ} \mathrm{F}$ Biaxial Stress-Rupture Data ..............

VII-7. $1300^{\circ} \mathrm{F}$ Biaxial Stress-Rupture Tests .............

VII-8. Biaxial Stress-Rupture of Coated Incoloy -800 at $1300^{\circ} \mathrm{F}$....

VII-9. $1300^{\circ} \mathrm{F}$ Biaxial Stress-Rupture Data ..............

VII-10. Hoop Stress vs Rupture Life for Hastelloy-N at $1400^{\circ} \mathrm{F}$....

VIII-1. Composite Impact-Test Specimens ...............

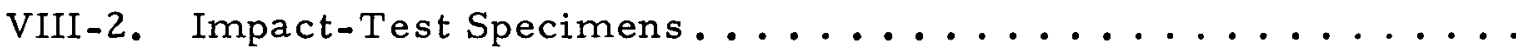

VIII-3. Impact-Test Results for Cylindrical Shells with an $\mathrm{R} / \mathrm{t}$ Ratio of $20 \ldots \ldots \ldots \ldots \ldots$ 


\section{FIGURES}

Page

VIII-4. Deformation for Cylindrical Shells (L/D ratio of 1.5 ,

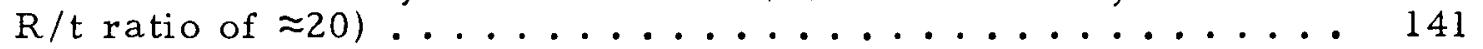

VIII-5. Deformation for 1020 Steel Projectiles with Lithium

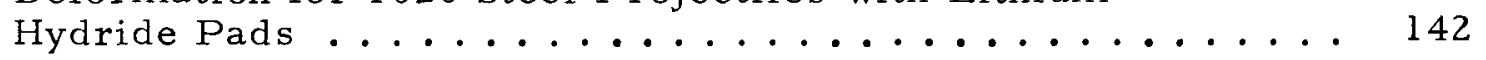

VIII-6. Post-Impact Configurations for Composite Model No. 1 for Impact at $350 \mathrm{ft} / \mathrm{sec} \ldots \ldots \ldots . \ldots \ldots$

VIII-7. Post-Impact Configurations for Composite Model No. I for Impact at $600 \mathrm{ft} / \mathrm{sec} \ldots \ldots \ldots . . \ldots \ldots 144$

VIII-8. Post-Impact Configurations for Composite Model No. 2 for Impact at 350 and $450 \mathrm{ft} / \mathrm{sec} \ldots \ldots \ldots \ldots$

VIII-9. Post-Impact Configurations for Composite Model No. 2 for Impact at $600 \mathrm{ft} / \mathrm{sec} \ldots \ldots \ldots 147$

VIII-10. Effect of $R / t$ Ratio on the $K$ Factors for Cylindrical

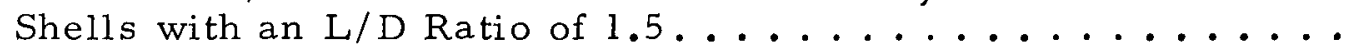

VIII-11. Effect of Thickness in the $K$ Factors for the 2-in.-diam

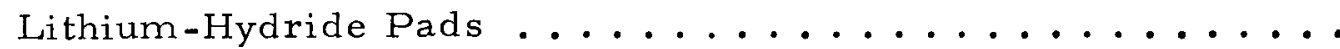

VIII-12. Deformation of 2-in.-diam 1020 Steel Projectiles With and Without Lithium-Hydride Pads ..............

VIII-13. Post-Impact Configurations of Stainless-Steel Cylindrical Shell Filled with Lithium Hydride for Impact at 100 and

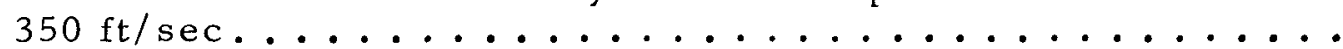

VIII-14. Post-Impact Configurations of Stainless-Steel Cylindrical Shell Filled with Lithium Hydride for Impact at 600 and

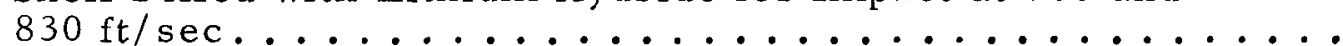

VIII-15. K Factor for 2-in.-diam 0.16-in. Wall, 321 StainlessSteel Cylinder Filled With Lithium Hydride .......... 152

VIII-16. Post-Impact Configuration for Inconel-800 . . . . . . . . 154

VIII-17. K Factors for Inconel-800 Rod..............155

VIII-18. Temperature Coefficient of Reactivity, Unpoisoned Reactor with Beryllium Reflector............. 157

VIII-19. Temperature Coefficient of Reactivity Experimental Data . . 159

VIII-20. Temperature Coefficient of Reactivity Gadolinium Poison,

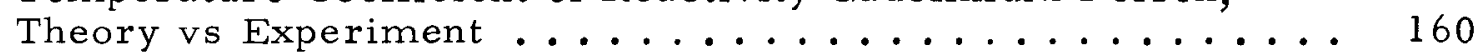

VIII-21. Temperature Coefficient of Reactivity Samarium and Europium Poisons, Theory vs Experiment...........

The previous report in this series was AI-AEC-12953, "SNAP Reactor Programs Progress Report, February-April 1970." 
BLANK 


\section{INTRODUCTION}

\section{A. PROGRAM SCOPE AND OBJECTIVES}

The SNAP Program activities covered in this report include the following major tasks:

1) SNAP 8 developmental reactor (S8DR) test

2) Reference zirconium hydride reactor engineering

3) Reference reactor - thermoelectric system engineering

4) Compact thermoelectric converter development

5) Component development

6) Fuel development

7) Aerospace nuclear safety.

The S8DR reactor test effort includes all activities necessary for the installation, checkout, operation, test support, disassembly and examination of the S8DR. The GFY 1971 objective consists primarily of completion of the post-test analysis of the S8DR.

The reference $\mathrm{ZrH}$ reactor engineering effort provides preliminary engineering for a reference space reactor capable of a broad range of performance. The design must also be suitable for use with thermoelectric (TE), mercuryRankine, Brayton, or organic cycle power-conversion systems, and must be capable of operation in either a shadow-shielded or a $4 \pi$-shielded configuration.

The reference reactor-TE system engineering effort includes preliminary system definition and related application and integration studies.

The compact thermoelectric converter technology program is being carried out by the Astronuclear Laboratory of Westinghouse Electric Corporation under subcontract to Atomics International. This program is intended to provide the $\mathrm{TE}$ power-conversion subsystem for use with a $\mathrm{ZrH}$ reactor-TE space-power system.

The component development tasks include the development and testing of reflector components, shielding, and liquid-metal components in support of 
the S8DR, the reference $\mathrm{ZrH}$ reactor, and the reactor-TE system development programs.

The fuel-development tasks provide for basic understanding, substantiation, and improvements in the technology of $\mathrm{ZrH}$-type fuel-moderator elements in support of the S8DR and reference $\mathrm{ZrH}$ reactor programs.

The Aerospace Nuclear Safety Program work includes analyses and tests to determine post-reentry and post-impact and configurations of reactor systems. Impact disassembly studies will provide analysis and tests to develop analytical models and scaling laws to predict post-impact configuration.

\section{B. SUMMARY OF PROGRESS}

The screening-examination phase of the S8DR post-test examination was completed during the reporting period. Fuel-element data from visual examination by Kollmorgen, profilometer and gamma scans, and neutron radiography were collected and stored on a computer tape for subsequent analysis. Of the 211 fuel elements in the core, 52 were found to contain cracks in the cladding. Some 41 elements and 30 alternates have been selected for detailed destructive examination in the Hot Cell. Selections were made which will allow investigation of the significant potential failure mechanisms.

In the reference $\mathrm{ZrH}$ Reactor engineering program, core hydraulic design and analysis advanced significantly through the use of the GE $\varnothing \mathrm{M} 2$ code. Channelto-channel coolant mixing provided by integral spiral fins on the fuel elements was found to be a powerful means of minimizing radial-coolant temperature gradients in the core. The smoothing of temperature gradients results in favoring of core designs consisting of two or three annular zones of fuel elements with constant-diameter fin envelopes. Cladding tube outside diameter in each zone is selected to provide the desired flow-channel area to achieve flow/power distribution matching. The incentive to reduce fuel-element diameter to lower fuel temperature was determined to be insufficient to warrant change from the S8DR-type element dimensions. Thus current designs retain 295 fuel elements.

A series of trade studies was made with the purpose of selecting a design point for a reactor-thermoelectric power system based on the most current Space Station requirements. A 3-loop system was selected for the 37-kwe 5-yr power-system requirement. The system including the radiation shield weighs $28,1401 b$. 
During this quarter ten of the 5.25-volt prototype reactor TE power modules were tested to provide data on module performance as a function of temperature and temperature cycling. Examination of these modules has lead to a better understanding of the module distortion and interelement diffusion problems. A module redesign (TEM-X series) has been accomplished to eliminate these problems. The first experimental module to evaluate the changes in this redesign (TEM-X SN-2) was fabricated. Supporting technology efforts in the areas of materials and processing continue. The first batches of the improved performance ternary $\mathrm{PbTe}$ material have been prepared.

Current component-development efforts include fuel-element and core heat transfer and hydraulic studies. Hydraulic studies on a full-core S8DR model have shown the existence of two vortices in the inlet plenum area below the lower gridplate. Test sections are being fabricated for hydraulic tests to verify crossmixing of the coolant with spirally wound fins on the $\mathrm{ZrH}$ fuel elements. Fabrication and test of reactor control system components, including drum-drive actuator and bearings, continue. The fabrication of a large-diameter LiH shield casing is essentially complete. Casting of this shield in the new large LiH casting facility will be done next quarter.

Process development of integral finned clad tubes proceeded with evaluation of milling, hobbing, chem-milling, drawing, electrical-discharge grinding, and electrical-discharge machining. Coating work on the finned tubes is also being done with apparent improved stability of the tubes during process thermal cycles. Test runs were completed on the Autonetics Division equipment for simultaneous co-deposition of two rare-earth oxides and a stable third oxide. Various rareearth/stablizer atom ratios are being investigated. The operation and postirradiation-examination topical report for the NAR-120-4 test was published. The Incoloy-800 (NAR-83) irradiation tests and evaluation continue.

A series of reactor-disassembly impact tests were made on 321 -SS cylindrical shells, LiH pads, Inconel-800 cylinders, and composite models fabricated from stainless steel and LiH. This series of tests showed that scale-model testing is a feasible and reliable means for predicting the post-impact deformation of a prototype. The tests also showed that the geometry of the components and their relationships with the other components in the system affect their energy-absorbing capacity considerably. 
BLANK 


\section{SNAP 8 DEVELOPMENTAL REACTOR}

The SNAP 8 Developmental Reactor (S8DR) test effort includes all activities necessary for the installation, checkout, operation, test support, disassembly, and post-test examination of the S8DR. Current activities are devoted to posttest examination.

\section{A. SCREENING EXAMINATION}

The screening-examination phase of the S8DR post-test examination as outlined in Figure II-l was completed during the reporting period. All data collected during the course of the screening examination were stored on a computer tape for subsequent analysis. A summary of the types of data taken is given in Table II-1.
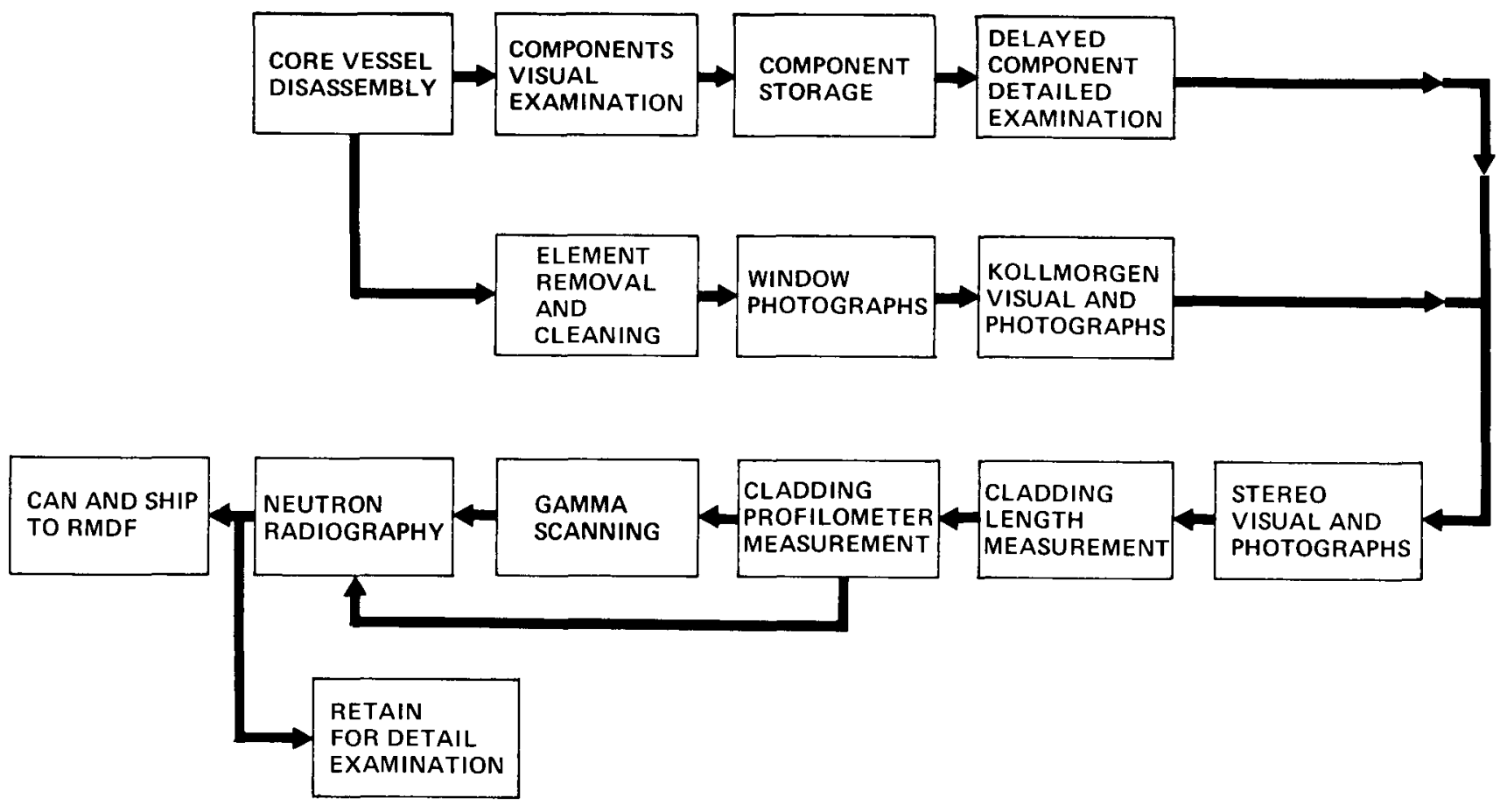

$70-$ MAl 3-51 -24

Figure II-1. SNAP 8 Developmental Reactor Screening-Examination Flowsheet

\section{Observations}

Visual examination was made throughout the course of the screening examination. Visual appearances of the various core structures and individual fuel elements were as described below.

$$
\text { AI- } \operatorname{AEC}_{15}-12975
$$


TABLE II-1

SNAP 8 DEVELOPMENTAL REACTOR SCREENING-EXAMINATION DATA SUMMARY

\begin{tabular}{l|c|c|c|c|c|c|c|c|c|c}
\hline \hline Ring No. & 9 & 8 & 7 & 6 & 5 & 4 & 3 & 2 & 1 & Totals \\
\hline Number of Elements & 42 & 42 & 36 & 30 & 24 & 18 & 12 & 6 & 1 & 211 \\
\hline Elements Examined: & & & & & & & & & & \\
\hline $\begin{array}{l}\text { Visual Examination } \\
\text { (Kollmorgen) }\end{array}$ & 42 & 42 & 36 & 30 & 24 & 18 & 12 & 6 & 1 & 211 \\
$\quad \begin{array}{l}\text { Profilometer Scan } \\
\text { (Dimensional) }\end{array}$ & 10 & 36 & 36 & 30 & 24 & 18 & 12 & 6 & 1 & 173 \\
$\quad$ Gamma Scan & 19 & 26 & 18 & 6 & 6 & 6 & 5 & 3 & 1 & 90 \\
$\quad$ Neutron & 42 & 42 & 36 & 30 & 24 & 18 & 12 & 6 & 1 & 211 \\
$\quad$ Radiography & 42 &
\end{tabular}

\section{a. Core Structures}

During the previous reporting period, core-disassembly operations reached the point where fuel-element removal had begun. During this reporting period the remainder of the fuel elements were removed from the core and the lowercore support structures (inlet plenum components) were removed and examined. The inlet-plenum components after removal from the core-vessel assembly but before cleaning are shown in Figure II-2. After cleaning, the appearance of the lower gridplate, baffle plate, and flow distributor was excellent, as shown in Figure II-3.

Close visual examination of the lower gridplate revealed only minimal film deposit on the upstream side of the plate, and no evidence of flow blockage in any of the inlet-plenum components.

\section{b. Fuel Elements}

The metallic film deposits found during the initial phases of the fuel-element removal process containued to be observed throughout the course of the screening examination. The typical appearance of this metallic film deposit on the fuel elements is shown in Figure II-4. An estimation of the film-deposition pattern throughout the core was made and the results given in Figure II-5. Analyses of the elemental constituents of this film were made on film samples taken from 


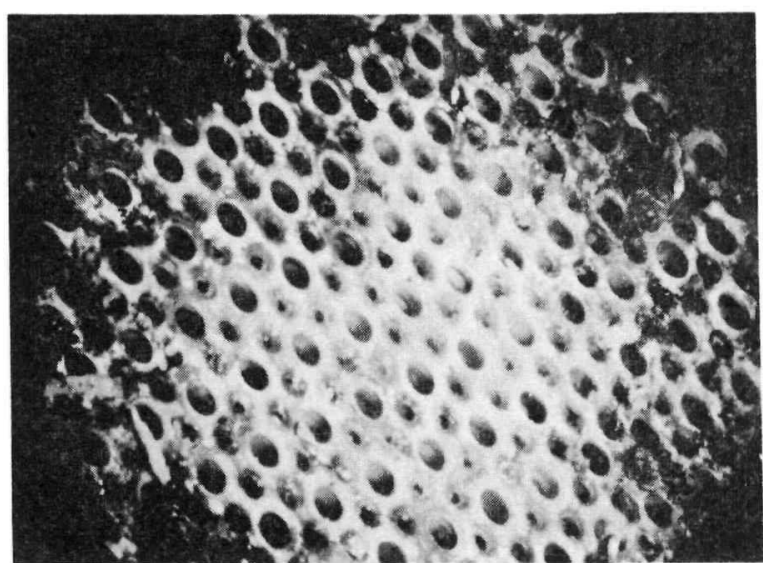

DR.54

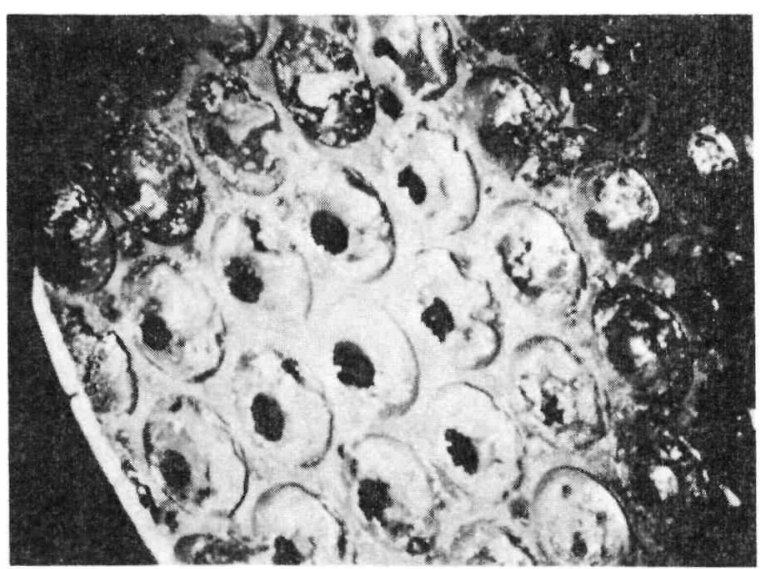

DR-62

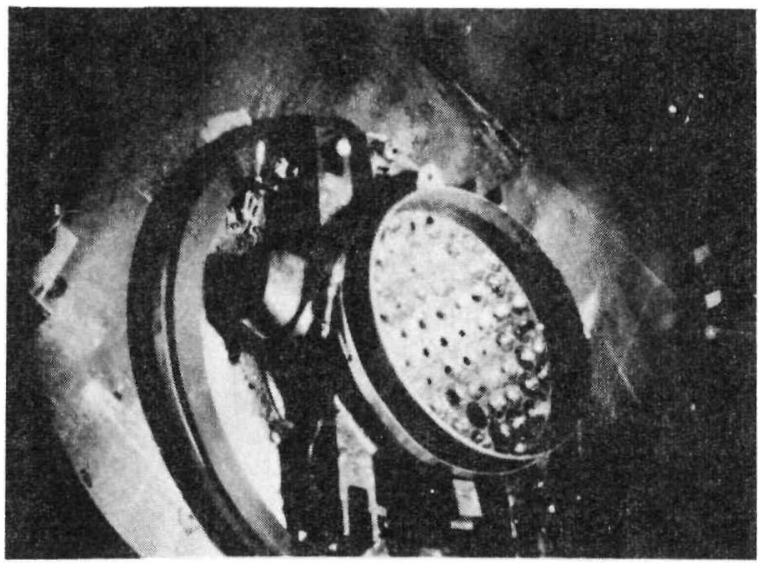

DR-61

INLET PLENUM ASSEMBLY WITH GRID PLATE REMOVED

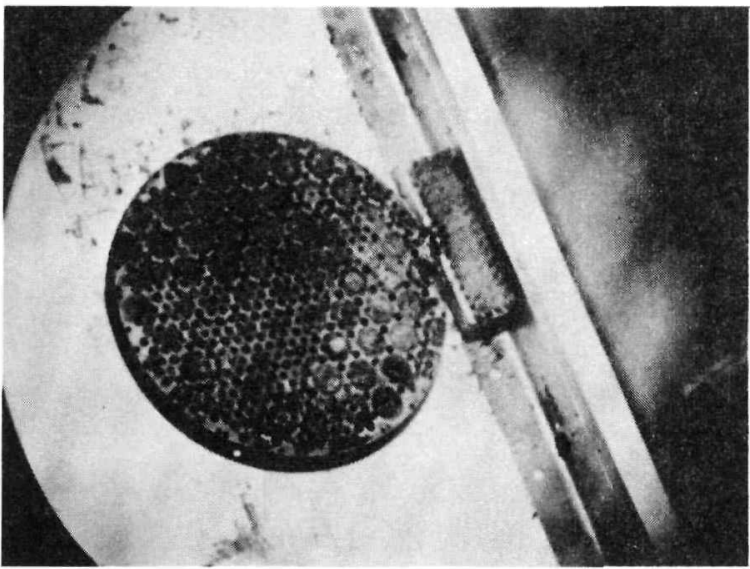

DR-56

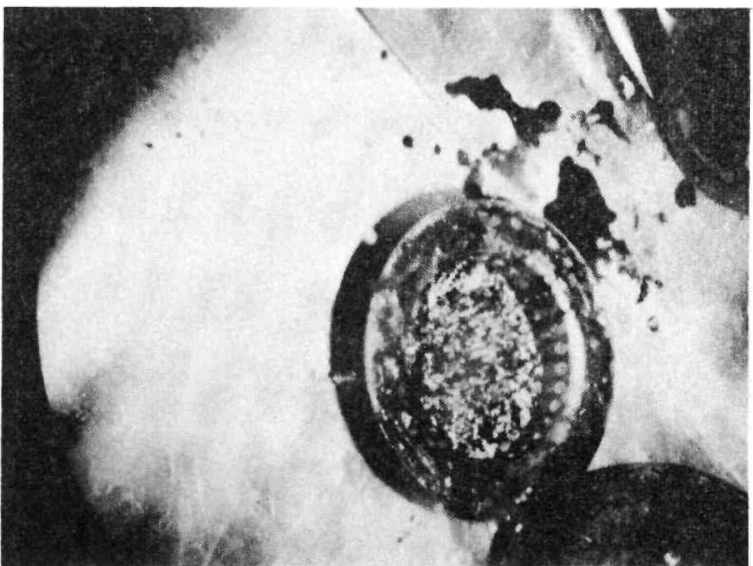

DR-64

FLOW DISTRIBUTOR

70-MA13-51-27

Figure II-2. Inlet-Plenum Components After Removal and Before Cleaning 


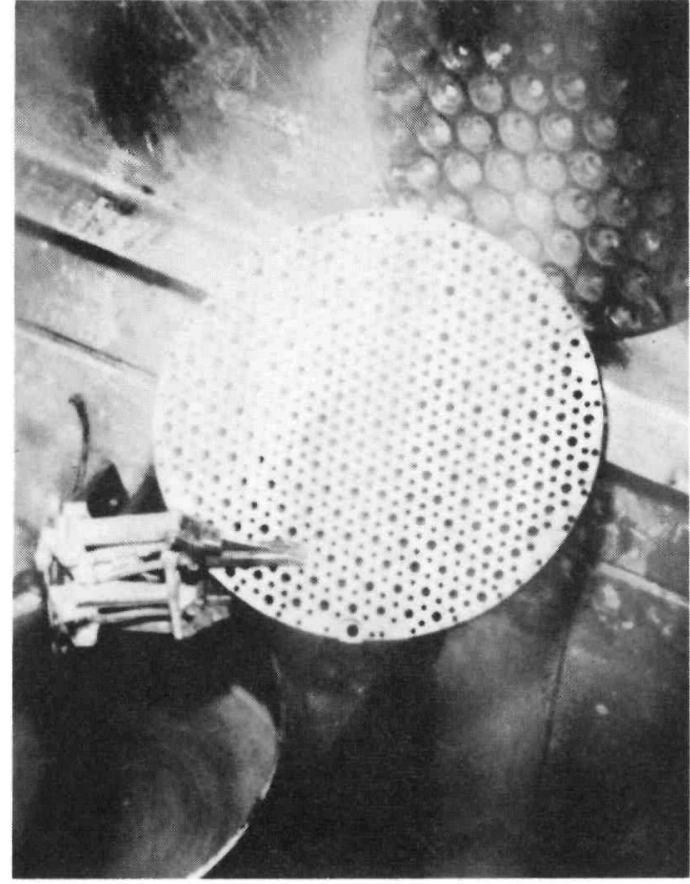

LOWER GRID

PLATE,

DOWNSTREAM

SIDE

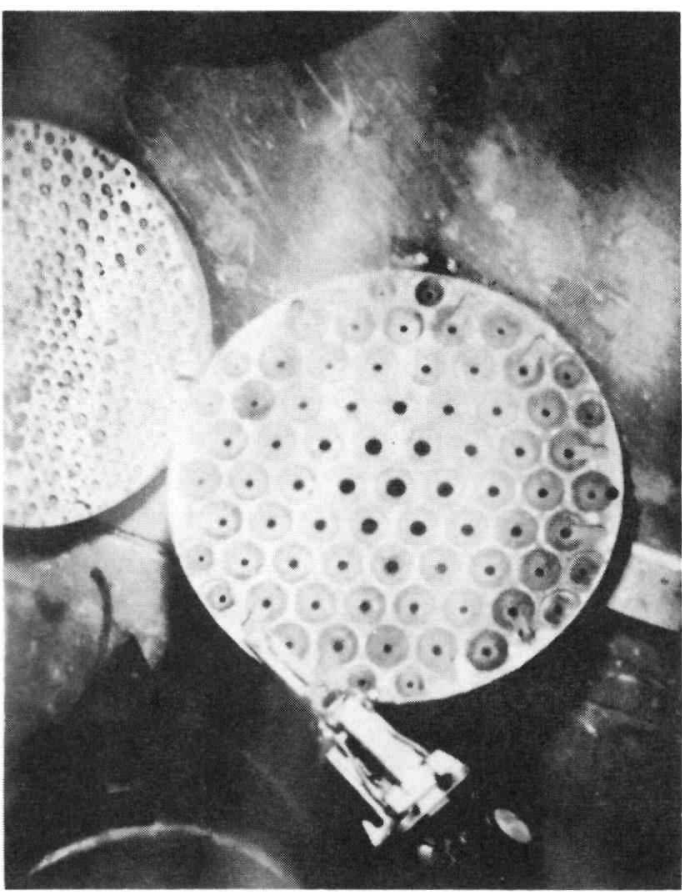

BAFFLE PLATE,

DR-66
SIDE

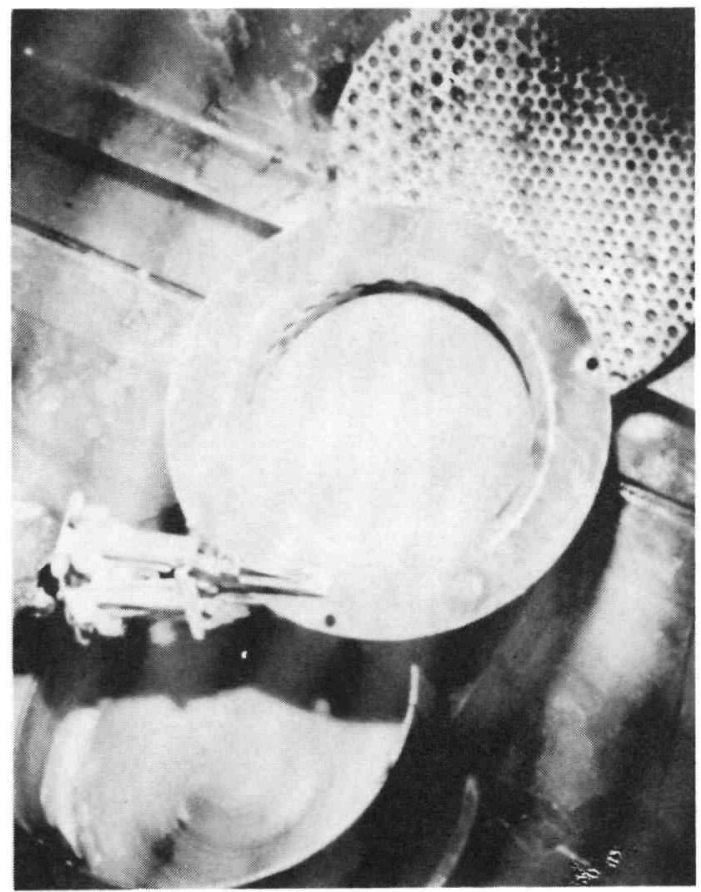

FLOW DISTRIBUTOR

DR-70

70-MA 13-51-30

Figure II-3. Inlet-Plenum Components After Cleaning

$$
\mathrm{AI}-\mathrm{AEC}-12975
$$




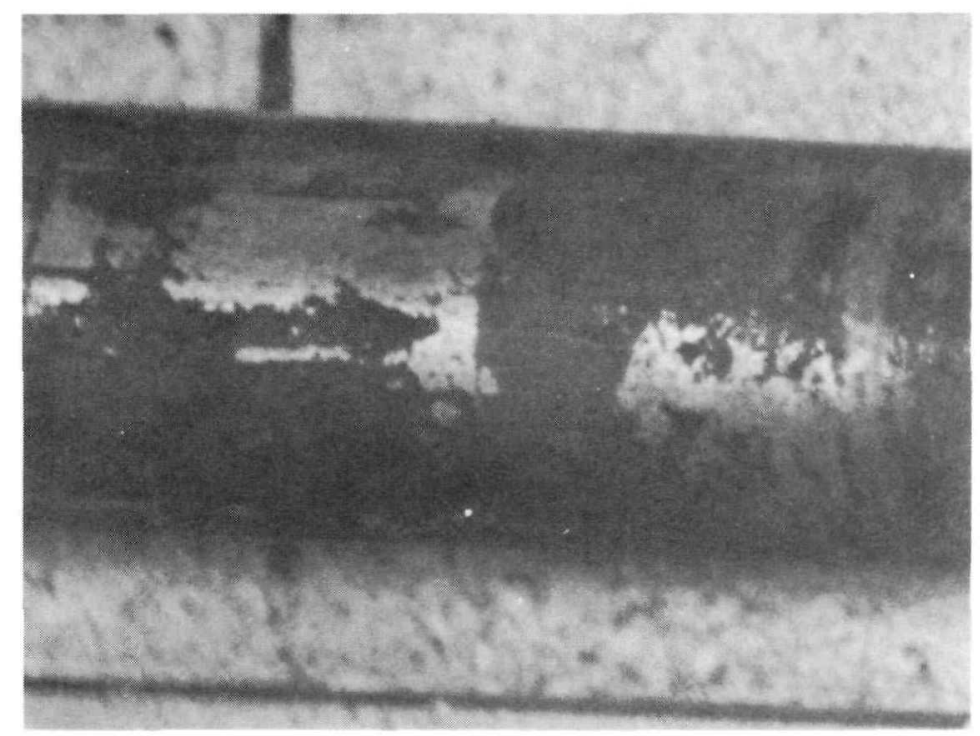

Figure II-4.

Typical Appearance of Metallic Film Deposit (outlet region of Element 5-06)

several fuel elements located in various regions of the core. The results (Table II-2) of these analyses confirmed those given in the previously quarterly report.

TABLE II-2

FILM ANALYSIS

\begin{tabular}{|c|c|c|c|c|}
\hline \multicolumn{2}{|c|}{ Element } & \multicolumn{3}{|c|}{$\begin{array}{c}\text { Constituent } \\
(\text { wt } \%)\end{array}$} \\
\hline $\begin{array}{l}\text { Core } \\
\text { Location }\end{array}$ & $\begin{array}{l}\text { Surface } \\
\text { Region }\end{array}$ & Iron & Nickel & Chromium \\
\hline IX -34 & Top 4 in. & $\begin{array}{l}46 \\
52(\mathrm{WC})^{*}\end{array}$ & $\begin{array}{l}32 \\
29(\mathrm{WC}) *\end{array}$ & $\begin{array}{l}9 \\
5(\mathrm{WC})\end{array}$ \\
\hline VI-12 & Top 4 in. & 40 & 37 & 10 \\
\hline IV -10 & Top 4 in. & 37 & 40 & 10 \\
\hline III- 6 & Top 4 in. & 42 & 35 & 10 \\
\hline NaK Loop & $\begin{array}{l}\text { Downstream } \\
\text { of Intermediate } \\
\text { Heat Exchanger }\end{array}$ & 30 & 13 & 44 \\
\hline
\end{tabular}

*Wet Chemistry; all other analyses $\mathrm{x}$-ray fluorescence 


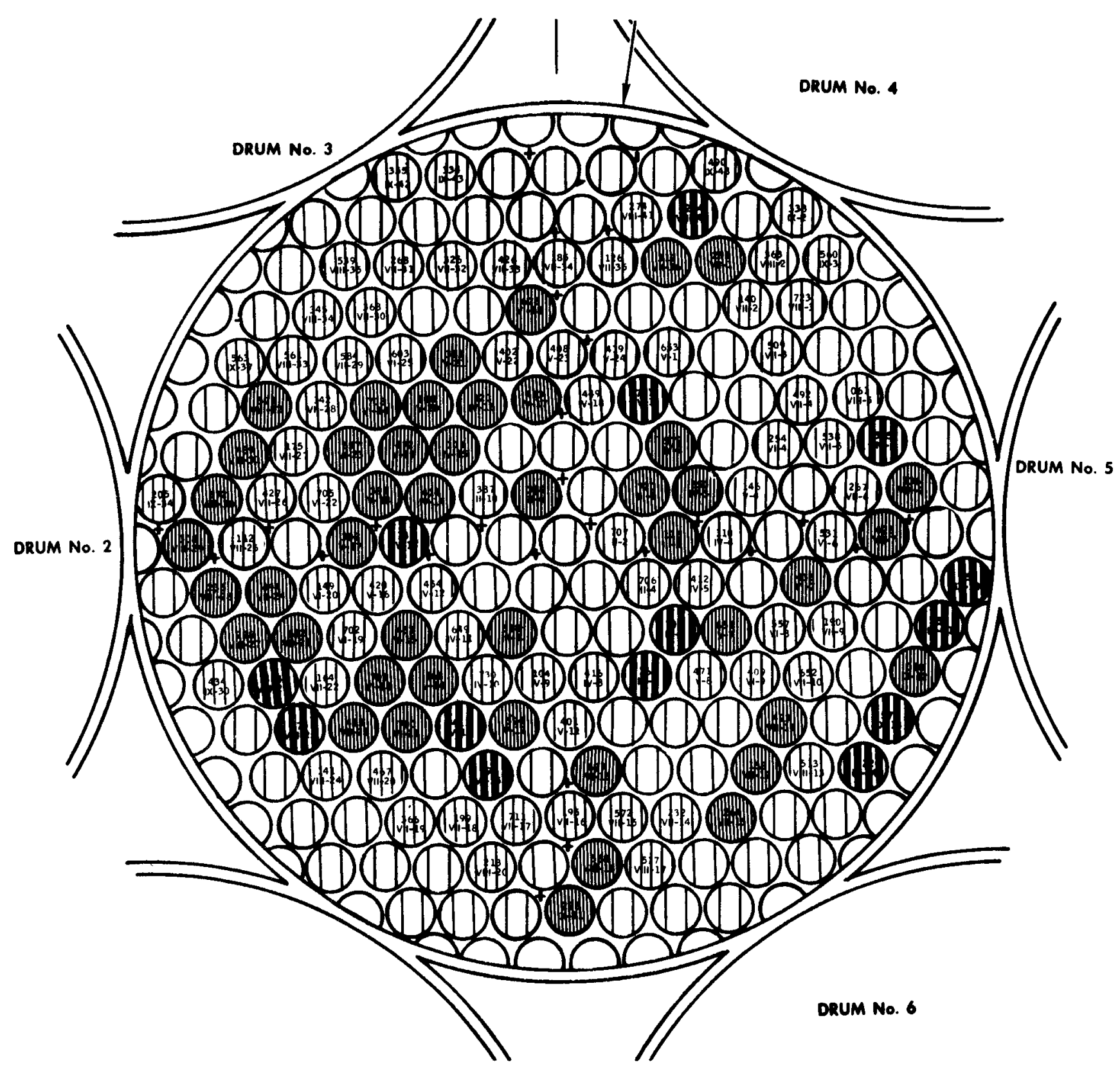

TOTAL SURFACE COVERED

70-JU3-034-13

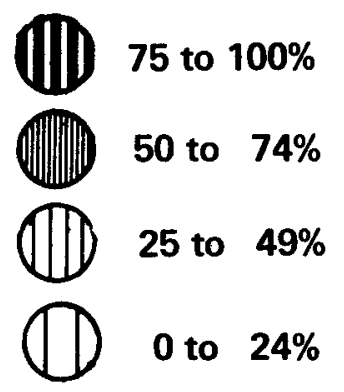

Figure II-5.

Distribution of Film Deposits on Fuel Elements

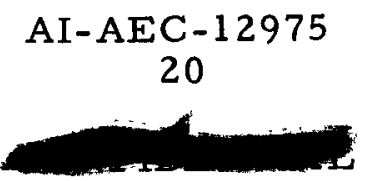


2. Fuel-Element Condition

a. Cracked/Intact Elements

A total of 52 cracked elements were found in the S8DR core (Figure II- 6). The cracked elements generally exist in a horseshoe pattern with the open end of the horseshoe being toward the Drum-1/Drum-6 region of the core. The appearance of typical cracks observed during the course of the screening examination is shown in Figure II-7. The cracks were of the longitudinal type, generally short (the majority being of the order of 1 -in.-long or less), and had the visual appearance characteristic of stress-rupture type cracks.

Generally cracked fuel elements were found to have multiple cracks although single ones were found in 18 elements. The axial location tended to favor the $\mathrm{Z} / \mathrm{L}$ region from 0.6 to 0.8 (see Figure II-8), although cracks were also observed in the bottom of some elements. The relative fuel and coolant-temperature profiles are shown in Figure II- 8 to illustrate that cracking generally occurred in the hot zone. The circumferential locations of the cracks in the cladding tends to favor the $15^{\circ}$ arc segment on either side of the line describing the closest approach of the cracked element with adjacent elements (see Figure II-9). The actual circumferential orientation of the cladding cracks is shown in Figure II- 10. The cracked/intact element findings during the course of the screening examination are summarized in Figure II-11.

b. Cladding Dimensional Data

Dimensional data taken on the fuel elements include bow, cladding diameter, and the fuel-element length. The bow and cladding-diameter data were taken using the profilometer. The fuel-element bow measurements were evaluated for orientation patterns but no strong clustering patterns were found. The bow data are shown in Figure II-12.

The profilometer scans indicated the presence of localized cladding diametral strain in several of the S8DR fuel elements, while scans of other elements indicated essentially no diametral change. The results of the cladding-diameter measurements are summarized in Figure II-13. Cladding diametral strains were calculated for both cracked and intact elements. The apparent strain capability of the coated Hastelloy $-\mathrm{N}$ cladding material used in the core is summarized in Figure II-14. 


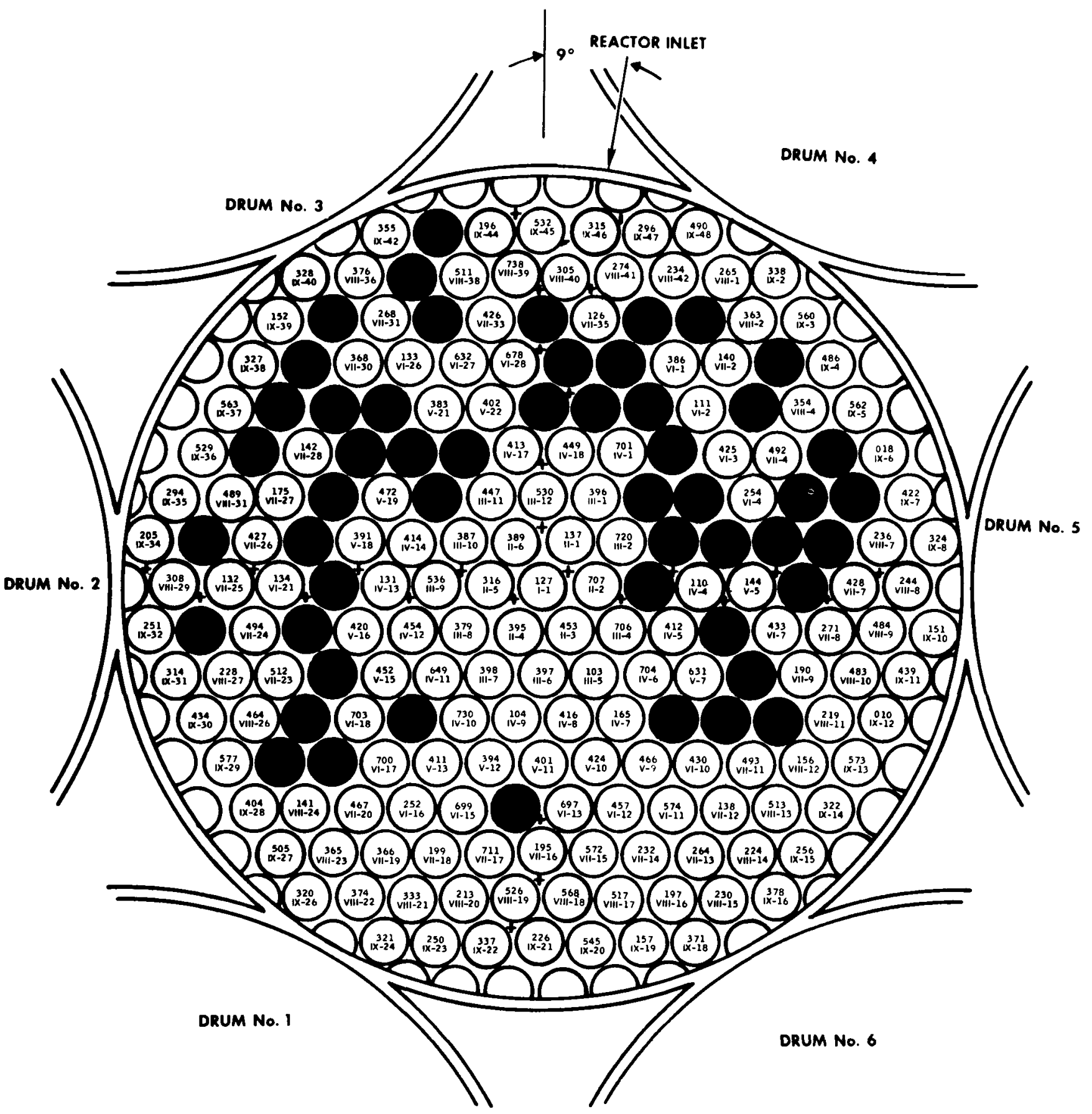

70-MA11-51-8A

Figure II-6. Core Locations of Cracked Elements (as viewed looking down on top of core) 


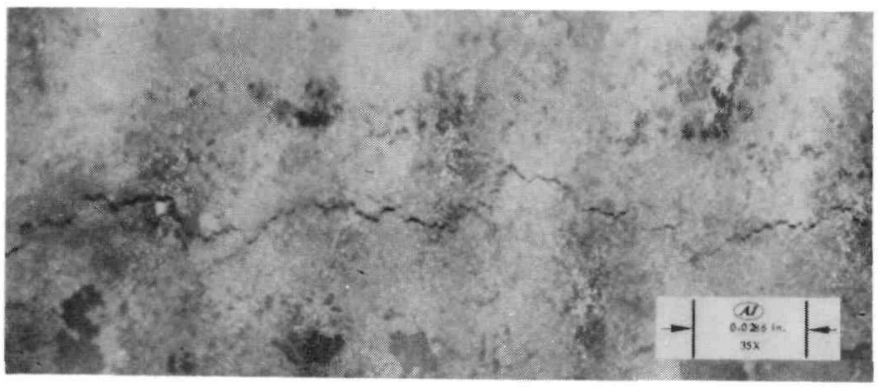

ELEMENT 6.24

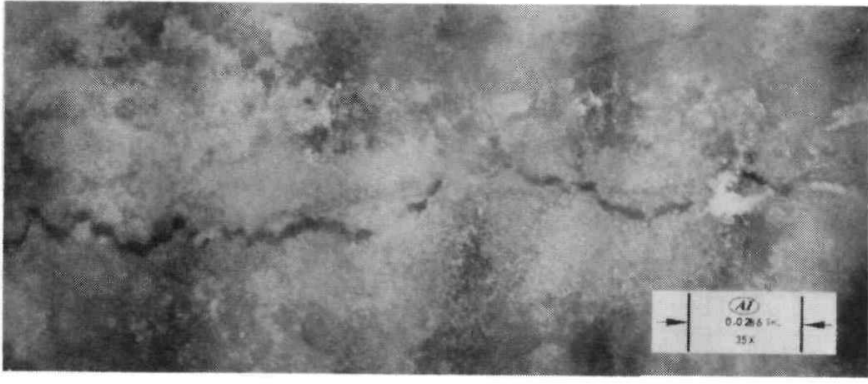

ELEMENT 6.05

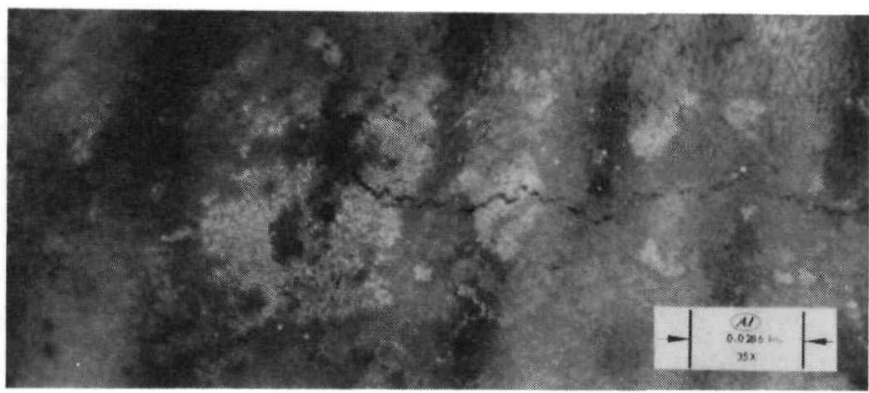

ELEMENT 620

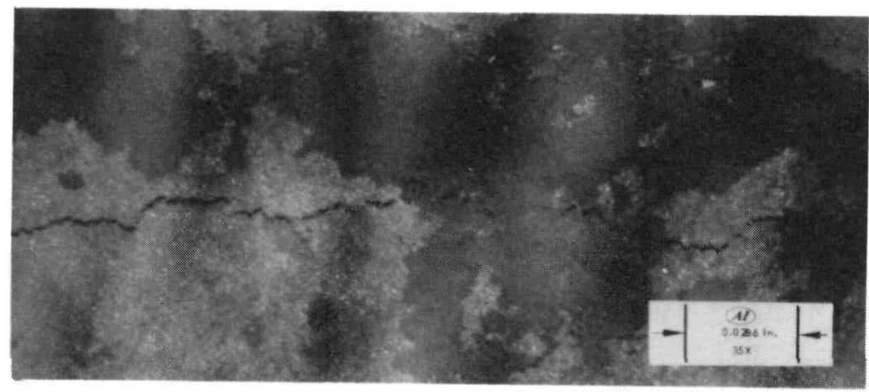

ELEMENT 62

DRS 7051

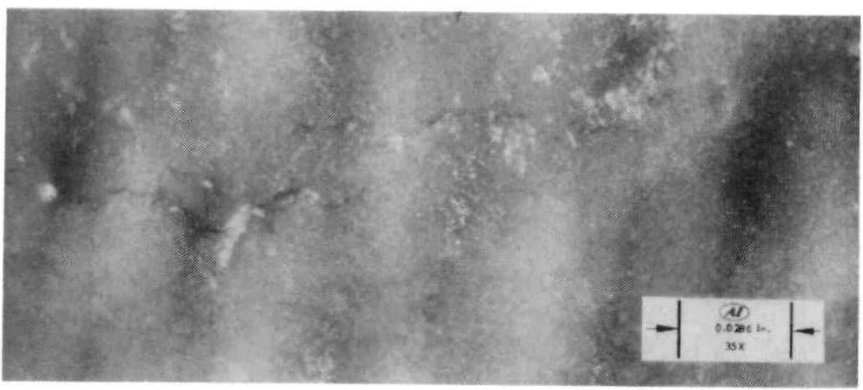

ELEMENT 734

DRS 1853

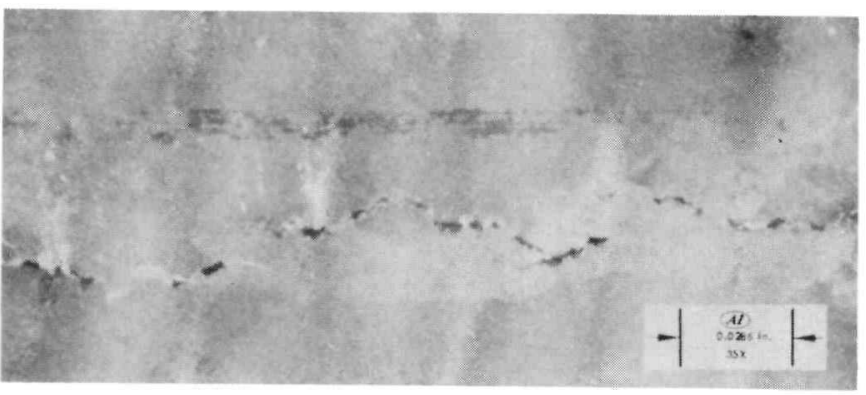

DRS 6531

ELEMENT 501

Figure II-7. Appearance of Some Typical Cracks

$$
\underset{23}{A I-A E C}-12975
$$



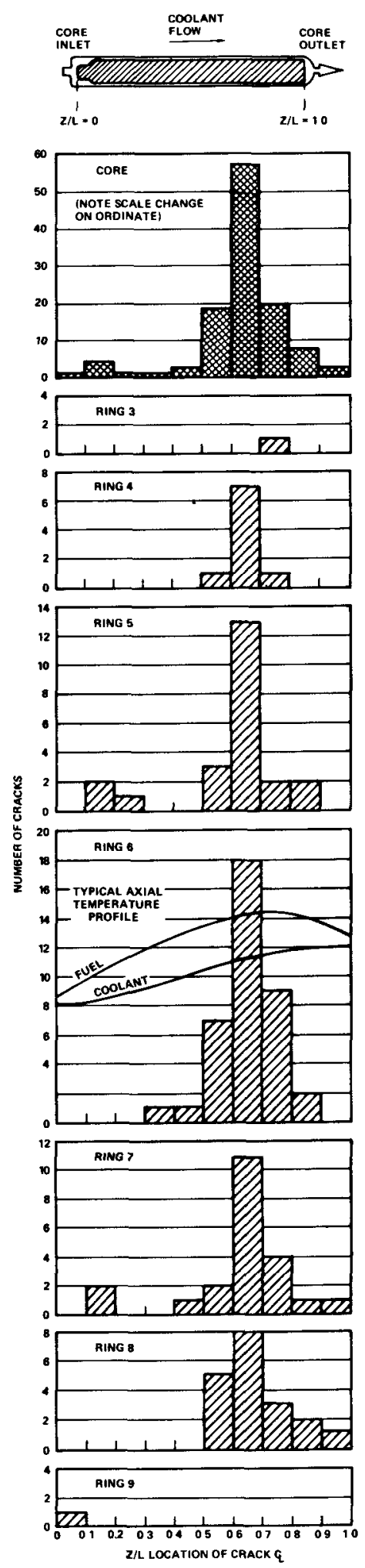

70 MA145154A

Figure II-8. Z/L Location of Crack Centerline
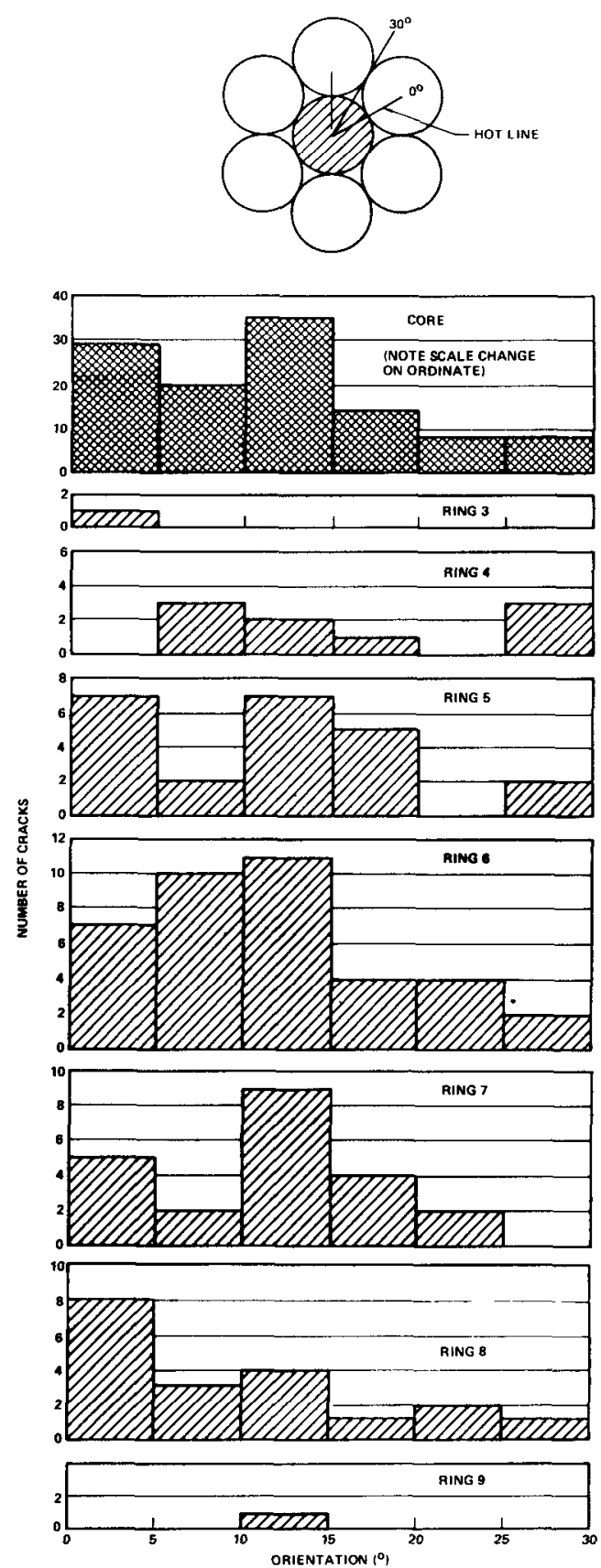

70 MA1451 52A

Figure II-9. Orientation of Cracks on Element-to-Element

Positioning Basis (degrees)

$10^{\circ}$ is on element-to-element line of center,i.e. the "hot line") 


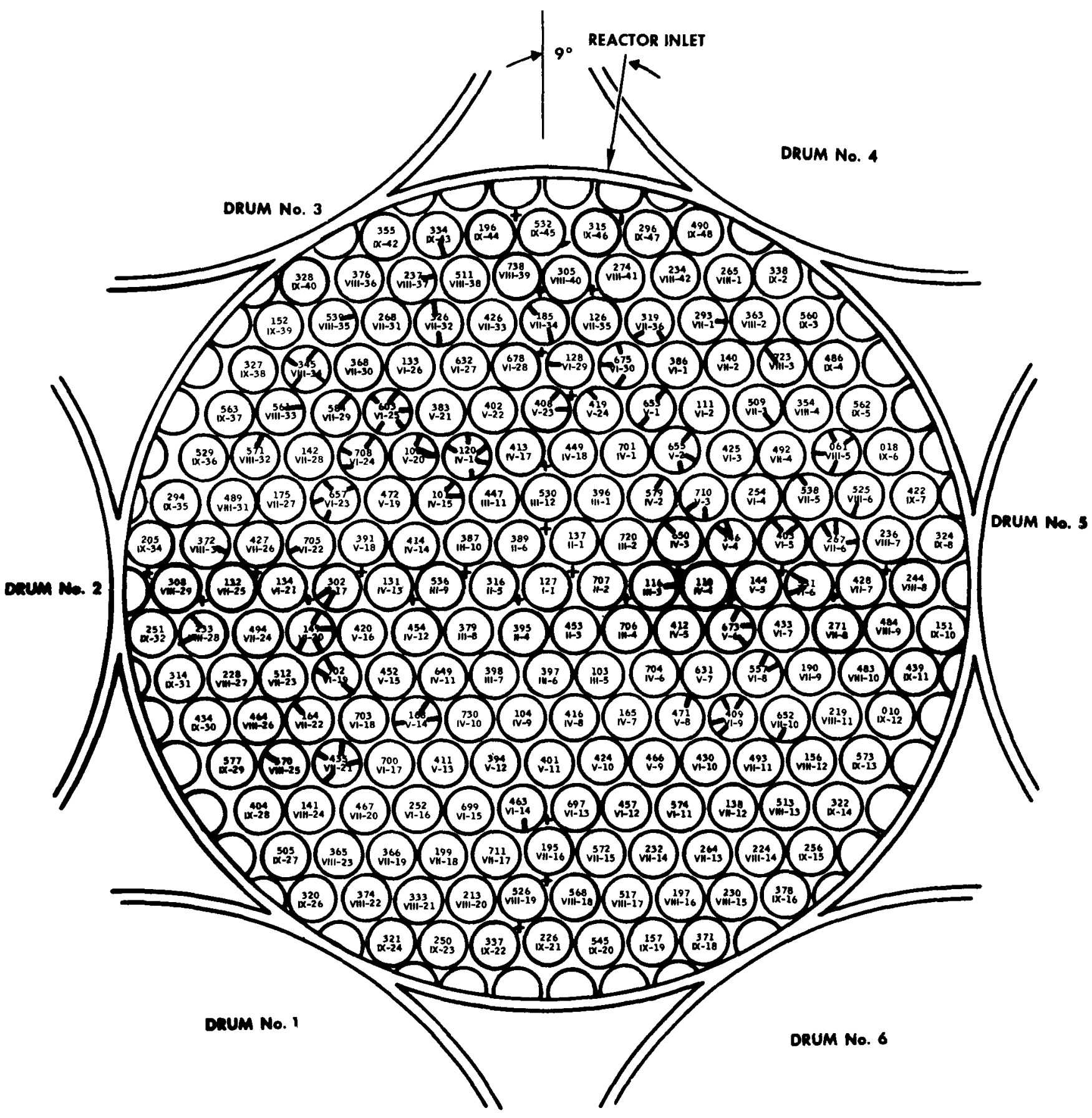

70-MA11-51-6A

Figure II-10. Azimuthal Orientation of Cladding Cracks (as seen looking down on tope of core) 


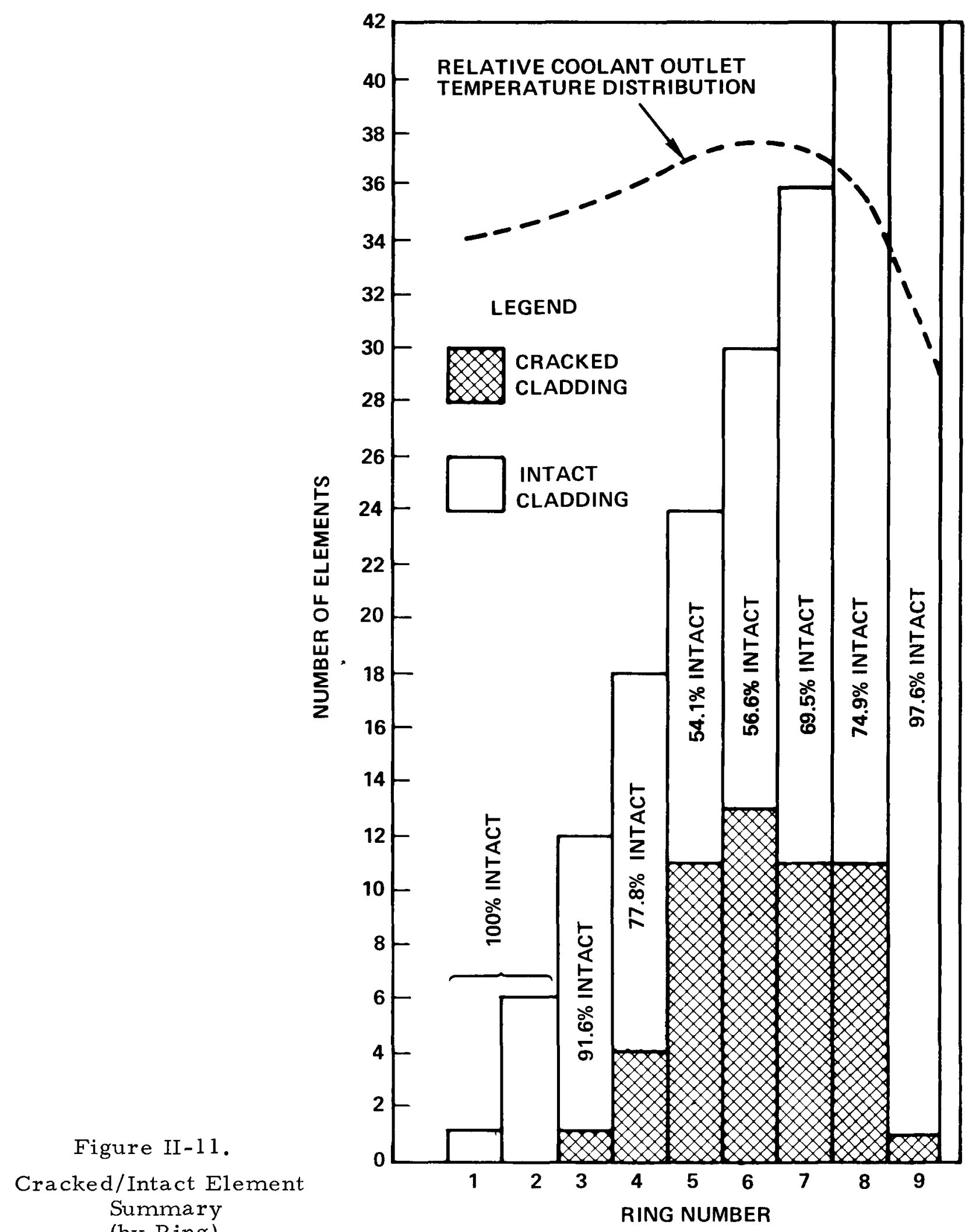

70-MA12-51-7A (by Ring) 


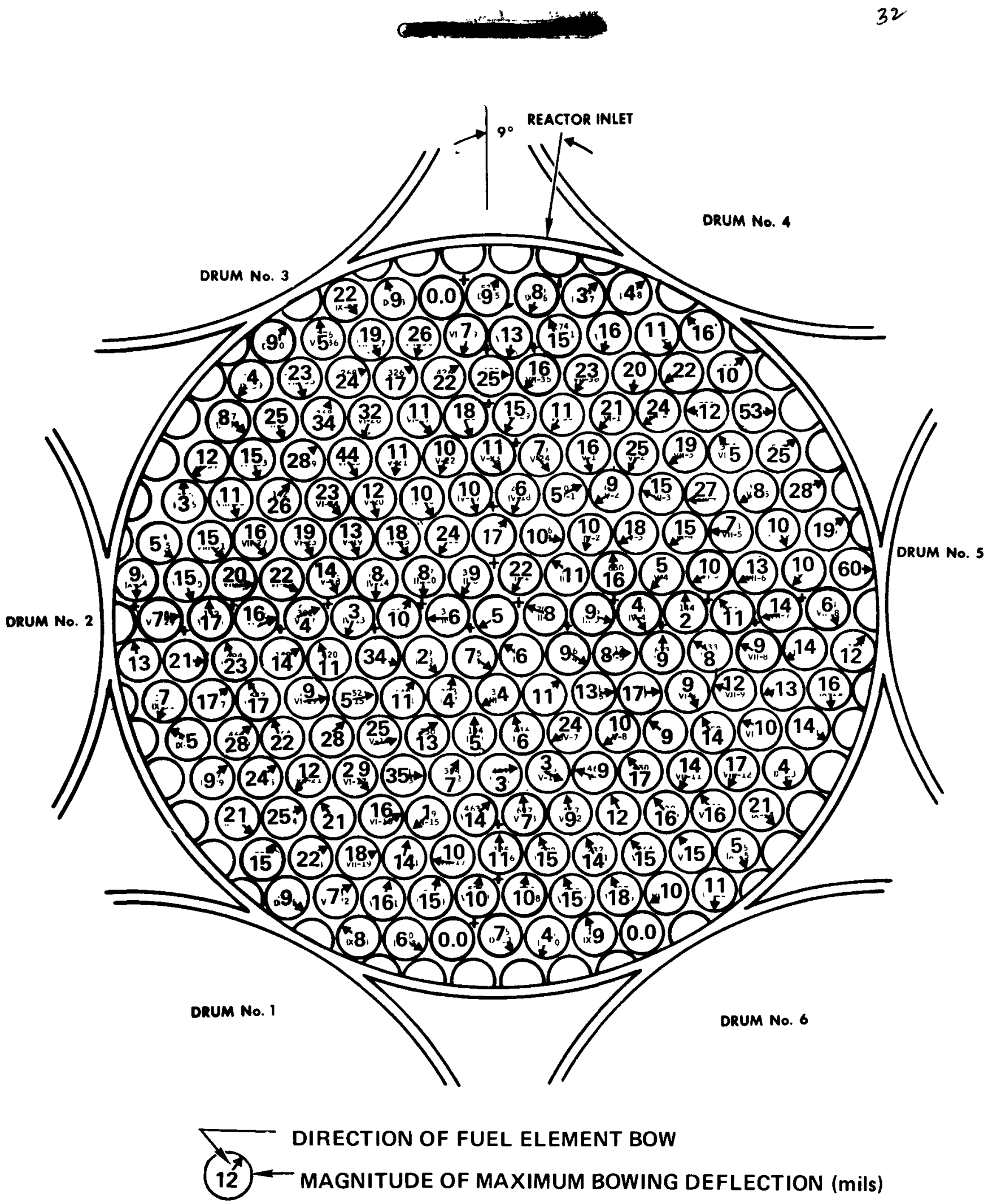

70-JU3-51-9C

Figure II-12. Fuel-Element Bow Measurements 


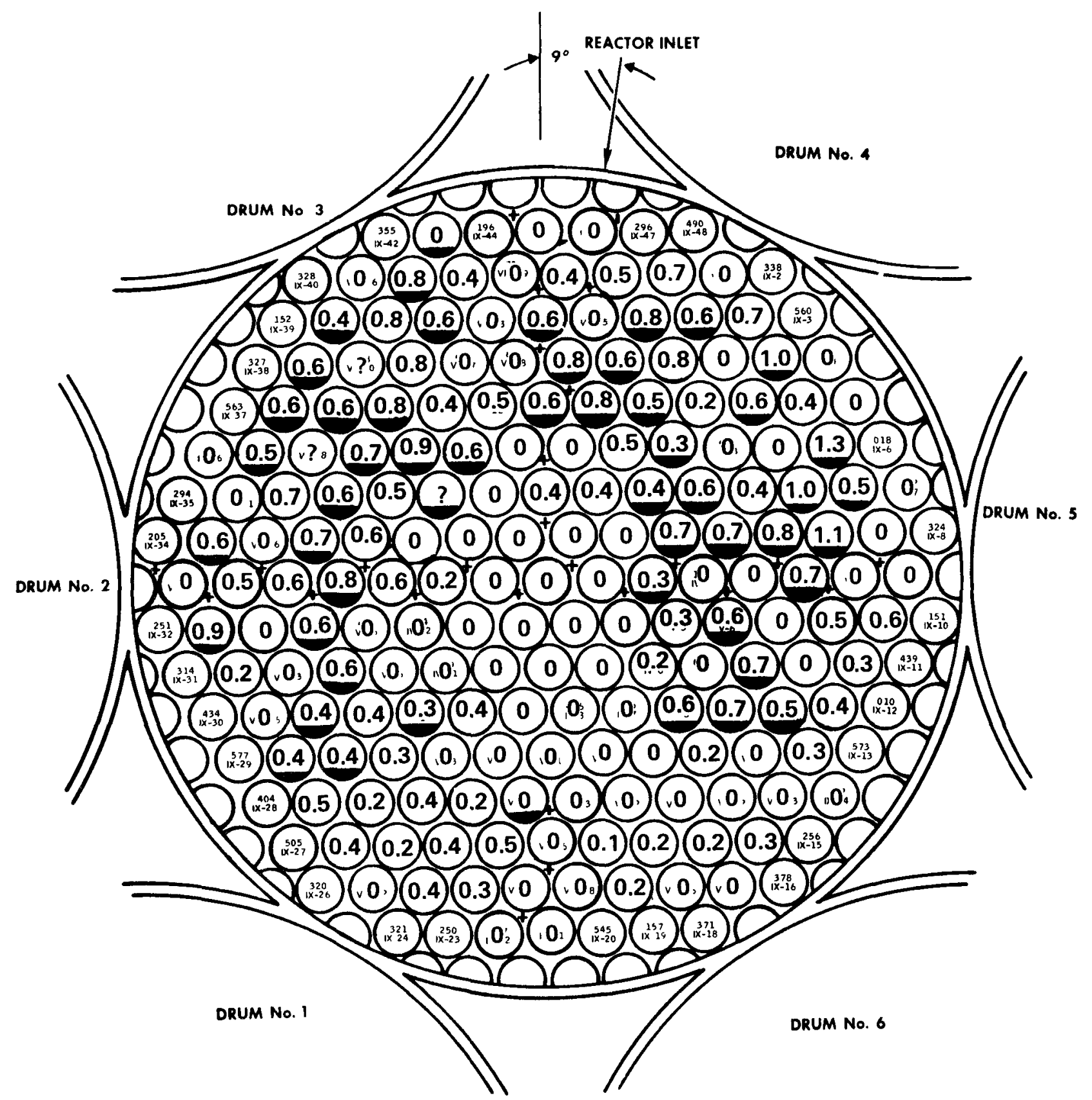

70-MA13-51-38C

0.7 - MAXIMUM DIAMETRAL STRAIN (\%) INDICATES CRACKED ELEMENT
?--CLADDING STRAIN COULD NOT BE INFERRED FROM TRACE

Figure II-13. Maximum Diametral Cladding Strain Inferred From Spiral-Scan Traces 


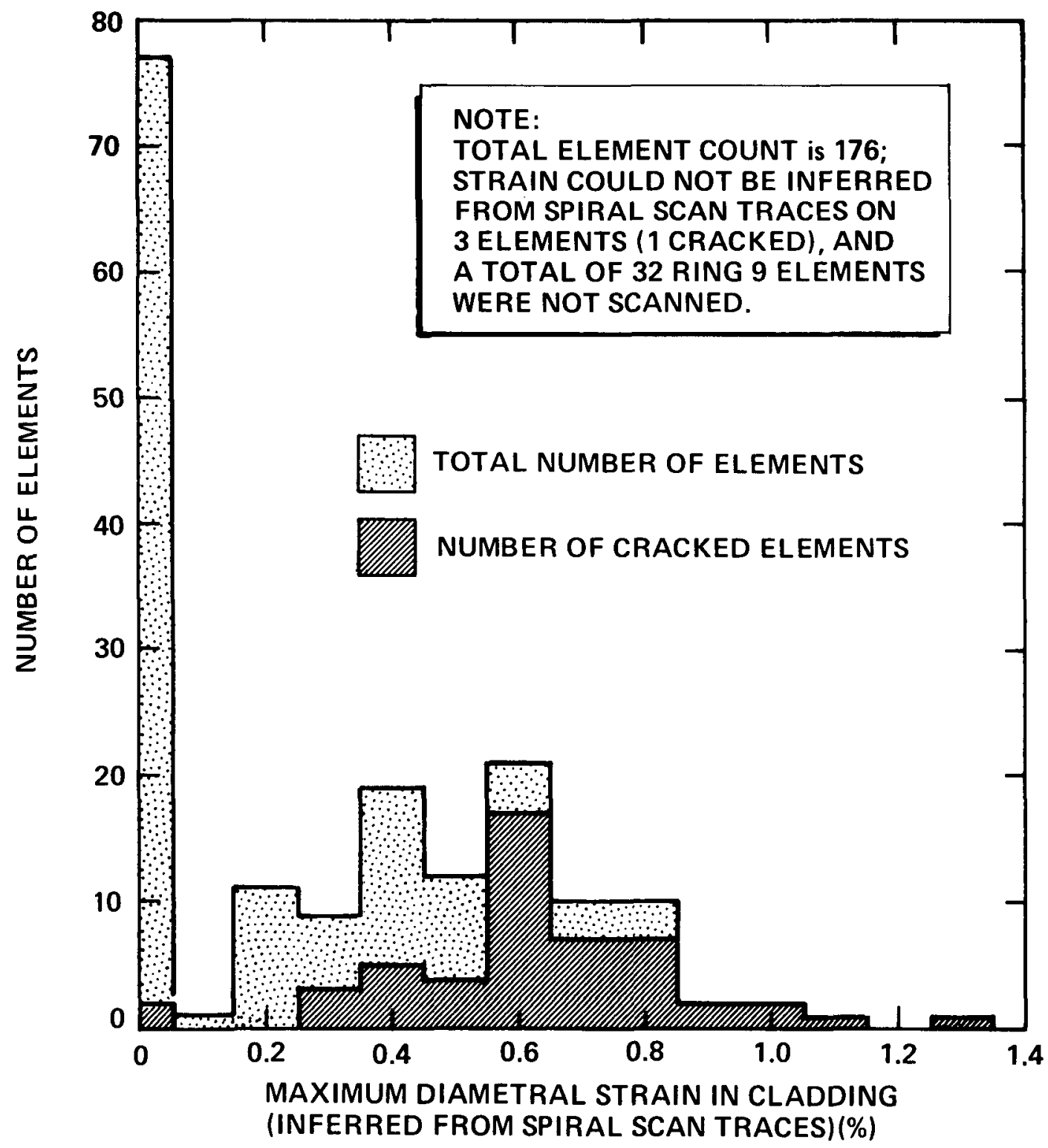

70-JU22-034-33

Figure II-14. Apparent Strain Capability of SNAP 8 Developmental Reactor Fuel-Element Cladding 
The overall fuel-element length changes were slight (being of the order of 15 to 20 mils) with the post-test element length generally being shorter than at pre-test.

c. Fuel-Rod Dimensional Data

Fuel-rod diameter and length measurements were obtained using a neutronradiography technique developed specifically for this purpose. Figure II-15 shows a typical neutron radiograph from which the fuel-rod diameter and length measurements are taken using a comparator. The neutron-radiography technique was also used to detect areas of gross hydrogen loss in the fuel rods and to locate any transverse or longitudinal cracks. A total of 28 fuel elements were found to contain fuel regions grossly depleted in hydrogen content (Figure II-16). A total of 66 fuel elements were found which contained fuel rods with one or more transverse cracks (Figure II-17).

The neutron-radiography dimensional data indicate that in intact elements some fuel rods have what is considered normal fuel growth while others show only slight diametral growth. All of the cracked elements contained fuel rods with only slight to moderate fuel-rod growth as deduced from neutron radiography. In no instance do the data for the cracked elements indicate that the fuel rod is in contact with the cladding. The fuel elements containing rods which appear to have lost a good deal of hydrogen also show only minimal to moderate fuel diametral growth.

The fuel-rod diametral-growth characteristics of intact S8DR fuel elements, not exhibiting high hydrogen loss nor anomalous apparent low diametral growth, are shown in Figure II-18. As can be seen from this figure, fuel-to-barrier contact probably existed in Rings 4, 5, 6 and possibly 7. The diameter changes shown in Figure II-18 are based upon the maximum measured growths in the appropriate elements. The maximum measured fuel growths can be seen to be generally higher than those predicted for this group of elements.

d. Gamma-Scan Data

Gamma-scan profiles were taken on a total of 90 elements in the S8DR core. The elements were selected to determine the gamma-activity (power) profiles toward both active and passive drums and an external radial-reflector-cusp 

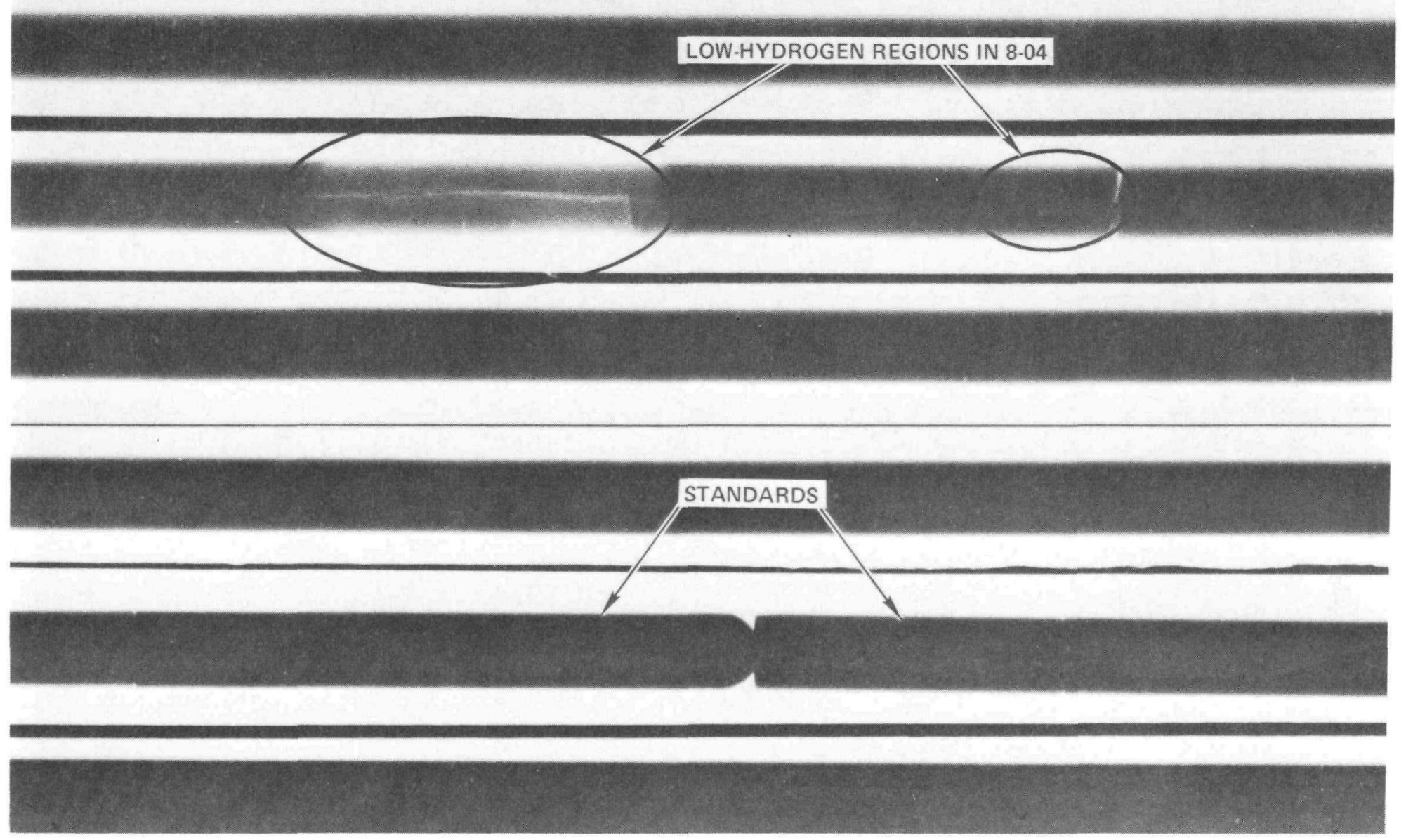

70-MA21-51-170

Figure II-15. Typical Neutron Radiograph (shot for fuel-rod cracks and gross hydrogen) 


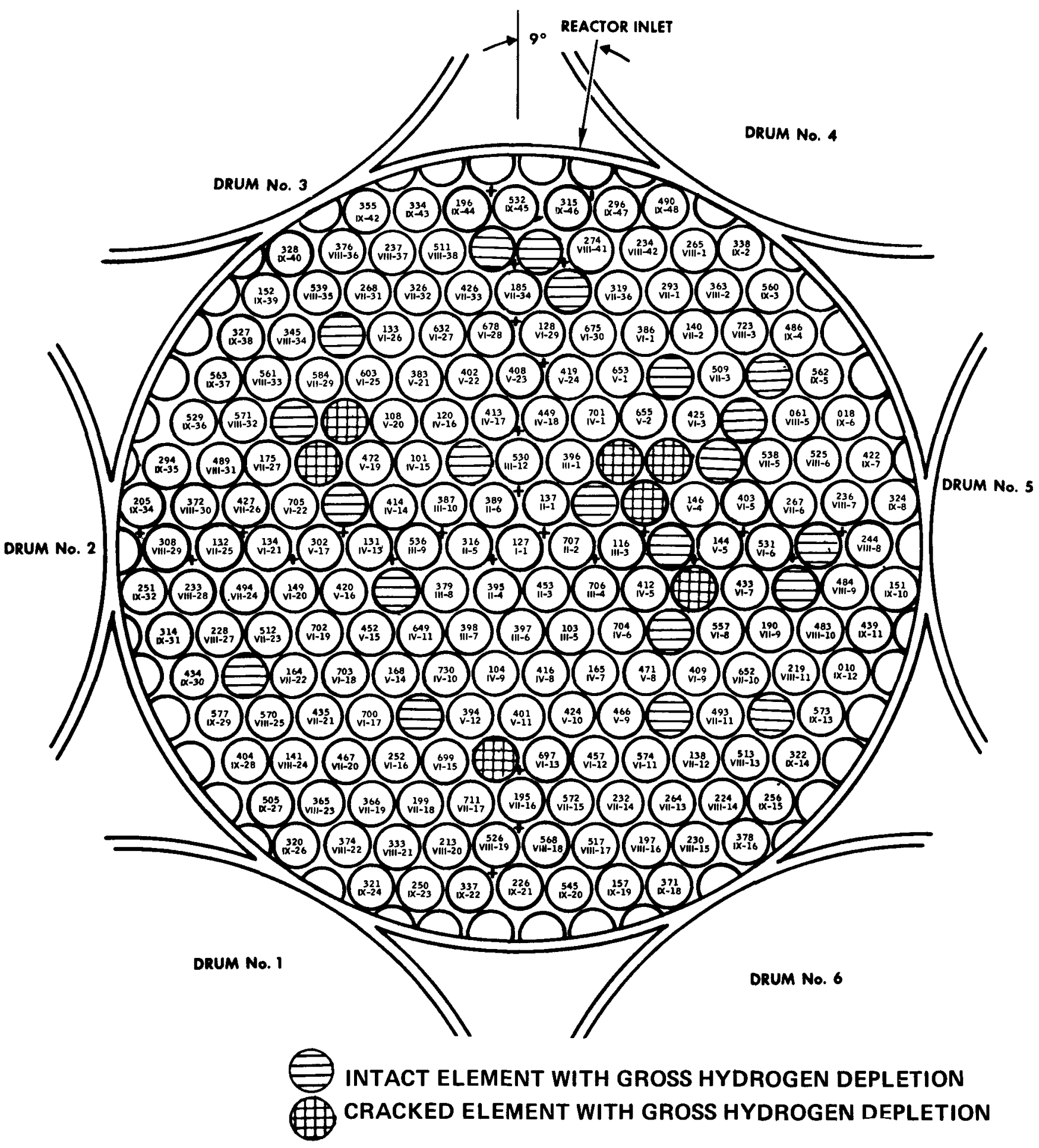

$70-J Y 2-034-40$

Figure II-16. Location of Fuel Elements Observed (by n-ray) to Have Fuel-Rod Regions Grossly Depleted in Hydrogen Content 


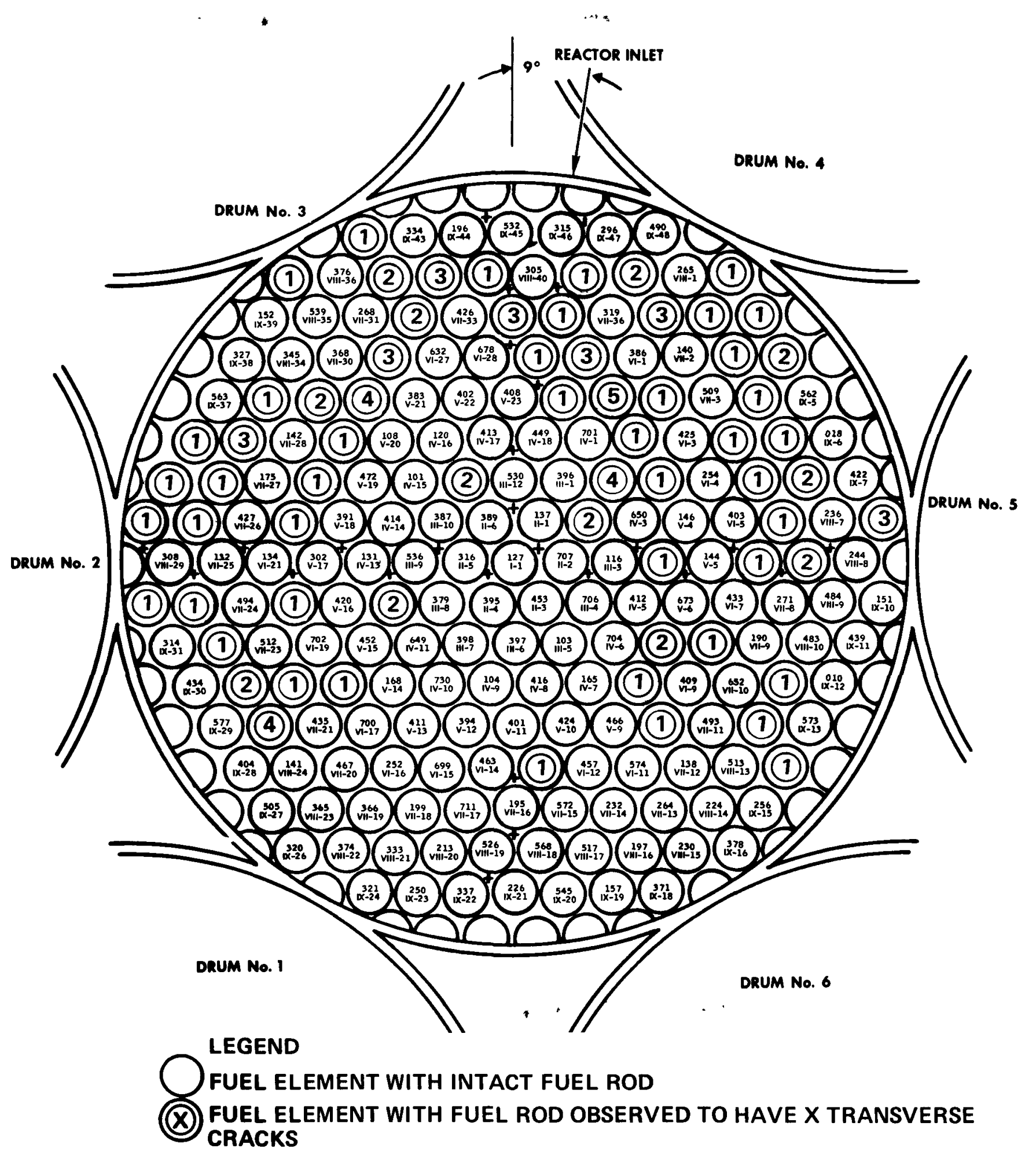

70-JY2-034-39

Figure II-17. Location of Fuel Elements Containing Fuel Rods With Transverse Cracks 


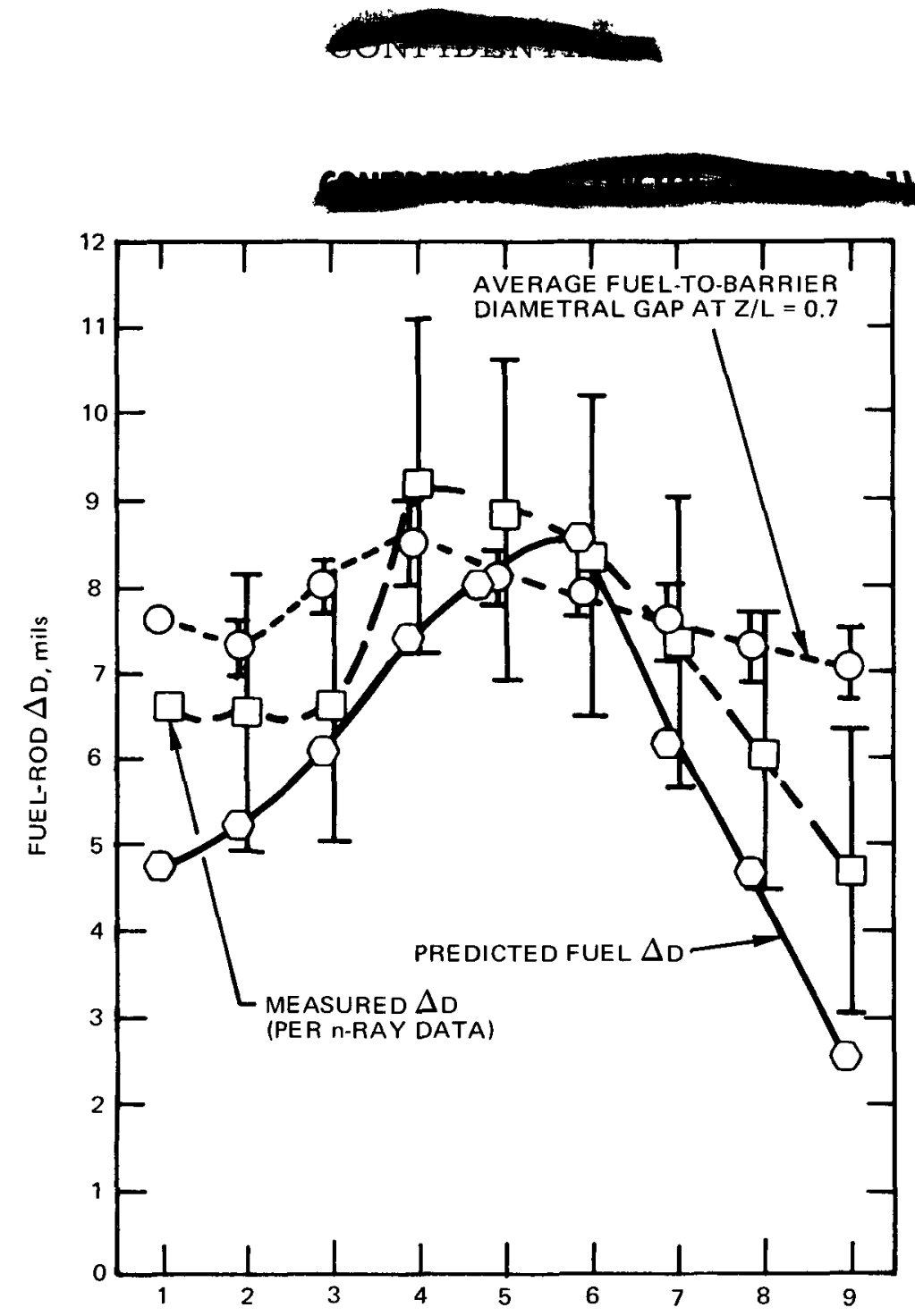

RING NUMBER

LEGEND

$\begin{array}{ll}\text { I } & 1 \sigma \\ \text { MAXIMUM FUEL } \triangle D \text { FOR INTACT ELEMENTS (AVERAGED FOR RING) } & 1 \sigma \\ \text { FUEL-TO-BARRIER DIAMETRAL GAP (AVERAGED FOR RING) } \\ \text { PREDICTED } \triangle D \text { AT } Z / L=0.7\end{array}$ (GP-1)

$7759-25190$

Figure II-18. S8DR Fuel-Rod $\triangle D$ Characteristics

(by Ring) Based upon $\mathrm{n}$-Ray Observations:

Intact Elements Only (with anomalous low growers deleted) 
region. The relative power distribution obtained by averaging the gamma-scan data for the appropriate $R / R_{0}$ locations is shown in Figure II-19. The radial peak-to-average power ratio in the S8DR core calculated from the data is 1.245 , which compares quite favorably with the predicted End-of-Life power ratio of 1.23 .

\section{B. DETAILED EXAMINATION}

The fixturing and cell preparation for the detailed examination of S8DR fuel elements was well under way at the end of the report period. A total of 41 elements and 30 alternates were selected for examination. Selections were made to allow investigation of potential failure mechanisms, which include: $\delta / \epsilon$ fuel swelling, $\beta$ fuel swelling, overstress due to fuel and/or element interaction, barrier degradation, and overstress due to internal pressure. Of the 41 primary elements, 17 are to be permeation-tested to evaluate hydrogen-barrier quality. All elements will be destructively examined. This will include metallurgy on fuel and clad, dimensional measurements, fission-gas analyses, cladding mechanical properties, fuel-hydrogen and density measurements, and burnup on selected elements.

\section{HYDRAULIC TESTING}

A full-core hydraulic mockup consisting of dummy metallic elements, plastic elements for visual observation, and metallic elements containing conductivity probes encased in a plastic vessel was built to determine the effects of surgetank gas entrainment in the coolant. Tests are in progress, and complete analysis of the results has not yet been made. Early in the test visual observation of two standing vortices in the inlet plenum was made at water flowrates as low as $30 \mathrm{gpm}$. The vortices remained at all higher flowrates used. The phenomenon appears to be caused by core-support lugs.

The vortices appear to cause agglomeration of the gas at low gas concentrations, with periodic release in small puffs. This observation is yet to be quantified. Pressure mapping of the lower gridplate and orifice-plate regions is underway. Further tests are planned to establish void fractions and flow patterns in the core. Mixing characteristics of the upper gridplate and thermocouple bridge will also be investigated. 


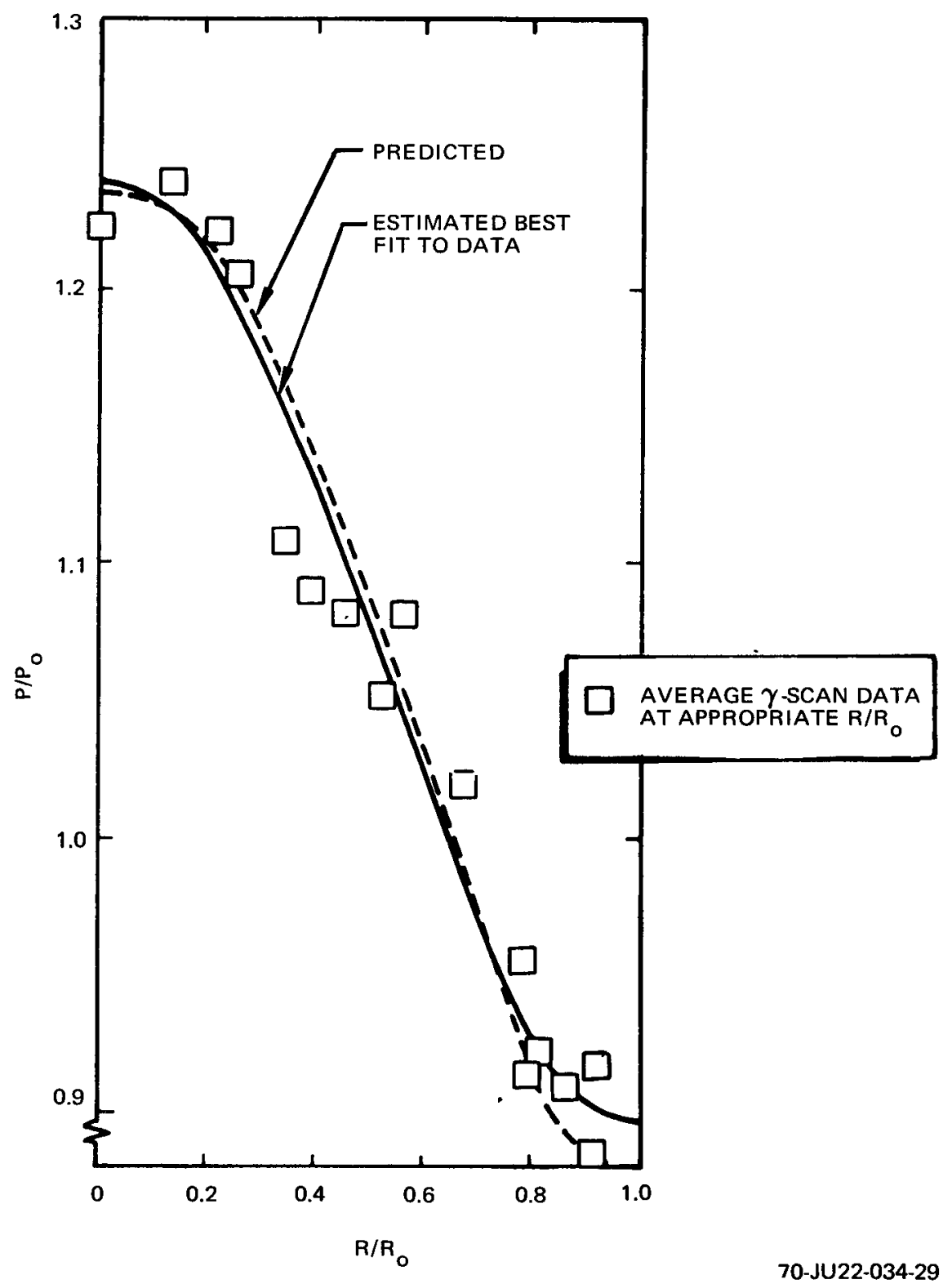

Figure II-19: Relative Radial Power Distribution in S8DR Core 


\section{REFERENCE ZIRCONIUM HYDRIDE REACTOR ENGINEERING}

\section{A. INTRODUCTION AND SUMMARY}

The incentive to reduce fuel-element diameter to lower fuel temperature was determined to be insufficient to warrant change from the S8DR-type element dimensions. Thus the current reference design retains 295 fuel elements.

Core hydraulic design and analysis advanced significantly through use of the GE $\varnothing \mathrm{M} 2$ code described briefly last quarter. Channel-to-channel coolant mixing provided by the integral spiral fins on the fuel elements was found to be a powerful means of minimizing radial coolant temperature gradients in the core. The smoothing of temperature gradients results in favoring of core designs consisting of two or three annular zones of differing fuel-element $O D$ to achieve flow/power distribution matching. In this concept all elements are located on a constant triangular-pitch array and have a constant-diameter fin envelope. Cladding-tube outside diameter in each zone is selected so as to provide the desired flow-channel area.

Analyses of hot-channel effects caused by element bowing to the limits permitted by manufacturing tolerances on fin-to-fin clearances were made. In addition the effect of displacement of fuel meat within the cladding tubes to a common channel was analyzed. Both of these hot-channel conditions were found to be extensively reduced by the current element design.

At the end of the quarter the factoring of the detailed core thermal environment into the fuel-element structural analysis and support-methods studies were begun.

\section{B. CORE THERMAL/HY DRAULIC ANALYSIS \\ 1. Analysis}

The GE $\varnothing \mathrm{M} 2$ code was used to perform a parametric analysis of possible configurations for the reference reactor. Variables used included element diameter, element spacing, coolant flowrate and core-edge treatment. The studies showed that interchannel coolant mixing is the single most important factor in reducing cross-element thermal gradients. Reducing element diameter (thereby increasing the number of elements) and reducing spacing show a very 
minor effect on coolant temperature distribution. Reducing the element diameter does, of course, reduce fuel temperature.

Increasing the coolant flowrate and thereby reducing the core-temperature rise results in low cross-element temperature gradients, but at the expense of increased pumping-power requirements. It appears at this time that a temperature rise of 100 to $150^{\circ} \mathrm{F}$ can be accommodated.

The core-edge treatment effect is a result of the reflector cooling which causes a transfer of heat from core-edge to reflector coolant. This heat loss results in rather severe thermal gradients across the edge elements. Two methods to overcome this effect are under consideration:

1) Use of a thermal barrier (insulation) between the core and reflector.

2) Reduction in channel area at the core edge so that the temperature loss is balanced by flow starving.

While final selection of core configuration has not been made, the desire to maximize reactivity márgin dictates that spacing be quite close. Methods of flattening power profiles to reduce spacing-variation requirements are under study as are zoning variations. Variable-clad OD with constart triangular pitch is the method used for spacing control. The possible reactivity gain of using variable fuel-meat diameter (constant clad thickness) is still under study.

\section{Hydraulic Tests}

A 19-element bundle is in fabrication to attain more accurate values of mixing rates than are currently available. Spare S8DR test elements, fins made from adhesive-backed plastic tapes to permit rapid change of fin configuration, have been used.

The bundle is encased in a plastic body to permit visual as well as instrumented data acquisition. The 19-element configuration was selected to minimize the effects of the containment vessel but still permit rapid test setup. Four of the elements are fitted with conductivity probes at 4-in. increments along the element length. Movable injectors are provided to permit a wide range of injection locations with respect to the probe locations. 
Use of both dye for visual inspection and salt for instrumented data is planned. Variation in fin pitch and number as well as a wide range in flowrate will be used to bound the range of mixing anticipated in the final core design. Pressure meas urements are also provided.

\section{NUCLEAR ANALYSIS}

Required excess reactivity, control worth, and the associated optimum poison loading were calculated for 600-kwt operation at two coolant-outlet temperatures and two mission lifetimes. Mission lifetimes of 20,000 and 44,000 hr were assumed outlet temperatures of 1200 and $1300^{\circ} \mathrm{F}\left(200^{\circ} \mathrm{F} \Delta \mathrm{T}\right)$. The effect of including tritium in the core to provide EOL (End-Of-Life) shutdown and waterimmersion subcriticality (pages 62 to 71 of Reference 1) was also investigated.

The data shown in Figure III-I indicate the currently expected range of excess and control requirements for the various combinations of operating conditions and present graphically the likelihood of being able to accomplish each postulated mission. The figure charts required excess reactivity (upper blocks) and control worth (lower blocks) against currently attainable values of each. The top of a given block corresponds to requirements with full margin allowances, the bottom to no margin allowance. Two sets of three dashed lines are also shown. The upper set corresponds to expected excess-reactivity capability of the $\mathrm{ZrH}$ reactor. The center line of the set represents current best estimate available excess; the lines on either side represent probable upper and lower limits on attainable excess. The lower set of three dashed lines defines similar regimes for expected attainable control worth. The center set of dashed lines corresponds to a core configuration very similar to the Core $\mathrm{C}$ configuration from the previous reporting period. $(2) *$

The items which effect the reactivity and control requirements of the reactor are shown schematically in Figure III-2. The unpoisoned cold excess of the reactor is determined by the physical configuration and composition of the reactor. Prepoison is added to the core to get the control swing within the desired envelope. Then the reactivity changes during reactor operation must be considered to determine the operational reactivity swing.

*Superscript numbers in parentheses identify References at end of this report. 


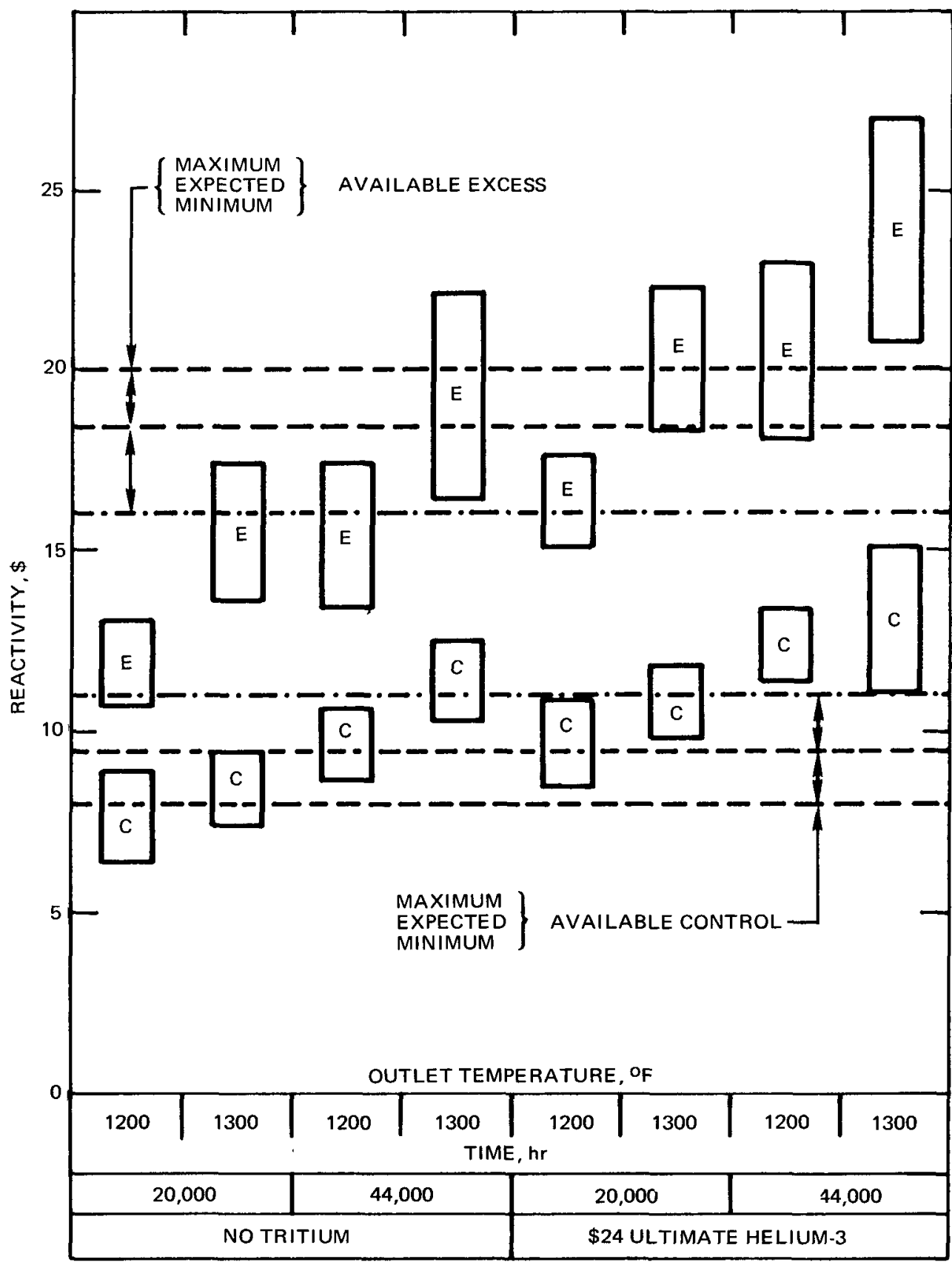

$7759-25217$

Figure III-1. Effect on ZrH Reactor of Temperature, Lifetime, and Tritium Excess and Control Requirements vs Available Excess and Control 

The "non-recoverable short-term loss" is the reactivity loss due to hydrogenredistribution within the core. While it is possible to regain the reactivity lost from this effect by slowly shutting down the reactor in a prescribed manner, normal scram of the reactor precludes this recovery.

"Recoverable short-term losses" occur during the first few days of reactor operation and include (1) losses from heating the reactor from ambient to operating temperature, (2) the loss from going to power at temper ature, and (3) Xenon poisoning. The shape of the "hot operating excess" curve is determined by the balance between the prepoison burnout and the losses from hydrogen loss, fuel burnout, and fission-product buildup. The effects of tritium decay must also be included if tritium is included in the core loading for EOL shutdown and waterimmersion subcriticality.

The "cold shutdown excess" and "cold shutdown reactivity" lines apply any time after hydrogen redistribution has taken place. The difference between the two lines is the control-drum worth. It is necessary for the "cold shutdown reactivity" to remain less than "minimum cold shutdown" line to retain the desired operational shutdown margin.

Figure III-3 illustrates the effect of initial prepoison loading on the required excess reactivity for $44,000-\mathrm{hr}$ operation at $600 \mathrm{kwt}$ and $1200^{\circ} \mathrm{F}$ outlet. The effect of the BOL (Beginning-Of-Life) reactivity margin and the EOL margin on the required excess is shown. The EOL margin is larger than the BOL because it includes the BOL margin plus allowances for uncertainty in the various reactivity-loss mechanisms. Thus the total required excess is the sum of the recoverable losses, the short-term non-recoverable and long-term losses, the residual EOL prepoison, and the margin requirements.

Figure III-4 indicates the changing control requirement as a function of the prepoison loading. Minimum control would be required if the "Hot operating excess" curve of Figure III-2 were flat for the entire operating time. In the actual case, since the curve either continues to drop monatomically with lifetime (for small prepoison loadings), or rise first (due to prepoison burnout) and then decrease, with the height of the rise being a function of the prepoison loading a minimum occurs in the control requirement. "Mismatch" refers to the sum of the reactivity drop and peak (if any). Since reactivity control of the reactor 


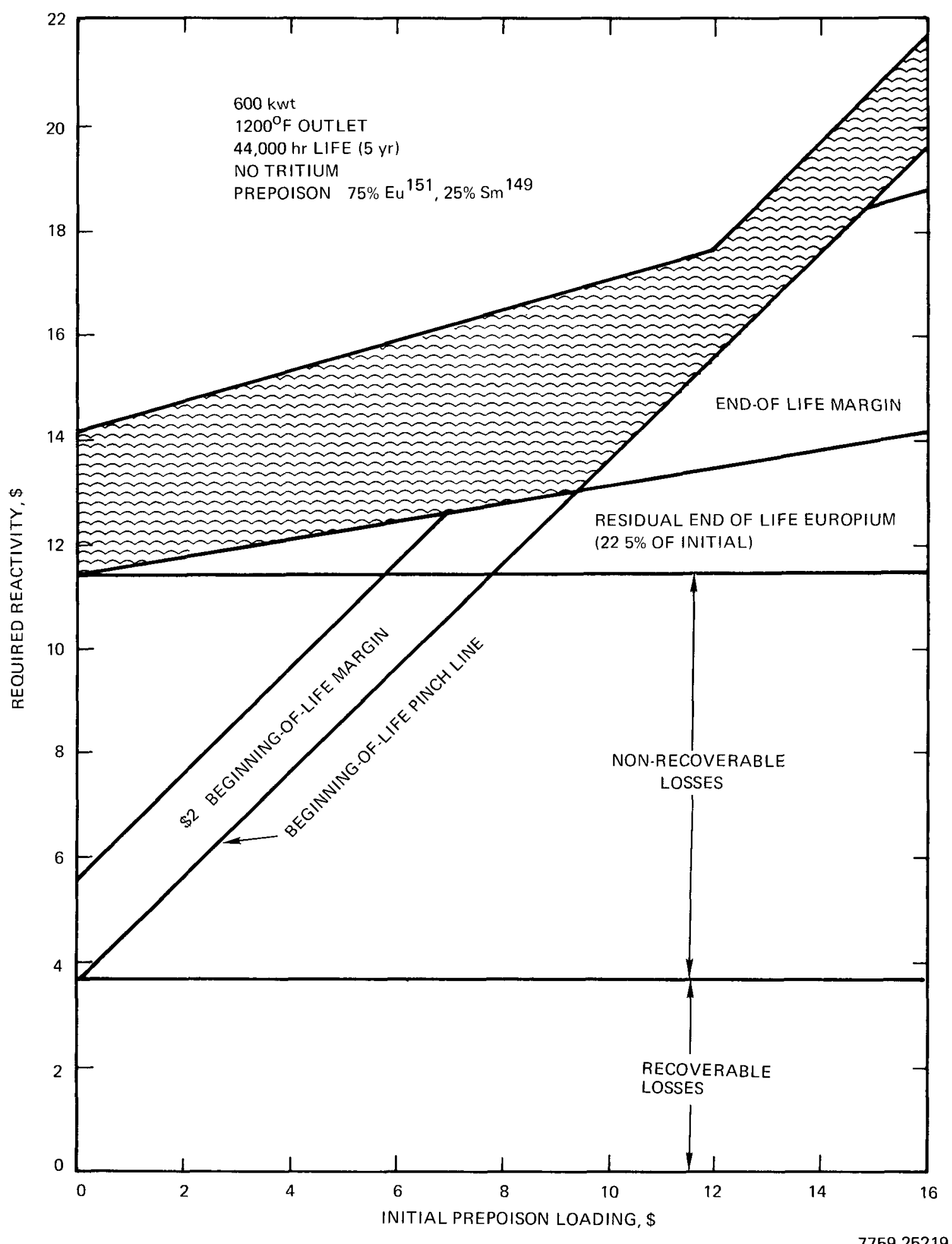

Figure III-3. Reference Zirconium-Hydride Reactor ExcessReactivity Requirernents vs Prepoison Loading 


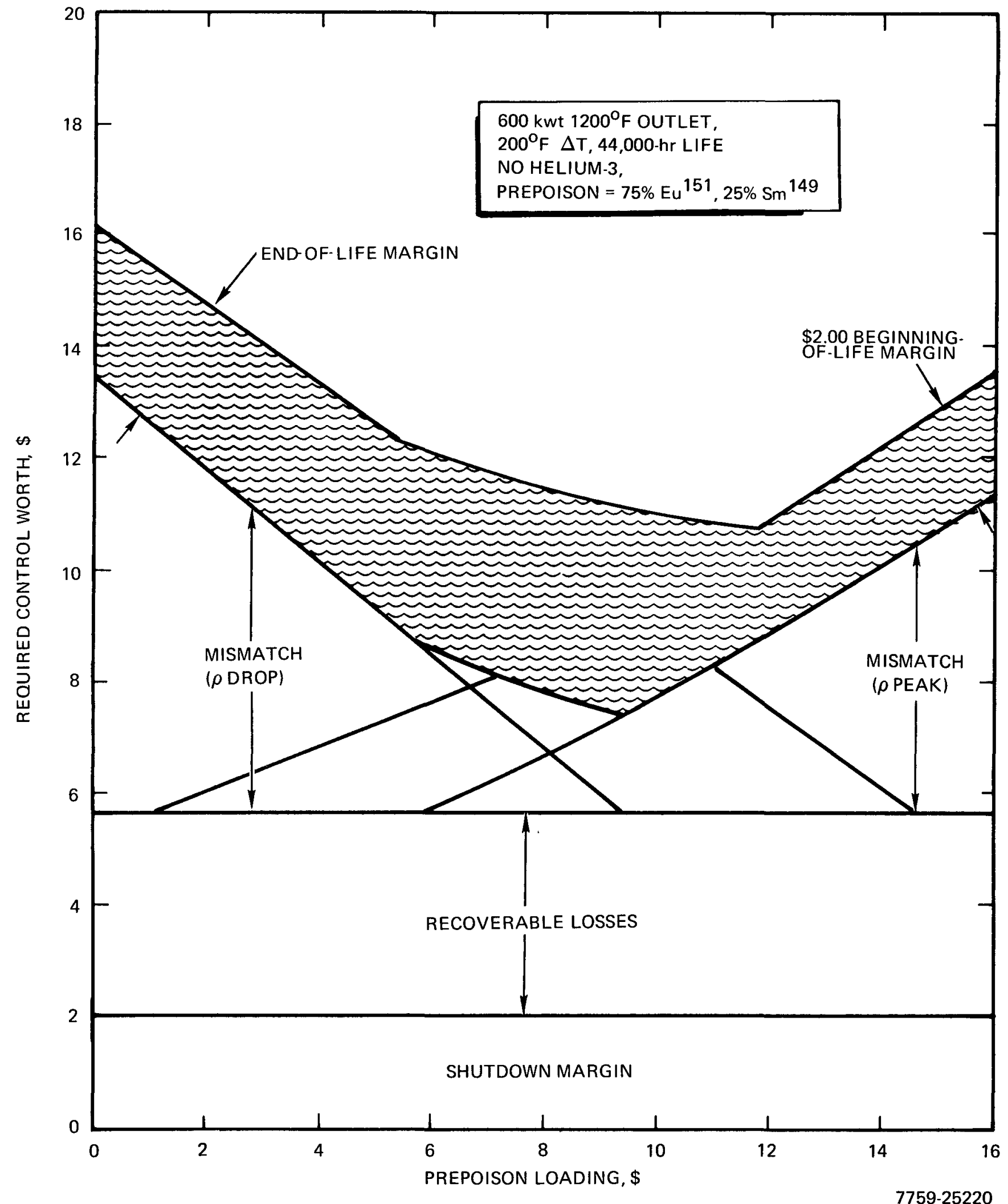

Figure III-4. Reference Zirconium-Hydride Reactor Control Requirements vs Prepoison Loading

$$
\text { AI-AEC- } 12975
$$


is taken to be limiting, the minimum control point sets the prepoison loading for a given application, which in turn sets the excess-reactivity requirement.

The data on Figure III- 3 and -4 can be cross-plotted to obtain curves, as in Figure III-5, showing required control-drum worth as a function of required excess reactivity. These curves include the margin requirements on reactivity . and control. A similar curve can be obtained for conditions without margins. The cases with and without margins then represent the extremes of the required excess and control boxes shown in Figure III- 1 .

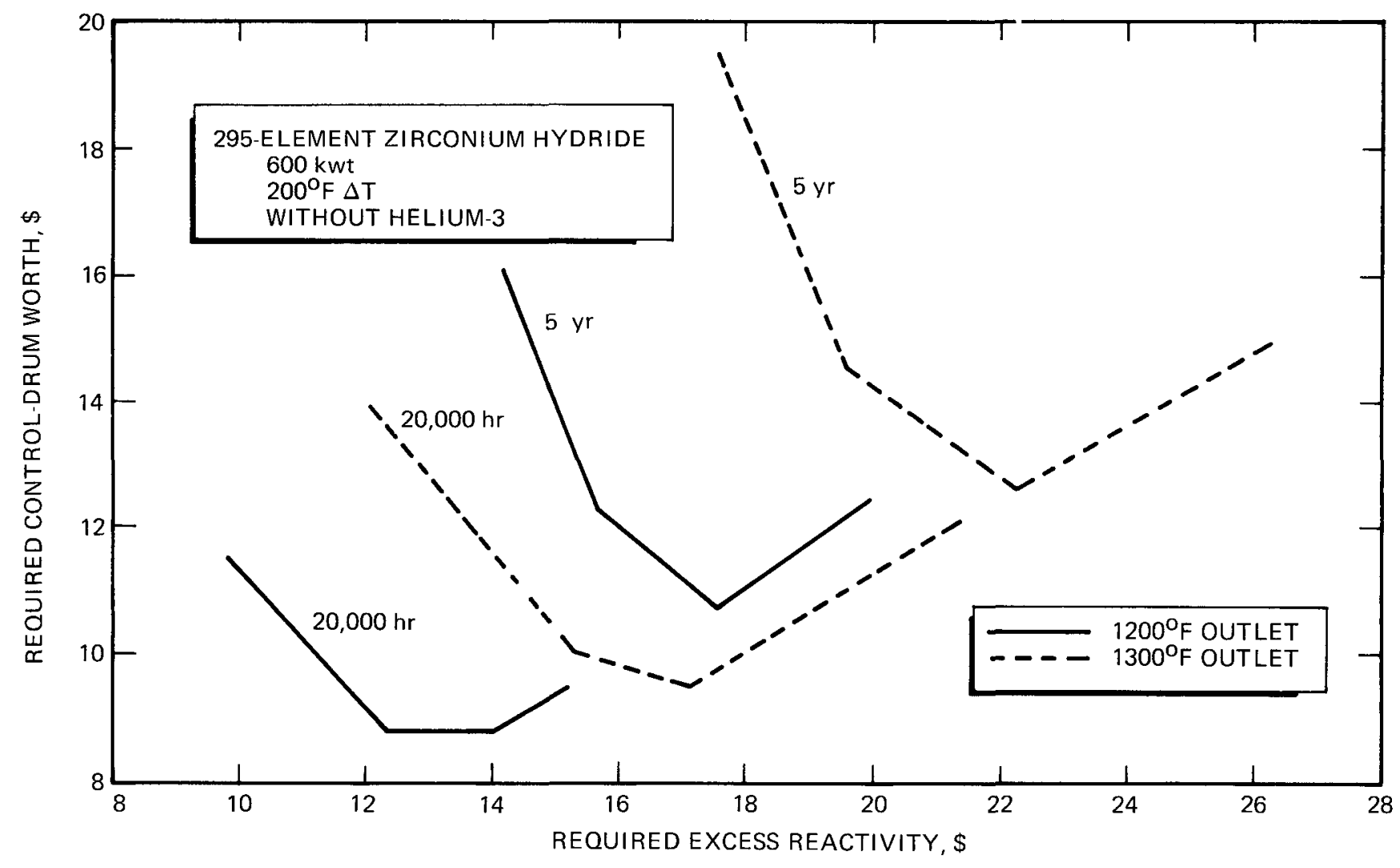

7759-25221

Figure III-5. Required Control Worth with Margins vs Required Excess Reactivity 


\section{BLANK}




\section{REACTOR-THERMOELECTRIC SYSTEM ENGINEERING}

A series of trade studies were made for selecting a design point for the reactor-thermoelectric power system based upon the most current space-station requirements. The basic requirements established for the power plant are:

1) $37 \mathrm{kwe}$ at the power-plant patch board.

2) Minimum system lifetime of $5 \mathrm{yr}$.

3) Complete package capable of Advanced Logistic Shuttle (ALS) resupply ( $15-\mathrm{ft}$-diam by $60-\mathrm{ft}-$ long with a maximum weight of 40,000 lb).

In addition to the above requirements it was deemed desirable to have the system capable of providing a 50\% power growth (55 to $60 \mathrm{kwe}$ ). A degree of freedom is permitted for radiator area in that an additional radiator may be connected into the heat-rejection loop to provide the additional growth power or increased system lifetime.

In performing the trade-off studies consideration was given to the degradation of the TE modules which is a function of temperature and time. Allowance was also made for the failure of some of the TE modules during the mission. Zirconium-hydride reactor thermal-power and outlet-temperature limitations were also considered in the studies. Candidate power systems were selected from a map that included all the above parameters.

A schematic of the selected configuration is shown in Figure IV-1. This configuration has three NaK loops in series carrying thermal power from the reactor to the intermediate heat exchanger, TE modules, and then NaK radiator. In the third $\mathrm{NaK}$ loop is a heat exchanger to transmit heat to the supplemental radiator when the latter is installed. The NaK loops are circulated by means of a triple-throat EM pump located in the gallery. The supplemental radiator has an organic coolant such as DC-200 that is driven by an electrically powered canned-rotor pump. An alternate radiator configuration is also being considered in which both the fixed and plug-in radiators are organic-cooled.

The performance characteristics of the preferred reactor power system based on the above studies and configuration are shown in Table IV-1. Performance is shown without and with the organic radiator operating. With only 


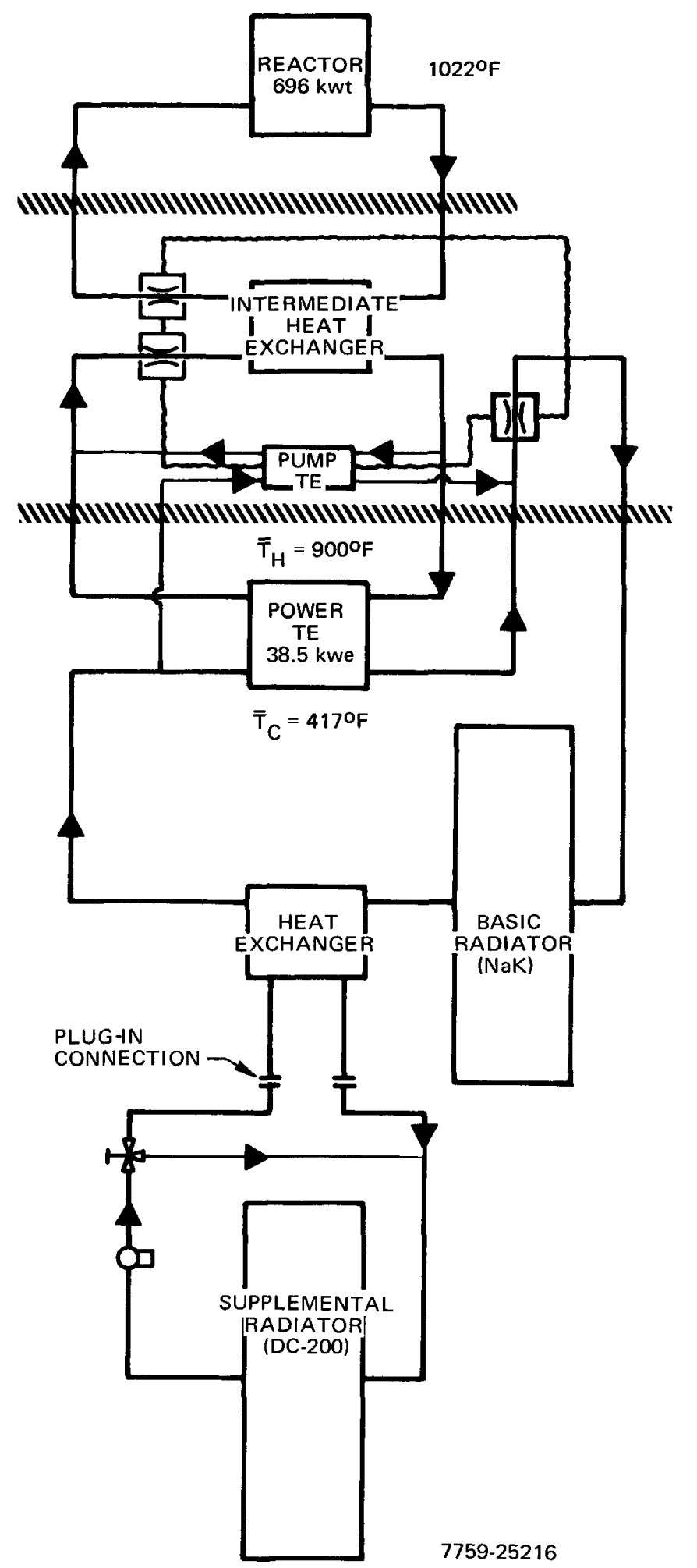

Figure IV-1. Reactor-Thermoelectric System with Supplemental Radiator

(Parameters shown for design point at $5 \mathrm{yr}$ ) 
TAB LE IV - 1

REACTOR-THERMOELECTRIC SYSTEM NaK BASIC RADIATOR, ORGANIC SUPPLEMENTAL RADIATOR

\begin{tabular}{|c|c|c|c|c|}
\hline \multirow{3}{*}{$\begin{array}{l}\text { Weight, lb } \\
\text { Radiator Area, } \mathrm{ft}^{2} \\
\text { Number of Thermoelectric Modules }\end{array}$} & \multicolumn{2}{|c|}{ Basic Package } & \multicolumn{2}{|c|}{$\begin{array}{c}\text { Supplemental } \\
\text { Radiator }\end{array}$} \\
\hline & \multicolumn{2}{|r|}{$\begin{array}{r}28,140 \\
1,890 \\
192\end{array}$} & \multicolumn{2}{|c|}{$\begin{array}{l}3,400 \\
1,910 \\
-\end{array}$} \\
\hline & Initial & $\begin{array}{l}\text { Without } \\
\text { Supplemental } \\
\text { Radiator } \\
5 \text { yr }\end{array}$ & $\begin{array}{l}\text { Design } \\
\text { Point, } \\
\text { at } 5 \text { yr }\end{array}$ & $\begin{array}{c}\text { Growth } \\
\text { Point }\end{array}$ \\
\hline \multicolumn{5}{|l|}{ Performance: } \\
\hline Reactor outlet temperature, ${ }^{\circ} \mathrm{F}$ & 1200 & $1200(1210)$ & 1022 & 1200 \\
\hline Thermoelectric modules operating & 192 & 186 & 186 & 192 \\
\hline Reactor power, kwt & 735 & $735(745)$ & 696 & 881 \\
\hline Thermoelectric output, kwe & 42.4 & $37.3(38.0)$ & 38.5 & 60.5 \\
\hline Power to organic pumps, kwe & - & - & 0.5 & 0.5 \\
\hline Power loss to patchboard, kwe & 1.0 & 1.0 & 1.0 & 1.5 \\
\hline Net power available, kwe & 41.4 & $36.3(37.0)$ & 37.0 & 58.5 \\
\hline $\begin{array}{l}\text { Average thermoelectric cold- } \\
\text { clad, }{ }^{\circ} \mathrm{F} \\
\text { Peak organic film temperature, } \\
{ }^{\circ} \mathrm{F}\end{array}$ & 540 & $54 u(550)$ & 417 & 440 \\
\hline
\end{tabular}


the $\mathrm{NaK}$ radiator operating and with allowance for $\mathrm{TE}$ module failure and degradation, $36.3 \mathrm{kwe}$ can be delivered at $1200^{\circ} \mathrm{F}\left(37.0\right.$ at $\left.1210^{\circ} \mathrm{F}\right)$ outlet temperature after $5 \mathrm{yr}$. The effectiveness of using a supplemental radiator is shown at the nominal power condition where $37.0 \mathrm{kwe}$ can be delivered with consistent failure and degradation assumptions at a reactor-outlet temperature of only $1022^{\circ} \mathrm{F}$ at $5 \mathrm{yr}$. The extra radiator also permits a maximum power of 58.5 kwe at $1200^{\circ} \mathrm{F}$.

The basic power-system weight of 28,140 $\mathrm{lb}$ includes the radiation shield. The shield constraints include a dose-plane diameter of $130 \mathrm{ft}$, separation distance of $200 \mathrm{ft}$, gallery height of $10.5 \mathrm{in}$, doserate at $90^{\circ}$ and $100 \mathrm{ft}$ of $100 \mathrm{rem} /$ $\mathrm{hr}$, and a crew doserate from the reactor source of $25-\mathrm{rem} / 6$-months. 


\section{THERMOELECTRIC CONVERTER DEVELOPMENT \\ (Prepared by Westinghouse Astronuclear Laboratory)}

\section{A. REACTOR TUBULAR POWER MODULES}

During the past quarter ten first-generation 5.25-volt (TEM-13G series) prototype reactor modules were tested. At AI three (TEM-13G SN-1, -2, and -5) were tested individually in the liquid-metal loop and four (SN-6, - 7, -8 , and -9) as a part of Converter Module SN-1. At WANL two modules (TEM-13G SN-4 and -11) were tested in static test stands and one (SN-12) in a liquid-metal loop system.

\section{Performance Data}

Three of the first-generation 5.25-volt prototype modules remained on loop test at $\mathrm{AI}$ in individually shrouded test assemblies during the past quarter. Examination of performance data recorded during this time, including some unscheduled shutdowns and subsequent restarts, indicates that TEM-13G SN-1 and -5 have experienced some intercouple shorting. This shorting was evidenced by a concurrent reduction in both open-circuit voltage and internal resistance and resulted in decreasing power output and efficiency. Both modules are now scheduled for destructive examination to ascertain the extent of the intercouple shorting.

The shorting observed in the TEM-13G series modules is due to distortions in the circuit resulting from axial differential expansion of the outer and inner clads during thermal transients. This problem should be eliminated through the use of a low-expansion refractory inner-clad discussed in Sections A-2 and -3 .

TEM-13G SN-2, the third module individually tested in a loop, has accumulated $6689 \mathrm{hr}$ of operation. A statistical analysis of power-output data from this module indicates a degradation rate of $12 \% / 10,000 \mathrm{hr}$. Although this module has experienced six thermal cycles to date, no indication of intercouple shorting has appeared. However, evidence exists that the degradation rate has been accelerated by cyclic operation. The probable cause for the change in degradation rate is increased cracking of the mica insulating washers during cyclic operation which results in accelerated diffusion of tellurium. The steps taken to prevent this problem in subsequent modules are described in Section A-3. 
Converter Module SN-1 remains on test in a NaK loop at AI. The degradation rate of the modules in the four-pack configuration is significantly greater than the degradation measured on individual modules in comparable loop or static tests. The possibility of a packaging stress-induced module distortion will be evaluated when the testing is completed.

TEM-13G SN-4 is being tested in a static-test stand at WANL with a coldside NaK jacket providing thermal contact between the module outer-clad and cooling fin base. Initial data from this experiment are being evaluated and compared with that accrued previously during static testing with a conventional Thermon layer between the cooling fin and module.

Static testing of TEM-13G SN-11 at $\overline{\mathrm{T}}_{\mathrm{H}}=1125^{\circ} \mathrm{F}$ and $\overline{\mathrm{T}}_{\mathrm{C}}=570^{\circ} \mathrm{F}$ was completed during the past quarter. The module was tested for $380 \mathrm{hr}$ under steadystate conditions except for one thermal cycle produced by a laboratory power failure just before completion of the initial heatup. The module has been removed from test for destructive examination.

An additional TEM-13G series module completed a series of short-term tests during the reporting period. This module, SN-12, was installed into a liquid-metal loop system and a series of short-term "temperature-mapping experiments" was carried out. The objectives of this test were to (1) generate experimental data for evaluating the accuracy of the primary and secondary boundary layer (film) temperature drops, (2) correlate calculated module performance with experimental data taken over a wide range of operating temperatures, (3) compare static and loop-test data using a common data-acquisition system, and (4) generate data to use in debugging computer codes written to reduce loop-test data.

Figures V-1 through - 3 (voltage, resistance, and power output respectively) show excellent agreement between calculated performance and experimental data for SN-12 over the entire temperature range. The strong functional dependency of each of these parameters on both $\overline{\mathrm{T}}_{\mathrm{H}}$ and $\overline{\mathrm{T}}_{\mathrm{C}}$ is obvious from the slopes of the plotted curves. The high degree of correlation between the calculated and experimental data attests to the accuracy of the module-performance and film-drop calculations. 


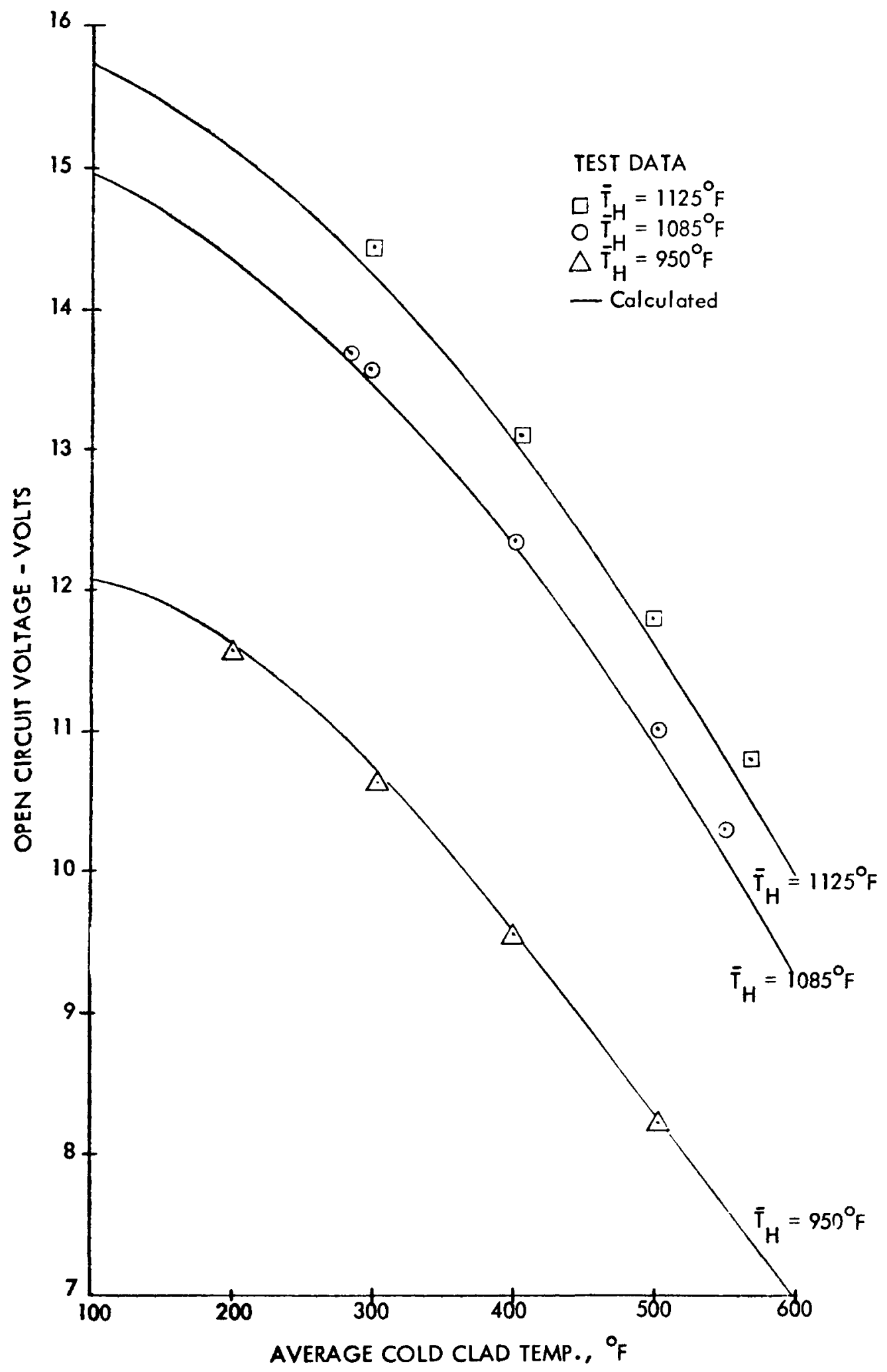

Figure V-1. Comparison of TEM-13G SN-12 Open-Circuit Voltage Data with Performance Calculations 


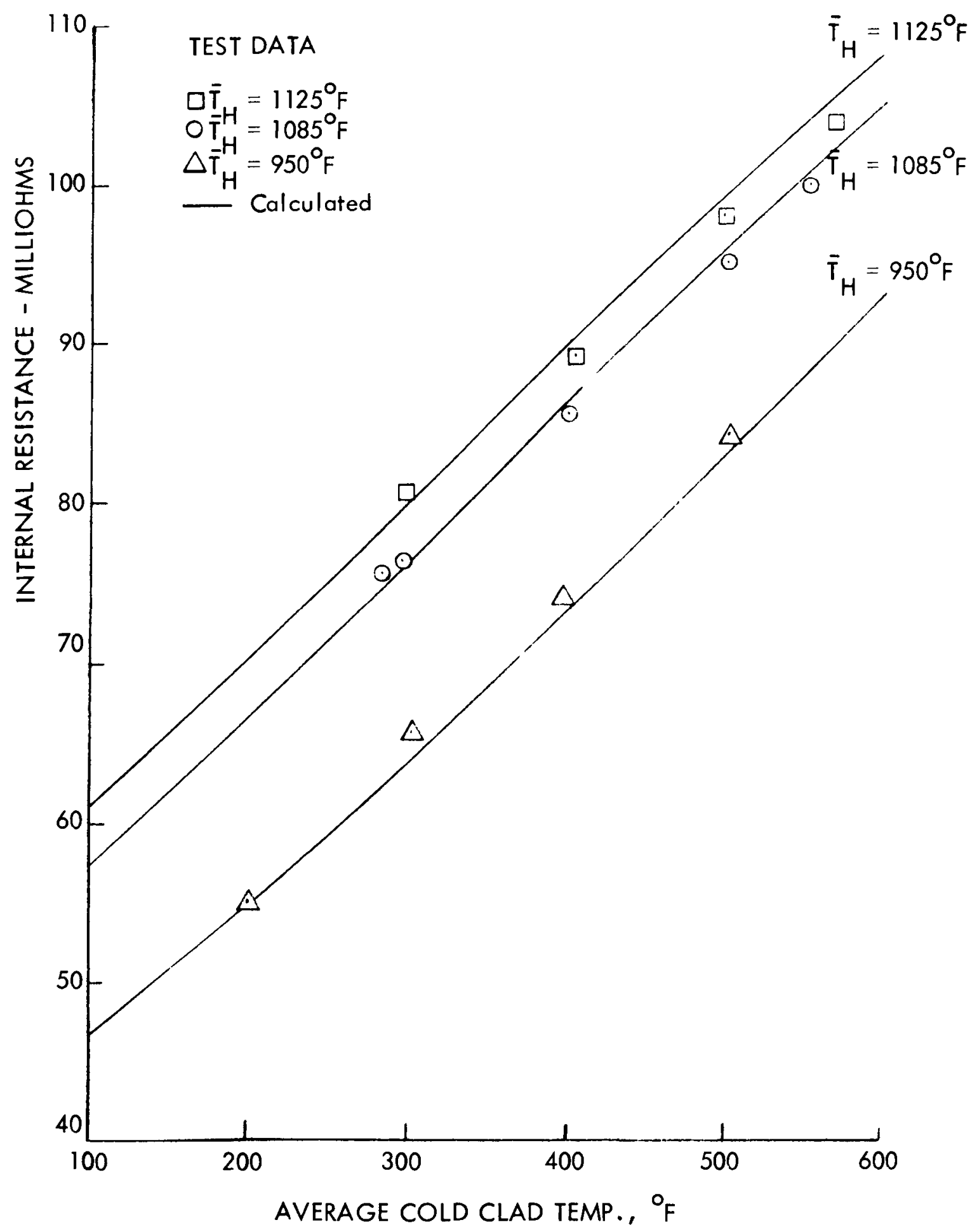

Figure V-2. Comparison of TEM-13G SN-12 Internal-Resistance Data with Performance Calculations 


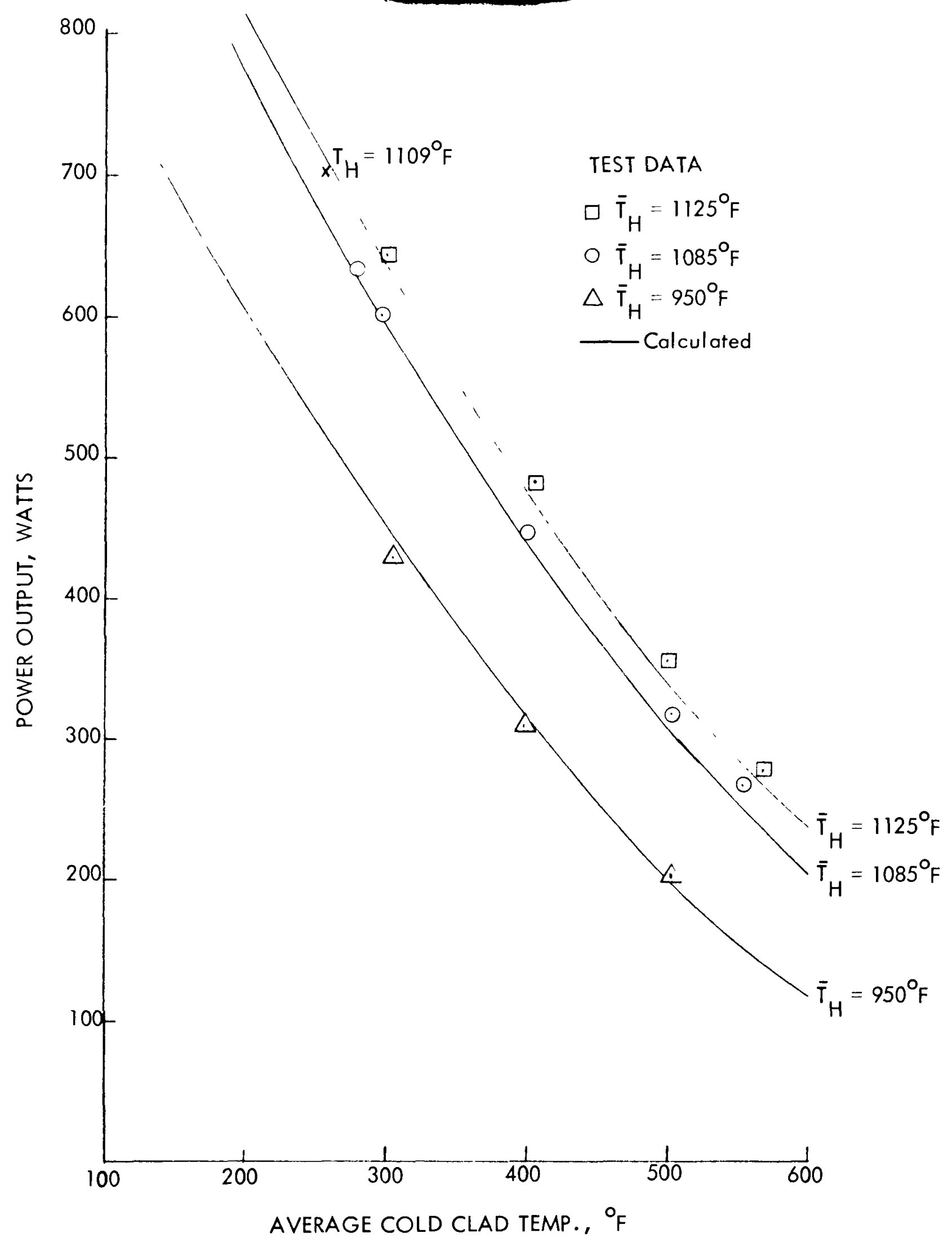

Figure V-3. Comparison of TEM-13G SN-12 Power-Output Data with Performance Calculations

$$
\mathrm{AI}-\mathrm{AEC}-12975
$$


Figure V-4 shows overall module efficiency (including end losses) as a function of $\overline{\mathrm{T}}_{\mathrm{C}}$. The data at $\overline{\mathrm{T}}_{\mathrm{H}}=950^{\circ} \mathrm{F}$ agree quite well with predictions, while at $\overline{\mathrm{T}}_{\mathrm{H}}=1085$ and $1125^{\circ} \mathrm{F}$ the efficiency achieved appears to be somewhat higher than that predicted. Although there is no definitive explanation for the apparent discrepancy in the efficiency data, it is expected that the inaccuracies of the flow-measurement devices contribute significantly to this effect.

\section{TEM-X SN-2}

Fabrication of TEM-X SN-2, the first module incorporating the bimetal Ta-10W/SS-316 inner-clad designed to eliminate module circuit distortion, was completed during the past quarter. Component parts except for inner-clad, plugs, and mandrel had been fabricated earlier and are identical to TEM-13G parts. Radiographic examination and liquid dye-penetrant tests performed on the bimetal inner-clad indicated successful bonding of the 316 end segment to the Ta-10W. Currently the module is being instrumented for static testing at WANL.

This module will undergo a short (24-hr) steady-state operating period at $\overline{\mathrm{T}}_{\mathrm{H}}=1125^{\circ} \mathrm{F}$ and $\overline{\mathrm{T}}_{\mathrm{C}}=570^{\circ} \mathrm{F}$, following which it will be subjected to a series of 50 controlled thermal cycles. Each cycle will use thermal transients conducted at $30^{\circ} \mathrm{F} / \mathrm{min}$ ramp rates. Following thermal-cyclic operation the module will be removed from test for destructive examination.

\section{TEM-X SN-3}

The design of TEM-X SN-3 was completed during the past quarter. The design is based on the use of the duplex Ta-10W/SS-316 inner-clad, 10 volts per kilowatt power output, and an interelement diffusion barrier. Resizing of axial dimensions of all circuit components was necessary to achieve the revised voltage requirements. Radial dimensions of the redesigned module were not changed and are the same as those of the TEM-13G and - 15 series modules.

The circuit design of the TEM-X SN-3 module was determined from a parametric study using $T E M \varnothing D$, the thermoelectric ( $T E$ ) module performance prediction code. In this study the number of $\mathrm{TE}$ couples was varied while the total circuit length was held constant at 15 in. In this manner the voltage-topower ratio was varied. 


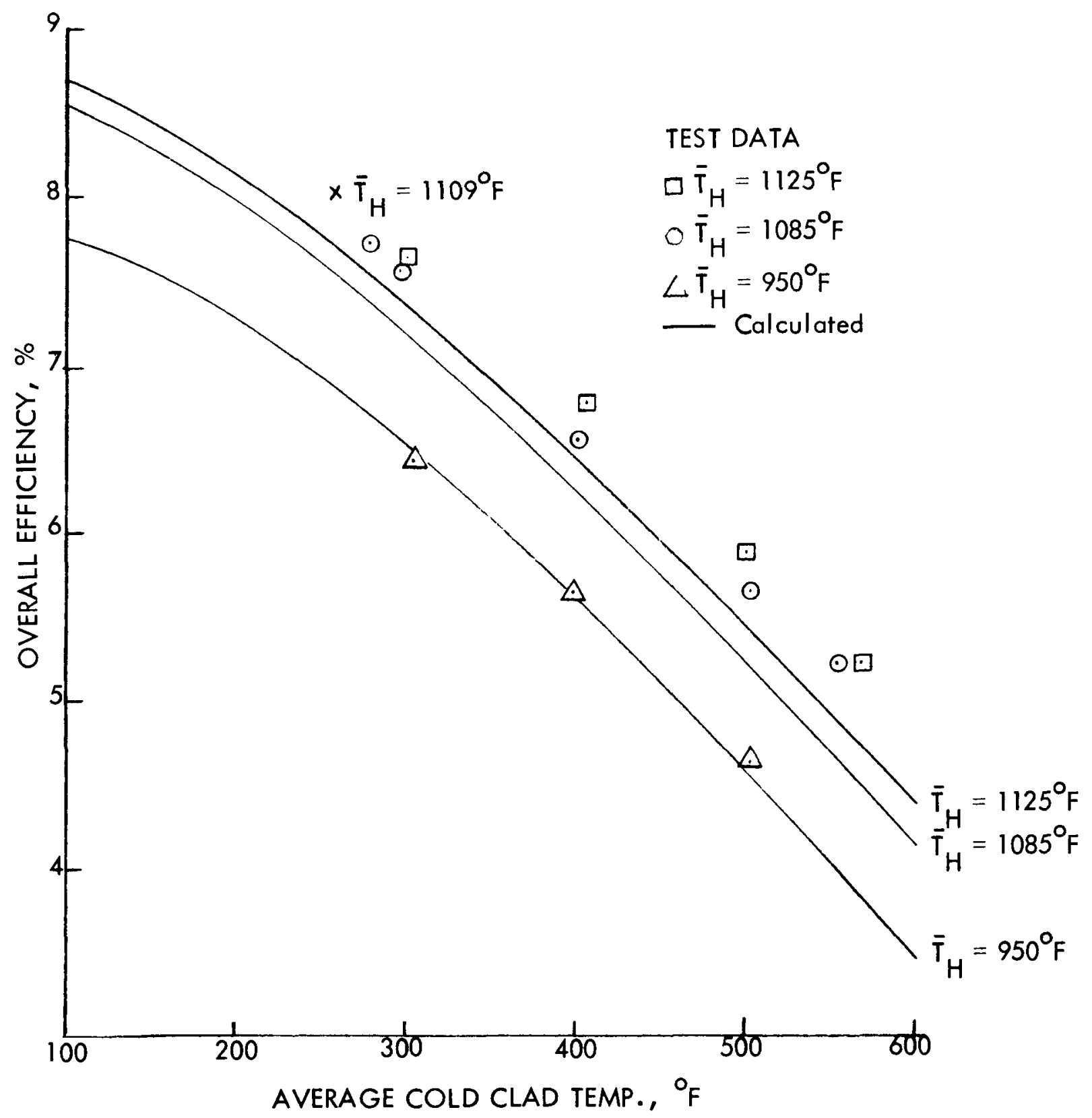

Figure V-4. Comparison of TEM-13G SN-12 Overall Efficiency Data with Performance Calculations 
Figure V-5 shows the calculated relationship between the voltage-to-power ratio and number of $\mathrm{TE}$ couples for a reactor module having $\mathrm{TEM}-13 \mathrm{G}$ radial dimensions, a 15-in. total circuit length, and operating at $\overline{\mathrm{T}}_{\mathrm{H}}=1125^{\circ} \mathrm{F}$ and $\overline{\mathrm{T}}_{\mathrm{C}}=570^{\circ} \mathrm{F}$. In the range of interest (greater than 10 couples) the relationship can be seen to be nearly linear. This follows from the fact that in this range the voltage is directly proportional to the number of couples whereas the power output is very nearly constant. As the number of couples is reduced from ten, however, the power falls off rapidly (due to excessive Joule heating losses in the conductor rings and power take-off pins) whereas the voltage relationship remains linear. This is the cause of the rapid voltage-to-power ratio increase at the low end of the curve; however, this area of the curve is of no practical interest to this program and requires no further investigation.

The study revealed that for $\overline{\mathrm{T}}_{\mathrm{H}}=1125^{\circ} \mathrm{F}$ and $\overline{\mathrm{T}}_{\mathrm{C}}=570^{\circ} \mathrm{F}$ operation the required 10 volts (at matched-load) per kilowatt of operation is achieved with a module having 38 rather than 78 couples. Figure V-6 gives a comparison of TEM-13G and TEM-X SN-3 cross-sections. All items which differ in the two designs are pointed out in the figure. Based on the design calculations the TEM-X SN-3 series modules will have TE washers approximately twice the length of the $13 \mathrm{G}$ washer $(0.188 \mathrm{in}$. compared to 0.091$)$, thus reducing the effects of intercouple diffusion. The number of conductor pins was changed and their method of attachment to the collector ring was redesigned since the reduced voltage significantly reduced the resistance of the module circuit, thereby increasing the significance of the conductor-pin resistance. The radial dimensions of the module prohibits the use of larger-diameter pins; therefore, to reduce the overall resistance of the module, eight pins will be used instead of the conventional four. They will be threaded into the conductor rings to assure their positive retention.

The TEM-X SN-3 design incorporates the duplex stainless-steel/Ta-10W clad replacing the single-piece Inconel clad of the TEM-13G series modules. The refractory portion of the clad, which extends over the entire length of the $T E$ circuit, is designed to eliminate relative inner - and outer-clad motion during transient operation. This is accomplished by matching $\alpha \Delta \mathrm{T}$ of the inner and outer clads, where $\alpha$ is the linear coefficient of thermal expansion and $\Delta \mathrm{T}$ is the temperature difference between the design operating conditions and room temperature. 


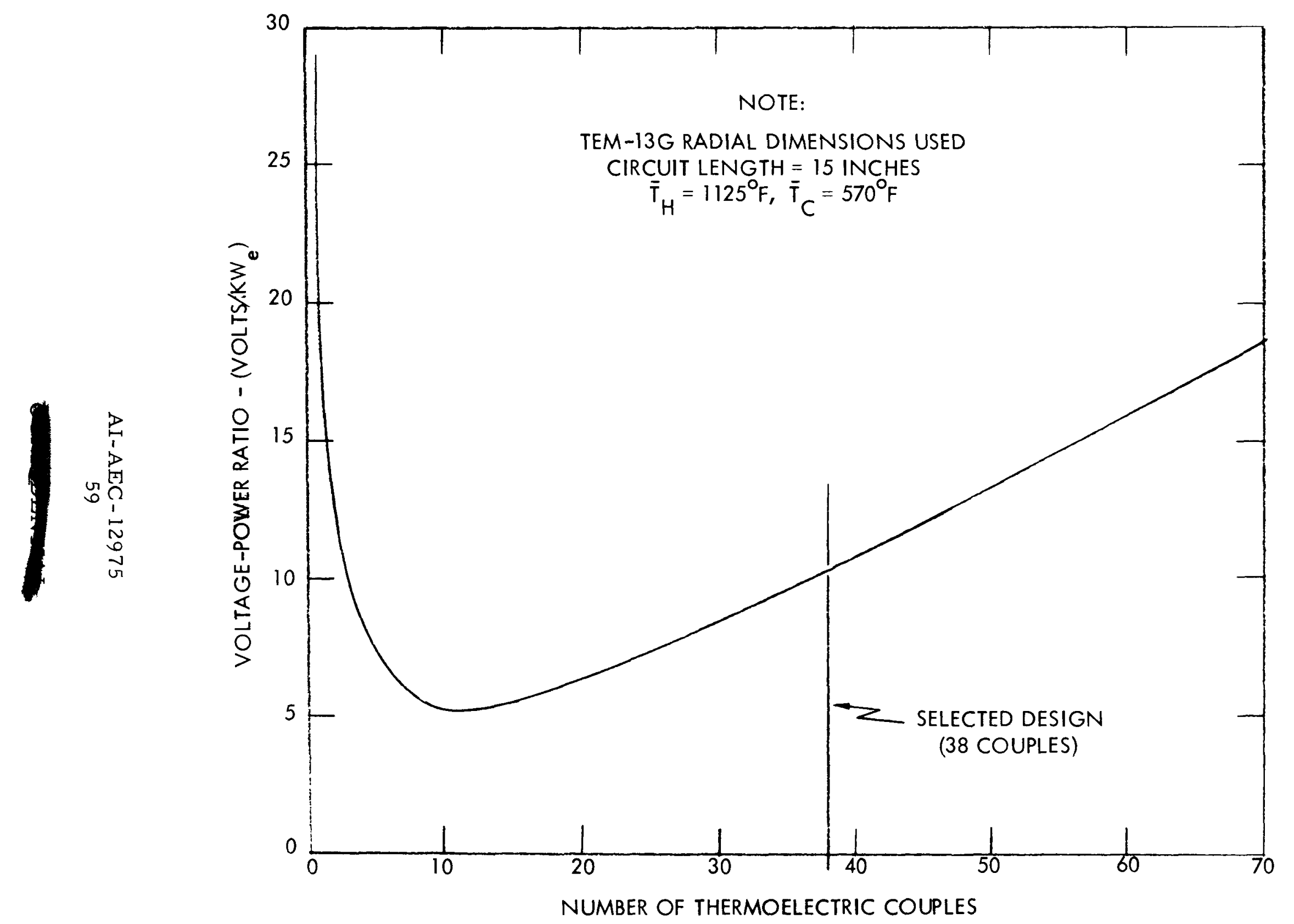

Figure V-5. Relationship Between Voltage-to-Power Ratio and Number of Thermoelectric Couples for a TEM-X-3 Module 


\section{TEM-13G}

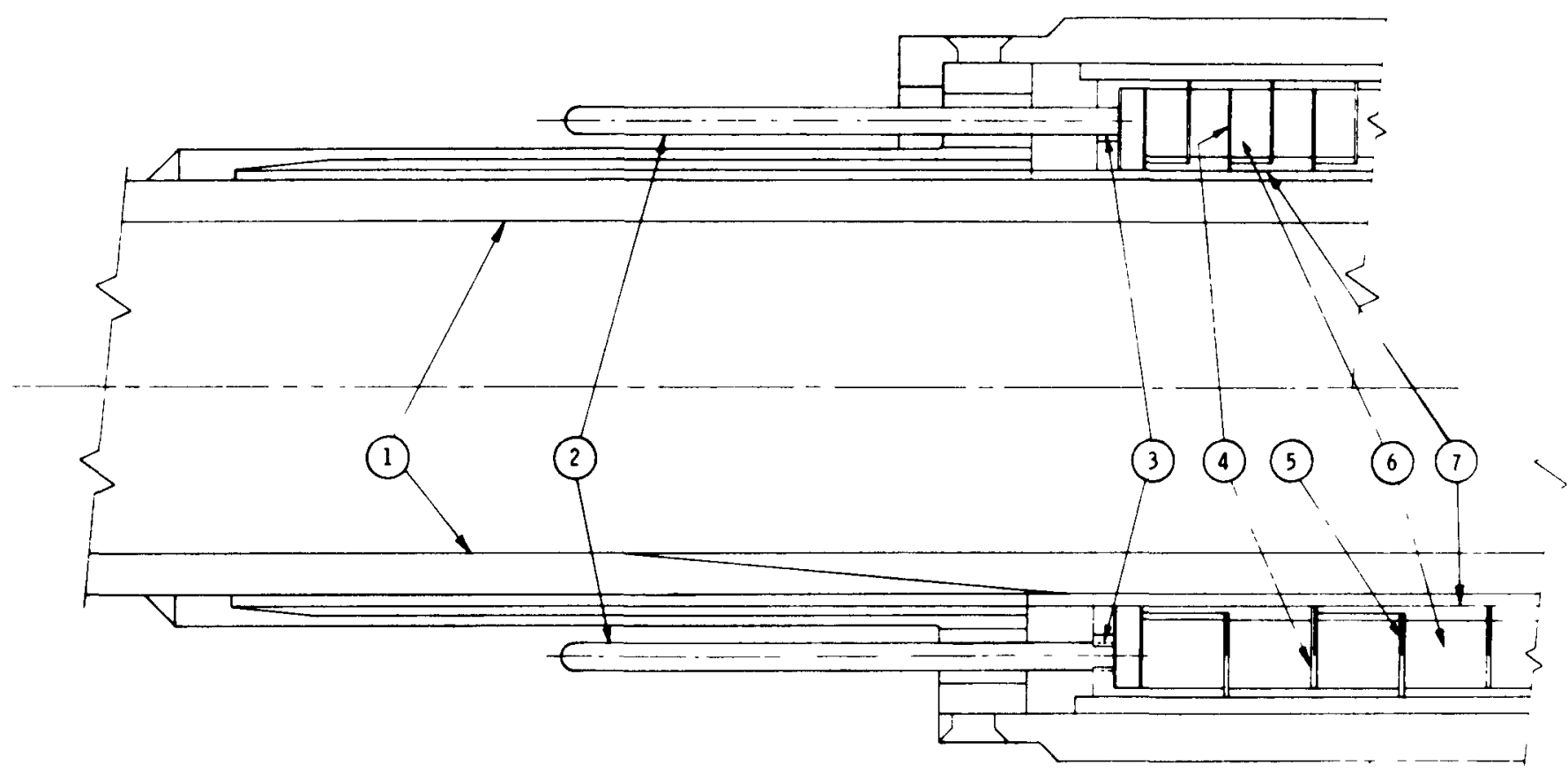

TEM-X S/N-3

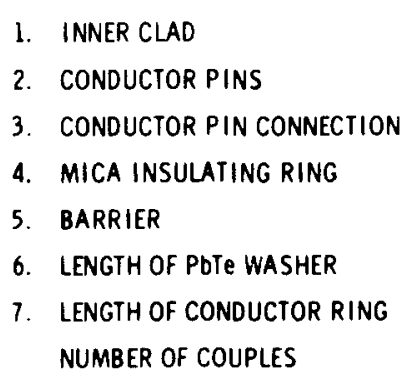

\begin{tabular}{|c|c|}
\hline IEM-13G & TEM-XS/N-3 \\
\hline INCONEL 718 & DUPLEX Ta-10W/316 \\
\hline 4 PER END & 8 PER END \\
\hline PRESSED & THREADED \\
\hline .005 THK. & $010 \mathrm{THK}$ \\
\hline- & $0005 W$ FOIL \\
\hline .091 & 188 \\
\hline .187 & .386 \\
\hline 79 & 38 \\
\hline
\end{tabular}

Figure V-6. Comparison of TEM-13G and TEM-X SN-3 Modules 
TEM-X SN-3 has been designed with 0.0005-in. tungsten-foil washers extending radially outward from the couple hot junction (lead telluride/innerconductor-ring interface) to a point midway between the hot and cold junctions (lead telluride/outer-conductor-ring interface). The foil is "sandwiched" between two 0.005-in. mica washers as shown in Figure V-6. The foil provides an absolute diffusion barrier in the region most susceptible to intercouple contamination resulting from diffusion of tellurium through the mica insulators. Shunt-heat loss through the tungsten foil is reduced by minimizing the foil axial length ( $0.0005 \mathrm{in}$.) and terminating the foil at the radial midpoint of the $\mathrm{TE}$ washer. The selection of foil diameter is based on a review of Seebeck probe data from module destructive examination, which indicates that diffusion does not occur below the temperature existing at the radial midpoint of the $T E$ washers in the TEM-X SN-3 module.

The use of 0.010-in. mica insulation (two 0.005-in. insulators) was based on the success of the TEM-14 series modules which also have 0.010-in. mica insulation, and on the results of capsule experiments. Degradation in the TEM-14 series modules has been virtually non-existent during $10,000 \mathrm{hr}$ of testing at $\overline{\mathrm{T}}_{\mathrm{H}}=1125^{\circ} \mathrm{F}$. Capsule experiments made recently have also demonstrated the effectiveness of thicker mica. Data from one experiment showed no material transport through 0.010 -in. mica with $0.0005-$ in. foil after $1900 \mathrm{hr}$ of operation at $1200^{\circ} \mathrm{F}$. Since $\mathrm{TE}$ washer axial dimensions have been increased by a factor of two (over the TEM-13G design), doubling the mica washer thickness will not result in a significant performance penalty.

Currently six TEM-X SN-3 series modules are scheduled for fabrication. All will be identical to SN-3 discussed above except TEM-X SN-3A. The latter will differ only in that the tungsten-foil diffusion barrier will not be incorporated.

\section{B. PUMP TUBULAR POWER MODULES \\ 1. Performance Sumriary of Prototype Pump Modules}

Three tubular modules designed to deliver power to an electromagnetic (EM) pump continued on test at WANL during the past quarter. These prototype pump modules, designated TEM-14A SN-1, 2, and -3, have been endurance-tested at nominal average clad temperatures, $\overline{\mathrm{T}}_{\mathrm{H}}=1125^{\circ} \mathrm{F}$ and $\overline{\mathrm{T}}_{\mathrm{C}}=570^{\circ} \mathrm{F}$. 
Electrical-current and electrical-power output data recorded from the TEM-14A series modules are given in Figures $\mathrm{V}-7$ and -8 , respectively. The beginning-of-life (BOL) data from TEM-14A SN-2 and -3 agree to within $1 \%$ of the design levels. Excellent performance stability has been realized in the TEM-14 series pump modules. Performance-degradation rates for each of these modules, determined using a statistical analysis of power-output data, range from 0 to $3 \% / 1000 \mathrm{hr}$.

Testing of TEM-14A SN-3 has been completed. During the $7727 \mathrm{hr}$ of life testing this module was subjected to five sets of ten thermal cycles done with $30^{\circ} \mathrm{F} / \mathrm{min}$ average hot-clad temperature ramp rates. None of the sets of thermal cycles produced any deleterious effects on module performance. There has been absolutely no degradation in electrical-power output for this module. TEM-14A SN-3 has been removed from test for destructive examination.

The long-term stable performance capabilities of the tubular module incorporating lead-telluride TE materials are clearly demonstrated by the performance data from the TEM-14 series pump modules. The fifty controlled thermal cycles on SN-3 and the various uncontrolled shutdowns of all three modules (see Figures V-7 and -8) indicate that the TEM-14 design is insensitive to thermal cycling.

\section{SUPPORTING TECHNOLOGY DEVELOPMENT \\ 1. Sublength Module}

The TEM- 15 series modules were designed as a part of the support technology development phase of the Compact Thermoelectric Converter System Technology Program. These modules were designed with radial dimensions similar to those of the TEM-13G reactor-power modules, but with circuit lengths reduced from 15.0 to 4.0 in. The purpose for fabricating and testing these modules is to evaluate the effects of varying processing techniques, as sembly clearances, and intercouple insulating methods on module performance.

a. TEM-15A Series Modules

Al1 TEM-15A series modules utilize a single-piece 0.005-in,-thick mica insulator between adjacent $\mathrm{TE}$ washers. These modules were designed to 


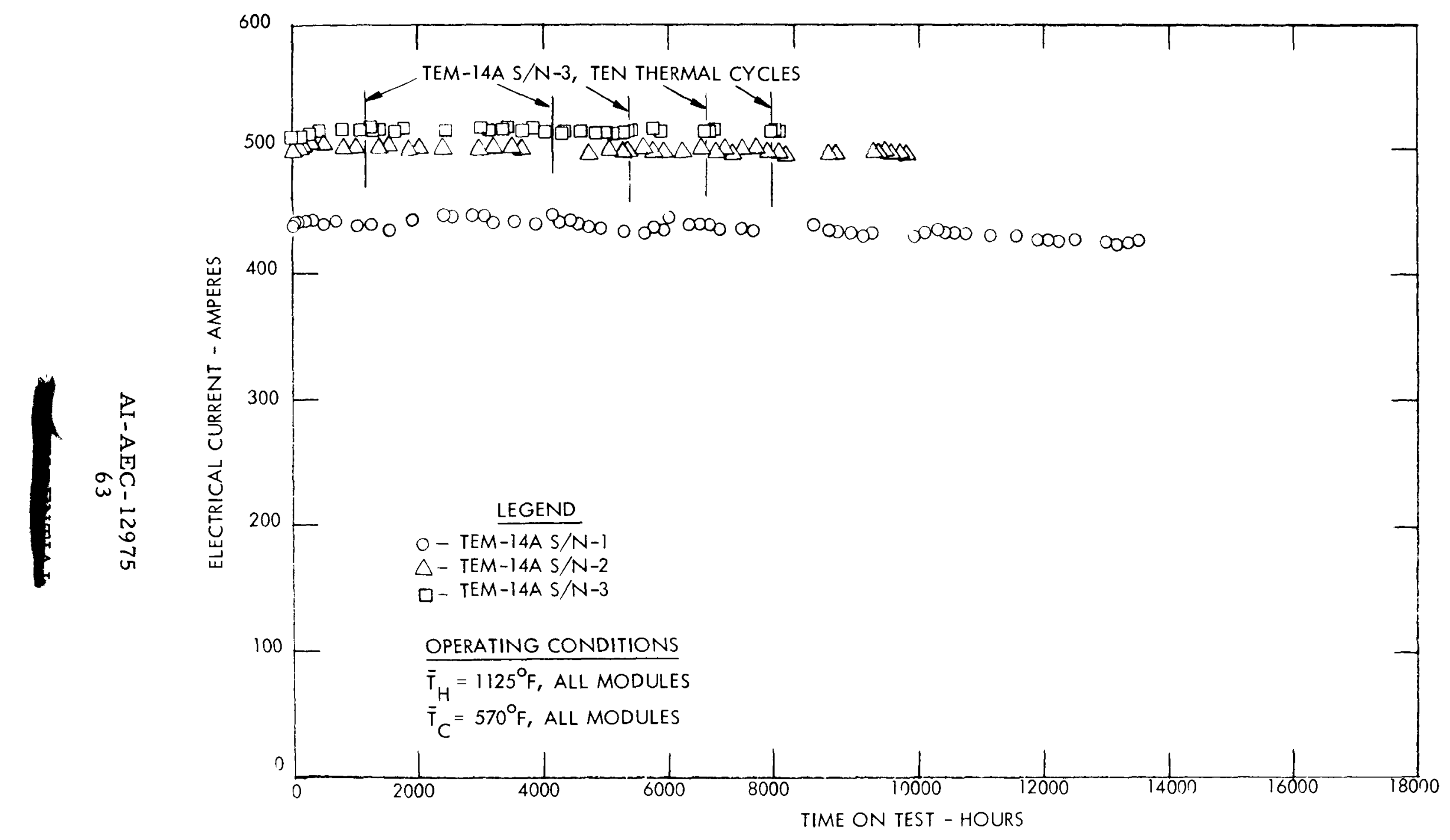

Figure V-7. Electrical-Current Data from Three Prototype Pump-Power Modules 


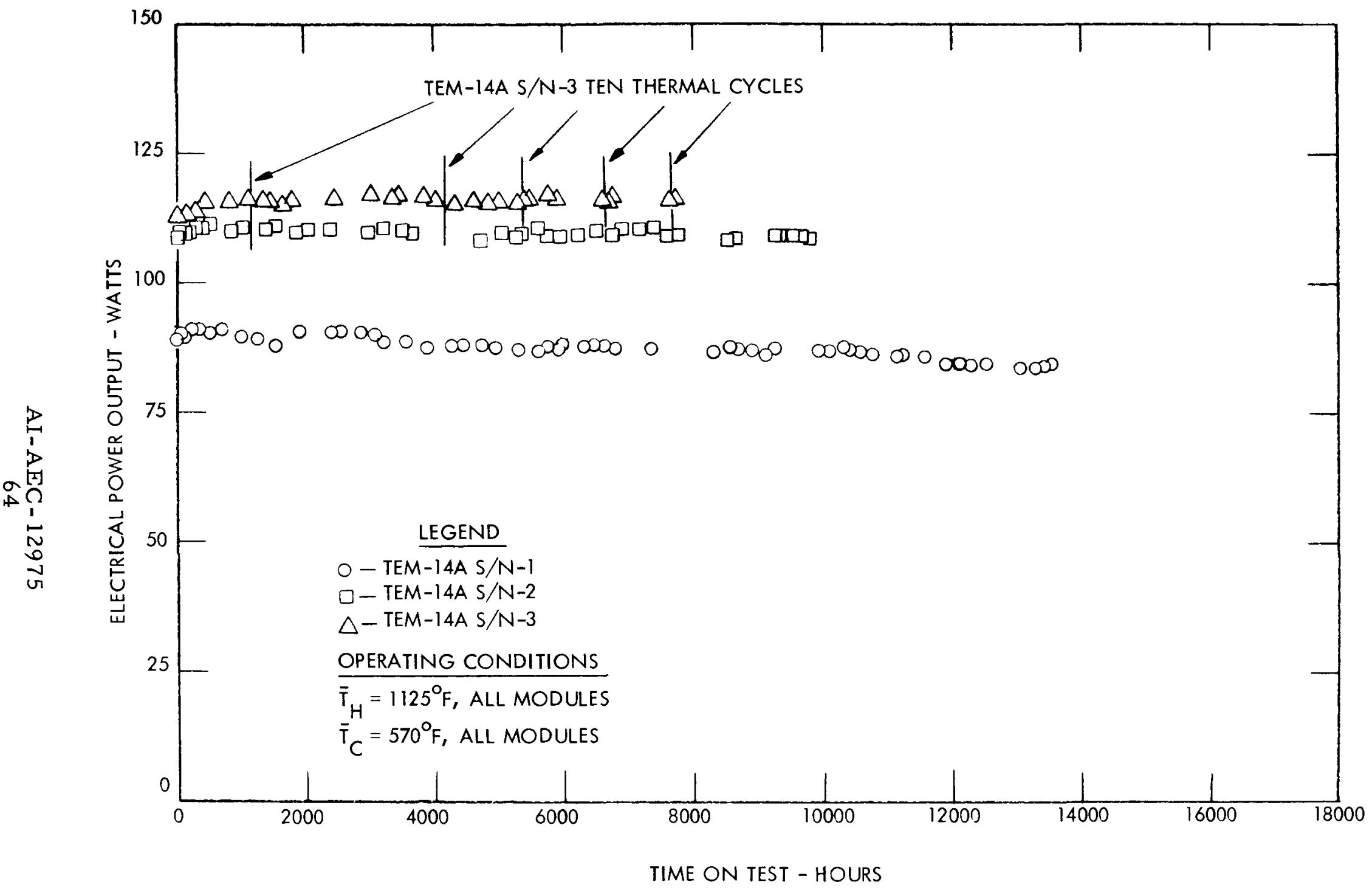

Figure V-8. Power-Output Data from Three Prototype Pump-Power Modules 
investigate the influence of mica radial clearance on mica deformation during processing, the influence of weld shrinkage on circuit alignment and mica deformation, and the influence of axial preload on mica deformation and circuit alignment in a module incorporating standard 0.005-in.-thick mica insulators.

Testing of three TEM-15A series modules, SN-1, $-4 \mathrm{D}$, and -5 , continued throughout the past quarter. In addition one new module, $-4 E$, was placed on test. All of these were tested under steady-state conditions at nominal $\overline{\mathrm{T}}_{\mathrm{H}}=$ $1125^{\circ} \mathrm{F}$ and $\overline{\mathrm{T}}_{\mathrm{C}}=570^{\circ} \mathrm{F}$ clad temperatures in static test facilities at WANL. Electrical-power output data and overall efficiency are shown in Figures V-9 and -10 respectively as a function of elapsed testing time for these four modules.

TEM-15A SN-4E is identical in design to the baseline SN-4 module. The SN-4E module, however, was not hydrogen-purged during its processing. The hydrogen-purge step was eliminated from the processing sequence to evaluate its effect on module performance stability. This was done in anticipation of modules currently being designed with refractory clads which cannot be hydrogenpurged due to the formation of hydrides.

The BOL performance data from TEM-15A SN-4E is compared in Table V-1 to that from other TEM-15A series modules and to predicted values. Voltage and internal resistance from $\mathrm{SN}-4 \mathrm{E}$ are the high side of the data band formed by TEM-15A modules but agree well with calculations. Insufficient testing time has been accrued to determine whether the elimination of the hydrogen purge has influenced the performance stability of this module.

b. TEM-15B Series Modules

All TEM-15B series modules utilize tungsten-foil diffusion barriers positioned between two mica electrical insulators. The TEM-15B series module SN-4 was designed with a 0.0005-in.-thick layer of tungsten "sandwiched" between two 0.00225-in.-thick mica washers. The purpose of the tungsten is to ensure an absolute diffusion barrier between adjacent lead-telluride washers.

TEM-15B SN-4 was tested for $3637 \mathrm{hr}$ at $\overline{\mathrm{T}}_{\mathrm{H}}=1125^{\circ} \mathrm{F}$ and $\overline{\mathrm{T}}_{\mathrm{C}}=570^{\circ} \mathrm{F}$. A statistical analysis of data from this module shows no reduction in electricalpower output during this time, although internal resistance and open-circuit voltage both increased. The power-output data are presented in Figure V-11. 


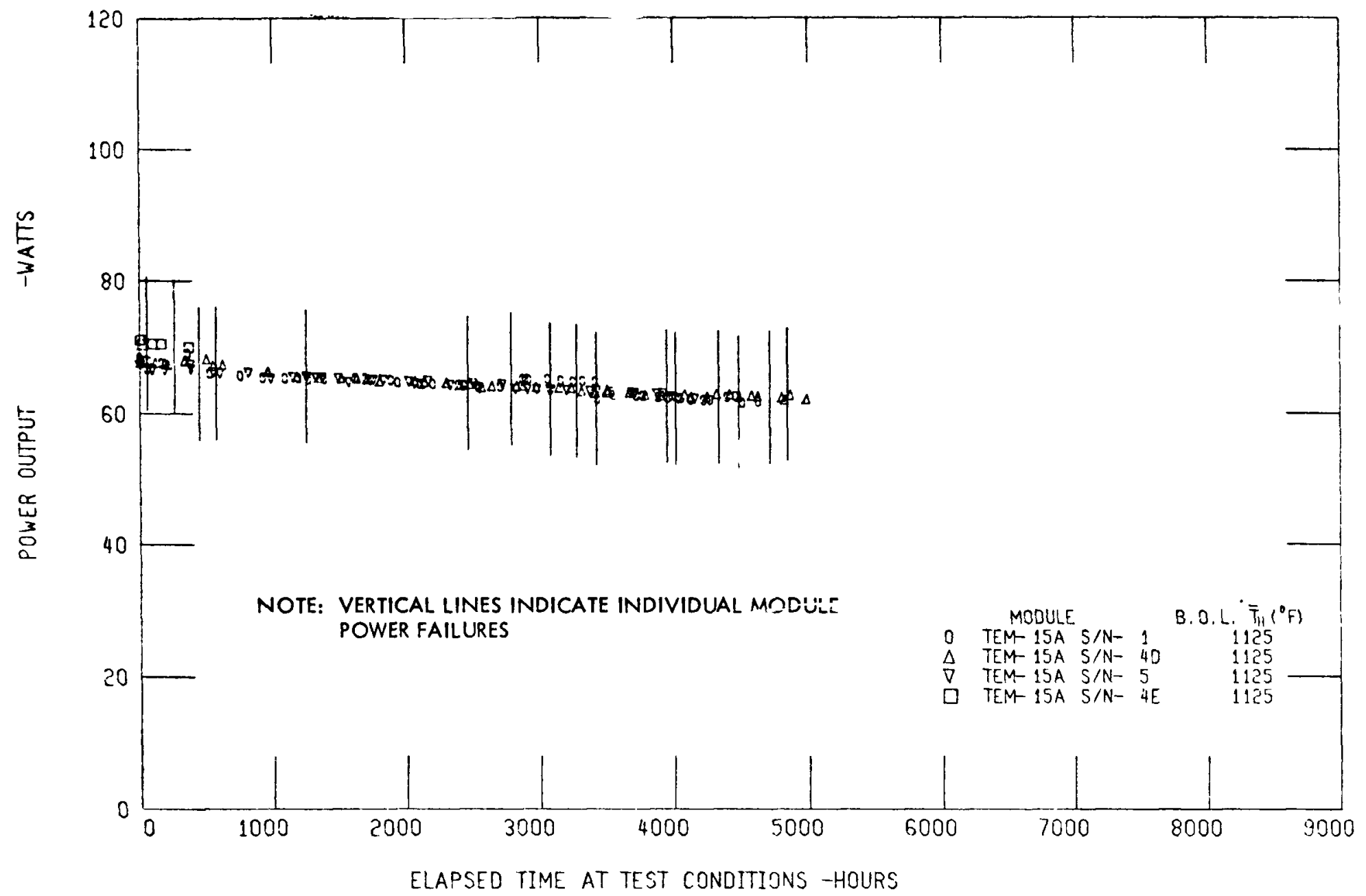

Figure V-9. Comparison of Steady-State Power-Output Data from TEM-15A Series Modules 


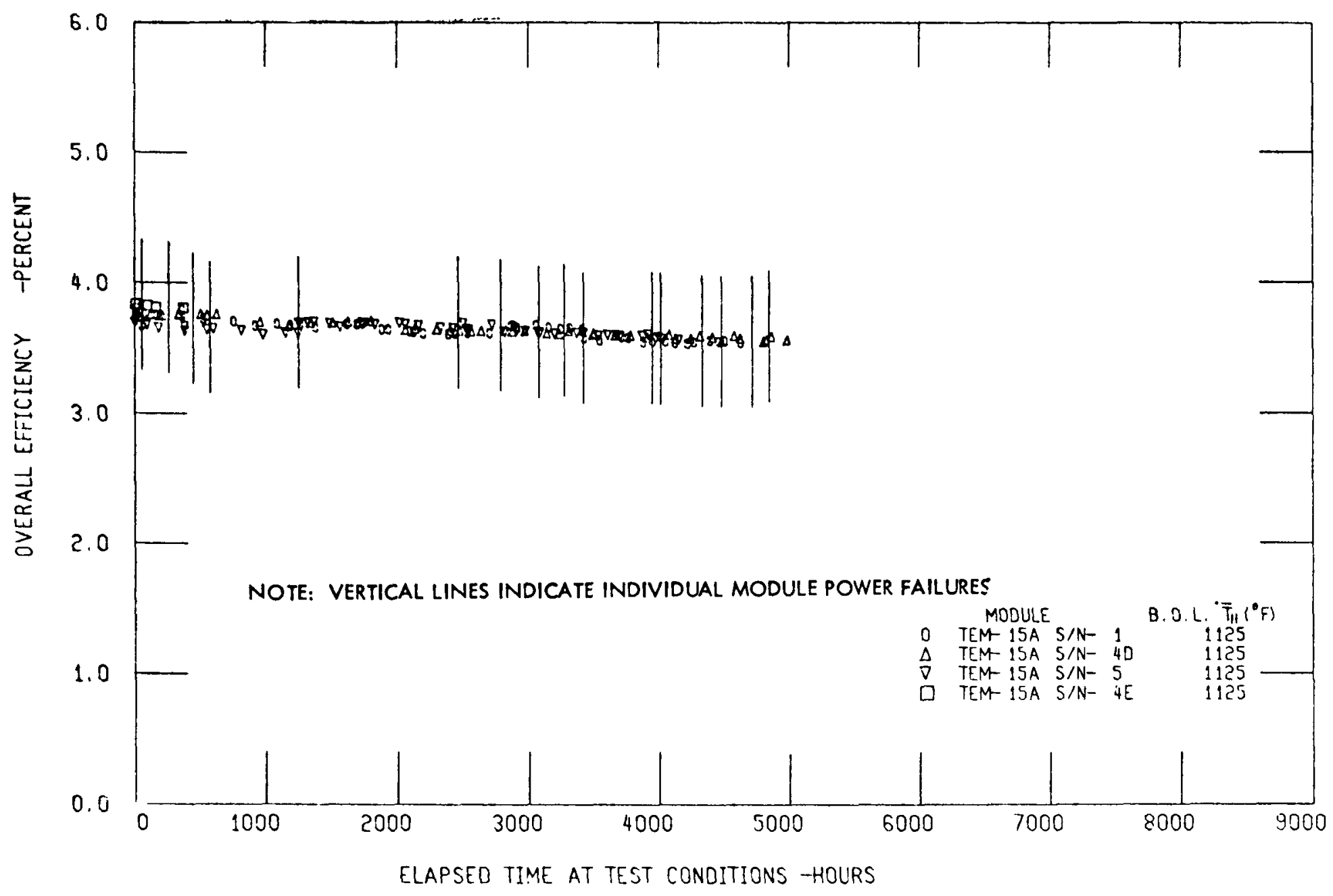

Figure V-10. Comparison of Steady-State Overall Efficiency Data from TEM-15A Series Modules 


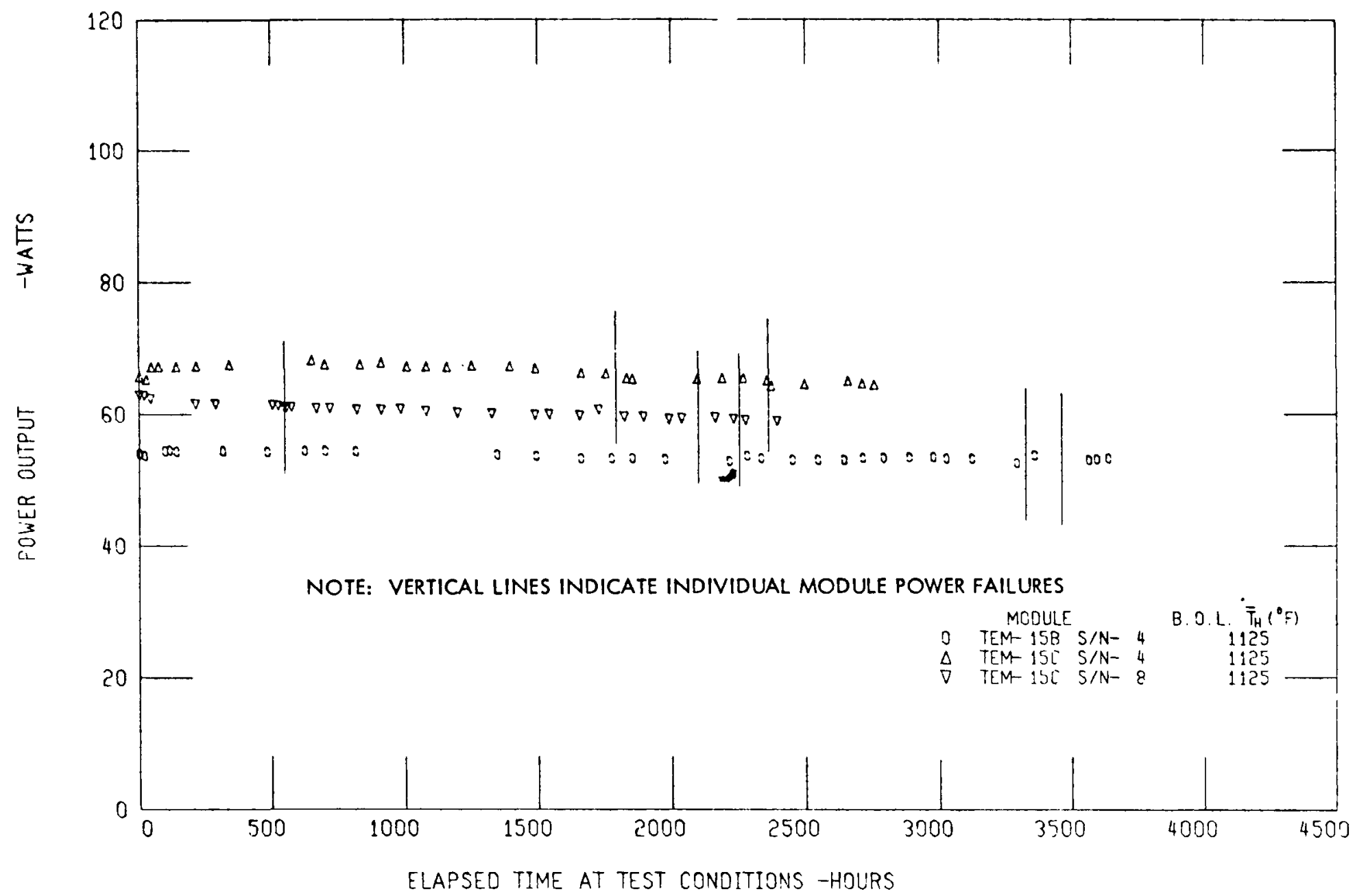

Figure V-11. Electrical-Power Output vs Elapsed Time at Test Conditions for TEM- 15 Modules Fabricated with Diffusion Barriers in the Mica Insulators 
TAB LE V -1

COMPARISON OF TEM-15 MODULE BEGINNING-OF-LIFE TEST RESULTS WITH CALCULATED PARAMETERS $\operatorname{FOR} \overline{\mathrm{T}}_{\mathrm{H}}=1125^{\circ} \mathrm{F}$ AND $\overline{\mathrm{T}}_{\mathrm{C}}=570^{\circ} \mathrm{F}$ MATCHED-LOAD OPERATION

\begin{tabular}{c|c|c|c|c|c}
\hline \hline Module & $\begin{array}{c}\mathrm{Q} \\
\text { (watts) }\end{array}$ & $\begin{array}{c}\mathrm{V}_{\mathrm{oc}} \\
\text { (volts) }\end{array}$ & $\begin{array}{c}\mathrm{R}_{\mathrm{g}} \\
(\mathrm{m} \Omega)\end{array}$ & $\begin{array}{c}\mathrm{P}_{\mathrm{e}} \\
\text { (watts) }\end{array}$ & Percent \\
\hline TEM-15A SN-4 & 1810 & 4.71 & 78.3 & 70.8 & 3.91 \\
-4C & 1812 & 4.75 & 82.1 & 68.7 & 3.79 \\
$-4 \mathrm{D}$ & 1809 & 4.73 & 81.0 & 69.1 & 3.82 \\
$-4 \mathrm{~F}^{*}$ & 1807 & 4.69 & 80.9 & 67.8 & 3.75 \\
TEM-15A Calculated & 1850 & 4.87 & 84.4 & 70.2 & 3.79 \\
TEM-15D SN-4 & 1746 & 4.77 & 84.7 & 67.0 & 3.84 \\
TEM-15D Calculated & 1764 & 4.22 & 75.7 & 58.9 & 3.34 \\
TEM-15B SN-4A Calculated & 1954 & 4.25 & 79.9 & 56.6 & 2.90 \\
\hline
\end{tabular}

*Same design as other TEM-15A SN-4 modules but no $\mathrm{H}_{2}$ purge.

†Incorporates $0.010-$ in. mica and 33 couples rather than $0.005-i n$. mica and 36 couples.

§Incorporates 0.010 -in. mica with $50 \%$-radial $0.0004-\mathrm{in}$. tungsten foil and 33 couples.

$\mathrm{SN}-4$ has been removed from test and is being destructively examined. Examination of the module after sectioning indicated that the tungsten liners, although badly deformed during radial compaction, remained continuous across the entire washer radial thickness. Curling of 0.0005-in. tungsten barriers a round the $O D$ of the large and ID of the small mica insulators could have produced local electrical shorts. This shorting would explain the BOL performance anomalies ( $\mathrm{V}_{\mathrm{oC}}, \mathrm{R}_{\mathrm{g}}$, and $\mathrm{P}_{\mathrm{e}}$ all 6 to $8 \%$ lower than expected).

Future modules containing tungsten-foil diffusion barriers will not be susceptible to this type of shorting since the barriers will not extend to the vicinity of the outer-conductor rings. 
An additional TEM-15B series module designated TEM-15B SN-4A, was designed and fabricated. This module incorporates $0.0004 \pm 0.0001-\mathrm{in}$. tungsten foil extending radially outward from the module hot junction to a point midway between the hot and cold junction and sandwiched between two 0.005-in. mica washers similar to the design of TEM-X SN-3 discussed in Section V-A-3. Predicted performance of TEM-15B SN-4A is given in Table V-l.

\section{c. TEM-15C Series Modules}

TEM-15C series modules are designed with two-piece mica washers coated with thin films of molybdenum deposited by electron-beam (EB) evaporation. The washers used in SN-4 were made from 0.0025-in.-thick mica sheets upon which 1000 to $2000 \AA$ of Mo were deposited. Two washers are used at each mica position (Mo-coated faces together) so that the total barrier thickness is 2000 to $4000 \AA$ at each position. The design of SN-4, with the exception of the molybdenum-coated mica, is identical to that of the reference module TEM-15A$\mathrm{SN}-4$ module.

The purpose of the Mo barrier is to eliminate the diffusion of Te between adjacent lead-telluride washers. Since the total EB-deposited film is approximately $3 \%$ as thick as the tungsten barrier used in the mica washers of TEM-15B SN-4, shunt-heat losses in TEM-15C series modules are negligible. Poweroutput data from TEM-15C SN-4 are shown in Figure V-11 along with similar TEM-15B SN-4 and 15C SN-8 data.

Testing of TEM-15C SN-4 has been completed. After $2754 \mathrm{hr}$ of life testing at $\overline{\mathrm{T}}_{\mathrm{H}}=1125^{\circ} \mathrm{F}$ and $\overline{\mathrm{T}}_{\mathrm{C}}=570^{\circ} \mathrm{F}$ the module was removed from test and destructive examination begun.

TEM-15C SN-8, identical to 15C SN-4 except for an increased clearance between the large mica insulator OD and outer boron nitride ID, has accrued $2391 \mathrm{hr}$ at the average clad temperatures of $\overline{\mathrm{T}}_{\mathrm{H}}=1125^{\circ} \mathrm{F}$ and $\overline{\mathrm{T}}_{\mathrm{C}}=570^{\circ} \mathrm{F}$. Power-output data from this module are shown in Figure V-11.

d. TEM-15D Series Modules

During the past quarter the first module of the TEM-15D series (SN-4) was designed, fabricated, and placed on static test at $\overline{\mathrm{T}}_{\mathrm{H}}=1125^{\circ} \mathrm{F}$ and $\overline{\mathrm{T}}_{\mathrm{C}}=570^{\circ} \mathrm{F}$ operating conditions. The TEM-15D designation applies to modules designed 
with 0.010-in. mica insulators containing no additional diffusion-barrier mechanisms. A discussion of the use of 0.010-in. mica insulation is given in Section $\mathrm{V}-\mathrm{A}-3$ in a description of the TEM-X SN-3 design.

TEM-15D SN-4 contains 33 TE couples as opposed to 36 used in all previously fabricated TEM-15 series modules. The reduction in the number of couples was required to accommodate the increased mica thickness within the 4.0 -in. (nominal) circuit length.

BOL performance data from TEM-15D SN-4 are compared in Table V-1 to predicted values. Although voltage and resistance are lower than predicted they agree to within $3 \%$ of the predicted values. Insufficient testing time has been accrued to ascertain the efficiency of the 0.010-in.-thick mica insulation. e. TEM-15 Performance Stability Analysis

Table V-2 summarizes results of the most recent degradation-rate analysis of all TEM-15 series modules having steady-state testing times over $1000 \mathrm{hr}$; (the minimum time required to establish performance trends). Degradation rates for four parameters (resistance, open-circuit voltage, power output, and overall efficiency all adjusted to account for minor testing temperature variations) are shown.

TAB LE V-2

TEM- 15 PERFORMANCE-ANALYSIS SUMMARY (rates shown as percent increases per 10,000 hr;

$\left.\overline{\mathrm{T}}_{\mathrm{H}}=1125^{\circ} \mathrm{F}, \overline{\mathrm{T}}_{\mathrm{C}}=570^{\circ} \mathrm{F}\right)$

\begin{tabular}{l|c|c|c|c|c|c}
\hline $\begin{array}{c}\text { Module } \\
\text { (TEM-) }\end{array}$ & $\begin{array}{c}\text { Time } \\
(\mathrm{hr})\end{array}$ & $\mathrm{R}_{\mathrm{g}}$ & $\mathrm{V}_{\mathrm{oc}}$ & $\mathrm{P}_{\mathrm{e}}$ & $\eta$ & $\begin{array}{c}\text { Number of } \\
\text { Cycles }\end{array}$ \\
\hline 15A SN-1 & 4625 & 28 & +4 & -19 & -13 & 5 \\
15A SN-4* & 2349 & 29 & +4 & -19 & -6 & 2 \\
15A SN-4B & 2174 & 35 & +12 & -9 & -8 & 50 \\
15A SN-4D & 4983 & 30 & +5 & -18 & -11 & 3 \\
15A SN-5 & 4152 & 28 & +5 & -16 & -6 & 6 \\
15A SN-8* & 2442 & 29 & +2 & -23 & -13 & 52 \\
15B SN-4* & 3637 & 12 & +6 & 0 & -2 & 2 \\
15C SN-4* & 2753 & 29 & +7 & -14 & -14 & 2 \\
15C SN-8 & 2391 & 31 & +4 & -22 & -11 & 3 \\
\hline
\end{tabular}

*Testing terminated 
2. Module Examination

a. TEM-15 Cyclic Modules

A series of TEM-15 modules was subjected to various thermal cycles to investigate the effect on circuit distortion. Destructive examination of these modules showed there was a relationship between washer displacement and thermal-cycling rate.

Two additional TEM-15 modules were designed to lock the inner and outer clads together to prevent independent axial expansion during transient operation. These modules were subjected to the maximum thermal-cycling rate of $60 \mathrm{~F}^{\circ} /$ min. Evaluation of these modules showed that suppressing the relative axial expansion of the inner and outer clads successfully restricted the relative displacement of the conductor rings. As a result, chevroning of the $T E$ washers due to thermal cycling was essentially eliminated.

b. TEM-15B and $15 \mathrm{C}$

(1) Destructive Examination

Destructive examination is in process on two TEM- 15 modules which contained diffusion barriers between the mica insulating washers. TEM-15B SN-4 mica washers incorporated a thin tungsten foil between two 0.0025-in.-thick mica washers. TEM-15C SN-4 incorporated two 0.0025-in. mica washers, with the inside face of each washer coated with a thin layer of electron-beam vapordeposited molybdenum.

A 1 -in. section of TEM-15B SN-4 was mounted in epoxy and sectioned axially to expose the electrical circuit. Figure V-12 is a photomacrograph of a typical portion of the cross-section examined. The tungsten foil was continuous throughout the radial thickness of every mica washer examined in this section. No cracks or holes were observed in the foil. Further, the foil was found to be extremely ductile, as is evident by the many bends in the foil shown in Figure $\mathrm{V}-12$.

Detailed examination of TEM-15B SN-4 and 15C SN-4 using the Seebeck probe to evaluate the $\mathrm{TE}$ materials is continuing. 


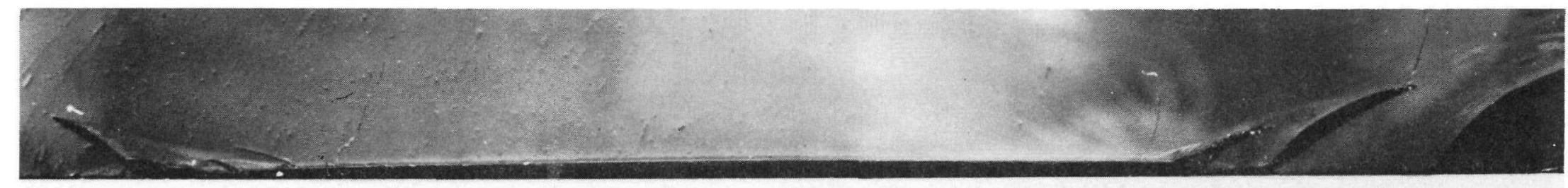

$\sqrt{1+111.1110111}$

Figure V-12. Cross-Section of TEM-15B SN-4 


\section{c. TEM-13G Modules}

Series module SN-10 was destructively examined, evaluated, and compared to a similar $13 \mathrm{G}$ module tested at a more severe thermal-cycling rate. The results from this investigation fitted those from the more extensive TEM- 15 test program. Namely, the degree of circuit distortion could be directly related to the number of thermal cycles and thermal-cycle rate.

\section{Mica Evaluation}

An evaluation has been completed on EXC capsules which contained coated and uncoated mica as barriers to inter-type TE-material contamination. Testing was done at $1202^{\circ} \mathrm{F}\left(650^{\circ} \mathrm{C}\right)$ for time periods up to $3000 \mathrm{hr}$. Electron-microprobe analysis of selected mica interfaces showed the molybdenum coating on the mica acted as an effective getter for tellurium. The barrier layer between the mica washer was composed of a $\mathrm{Mo}_{x} \mathrm{Te}_{\mathrm{y}}$ compound. Electrical examination of the $\mathrm{TE}$ material disclosed that the coated mica, while not completely effective over the longest time periods, reduced the degree of contamination below that produced by uncoated mica.

Another series of capsules designed for comparative evaluation of 5 - and 10-mil mica are on test.

4. Improved Thermoelectric Materials

During this quarter melting of ingots and processing of ingots and test specimens of experimental $\mathrm{PbTe}$ base ternary alloys ( $\mathrm{P}$-type $\mathrm{PbTe}-\mathrm{PbSe}$ and $\mathrm{N}$-type $\mathrm{PbTe}-\mathrm{GeTe}$ ) were reduced to near-routine procedures.

To date, 23 ingots have been successfully prepared and 198 test specimens fabricated; 66 of the latter have been tested at WANL. These totals do not include numerous control specimens of GE-NL and TEGS-2P PbTe materials processed and tested with the experimental materials to provide process integrity checks.

\section{a. P-Type PbTe 0.95 Se 0.05 Alloys}

The first $\mathrm{P}$-type ingot was made to the reported RCA reference composition $\mathrm{PbTe}_{0.95^{\mathrm{Se}}} \mathrm{S.05}^{\mathrm{Na}} 0.007^{\circ}$ However, test results on specimens made from that ingot indicated much too low a carrier concentration, and it was postulated that 
this was due to a severely limited solubility of sodium in the strictly stoichiometric $\mathrm{PbTe}_{0.95} \mathrm{Se}_{0.05}$ alloy. It was further postulated, based on a knowledge of TEGS-2P P-type PbTe, that the sodium solubility could be increased by adding excess tellurium ${ }^{*}$ to the composition. Accordingly, additional compositions were prepared incorporating both excess tellurium and higher sodium content. In all, the five compositions in Table V-3 were investigated:

TAB LE V-3

EXCESS TELLURIUM, SODIUM COMPOSITIONS

\begin{tabular}{|c|c|c|}
\hline Composition & $\mathrm{Te}: \mathrm{Pb}$ & Excess $\mathrm{Te}: \mathrm{Na}$ \\
\hline $\mathrm{PbTe}_{0.95^{\mathrm{Se}}} 0.05^{\mathrm{Na}} 0.007^{(\mathrm{RCA})}$ & $0.9500: 1$ & 0 \\
\hline $\mathrm{PbTe}_{0.957^{\mathrm{Se}}}{ }_{0.05} \mathrm{Na}_{0.007}$ & $0.9570: 1$ & $1: 1$ \\
\hline $\mathrm{PbTe}_{0.96} \mathrm{Se}_{0.05^{\mathrm{Na}}} 0.007$ & $0.9600: 1$ & $10: 7$ \\
\hline $\mathrm{PbTe}_{0.96} \mathrm{Se}_{0.05^{\mathrm{Na}}} 0.01$ & $0.9600: 1$ & $1: 1$ \\
\hline $\mathrm{PbTe}_{0.9643^{\mathrm{Se}}} 0.05^{\mathrm{Na}} 0.01$ & $0.9643: 1$ & $10: 7$ \\
\hline
\end{tabular}

If sodium solubility is enhanced by one sodium atom per excess-tellurium atom, and if an excess-tellurium atom for which there is no corresponding sodium atom does not affect the carrier concentration (in these restricted excess-tellurium concentration ranges), then it is expected that the transport properties of the second and third compositions would be virtually identical, as would the properties of the last two compositions. It is more reasonable, however, to assume that a $\mathrm{Te}: \mathrm{Na}$ ratio greater than $1: 1$ is necessary to ensure solution of all sodium atoms (principally because some of the excess Te atoms will be in equilibrium correspondence with vacant $\mathrm{Pb}$ sites in the lattice, and these will not affect sodium solubility); hence, it is expected that the third composition (with its 10:7 ratio of excess $\mathrm{Te}: \mathrm{Na}$ ) would exhibit a somewhat higher carrier concentration than the second composition (1:1 ratio), and similarly that the fifth composition (10:7 ratio) would exhibit a higher carrier concentration than the fourth (1:1 ratio).

*In this case, "excess tellurium" would be represented by a Te:Pb ratio greater than $0.95: 1.00$ in the overall alloy composition. 
Reading down the composition list we expect to see an increasing carrier concentration manifested by (1) a decreasing electrical resistivity and (2) a slightly decreasing peak Seebeck coefficient occurring at increasing temperatures. Figures $\mathrm{V}-13$ and -14 indicate that for $650^{\circ} \mathrm{C}$-treated test specimens made from $650^{\circ} \mathrm{C}$-treated powder the measured properties of the materials prepared to date are in agreement with the above expectations, although the difference between $1: 1$ and 10:7 excess Te:Na ratios is rather small. In addition the (typical) data shown in Figure V-15 for the composition $\mathrm{PbTe}{ }_{0.96} \mathrm{Se}_{0.05} \mathrm{Na}_{0.01}$ indicate that the materials are stable at heat-treating temperatures as high as $750^{\circ} \mathrm{C}$.

Although the electrical properties of these materials do not correspond exactly to the RCA data, a comparison of the power factor, $\alpha^{2} / \rho$, does show comparable agreement over the measured temperature range. Accordingly the power output of a properly selected material composition would be equivalent to RCA predictions, and when coupled with the lower thermal conductivity produced by alloying would be expected to yield an improved figure-of-merit comparable to that reported by $\mathrm{RCA}$.

All the data obtained to date on the various P-type alloys have been from cold-pressed test specimens with densities in the range 91 to $95 \%$ of theoretical. Because of this, the electrical resistivities measured are somewhat higher than the true values for the various compositions. Accordingly work now in progress is directed toward fabrication and measurement of hot-pressed specimens having near-theoretical densities. The results of these measurements will permit selection of the optimum composition on a maximum figure-of-merit basis. b. N-Type $\mathrm{Pb} 0.95 \underline{\mathrm{Ge}} 0.05 \underline{\mathrm{Te} \text { and } \mathrm{Pb}} 0.97 \underline{\mathrm{Ge}} 0.03 \underline{\mathrm{Te} \text { Alloys }}$

The first $\mathrm{N}$-type ingot was made to the reported $\mathrm{RCA}$ reference composition $\mathrm{Pb}_{0.951} \mathrm{Ge}_{0.05} \mathrm{Te}\left(\mathrm{Pbl}_{2}\right)_{0.001}$. Some test specimens made from this and subsequent ingots exhibited properties close to the RCA reference values, but the material also exhibited significant property changes as a function of heattreating temperature. These changes appeared to be associated with a secondphase precipitation. To fully investigate this phenomenon a series of ingots of various compositions was prepared. These compositions included $\mathrm{Pbl}_{2}$ additions 


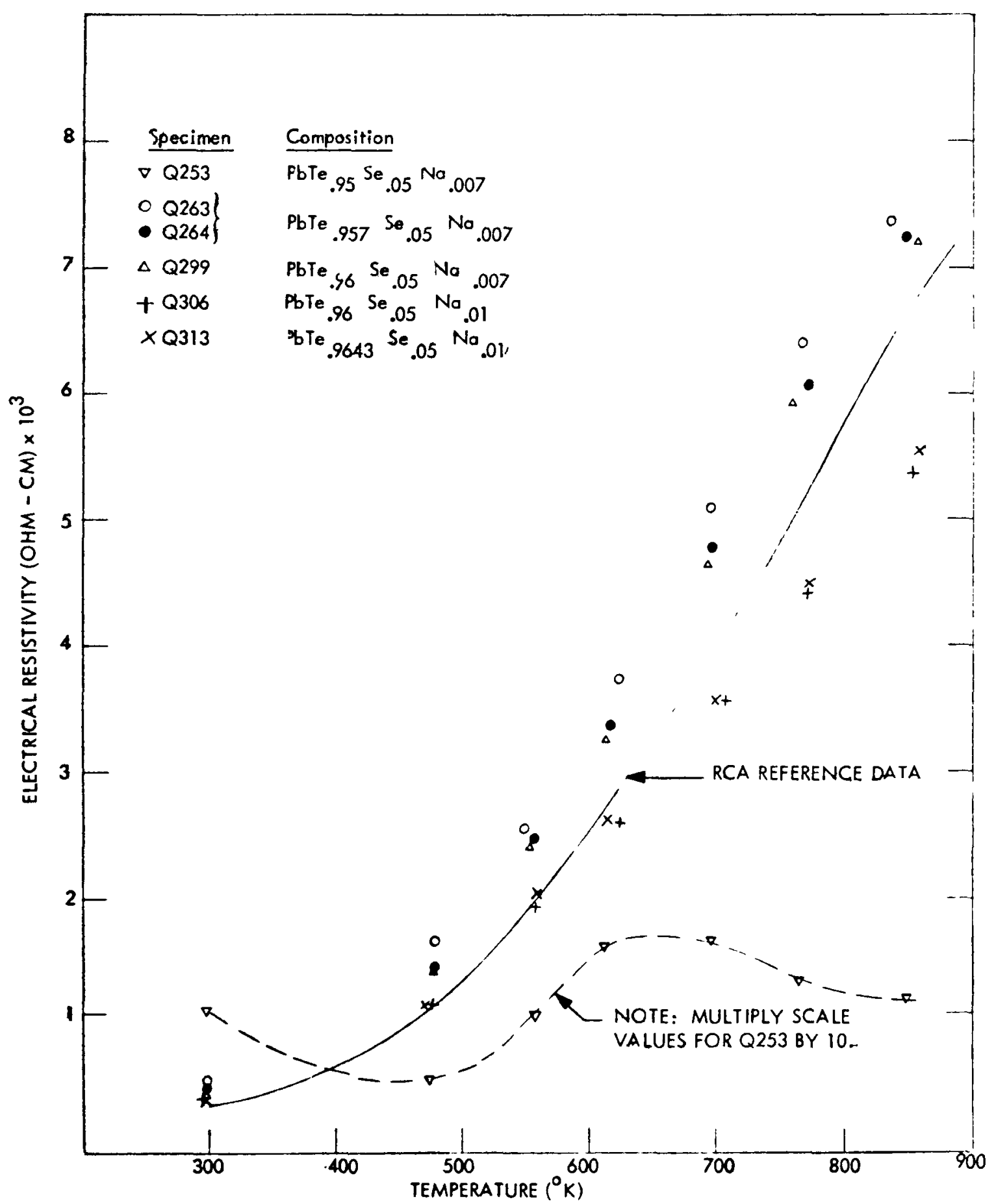

Figure V-13. Electrical Resistivity of $\mathrm{P}-\mathrm{Type} \mathrm{PbTe}_{0.95} \mathrm{Se}_{0.05}$ Alloys; $650^{\circ} \mathrm{C} / \mathrm{H}_{2}-\mathrm{Treated}$ Specimens, Pressed From $2650^{\circ} \mathrm{C} / \mathrm{H}_{2}-$ Treated Powder 


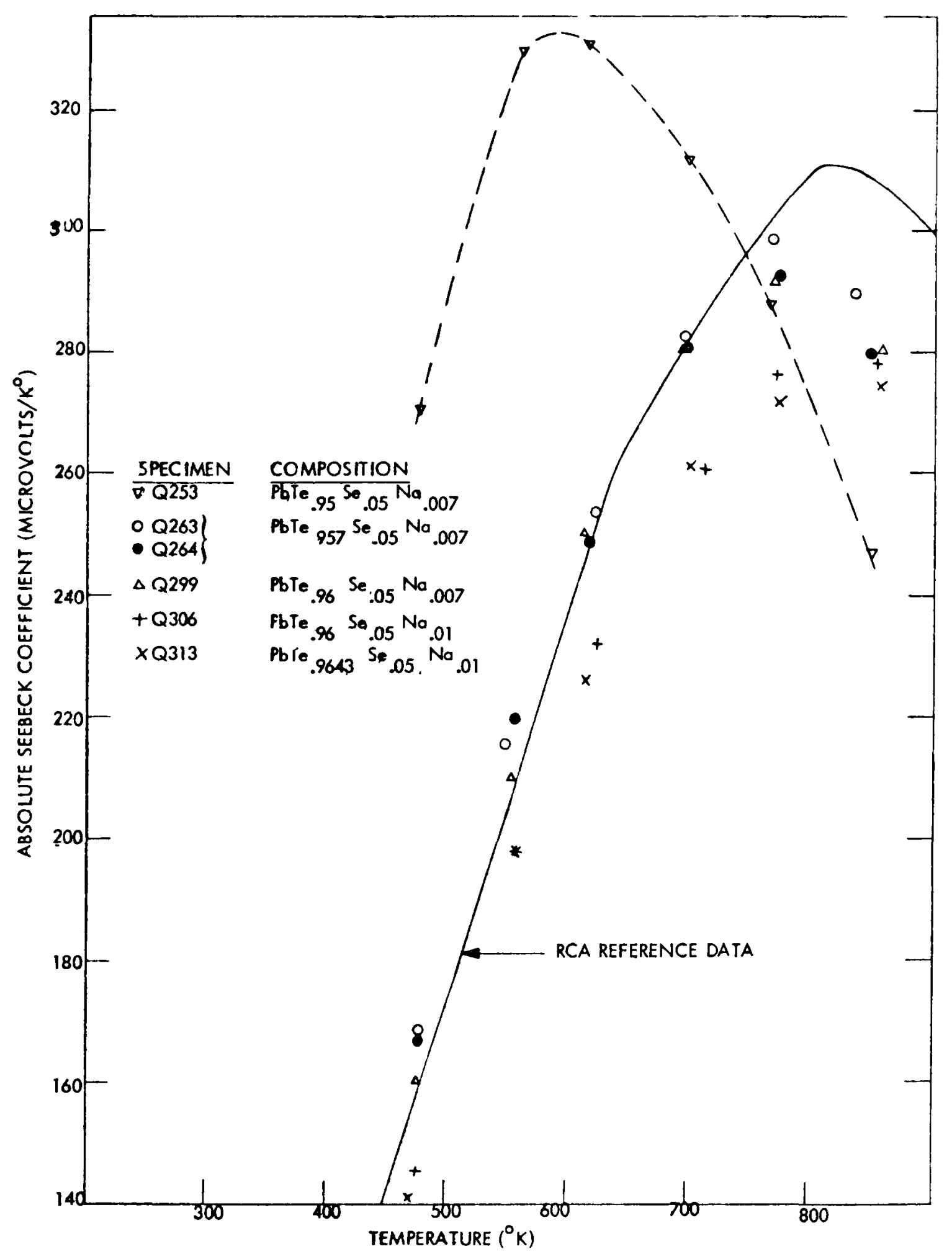

Figure V-14. Seebeck Coefficient of P-Type $\mathrm{PbT} \mathrm{e}_{0.95} \mathrm{Se}_{0.05}$ Alloys; $650^{\circ} \mathrm{C} / \mathrm{H}_{2}-$ Treated Specimens, Pressed From $650^{\circ} \mathrm{C} / \mathrm{H}_{2}-\mathrm{Treated}$ Powder 


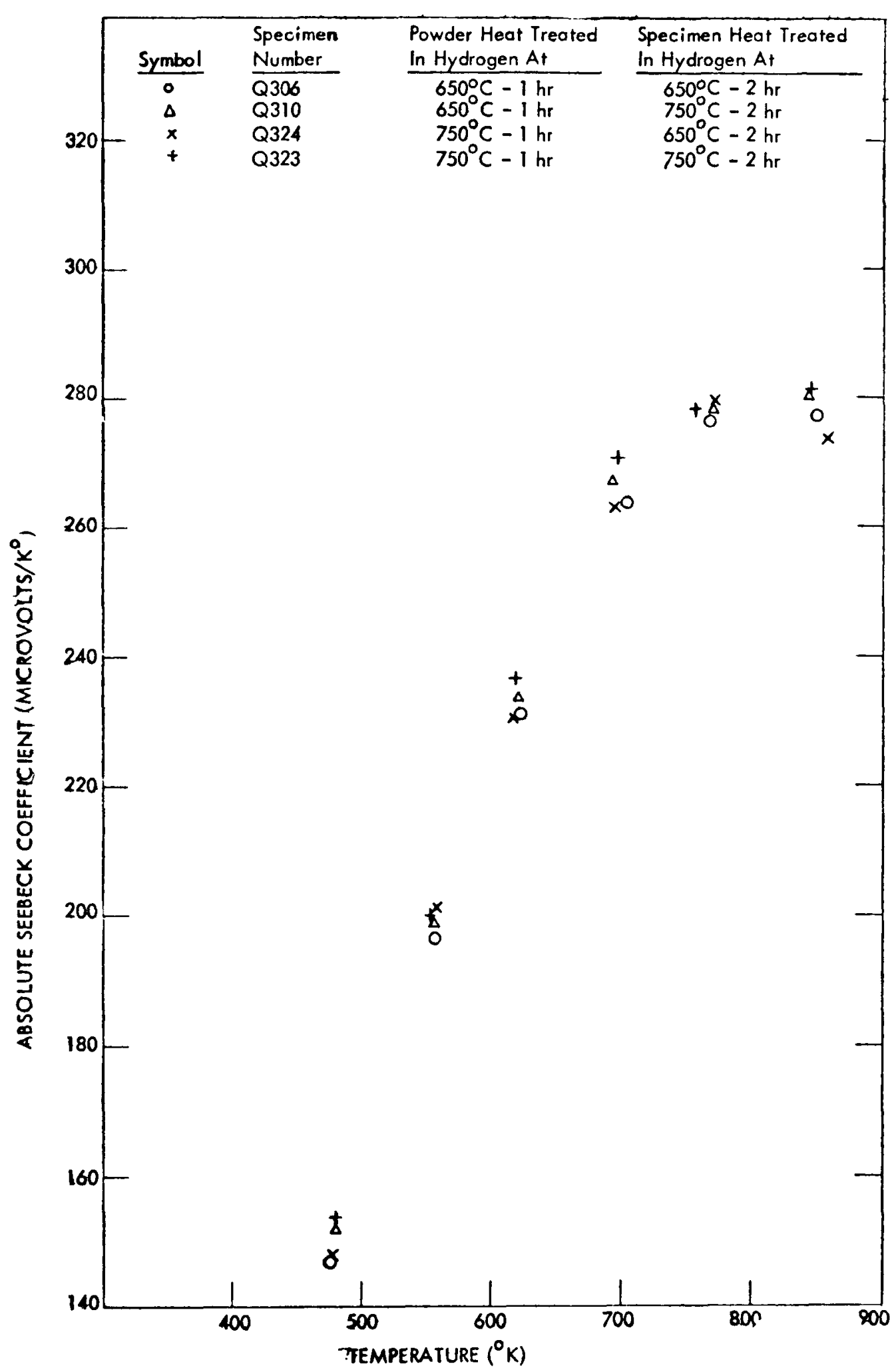

Figure V-15. Seebeck Coefficient of P-Type $\mathrm{PbTe}_{0.96} \mathrm{Se}_{0.05}{ }^{\mathrm{Na}}{ }_{0.01}$ Specimens 
of $0.001,0.0007$, and 0.00035 , each with and without a matching $\mathrm{Pb}$ addition to the two base compounds $\mathrm{Pb}_{0.95} \mathrm{Ge}_{0.05} \mathrm{Te}$ and $\mathrm{Pb}_{0.97} \mathrm{Ge}_{0.03} \mathrm{Te}$. Test specimens of each composition have been fabricated and heat-treated in hydrogen at 650 and $750^{\circ} \mathrm{C}$, and testing and evaluation of these is now in progress.

5. Process Development

a. Glass-Barrier Layers

Compatibility tests have been conducted on selected borate- and phosphatebased glass formulations whose softening points are appropriate with present module-processing conditions. Results from these compatibility tests indicate that the oxides of lead and the alkali metals included in these glasses are detrimental and should be avoided.

Present studies are concentrated on the aluminoborate glasses of Group II metal oxides, namely, the oxides of calcium, magnesium, strontium, barium, zinc, and cadmium. These ternary systems exhibit softening points compatible with our system, and also possess coefficients of expansion of the same order as the mica. Because the compounds are well documented, work is concentrated on regions which have a strong tendency to devitrify.

b. Electron-Beam Vapor Deposition of Tungsten

Deposition runs made over long time periods showed definite patterns of "powder" on the mica substrate. Indications were that the cause of these deposits was the system itself, namely scattering from the heat sink which became hot during longer runs and ion interference in the proximity of the electron beam. Modifications in the geometry of the heat sink have resulted in improved tungsten coatings of estimated thicknesses up to $600 \AA$ at distances of at least 12 in. from the source.

Further modifications in the heat sink have been implemented and additional runs are in progress. 


\section{COMPONENT DEVELOPMENT}

\section{A. INTRODUCTION AND SUMMARY}

Current component-development efforts comprise the fuel-element and core heat-transfer and hydraulic studies, and component-technology development. Component technology is being developed for the reactor control system, including the drum drive, actuator, bearing, and $4 \pi$ shieldable control drum, and the reactor shielding system.

In the area of core heat transfer, a test section designed to provide heattransfer characteristic data between the $\mathrm{NaK}$ coolant and the fuel-element cladding of the S8DR core is being fabricated.

Hydraulic studies on a full core model of S8DR have shown the existence of two vortices in the inlet-plenum area below the lower gridplate. Hydraulic studies are being made also to determine the cross-mixing of the coolant induced by the.spirally wound supporting fins on the $\mathrm{ZrH}$ fuel element. A simplified test section was designed and is being fabricated.

One S8DR design actuator continues its extended life test after 22,000 hr at $1125^{\circ} \mathrm{F}$ and 274 thermal cycles. Two sets of prototype advanced actuator coils and an advanced bearing have completed over $12,000 \mathrm{hr}$ of endurance test at 1300 and $1500^{\circ} \mathrm{F}$, respectively.

Fabrication of the $4 \pi$ shieldable control drum with a composite absorber $\left(\mathrm{B}_{4} \mathrm{C}\right.$ inserts in Ta-10W), designed to increase control worth and decrease drum weight, is nearing completion. A test is being designed to subject this drum as sembly to nuclearly induced thermal conditions.

Proof tests have demonstrated that the chemical vapor deposited (CVD) coating of tungsten will successfully minimize the oxygen absorption and resultant embrittlement of the $\mathrm{Nb}-1 \mathrm{Zr}$ used for the BeO reflector retaining-band and the $\mathrm{BeO}$ cladding. Adherence of the high-emittance iron-titanate coating to the tungsten coating is poor. Although better adherence can be achieved by substituting a plasma-spray-coating method for the tungsten undercoat, oxygen protection would then be marginal. A composite coating of CVD tungsten and plasmasprayed tungsten and iron-titanate is being evaluated. 
The fabrication of a large-diameter thin LiH shield casing is essentially completed. Evaluation of the 10,000-hr tests made to determine the benefit of adding carbon to the lead (potential gamma shield) for reducing the decarburization of the containment vessel was completed.

\section{B. FUEL-ELEMENT HEAT-TRANSFER STUDIES}

A series of experiments is being designed to generate data on the heattransfer characteristics of $\mathrm{NaK}$ flowing through channels formed by closely packed element bundles representative of the $\mathrm{ZrH}$ Reactor core. These data will be used to define the average and local NaK-to-fuel-element-cladding $\triangle T^{\prime} s$ and provide more accurate estimates of the fuel temperatures. Test sections will be built for both the S8DR and $\mathrm{ZrH}$ Reactor fuel-element designs.

The design of the heat-transfer study test section for the S8DR fuel-element design is shown in Figure VI-1. The first of four test sections was designed with a pitch-to-diameter ratio $(P / D)$ of 1 . The next test section will have $P / D=1.018$. Two asymmetrical configurations are planned, one with contact between two heater elements and the other with contact between three. Spacer rings are placed on each of the heater elements to assure proper spacing and location during the tests.

The heaters in the 19-rod bundle heat-transfer test are an equivalent of the nuclear fuel elements being evaluated in terms of diameter and heat-generation rate. The heaters are instrumented with small-diameter thermocouples attached to the inside surface of the heater cladding. Thus temperature measurement at selected circumferential locations on the heater cladding can be made without disturbing the coolant flow or cladding exterior. The 20-mil-diam clad TC's are attached to the 5/8-in. OD $\times 0.020$-in. -thick cladding by a laser-beam welding technique. The number of TC's per heater varies. The center heater in the 19-rod array has nine thermocouples to enable determination of the temperature variation around the cladding circumference.

Fabrication drawings of the assembly and component parts were prepared, reviewed for thermal stresses, material compatibility, and dimensional tolerances, and released. All materials for the first test section including the heater materials and heaters, are being procured. 

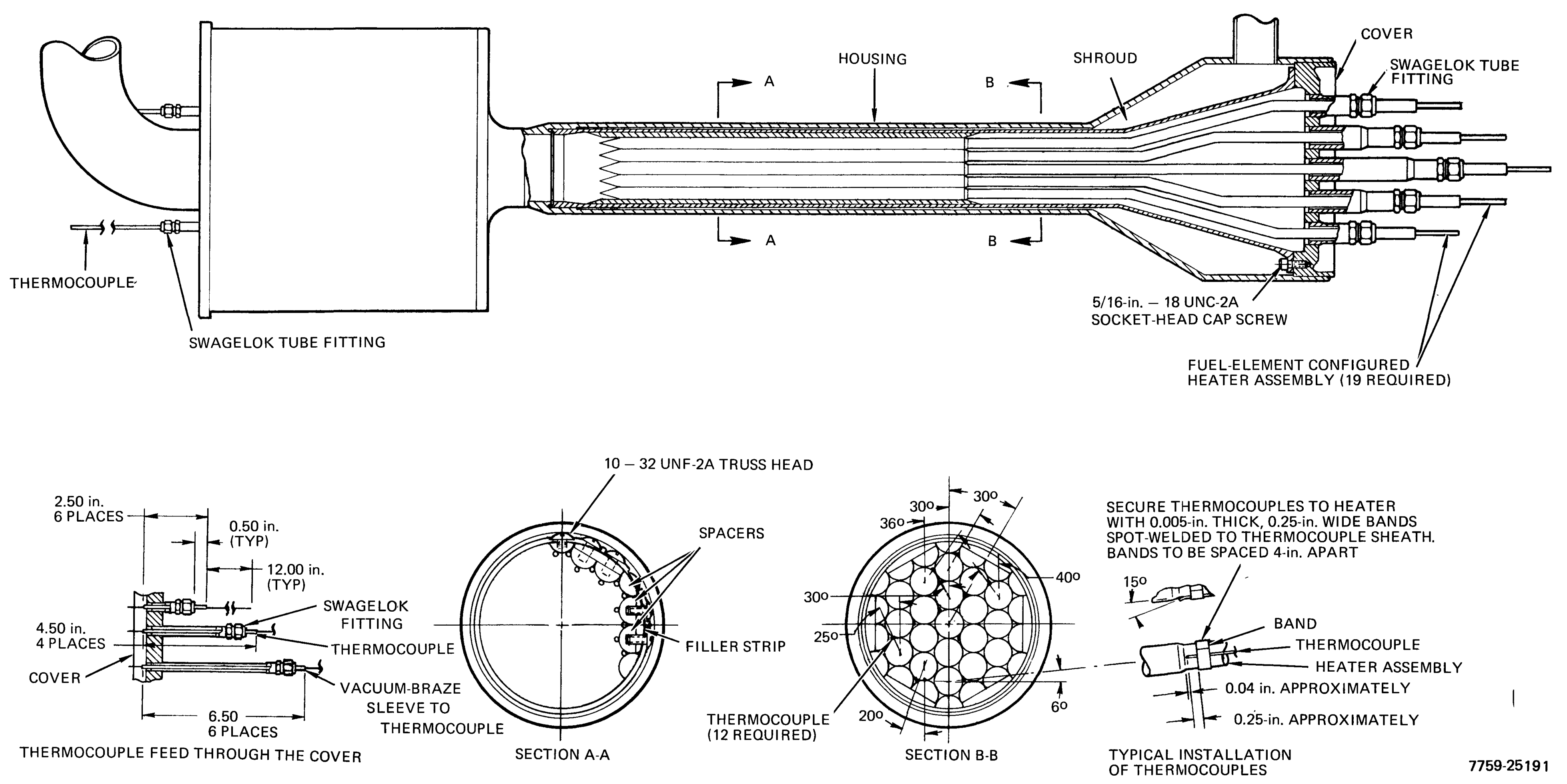
BLANK 
Two prototype heaters are being fabricated to demonstrate the various process steps for fabrication and assembly of the heater components.

Preparation for the installation of the first test section into the NaK loop was begun following initial shakedown operations on the loop. The materials, controls, and instrumentation required to integrate the test sections into the $\mathrm{NaK}$ test loop were ordered and/or located.

\section{FUEL-ELEMENT AND CORE HYDRAULICS}

Hydraulic studies are being carried out to characterize the coolant flow through the S8DR and the $\mathrm{ZrH}$ reactor cores. The parameters of interest are the pressure variation in the inlet plenum and its effect on individual channel flow, pressure drop through the core and through the interfuel-element flow channels, and interchannel mixing. Of particular interest are the effects of entrained gases on the coolant flow through the S8DR core. Data based on water tests will be analyzed to calculate the NaK-coolant-flow characteristics.

1. S8DR Core Hydraulic Studies

A hydraulic model of the S8DR core with simulation of the inlet piping is being studied with the following objectives:

1) Determination of coolant-flow patterns in the inlet plenum with and without gas in the liquid.

2) Photographically record flow behavior in the core-coolant channels using transparent "dummy" fuel rods.

3) Photograph flow behavior above upper gridplate.

4) Determine effects of gas in coolant on pressure distribution below lower gridplate.

5) Determine flow void fractions in the core flow channels.

6) Determine coolant flow distribution in core flow channels with and without gas introduction.

7) Qualitatively determine the mixing characteristics of flow beneath the upper gridplate. 


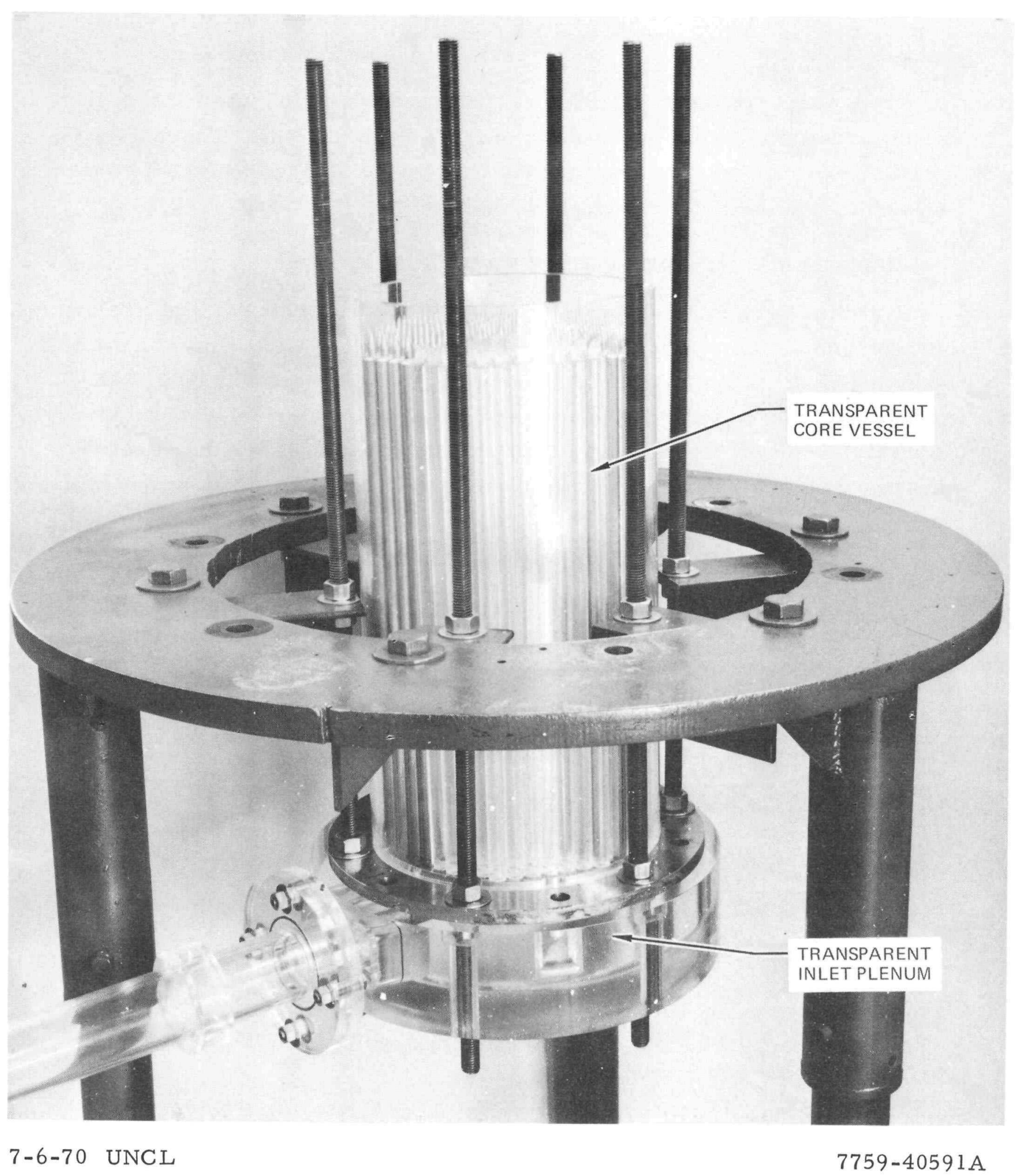

Figure VI-2. Partially Assembled S8DR Core Hydraulic Model

$$
\begin{gathered}
\mathrm{AI}-\mathrm{AEC}-12975 \\
86
\end{gathered}
$$


The core-hydraulics experimental program proceeded from the design and assembly phase to the operational phase during the past three months. Assembly of the transparent core model for visual and photographic studies and for pressure measurement beneath the lower gridplate was completed (see Figures VI-2, -3 , and -4). With the exception of inlet and outlet gridplates and a $3 / 4$ core load of stainless-steel dummy fuel rods and reflectors, all core model parts from the inlet pipe to the exit connection in the upper cylinder were made from transparent plastic fabricated to S8DR drawing configurations. Model operation with simultaneous liquid and gas flow was started to photographically record flow patterns and measure pressures between the lower gridplate and orifice plate. The pressure-probe locations are shown in Figure VI-5.

An initial study of flow in the lower plenum (fuel rods, reflectors, and upper gridplate not installed, Figure VI-6) showed two vortices existed near the inlet generally under the orifice-plate holes beneath fuel rods V-19 and -3. As indicated in Figure VI-7 these vortices appeared to collect gas in the coolant and preferentially channel this collected gas through the adjacent orifice-plate holes. In subsequent tests with core fully loaded with dummy fuel rods and the upper gridplate in place, these vortices still existed.

The flow mockup of a single electroded tri-cusp core fuel channel was assembled with flow, pressure, and temperature-instrumentation and gasinjection capability. Preliminary runs with noise-analys is data recording and processing equipment have shown a correlation between bubble size and probe signal and demonstrated the feasibility of the noise-analysis technique for measurements of liquid-and gas-flow characteristics in the full-core model. Tube blanks for the full-core instrumented rods have been fabricated and wiring and installation of electrodes are in progress.

These instrumented simulated fuel rods will be selectively placed in the fully loaded core model to measure gas-bubble size and velocity as they travel through the coolant channels.

\section{Zirconium Hydride Reactor Core Hydraulic Studies}

The initial efforts on the $\mathrm{ZrH}$ core hydraulic studies are concentrating on generating empirical interchannel cross-mixing and pressure-drop data as functions of the configuration parameters of the spiral fins on the fuel element. 


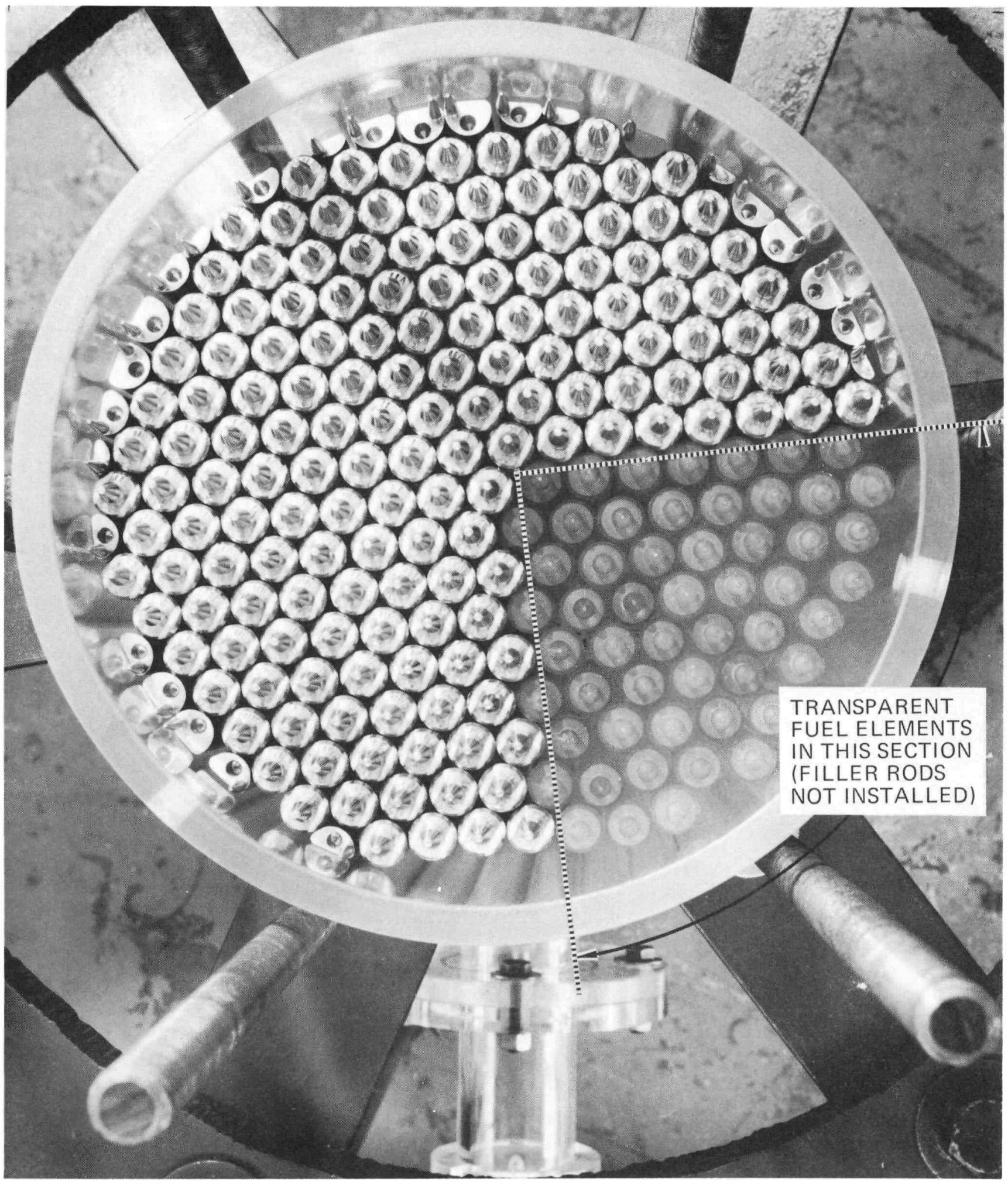

7-6-70 UNCL

7759-40590A

Figure VI-3. Top View of S8DR Core Model 


\section{CONEIDENTIAL:}

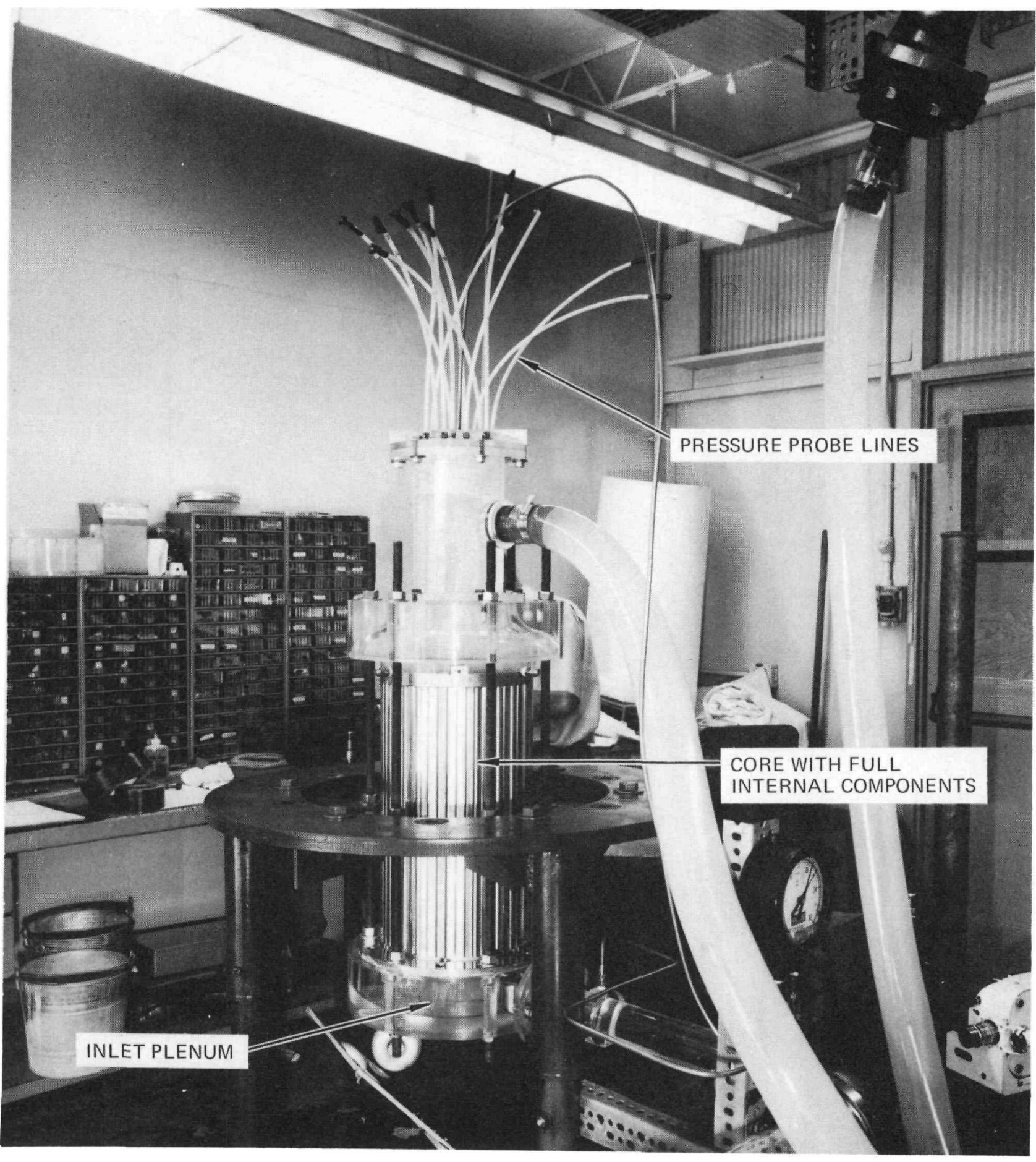

7-17-70 UNCL

$7759-40606 \mathrm{~A}$

Figure VI-4. S8DR Core Module Instrumented for Inlet Plenum Pressure Mapping 


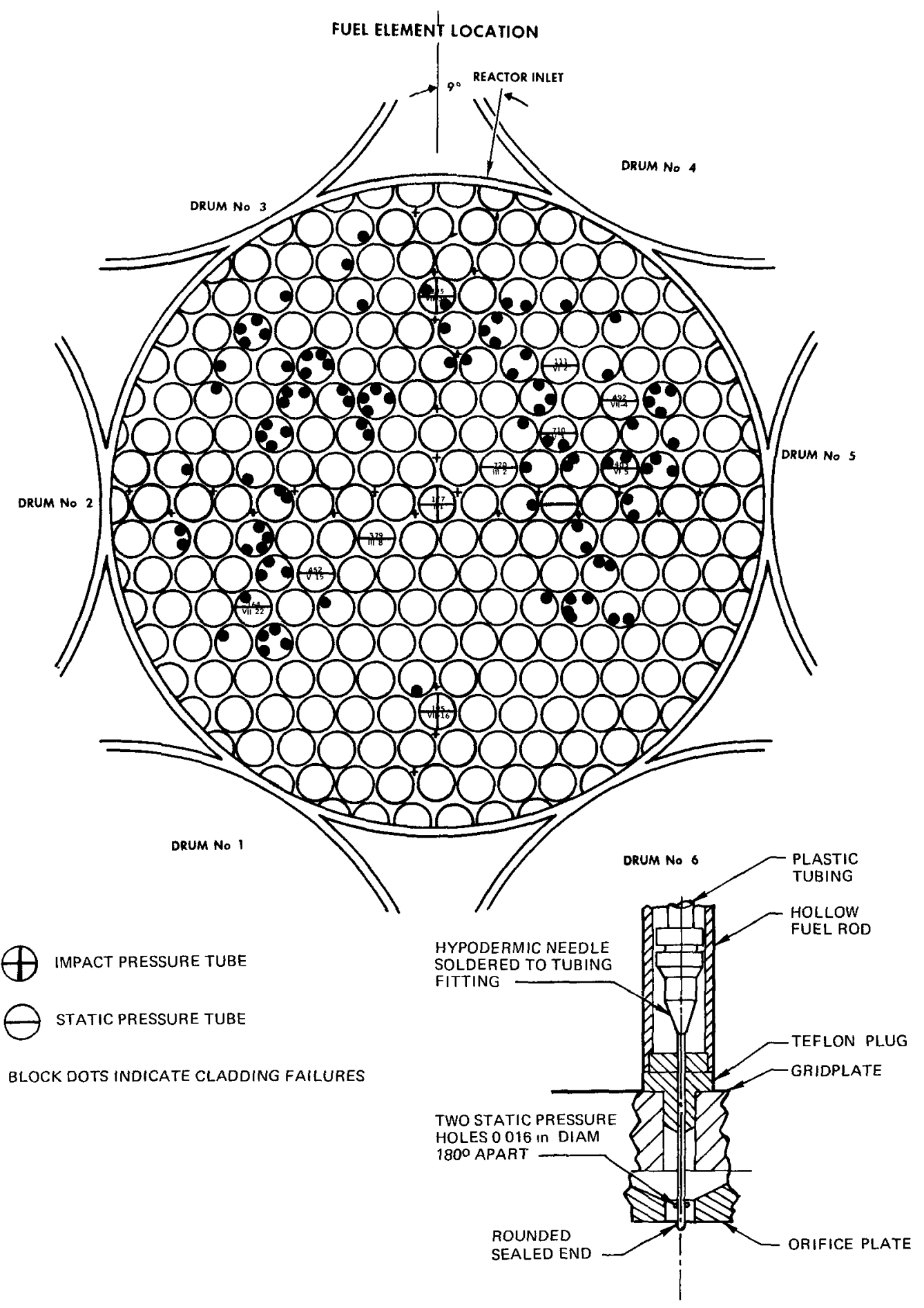

PROBE INSTALLATION UNDER GRIDPLATE

ISTATIC TUBE SHOWN, IMPACT TUBE SIMILAR BUT END OF TUBE SOUARE WITH \& AND OPEN END LOCATED AT ORIFICE EXIT NO STATIC HOLES)

775925192

Figure VI-5. Location of Pressure Probes Beneath Lower Gridplate S8DR Hydraulic Core Model 


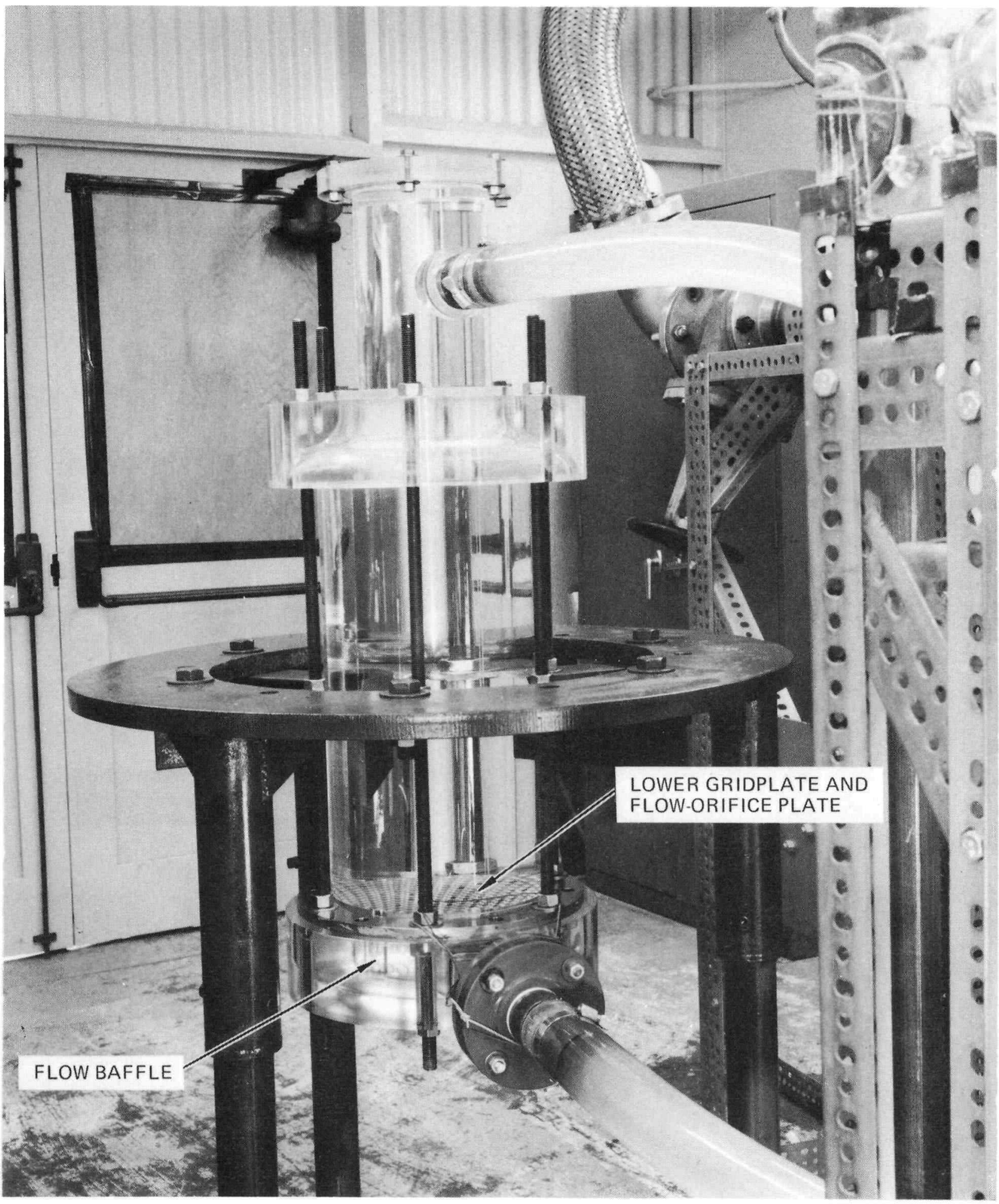

5-25-70 UNCL

$7759-4081 \mathrm{~A}$

Figure VI-6. S8DR Core Model Setup for Initial Bubble Tests (No Fuel Elements) 


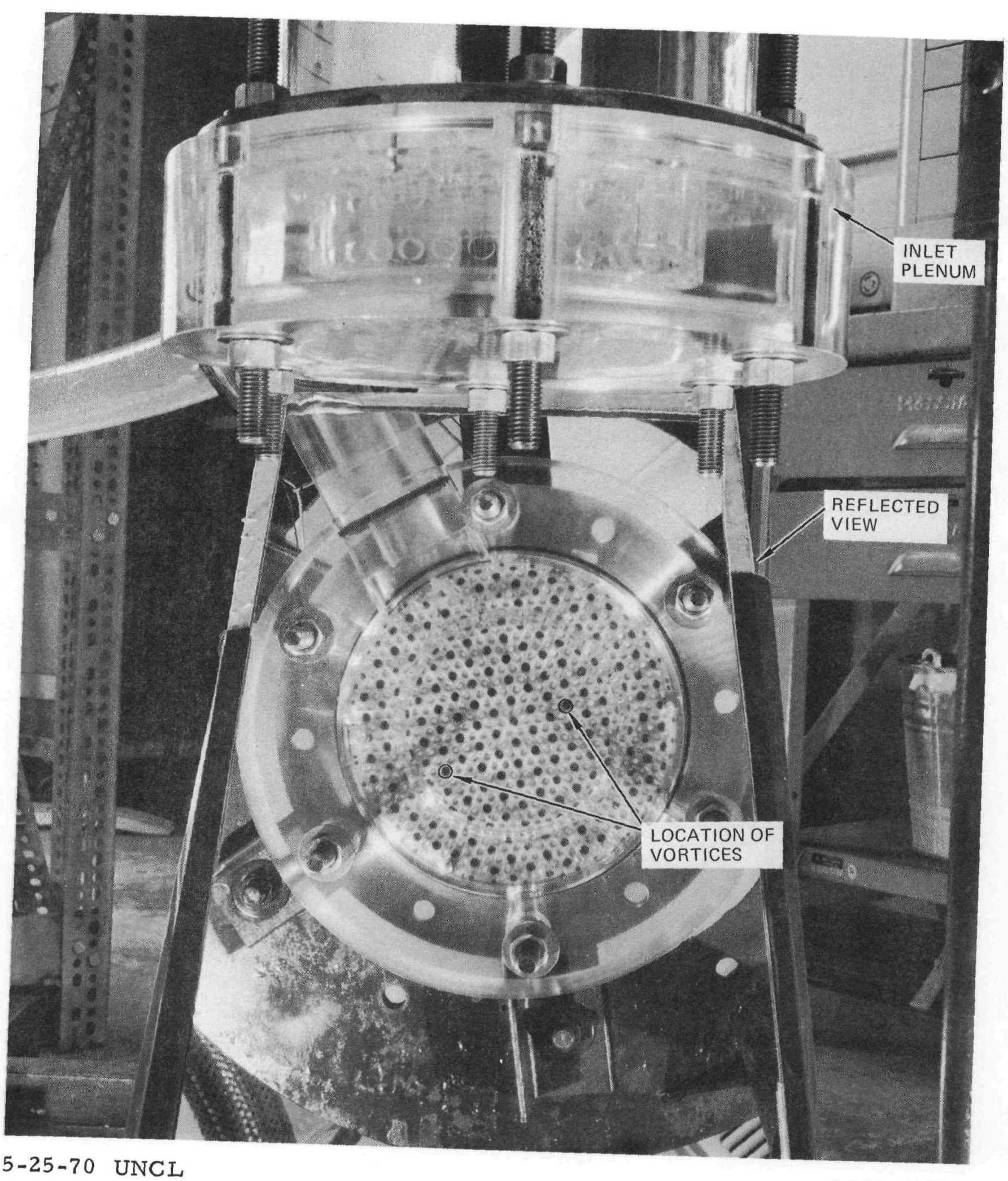

5-25-70 UNCL

7759-4080A

Figure VI-7. View of Inlet Plenum Showing Vortex Locations 
These fins are expected to promote cross - channel coolant mixing to reduce local clading hot-spots as well as providing physical support to minimize clustering.

The hydraulic model to be used for the initial tests is shown schematically in Figures VI- 8 and -9 . The use of 19 elements in the model is expected to produce data representative of the full 295 -element core. Elements with conductivity probes will be installed in selected locations to measure the change of the water conductivity for measurement of cross-flow. Noise-analysis techniques will be used to analyze the test data. Pressure measurement will be made with miniature probes.

Plastic and instrumented fuel elements from the S8DR studies are being used for this test. The fins are being simulated by attaching spirally wound plastic strip to the rod surface. Fabrication of the model is in progress.

\section{CONTROL-DRUM ACTUATOR}

The effort in this program is directed toward the development of advanced actuators for ZrH reactors.

\section{Testing}

Tests are being run to evaluate potential high-temperature high-reliability conductor materials for actuator coils. These tests are being made on coils wetwound with AI-1 cement on rectangular-shaped alumina bobbins. Three different conductor material have been tested or are under test as candidate material for the coils: nickel-clad silver, Cube alloy, and Oxalloy. The nickel-clad silver conductor consists of a fine silver core swaged in "A" nickel cladding. The composite wire is $80 \%$ silver by cross-sectional area. Cube-alloy conductor is a copper base or matrix, dispersion-hardened by addition of fine particles of beryl1ia. Oxalloy conductor consists of an oxygen-free high-conductivity copper core swaged in a chrome-iron alloy (430 stainless-steel) cladding. The composite wire is $72 \% \mathrm{Cu}$ by cross-sectional area.

A performance test of prototype actuator coils built to the configuration, bobbin shape and material, conductor size and number of turns, lead-wire termination, and fabrication process, and representative of the advanced actuator design, is underway. The test items originally consisted of six coils wound with Cube alloy, and six with Ni-clad Ag. After 40 thermal cycles and 2276 test hours, of which 2063 were at the test temperature of $1300^{\circ} \mathrm{F}$, two Cube-alloy coils failed. The coil failures were due to brittle fracture of the conductor 


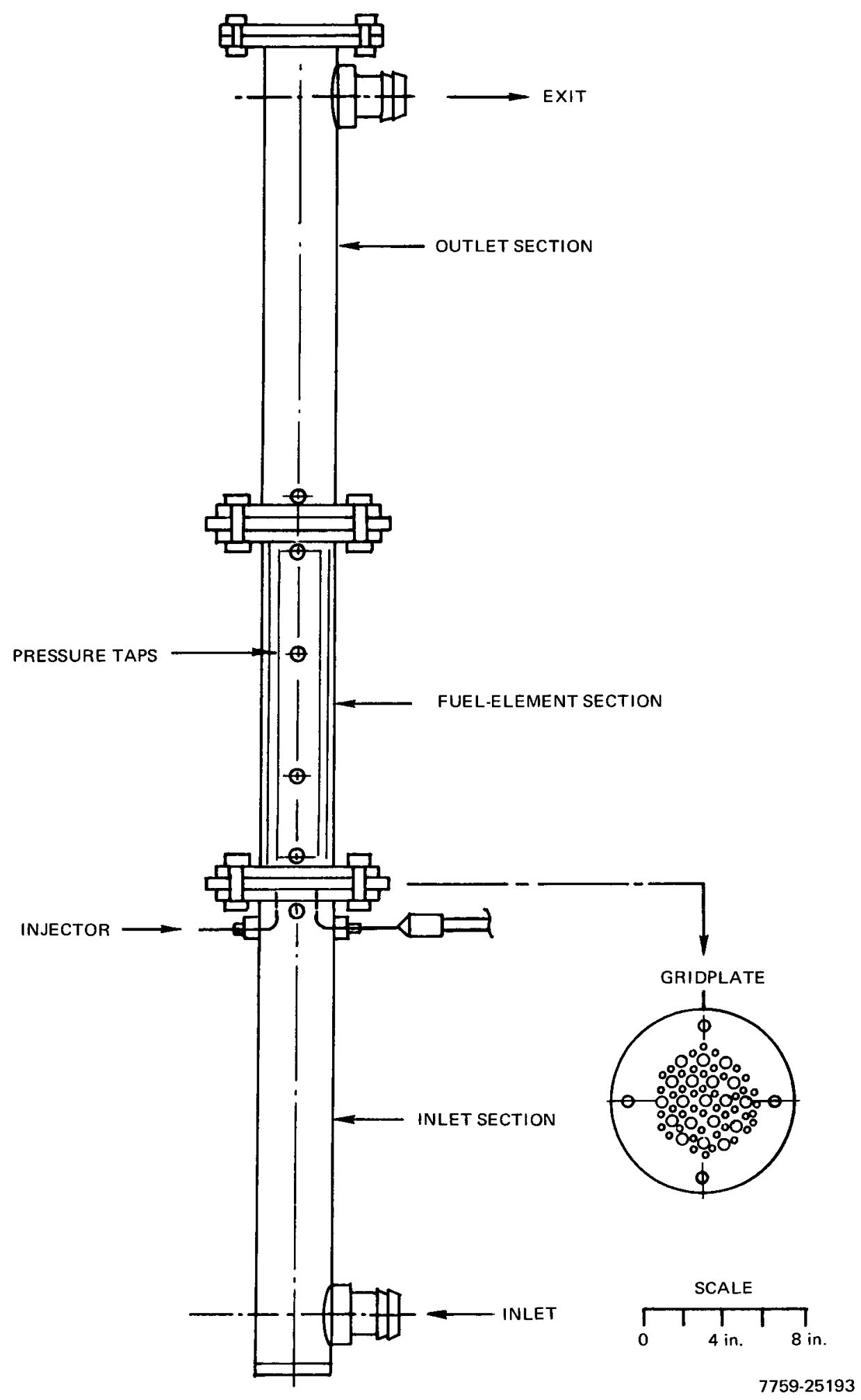

Figure VI-8. Nineteen-Element Zirconium Hydride Mixing Test 


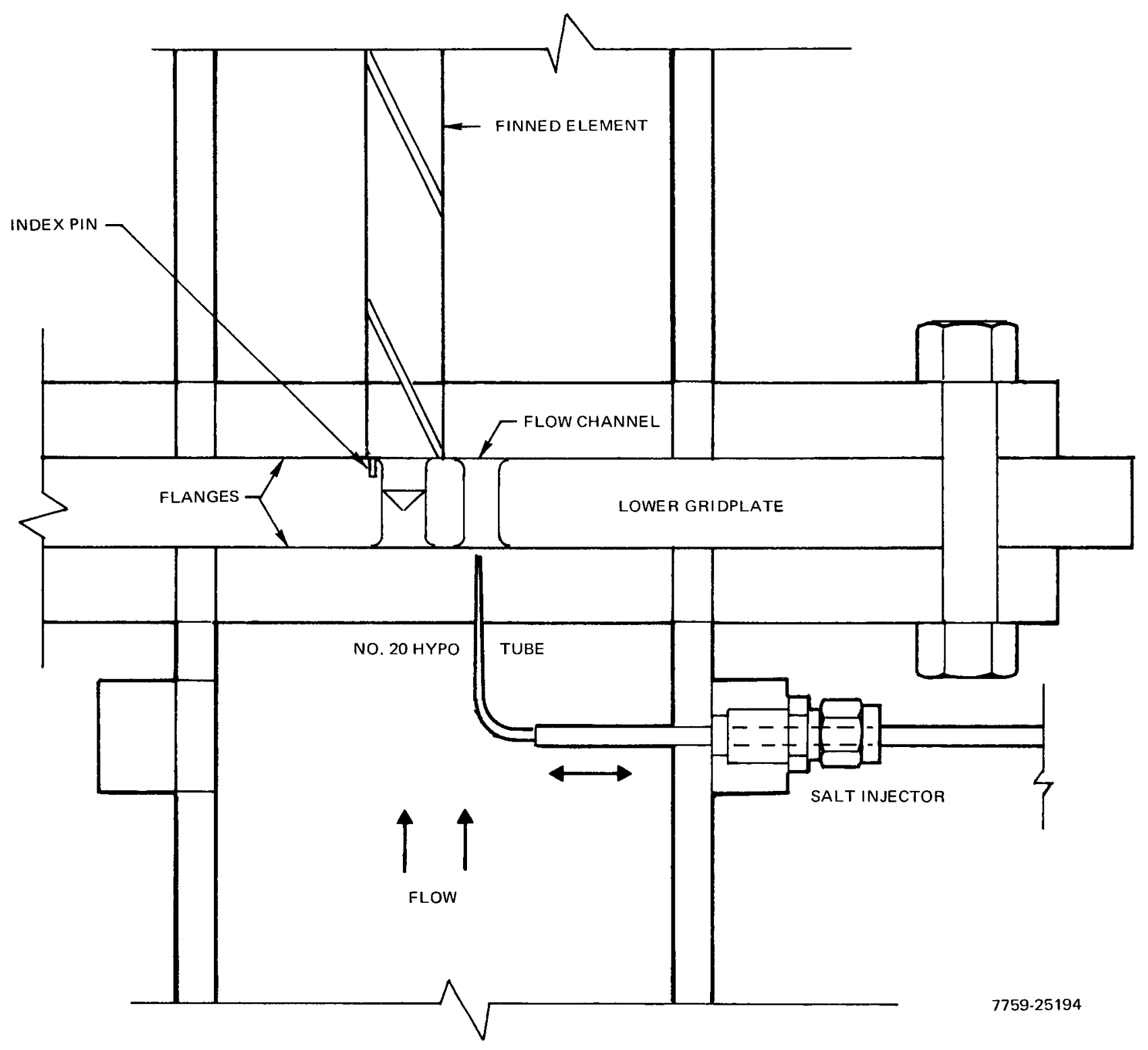

Figure VI-9. Injector Setup for Zirconium Hydride Mixing Test 
near the termination to the lead wire. This area of conductor is subject to mechanical flexing during the coil-fabrication process. The inherent stiffness of this conductor probably results in localized high stresses. This area of high stress is more subject to corrosion by the acidic solvent of encapsulant during the winding and curing cycles. Testing is continuing and the remaining ten coils have accumulated 101 thermal cycles and $11,285 \mathrm{hr}$ at $1300^{\circ} \mathrm{F}$ in a total test time of $12,123 \mathrm{hr}$ of a scheduled 20,000 .

\section{Performance}

After completion of the S8DR design-verification testing, one actuator, SN-Dev-013, was continued in test to demonstrate actuator performance at temperature for $20,000 \mathrm{hr}$ or more. The total test time on this actuator is now $22,048 \mathrm{hr}$ of which 20,306 have been at $1125^{\circ} \mathrm{F}$. Of 274 thermal cycles accumu lated, 139 have been startup. A startup cycle run in conjunction with alternate thermal cycle consists of operating the actuator at rate, speed, and current continuously for $25 \mathrm{~min}$ before thermal ramp and after maximum temperature is attained. These hours do not include the 5,340 of test at $\sim 1025^{\circ} \mathrm{F}$ made on mechanical parts before rebuild to the latest S8DR design. Performance of this actuator is normal.

The extended test run consists of the following at $1125^{\circ} \mathrm{F}$ :

a) 3000-hr endurance run (completed)

b) 2000-hr dwell (completed)

c) 3000-hr endurance run (completed)

d) 2000-hr dwell

e) 30-thermal cycles

This testing will result in a total of 300 thermal and 150 startup cycles, as well as approximately $21,500 \mathrm{hr}$ of testing at $1125^{\circ} \mathrm{F}$. Testing is in the final $2000-\mathrm{hr}$ dwell phase.

\section{Design}

The design effort, targeted towards the completion and review of the design layout near the end of this fiscal year, is continuing at a low level. The previously described ${ }^{(3)}$ mockup actuator, designed to provide an interface for the control-drum drive-train test, discussed in Section $E$ following, is being fabricated. 


\section{E. CONTROL-DRUM BEARING}

The objective of the bearing-development program is to extend the space bearing technology to meet the higher temperature (up to $1500^{\circ} \mathrm{F}$ ) and longer life ( 2 to $5 \mathrm{yr}$ ) requirements of the $\mathrm{ZrH}$ reactor system.

Simulated life testing at $10^{-8}$ tor $\mathrm{r}$ and $1500^{\circ} \mathrm{F}$ of the UHV high-temperature bearing with $\mathrm{Al}_{2} \mathrm{O}_{3}$-plated $\mathrm{Ta}-10 \mathrm{~W}$ vs carbon-graphite friction surfaces, has completed two 1000-hr dwell periods plus $10,260 \mathrm{hr}$ with periodic bearing rotation. Friction-torque, recorded for each rotation sequence having the equivalent travel of two full-in to full-out cycles of the control drum, is summarized in Figure VI-10. Maximum friction-torque throughout the test has been $7.1 \mathrm{in} .-1 \mathrm{~b}$, equivalent to a friction coefficient of 0.25 , and has occurred four times. The average friction value was calculated to be $5.5 \mathrm{in}$. $-1 \mathrm{~b}$. This compares to the bearing specification friction-torque limit of $18.0 \mathrm{in},-1 \mathrm{~b}$ at $1350^{\circ} \mathrm{F}$. The test will be continued to $20,000 \mathrm{hr}$ at temperature with a series of thermal cycles between $1500^{\circ} \mathrm{F}$ and $<450^{\circ} \mathrm{F}$ during the last $5000 \mathrm{hr}$ at test.

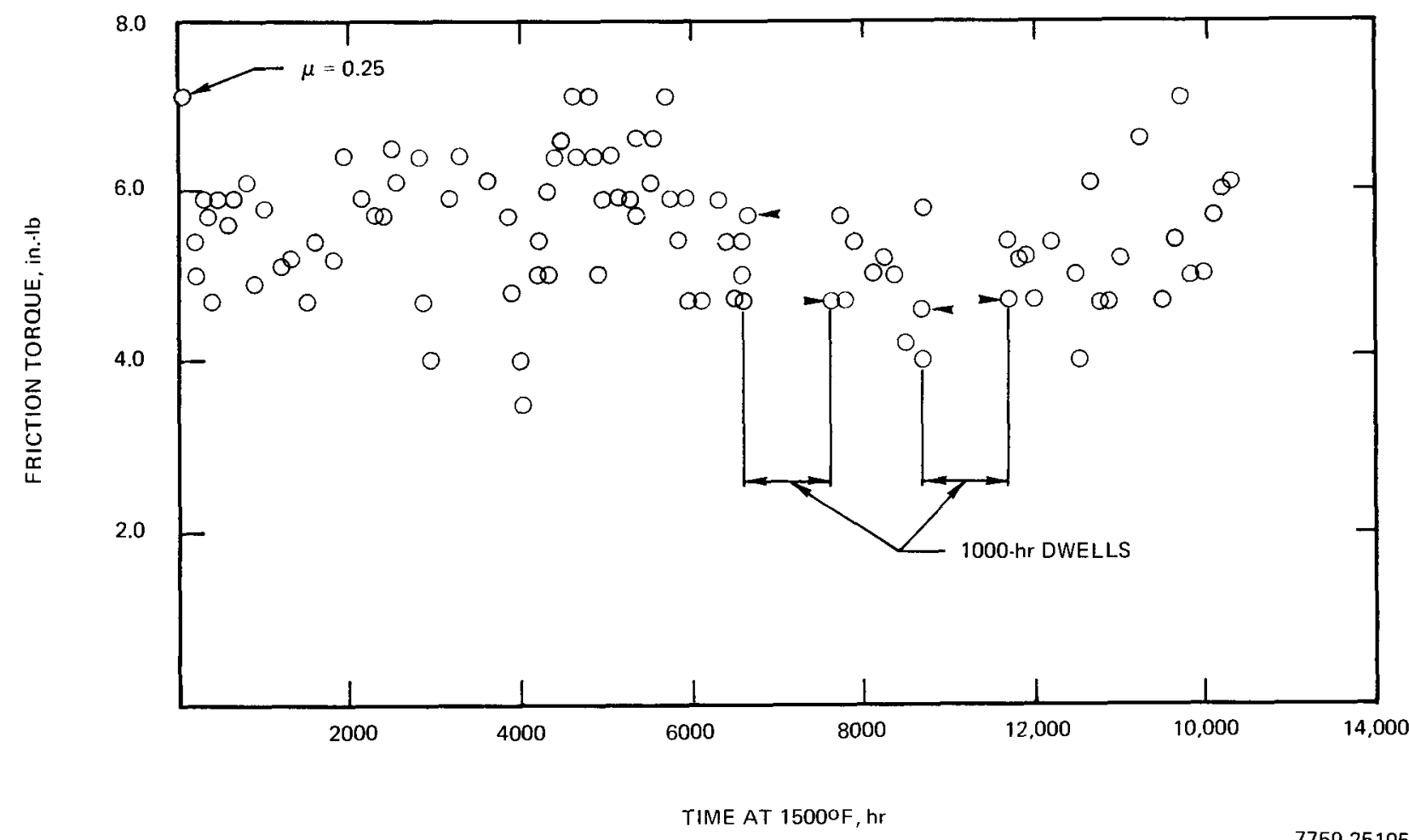

Figure VI-10. Advanced Zirconium Hydride Bearing Simulated Life Test Friction Torque at $1500^{\circ} \mathrm{F}, 10^{-8}$ torr, $\mathrm{Al}_{2} \mathrm{O}_{3}$ vs P5 Carbon-Graphite 
A material-evaluation test to study friction and wear of solid $\mathrm{Al}_{2} \mathrm{O}_{3}$ against itself is being made at $1500^{\circ} \mathrm{F}$ and $10^{-8}$ torr. Two specimen couples are being tested simultaneously with $2600 \mathrm{hr}$ at temperature accumulated to date. Figure VI- 11 shows static friction coefficients of the two couples for the test period. The maximum friction coefficient at $1500^{\circ} \mathrm{F}$ has been 0.32 and is approximately equivalent to a friction-torque of $9.1 \mathrm{in},-1 \mathrm{~b}$ on the UHV high-temperature bearing test. The friction coefficient has been increasing slightly, but following the high of 0.32 on couple No. 2, both specimen couples have tended to stabilize around a friction coefficient of 0.27 .

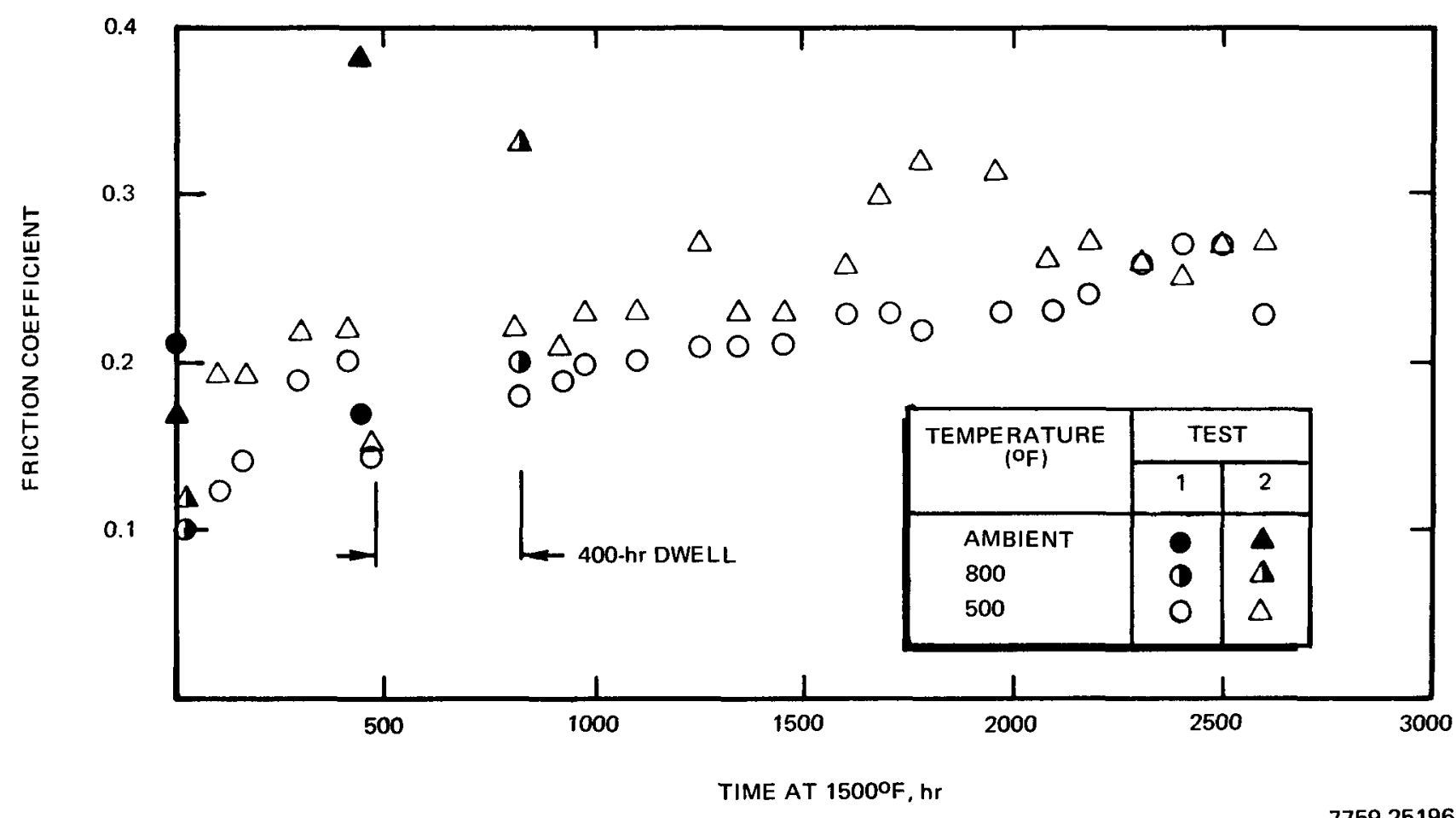

Figure VI-11. Advanced Zirconium Hydride Bearing Material-Evaluation Test Friction Coefficient vs Time at $1500^{\circ} \mathrm{F}, 10^{-8}$ torr, $\mathrm{Al}_{2} \mathrm{O}_{3}$ vs $\mathrm{Al}_{2} \mathrm{O}_{3}$

F. $4 \pi$ SHIELDABLE REFLECTOR

The objective of this project is to develop a reflector control drum for the $\mathrm{ZrH}$ reactor. This program currently consists of two main tasks: ControlDrum Development and Material Studies. 


\section{Drum Development}

\section{a. Development Drum No. 1 and 2}

As stated in the previous quarterly report one BeO block on Drum No. 1 fractured during the thermal or vibration tests. Design changes to thicken the band and enlarge the rivets were completed for both Drum No. 1 and No. 2 . Band materials and rivets have been ordered.

The sintered BeO blocks for Drum No. 2 were received and are being machined. All other parts are in fabrication.

b. Drum Thermal-Gradient Test

A thermal-gradient test of the control drum is planned using the STIR (Shield Test and Irradiation Reactor) as a neutron and gamma source to induce nuclear heating within the drum similar to that expected on the $\mathrm{ZrH}$ reactor.

A preliminary analysis was made of the energy-absorption $r$ ates of the $\mathrm{ZrH}$ reactor control drum (without $\mathrm{B}_{4} \mathrm{C}$ ) when tested in the STIR facility. Two cases were studied, one with the drum poison toward the reactor, and the second with the poison away from the reactor as shown in Figure VI-12. The calculated

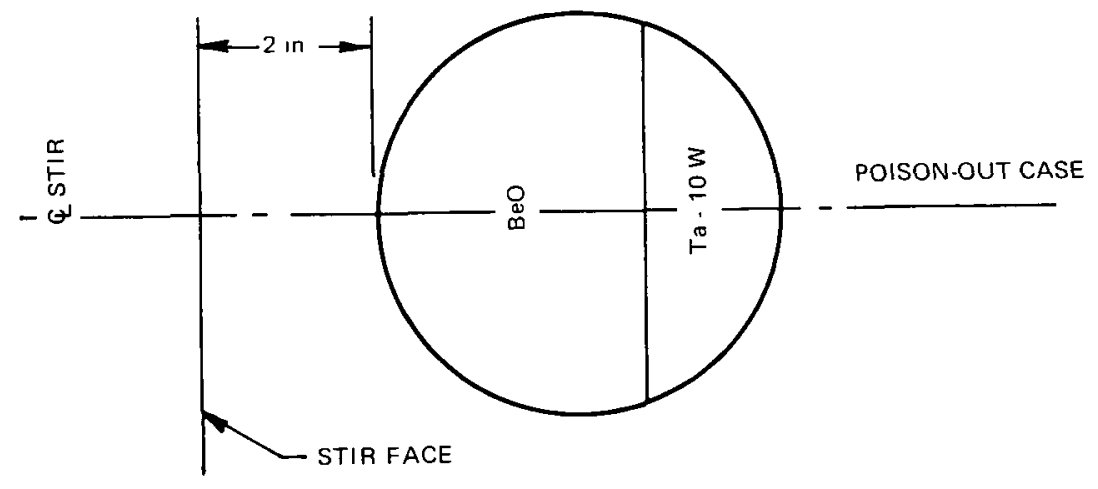

Figure VI-12. EnergyAbsorption Study Configurations

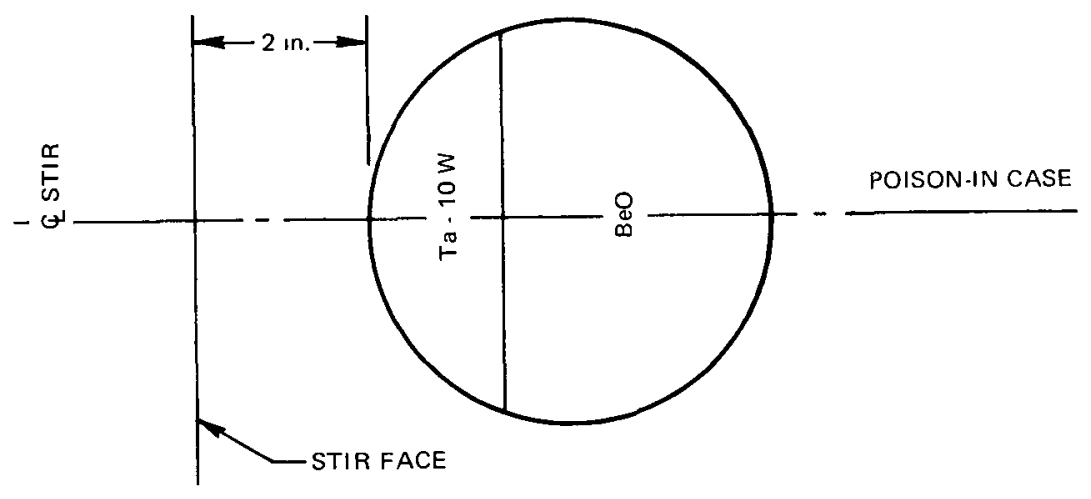




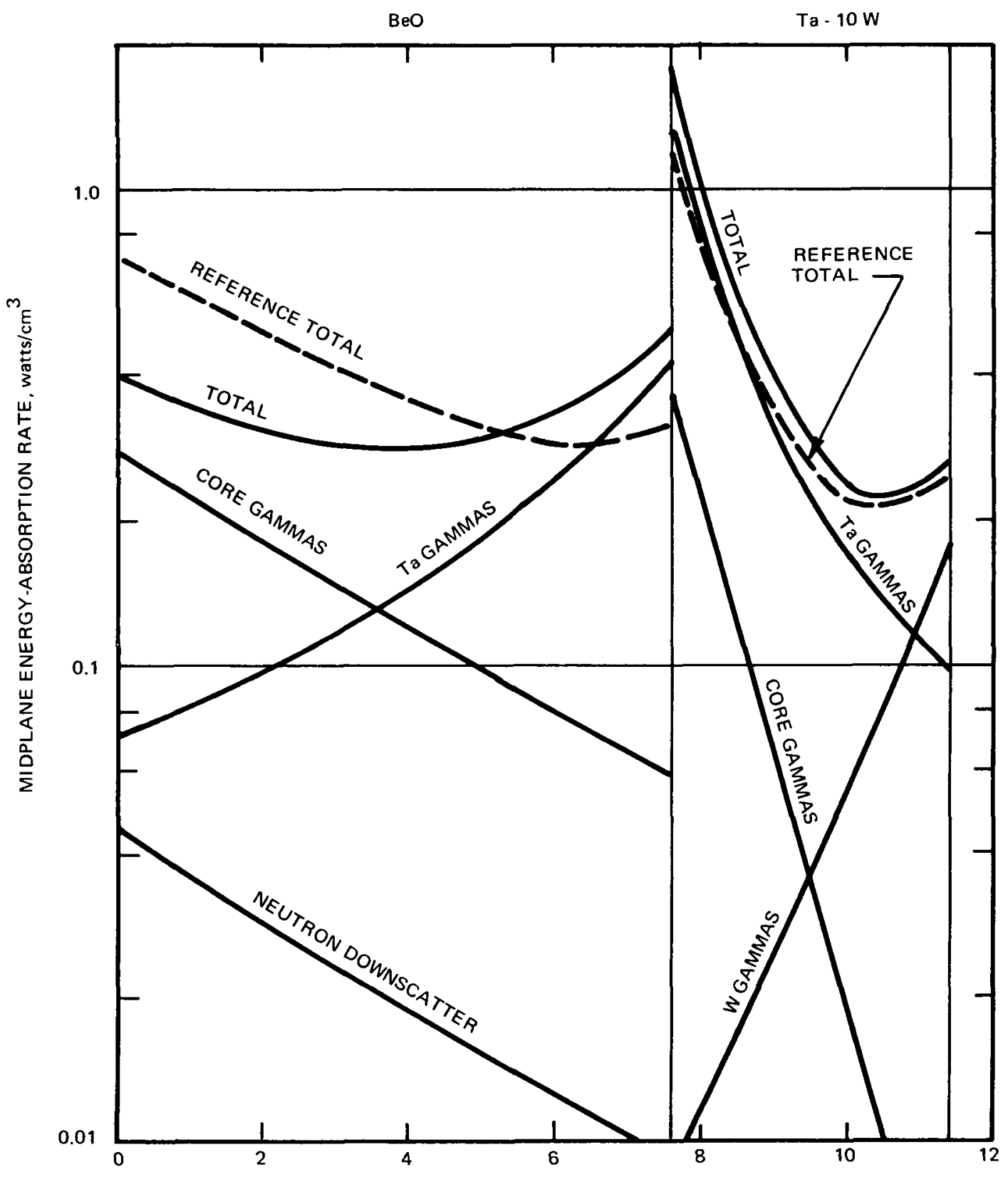

THICKNESS, $\mathrm{cm}$

Figure VI-13. Midplane Energy-Absorption Rates, Reference Zirconium Hydride Reactor Poison-Backed Drum in STIR Pool, Poison Out 
energy-absorption rates through the drum cross-section for the poison-out and poison-in orientations in STIR are shown in Figures VI-13 and 14, respectively. These rates are in reasonable agreement with the drum estimated energyabsorption rates for the $\mathrm{ZrH}$ reactor at $600 \mathrm{kwt}$.

Thermal studies, resulted in the conclusion that a device or a material with high thermal conductivity in direct contact with the dry well is needed to maintain the dry-well isothermal within $\pm 25^{\circ} \mathrm{F}$ in any given transverse plane through the well. A temperature-controlled liquid-sodium jacket and a heat-pipe jacket are being studied as a possible means of maintaining the isothermal condition.

A conceptual-design layout of the irradiation fixture is in progress. In the area where the drum is located the following features are included:

1) $\mathrm{ZrH}$ reactor reference-design control drum.

2) Control-drum bearings used in testing Development Drum No. 1. These are made of flight materials.

3) Stainless-steel dry well (with oxidized surface) around drum.

4) Vacuum inside dry well.

5) Approximately 1/2-in. liquid sodium around outside of dry well.

6) Metal containment shell around sodium with electric heaters fastened to outside of containment shell.

7) Gas annulus around containment shell.

8) Capsule metal wall which also provides double containment for the sodium.

Preliminary thermocouple requirements in the drum were established for calculating thermal stresses. These will be studied from the standpoint of practical assembly.

Preliminary calculations show the drum will bow approximately 0.002 -in. during STIR testing. Several means are being studied for measuring drum bow during testing. An optical method is considered the most accurate measuring means, but the cost is prohibitive. Others being considered are electrical pin switches, capacitance gages, and linear transducers. 


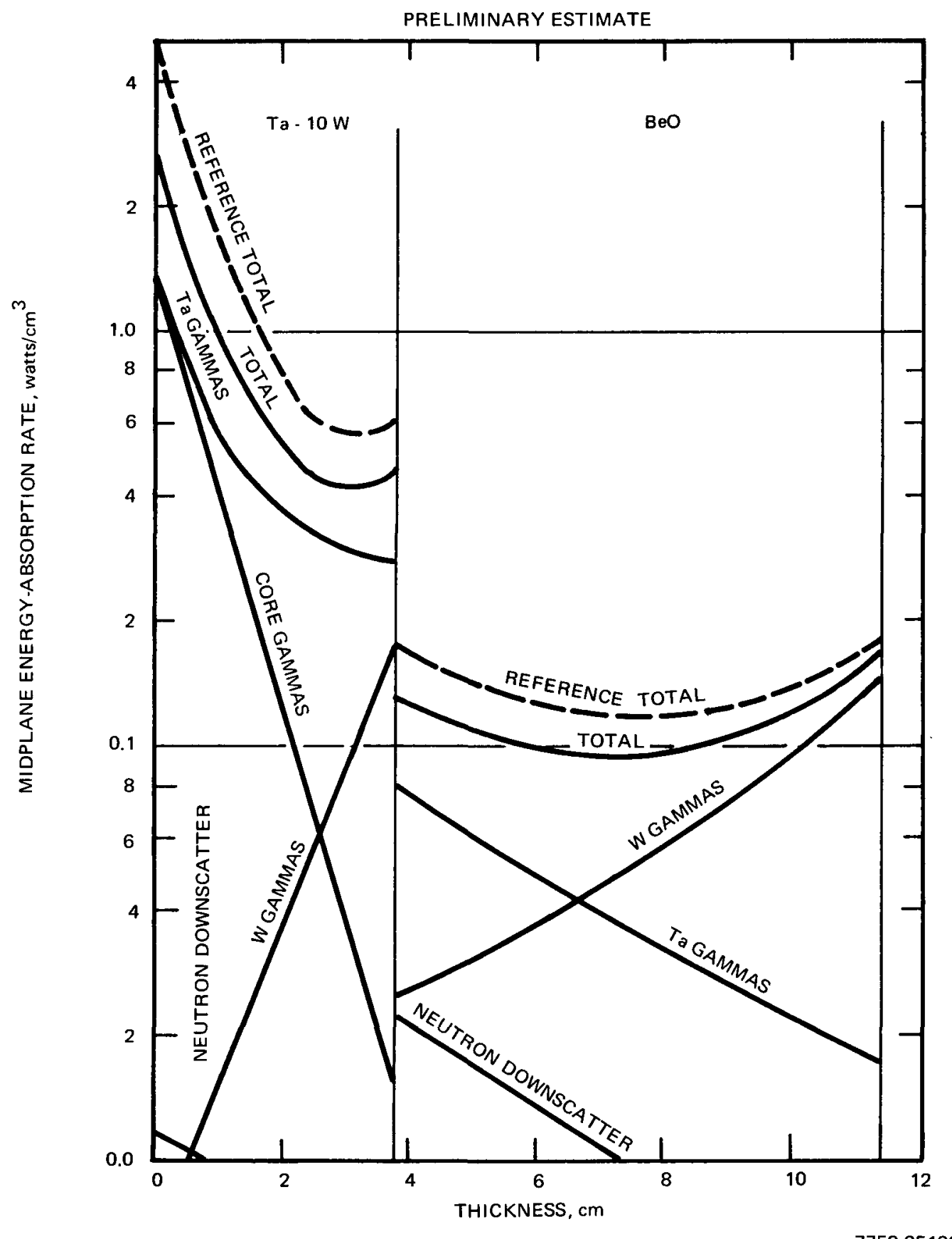

Figure VI-14. Midplane Energy-Absorption Rates, Reference Zirconium Hydride Reactor Poison-Backed Drum in STIR Pool, Poison In 


\section{Material Studies}

The material-study effort consists of nine subtasks: (a) Material Selection, (b) Material Compatibility Tests, (c) Emittance Test, (d) Coating Proof Tests, (e) Coating Evaluation Tests, (f) Dry-Well Coating Application Development, (g) Rivet Studies, (h) BeO Modulus of Rupture Tests, and (i) Thermal Expansion Tests.

\section{a. Material Selection}

The following changes and/or additions have been made to the material selections reported in a previous quarterly report, AI-AEC-12923.

Thickness of the bands was increased from 0.010 to $0.030 \mathrm{in}$. to provide a greater design margin in the bands, including tolerance for the large scatter of the thermal-expansion data reported in the literature. Uncertainty in the expansion data produces uncertainty in the calculated band stresses.

Coating for the absorber was selected as plasma-sprayed tungsten on the Ta-10W absorber with an outer emittance coating of plasma-sprayed iron titanate.

Chemical-vapor-deposited (CVD) tungsten was selected as the oxygen barrier for the bands. An emittance coating will not be applied to the bands because its absence will not significantly affect the drum temperatures due to the small surface area of the bands.

The tentative coating system selected for cladding over BeO consists of CVD tungsten applied to the $\mathrm{Cb}-1 \mathrm{Zr}$ substrate followed by a thin coat of plasmasprayed tungsten followed by an emittance coating of iron titanate. The CVD tungsten coating is needed to provide long-time protection against oxygen embrittlement; plasma-sprayed tungsten is needed under the iron titanate as the iron titanate will not satisfactorily adhere to CVD tungsten.

The adherence of the plasma-sprayed tungsten to the CVD tungsten-coated surface remains to be demonstrated.

b. Material-Compatibility Test

The bare-sample material-compatibility test was continued at $1800^{\circ} \mathrm{F}$ in the low $10^{-7}$ torr range with $8656 \mathrm{hr}$ completed at elevated temperature. 
Preparation of coated samples for testing is dependent on the final selection of the coatings.

\section{c. Emittance Tests}

Emittance tests were completed on eight samples of UOX $+0.5 \mathrm{MgO}$ Grade $\mathrm{BeO}$ in a vacuum at 1000,1500 , and $2000^{\circ} \mathrm{F}$. A formula for the BeO emittance based on the arithmetic mean of test data is given by

$$
\epsilon=0.597+2.9525(10)^{-4} \mathrm{~T}-1.45(10)^{-7} \mathrm{~T}^{2},
$$

where

$$
\begin{aligned}
& \epsilon=\text { total normal emittance (arithmetic mean), and } \\
& \mathrm{T}=\text { temperature between } 1000 \text { and } 2000^{\circ} \mathrm{F} .
\end{aligned}
$$

$\mathrm{BeO}$ emittance based on this equation in steps of $10^{\circ} \mathrm{F}$ are shown in Table VI-1.

TABLE VI- 1

TOTAL NORMAL EMITTANCE OF UOX + 0.5 MgO GRADE BeO

\begin{tabular}{c|c|c}
\hline \hline $\begin{array}{c}\text { Temperature, } \\
\left({ }^{\circ} \mathrm{F}\right)\end{array}$ & $\begin{array}{c}\text { Emittance, } \\
\text { Arithmetic } \\
\text { Mean }\end{array}$ & $\begin{array}{c}\text { Unbiased-Population } \\
\text { Standard Deviation } \\
\text { (test data) }\end{array}$ \\
\hline 1000 & 0.75 & 0.0168 \\
1100 & 0.75 & \\
1200 & 0.74 & \\
1300 & 0.74 & \\
1400 & 0.73 & \\
1500 & 0.71 & \\
1600 & 0.70 & \\
1700 & 0.68 & \\
1800 & 0.66 & 0.0095 \\
1900 & 0.63 & \\
2000 & 0.61 & \\
\hline
\end{tabular}

Emittance tests on eight samples of boron carbide were completed at 1000 , 1500 , and $2000^{\circ} \mathrm{F}$ in a vacuum. A formula for the emittance of this material is given by 


$$
\epsilon=0.679+3.404(10)^{-4} \mathrm{~T}-1.4525(10)^{-7} \mathrm{~T}^{2} \text {, }
$$

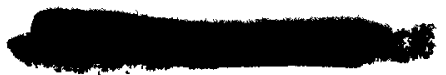

where

$$
\begin{aligned}
& \epsilon=\text { total normal emittance (arithmetic mean) } \\
& \mathrm{T}=\text { temperature between } 1000 \text { and } 2000^{\circ} \mathrm{F} .
\end{aligned}
$$

The calculated emittances of $\mathrm{B}_{4} \mathrm{C}$ per this equation in steps of $100^{\circ} \mathrm{F}$ are shown in Table VI-2.

TABLE VI-2

TOTAL NORMAL EMITTANCE OF BORON CARBIDE

\begin{tabular}{c|c|c}
\hline $\begin{array}{c}\text { Temperature, } \\
\left({ }^{\circ} \mathrm{F}\right)\end{array}$ & $\begin{array}{c}\text { Emittance, } \\
\text { Arithmetic } \\
\text { Mean }\end{array}$ & $\begin{array}{c}\text { Unbiased-Population } \\
\text { Standard Deviation } \\
\text { (test data) }\end{array}$ \\
\hline 1000 & 0.87 & 0.0057 \\
1100 & 0.88 & \\
1200 & 0.88 & \\
1300 & 0.88 & \\
1400 & 0.87 & 0.0048 \\
1500 & 0.86 & \\
1600 & 0.85 & \\
1700 & 0.84 & \\
1800 & 0.82 & 0.0087 \\
1900 & 0.80 & \\
2000 & 0.78 & \\
\hline
\end{tabular}

\section{d. Coating Proof-Tests}

Short-term coating proof-tests were completed on the types of samples shown in Table VI-3.

Two types of coating proof-tests were made: (1) endurance test at $1600^{\circ} \mathrm{F}$ at $50 \mu$ pressure (air bleed) for $240 \mathrm{hr}$, and (2) ten thermal cycles from room temperature to $1800^{\circ} \mathrm{F}$ at $50 \mu$ pressure (air bleed). The endurance-test temperature, pressure, and time were selected to permit uncoated $\mathrm{Cb}-1 \mathrm{Zr}$ to $\mathrm{ab}-$ sorb an equivalent amount of oxygen to that expected during 20,000 hr of ground testing. Thermal-cycling was included to determine the effects of differential thermal expansion on coating adhesion. Figure VI-15 is a view of how the samples were suspended for test (with heater removed). 
TABLE VI-3

TYPES OF COATING PROOF-TEST SAMPLES TESTED

\begin{tabular}{l|l|l}
\hline \hline Substrate & \multicolumn{1}{|c|}{ Undercoating } & $\begin{array}{c}\text { Outer Emittance } \\
\text { Coating, } \\
\text { Plasma-Sprayed }\end{array}$ \\
\hline $\mathrm{Ta}-10 \mathrm{~W}$ & Chemical-vapor-deposited (CVD) & Iron titanate \\
$\mathrm{Ta}-10 \mathrm{~W}$ & CVD tungsten & None \\
$\mathrm{Ta}-10 \mathrm{~W}$ & CVD tungsten + molybdenum & None \\
$\mathrm{Ta}-10 \mathrm{~W}$ & CVD tungsten + CVD molybdenum & Iron titanate \\
$\mathrm{Ta}-10 \mathrm{~W}$ & Plasma tungsten & None \\
$\mathrm{Ta}-10 \mathrm{~W}$ & Plasma tungsten & Iron titanate \\
$\mathrm{Ta}-10 \mathrm{~W}$ & None & None \\
\hline $\mathrm{Cb}-1 \mathrm{Zr}$ & CVD tungsten + CVD molybdenum & None \\
$\mathrm{Cb}-1 \mathrm{Zr}$ & CVD tungsten + CVD molybdenum & Iron titanate \\
$\mathrm{Cb}-1 \mathrm{Zr}$ & CVD tungsten & None \\
$\mathrm{Cb}-1 \mathrm{Zr}$ & CVD tungsten & Iron titanate \\
$\mathrm{Cb}-1 \mathrm{Zr}$ & Plasma tungsten & None \\
$\mathrm{Cb}-1 \mathrm{Zr}$ & Plasma tungsten & Iron titanate \\
$\mathrm{Cb}-1 \mathrm{Zr}$ & None & None \\
\hline
\end{tabular}

During testing it was found that the iron titanate would remain adherent only to the plasma-sprayed tungsten undercoat. The iron titanate flaked-off from all of the other undercoatings. Typical examples of the flaking are shown in Figure VI-16. Figure VI-17 shows the adherent iron titanate coated over an undercoat of plasma-sprayed tungsten. Figure VI-18 shows the iron titanate chippedoff from one side of one sample as a result of post-test handling. The cause of this chipping is being investigated.

Analyses of the test samples showed that the thin uncoated samples gained about $1 \%$ oxygen $(10,000 \mathrm{ppm})$ during endurance testing, while those coated with CVD tungsten or CVD tungsten plus CVD molybdenum gained only about 250-ppm oxygen, and the plasma-sprayed tungsten samples gained about 2500-ppm oxygen. Because the plasma-sprayed tungsten may not give adequate protection over extended reactor life and the iron titanate will not adhere to CVD tungsten or CVD moly, it was decided to evaluate a coating system of CVD tungsten followed with 


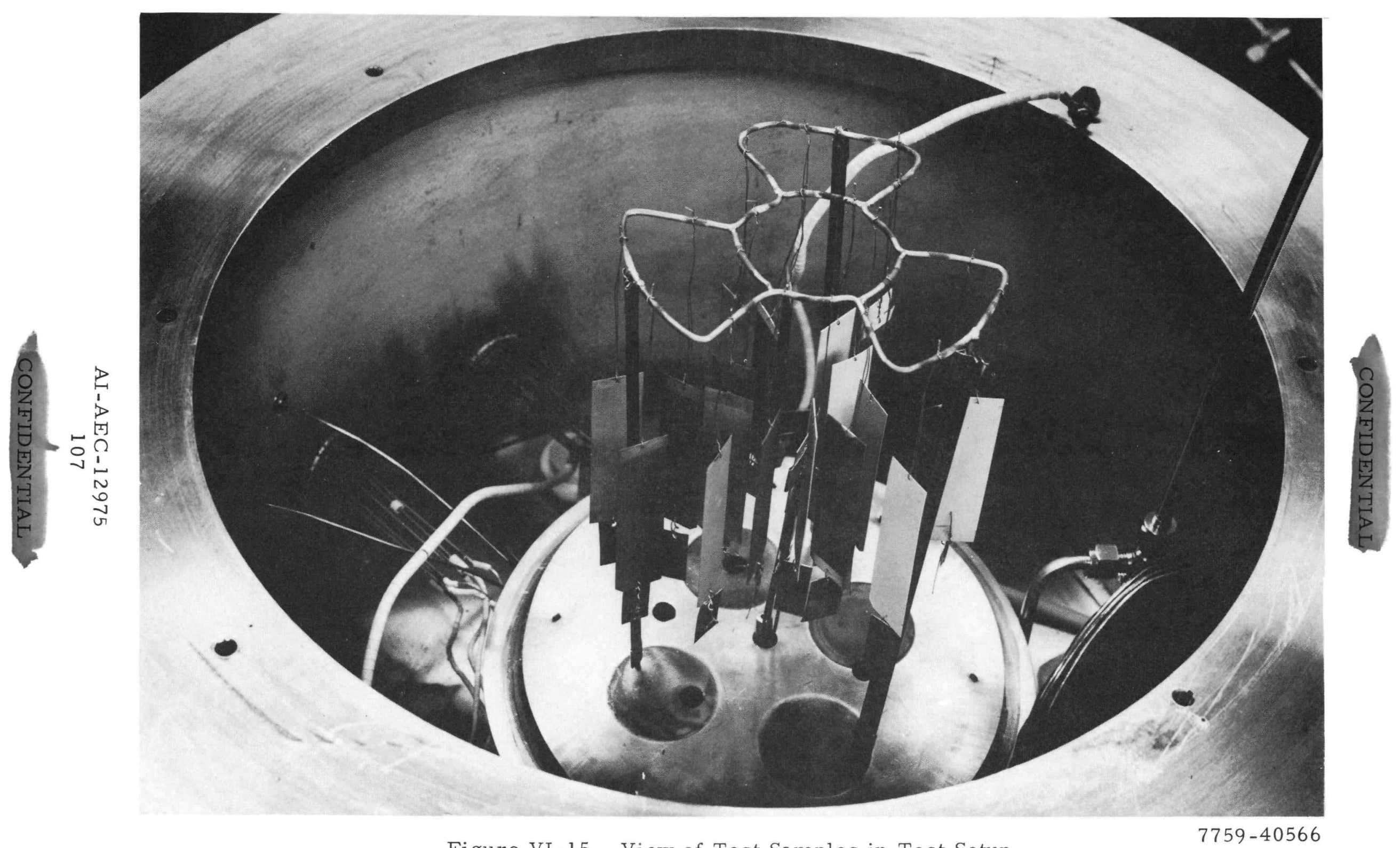

Figure VI-15. View of Test Samples in Test Setup 


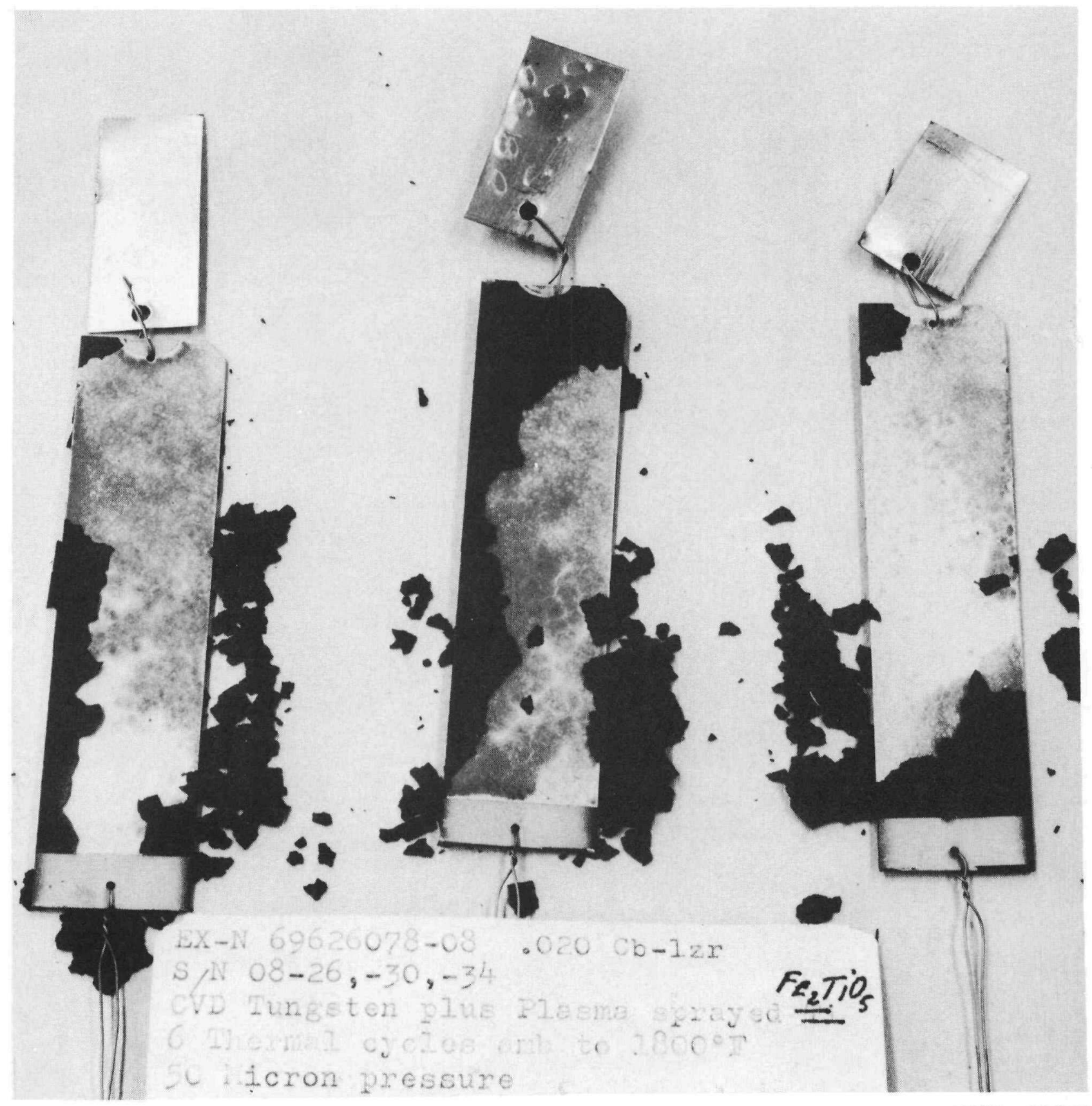

Figure VI-16. Failure of $\mathrm{Fe}_{2} \mathrm{TiO}_{5}$ Emittance Coating

$7759-40583$ (over CVD tungsten undercoat) 

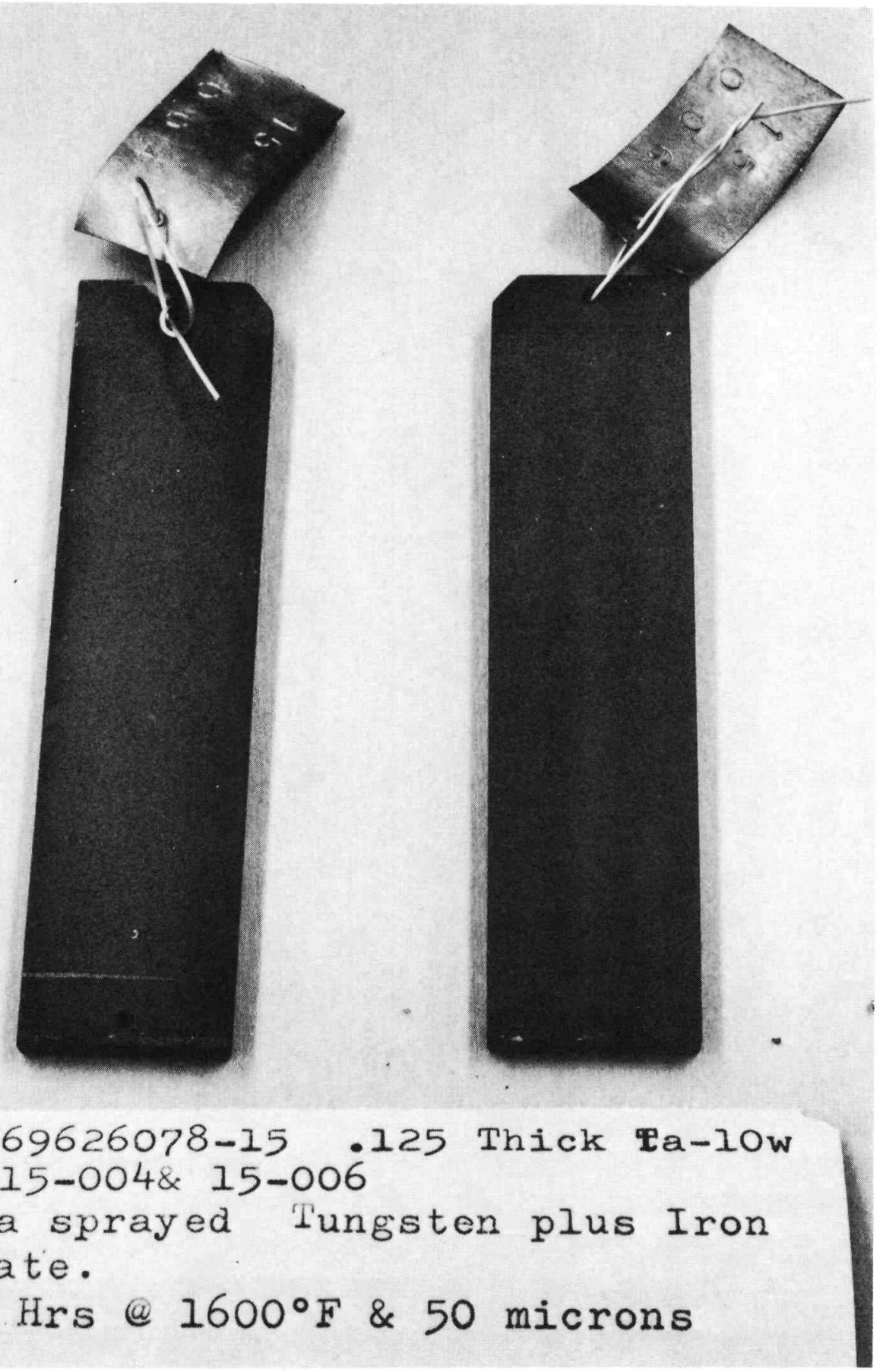

EX-N69626078-15.125 Thick Ta-10w $S / N$ 15-004\& 15-006

Plasma sprayed Tungsten plus Iron Titanate.

$239.6 \mathrm{Hrs} @ 1600^{\circ} \mathrm{F} \& 50$ microns

$7759-40585$

Figure VI-17. Adherent $\mathrm{Fe}_{2} \mathrm{TiO}_{5}$ Emittance Coating (plasma-sprayed tungsten undercoat) 

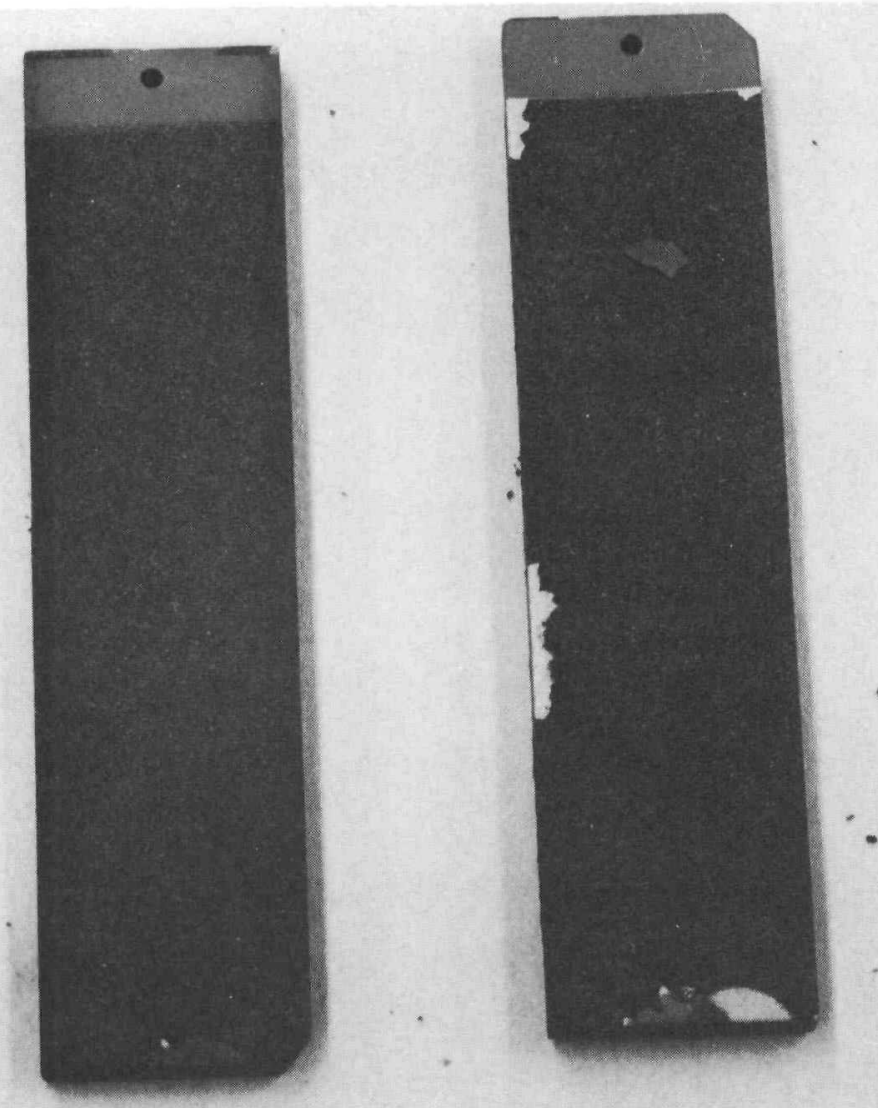
plasma tungsten followed with iron titanate. Samples of this combination are being prepared for application feasibility and adherence testing.

Long-term coating evaluation tests will be started when these proof-test results are evaluated and a coating selection made. Also a dry-well emittancecoating development program has been begun with tooling parts being designed and started into fabrication.

\section{e. Rivet Studies}

Test hardware to evaluate the performance of improved design cladding and band rivets was completed. Testing will start upon receipt of the rivets scheduled for early September.

f. BeO Modulus-of-Rupture Test

Modulus-of-rupture tests are planned to provide physical-property data of the actual $\mathrm{BeO}$ ( $\mathrm{UOX}+0.5 \mathrm{MgO}$ ) being used in the $\mathrm{ZrH}$ reactor control drums. These data will be compared with the calculated thermal stresses in the BeO. Tests will be made at $1000,1500,1800$, and $2000^{\circ} \mathrm{F}$ in a vacuum.

\section{g. Thermal-Expansion Tests}

Tests are planned to determine the coefficients of thermal expansion of the materials in the control drum. Data for the selected condition of the material are needed because the literature show large scatter of the data. Reliable data are required to establish design margin. Tests will be at 1000, 1250, 1500, 1700 , and $1900^{\circ} \mathrm{F}$.

Drawings of the test samples were completed and materials ordered.

\section{G. CONTROL-DRUM DRIVE SYSTEM}

The control-drive system for the $\mathrm{ZrH}$ reactor, Figures VI-19 and -20, consists of the control-drum assembly, its supporting bearings, the actuator with a built-in drum-locking mechanism, ${ }^{(4)}$ and the two flexible couplings connecting the drum to the actuator drive gear. Tests are planned to confirm that the integrated system of components will withstand the launch loads and perform as expected in the simulated operational temperature and vacuum environment. For these tests a mechanical mockup of the actuator ${ }^{(3)}$ and the rebuilt development control drum No. 1 will be used. 


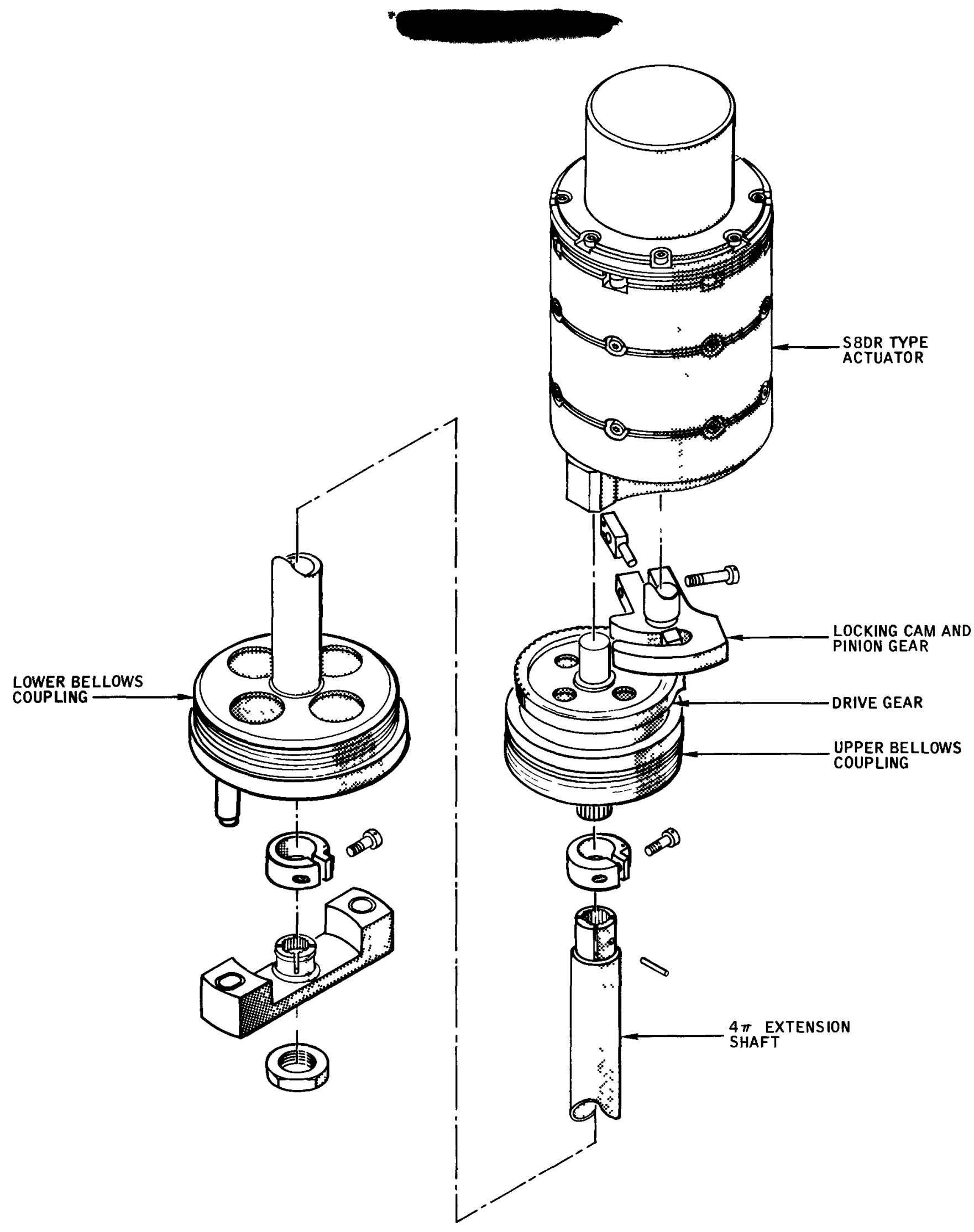

9-D17-141-9

Figure VI-19. Zirconium Hydride Reactor Control-Drum Drive Train

$$
\text { AI-AEC-12975 }
$$




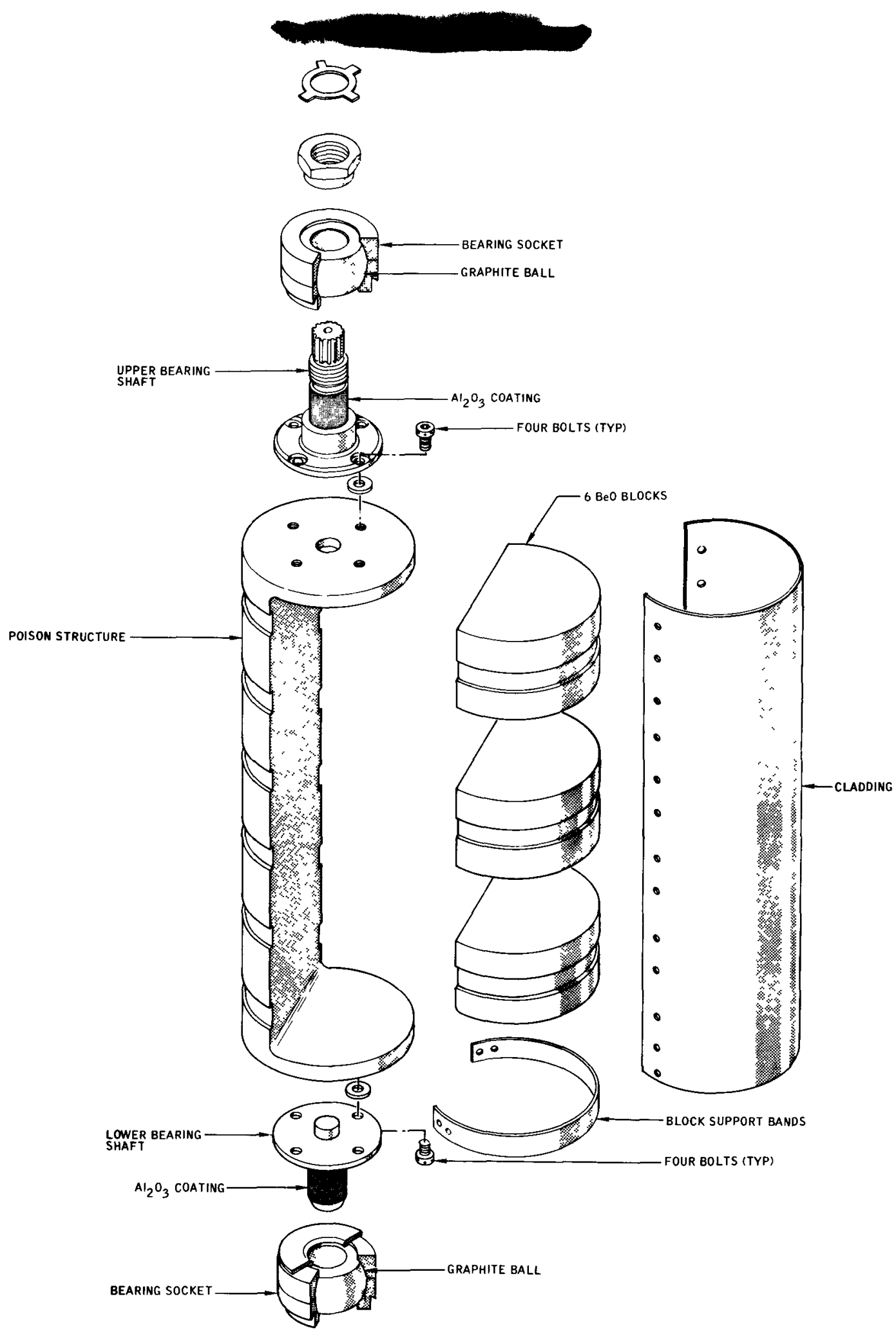

9-D17-141-10

Figure VI-20. Zirconium Hydride Reactor Control Drum and Bearings

AI-AEC-12975

113 
The fabrication of the flexible coupling assemblies was completed. The mockup actuator and the bearing assemblies are still being fabricated. The test fixture for the vibration test to simulate the launch condition is available. The test fixture for the thermal-vacuum operational test is now being built.

\section{H. SHIELD DESIGN AND FABRICATION}

Technology for a flight-type shield system is being developed. An evaluation of gamma-shielding materials is also being made.

\section{Material Studies}

An objective of the liquid-lead shielding program is to investigate the materials problems associated with the use of liquid $\mathrm{Pb}$ as a high-temperature gamma shield for the SNAP reactor-shield system. Earlier studies (5) of the effects of molten lead on the structural alloys Croloy 2-1/4 steel and 1020 carbon steel showed that the most significant effect was the decarburization of the alloys by the molten $\mathrm{Pb}$ at 1300 and $1500^{\circ} \mathrm{F}$ during the 10,000-hr test period.

The current program was started to determine the effectiveness of adding $\mathrm{C}$ to the $\mathrm{Pb}$ to minimize or stop the decarburization action by the $\mathrm{Pb}$ on the two alloys. Exploratory tests established that $\mathrm{C}$ added directly to the $\mathrm{Pb}$ in weighed amounts would dissolve in the $\mathrm{Pb}$ at the 1300 and $1500^{\circ} \mathrm{F}$ test temperature in $300 \mathrm{hr}$ or less. Two levels of $\mathrm{C}$ additions were selected, one level at the saturation solubility of $\mathrm{C}$ in $\mathrm{Pb}$ at the test temperature and the other at one-half that.

Test capsules were prepared in the identical manner as in the earlier tests; that is, a 6-in. length of tubing was pinched at one end, Heliarc-welded, and cleaned. Weighed amounts of $\mathrm{Pb}$ were added to each capsule in an argonatmosphere box. Weighed amounts of reactor-grade graphite were added to each capsule. In some capsules zirconium and magnesium corrosion-inhibitors also were added to the $\mathrm{Pb} .^{(5)}$ The capsules were pinched shut and Heliarcwelded in argon except for a 1/8-in. gap which was closed by electron-beam (EB) welding in a vacuum of $10^{-5}$ tor $r$. Each steel capsule was sealed in an evacuated quartz tube.

The capsules were heated in the horizontal position in two large box furnaces regulated at 1300 and $1500^{\circ} \mathrm{F}$. Capsules were removed for examination after 
2500 , 5000, and $10,000 \mathrm{hr}$. The results of the shorter-term tests were described in earlier reports. $(6,3)$

were described last quarter. ${ }^{(1)}$

The initial results from the $10,000-h r$ test

The results of the metallographic examination of the $10,000-\mathrm{hr}$ tests are summarized as follows:

a. 1020 Carbon Steel

(1) Heated Control

The capsule of 1020 carbon steel, heated at $1500^{\circ} \mathrm{F}$ without lead to provide a control, was found to have a microstructure consisting mainly of large grains of ferrite and pearlite. These grains were larger than those observed in the 2500 - and 5000-hr controls as would be expected from the extended heating. The carbide particles were small and scattered throughout the ferrite grains.

(2) Effect of Carbon Additions on Decarburization

Examination of the 1020 carbon steel capsules containing $\mathrm{Pb}$ with sufficient $C$ to half-saturate the $\mathrm{Pb}$ revealed the depth of decarburization to be 2.4 and $2.6 \mathrm{mils}$ at 1300 and $1500^{\circ} \mathrm{F}$ respectively. The surface of the $1300^{\circ} \mathrm{F}$ capsule was flecked with particles which indicated that recarburization of the steel from the $\mathrm{C}$ in the $\mathrm{Pb}$ was beginning. This effect was not visible in the $1500^{\circ} \mathrm{F}$ capsule.

The addition of sufficient $C$ to saturate the $\mathrm{Pb}$ was seen to reduce the decarburization significantly. At $1300^{\circ} \mathrm{F}$ the steel appeared to have started some recarburization, whereas at $1500^{\circ} \mathrm{F}$ the pearlite grains extended completely to the surface of the steel in contact with the $\mathrm{Pb}$. Further examination of the $1300^{\circ} \mathrm{F}$ test capsule clearly showed a band of ferrite separating the pearlite in the main body of the steel and the pearlite on the surface. This strongly suggested that recarburization of the steel was occurring. Table VI-4 shows the depths of decarburization observed in this and the previous 2500- and 5000-hr tests.

(3) Effect of Carbon Additions on Corrosion-Inhibitors

Examination of the earlier-tested 10,000-hr test capsules of 1020 carbon steel containing $\mathrm{Pb}$ with and without $\mathrm{Zr}$ and $\mathrm{Mg}$ corrosion-inhibitors revealed decarburized layers of 1.2 and 5 mils respectively at $1300^{\circ} \mathrm{F}$, and 2.0 and 
TABLE VI-4

DEPTH OF DECARBURIZATION OF 1020 CARBON STEEL

AT VARIOUS TEST CONDITIONS

\begin{tabular}{|c|c|c|c|c|c|c|c|c|c|c|c|c|c|}
\hline \multirow{9}{*}{ 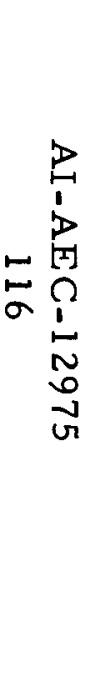 } & \multirow{3}{*}{$\begin{array}{c}\text { Temperature } \\
\text { Condition } \\
\text { Hours } \\
\end{array}$} & \multicolumn{6}{|c|}{$1300^{\circ} \mathrm{F}$} & \multicolumn{6}{|c|}{$1500^{\circ} \mathrm{F}$} \\
\hline & & \multicolumn{3}{|c|}{$\begin{array}{c}\text { Lead } \\
\text { (values at } 10^{-3} \text { in.) }\end{array}$} & \multicolumn{3}{|c|}{$\begin{array}{c}\text { Vapor } \\
\text { (values in mils) }\end{array}$} & \multicolumn{3}{|c|}{$\left|\begin{array}{c}\text { Lead } \\
\text { (values at } 10^{-3} \text { in.) }\end{array}\right|$} & \multicolumn{3}{|c|}{$\begin{array}{l}\text { Vapor } \\
\text { (values in mils) }\end{array}$} \\
\hline & & 2500 & $|5000|$ & $10,000 \mid$ & 2500 & 5000 & $|10,000|$ & $|2500|$ & 5000 & $|10,000|$ & 2500 & 5000 & 10,000 \\
\hline & Additives: & & & & & & & & & & & & \\
\hline & None & 4.0 & $4.5^{*}$ & $\sim 5$ & 4.0 & $4.5^{*}$ & $=4.5^{\dagger}$ & 5.9 & $6.0^{*}$ & 4.8 & 5.3 & $5.3^{*}$ & $4.8^{\dagger}$ \\
\hline & Carbon, Half-Saturated & 2.5 & 2.5 & 2.4 & 2.7 & 3.0 & 2.5 & 4.0 & 4.0 & 2.6 & 4.0 & 5.0 & 4.8 \\
\hline & Carbon, Saturated & 2.0 & 2.0 & 0 & 2.6 & 2.5 & 2.5 & 3.3 & 3.0 & 0 & 4.0 & 4.5 & 4.4 \\
\hline & Zirconium, Magnesium & $\sim 1$ & $1.0^{*}$ & 1.2 & $\sim 1$ & $2.0^{*}$ & 2.8 & $<1$ & $1.5^{*}$ & 2.0 & 4.2 & $4.5^{* *}$ & 4.8 \\
\hline & Zirconium, Magnesium + Carbon & 1.3 & 1.5 & 2.5 & 1.8 & 1.5 & 2.5 & 2.7 & 3.0 & 3.0 & 3.3 & 4.0 & 4.2 \\
\hline
\end{tabular}

*Interpolated from earlier test data

$\dagger$ Earlier unreported data 
4.8 mils respectively at $1500^{\circ} \mathrm{F}$. Examination of the capsules from the current $10,000-\mathrm{hr}$ test at $1300^{\circ} \mathrm{F}$ reveals that the addition of $\mathrm{C}$ to the $\mathrm{Zr}$ and $\mathrm{Mg}$ about doubles the existing amount of decarburization, although it is considerably less than when no additives of any type are present. At $1500^{\circ} \mathrm{F}$ a similar change was noted. It was concluded that the addition of $\mathrm{C}$ to $\mathrm{Pb}$ containing $\mathrm{Zr}$ and $\mathrm{Mg}$ was not beneficial. This confirmed the conclusions made after the $2500-$ and $5000-\mathrm{hr}$ tests.

b. Croloy 2-1/4 Steel

(1) Heated Control

The capsule of Croloy 2-1/4 steel heated at $1500^{\circ} \mathrm{F}$ without $\mathrm{Pb}$ to provide a control was found to have a microstructure consisting of large grains of pearlite in a ferrite matrix very similar in appearance to the 1020 carbon steel control.

(2) Effect of Carbon Additions on Decarburization

Examination of the $1300^{\circ} \mathrm{F}$ capsule containing $\mathrm{Pb}$ with $\mathrm{C}$ to half-saturate the $\mathrm{Pb}$ revealed about $3 \mathrm{mils}$ of decarburization after 10,000 hr. Several pits and fissures were observed which could not be attributed to the tube finishing operation. The $1500^{\circ} \mathrm{F}$ capsule showed considerable mass transfer. The transferred layer was basically pearlite with scattered ferrite, whereas the basemetal surface layer was basically ferrite with scattered pearlite. The depth of decarburization, considering only the parent metal, was found to be about 2.6 mils. It appeared that the ferrite transferred from a slightly warmer region to the present location and then converted to pearlite under the test conditions.

At the higher $\mathrm{C}$ concentration (C-to-saturate) the $1300^{\circ} \mathrm{F}$ Croloy $2-1 / 4$ steel capsule showed little or no decarburization, whereas the $1500^{\circ} \mathrm{F}$ capsule had about 6 mils of decarburization. No evidence of mass transfer was observed.

(3) Effect of Carbon Additions on Corrosion Inhibitors

Examination of the current capsules containing $\mathrm{Pb}-\mathrm{Zr}-\mathrm{Mg}$ plus $\mathrm{C}$ revealed about 1 mil of decarburization at $1300^{\circ} \mathrm{F}$ and about $4.6 \mathrm{mils}$ at $1500^{\circ} \mathrm{F}$. Table VI-5 shows that increases in the depth of decarburization, as compared to $\mathrm{Pb}-\mathrm{Zr}-\mathrm{Mg}$ without C, were previously observed after 2500 and $5000 \mathrm{hr}$ of exposure at $1500^{\circ} \mathrm{F}$. Both of the current capsules showed extensive fissuring of the leadexposed Croloy 2-1/4 steel surface.

$\mathrm{AI}-\mathrm{AEC}-12975$

117 
TAB LE VI - 5

DEPTH OF DECARBURIZATION OF CROLOY 2-1/4 STEEL AT VARIOUS TEST CONDITIONS

\begin{tabular}{|c|c|c|c|c|c|c|c|c|c|c|c|c|c|}
\hline \multirow{9}{*}{ 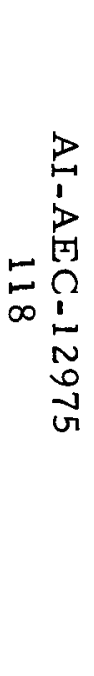 } & \multirow{3}{*}{$\begin{array}{cc}\text { Temperature } \\
\text { Condition } \\
\text { Hours } \\
\end{array}$} & \multicolumn{6}{|c|}{$1300^{\circ} \mathrm{F}$} & \multicolumn{6}{|c|}{$1500^{\circ} \mathrm{F}$} \\
\hline & & \multicolumn{3}{|c|}{$\begin{array}{c}\text { Lead } \\
\text { (values at } 10^{-3} \text { in.) }\end{array}$} & \multicolumn{3}{|c|}{$\begin{array}{c}\text { Vapor } \\
\text { (values in mils) }\end{array}$} & \multicolumn{3}{|c|}{$\left|\begin{array}{c}\text { Lead } \\
\left.\mid \text { (values at } 10^{-3} \text { in. }\right)\end{array}\right|$} & \multicolumn{3}{|c|}{$\begin{array}{c}\text { Vapor } \\
\text { (values in mils) }\end{array}$} \\
\hline & & 2500 & 5000 & 10,000 & 2500 & 5000 & 10,000 & 2500 & 5000 & 10,000 & 2500 & 5000 & 10,000 \\
\hline & Additives: & & & & & & & & & & & & \\
\hline & None & $\sim 1$ & $\sim 1^{*}$ & 4.1 & 1.6 & $\sim^{*}$ & $\sim_{1}^{\dagger}$ & 4.5 & $3.0^{* k}$ & 2.6 & 3.0 & $3.3^{*}$ & $3.2^{\dagger}$ \\
\hline & Carbon, Half-Saturated & $\sim 1$ & $<1$ & 3.0 & $\sim 1$ & $\sim 1$ & $<1$ & 3.6 & 2.4 & 2.6 & 3.3 & 3.3 & 2.6 \\
\hline & Carbon, Saturated & 1.1 & 2.0 & 0 & $\sim 1$ & $\sim 1$ & $<1$ & 3.6 & 5.3 & 6.0 & 3.0 & 4.0 & 3.3 \\
\hline & Zirconium, Magnesium & $<1$ & $1.5^{*}$ & 1.2 & $<1$ & $1.4^{*}$ & 1.6 & 1.1 & $1.1^{*}$ & 1.2 & 3.5 & $3.6^{*}$ & 4.4 \\
\hline & Zirconium, Magnesium + Carbon & $<1$ & $\sim 1$ & $\sim 1$ & $<1$ & $<1$ & $<1$ & 5.5 & 5.6 & 4.6 & 2.2 & 1.5 & 1.3 \\
\hline
\end{tabular}

* Interpolated from earlier test data

†Earlier unreported data 


\section{c. Capsule Welds}

Examination of sections through the weld joints on the flattened ends of the $1500^{\circ} \mathrm{F}$ control capsules of 1020 carbon steel and Croloy 2-1/4 steel revealed that the weld joints had virtually disappeared during the prolonged heating.

Similarly the weld joints on the 1020 carbon steel and Croloy 2-1/4 steel test-capsules heated at $1500^{\circ} \mathrm{F}$ for $10,000 \mathrm{hr}$ were not visible, although the weld joints on the $1300^{\circ} \mathrm{F}$ test-capsules could be identified.

The depth of decarburization of the welded alloys heated at $1300^{\circ} \mathrm{F}$ was roughly the same as those observed for the parent metals. The $1500^{\circ} \mathrm{F}$ testcapsule welds all exhibited decarburization to a depth of about 5 mils, except the Croloy 2-1/4 steel capsule containing sufficient $C$ to saturate the lead; this one had 7 to 8 mils of decarburization.

In general it was concluded that the weld joints had not suffered differently from the parent metal; in fact, the weld joints were hardly distinguishable from the parent metal after heating at $1500^{\circ} \mathrm{F}$ for $10,000 \mathrm{hr}$.

\section{d. Chemical Analysis of the Lead}

The $\mathrm{Pb}$ from the 5000- and 10,000 -hr test-capsules were analyzed for iron, zirconium, and magnesium. Because of the separation of the additives from the main body of the $\mathrm{Pb}$ during the slow cooldown in the furnace, it was difficult to obtain a representative sample. In general, Fe was found in all $\mathrm{Pb}$ samples.

$\mathrm{Mg}$ was found in amounts roughly equal to the $400 \mathrm{ppm}$ originally added. $\mathrm{Zr}$ was not found in most cases, as would be expected if the $\mathrm{Zr}$ forms a layer on the surface of the steel to act as a corrosion inhibitor.

\section{e. Conclusions}

The addition of $\mathrm{C}$ to the $\mathrm{Pb}$ was found to reduce the decarburization of the 1020 carbon steel at 1300 and $1500^{\circ} \mathrm{F}$ during the $10,000 \mathrm{hr}$ of exposure. A reduction of the decarburization of the Croloy 2-1/4 steel was observed at $1300^{\circ} \mathrm{F}$, but at 1500 the addition of C apparently increases the decarburization.

The addition of $\mathrm{C}$ to $\mathrm{Pb}$ containing $\mathrm{Zr}$ and $\mathrm{Mg}$ corrosion-inhibitors was found to be detrimental, increasing the amount of decarburization.

No significant differences were found between the action of the liquid $\mathrm{Pb}$ or the parent metal and the weld joints. 
No beneficial effect was achieved by the addition of $\mathrm{C}$ to $\mathrm{Pb}$ which was not provided by the addition of the $\mathrm{Zr}$ and $\mathrm{Mg}$ corrosion-inhibitors to a greater extent. Further, the addition of $\mathrm{C}$ to $\mathrm{Pb}$ containing $\mathrm{Zr}$ and $\mathrm{Mg}$ was detrimental, actually increasing the amount of decarburization.

2. Design and Fabrication Development

a. Liquid-Lead Shield

The fabrication of the previously discussed $(7)$ liquid-lead shield vessel is in progress.

b. The Lithium-Hydride Checkout Shield

The fabrication of casing for the LiH checkout shield previously described ${ }^{(7)}$ and the shield casting hardware was completed. The shield casing is being prepared for the filling and casting of $\mathrm{LiH}$ at the Large Shield Casting Facility, Building 042, Santa Susana.

c. The Annular Lithium-Hydride Shield

The next shield selected for fabrication is the Annular LiH Shield which surrounds the periphery of the $\mathrm{ZrH}$ reactor. Figure VI-2l shows a conceptual design of this shield. 


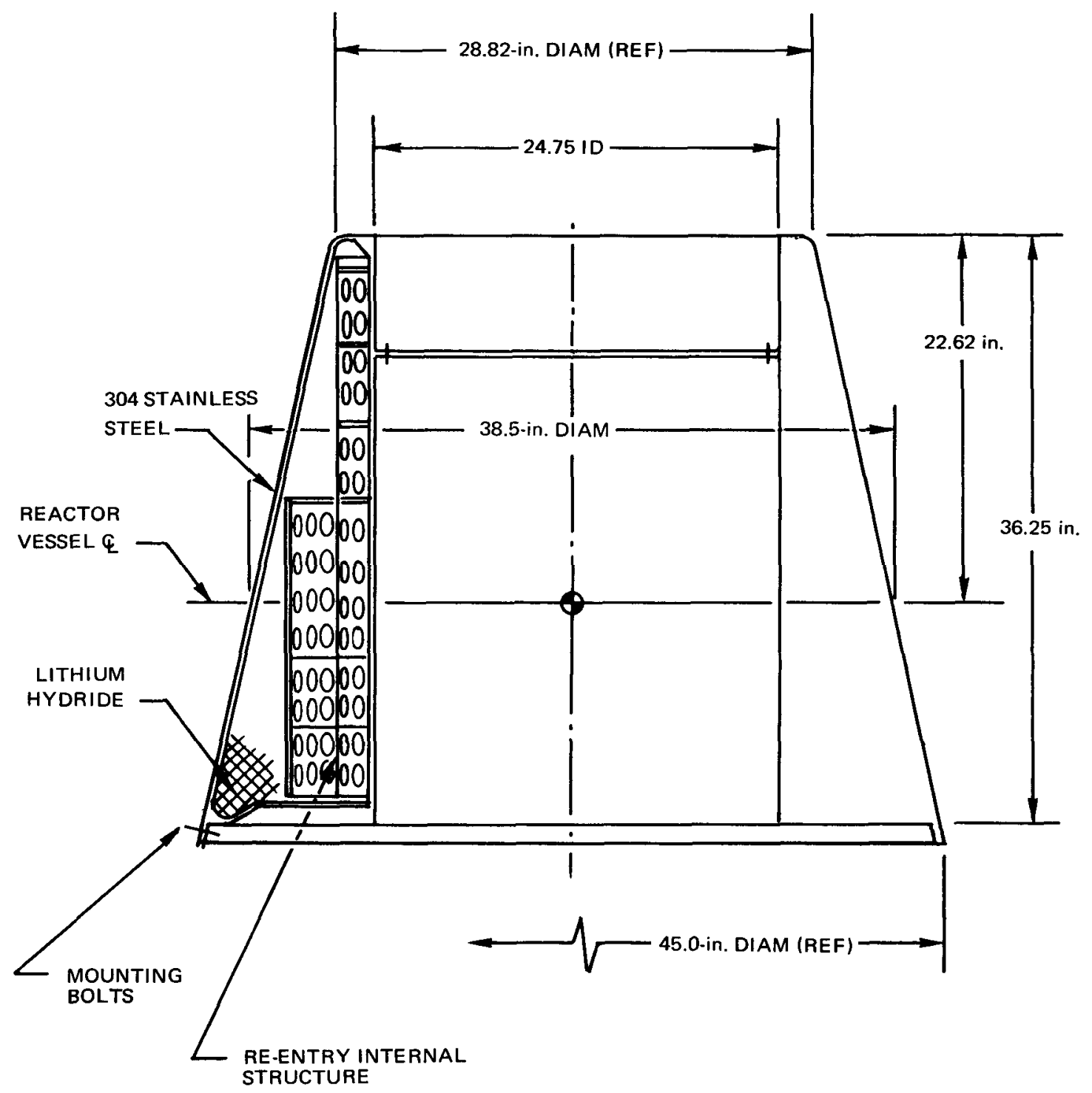

$7759-25202$

Figure VI-21. Annular Neutron Shield 


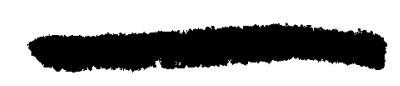

BLANK 


\section{FUEL DEVELOPMENT}

This program has the primary objective of producing a fuel element which meets the design requirements of both the Test Reactor and the Advanced $\mathrm{ZrH}$ Reactor. Inherent in this objective is the generation of the basic material properties required for fuel-element design and analyses, and the improvement of fabrication processes to ensure that the design goals are achieved. To meet this broad objective, variations in Incoloy -800 composition are being investigated. This work includes both the coating-processing parameters and the resultant performance in simulated reactor environments. A vapor-deposition process is being developed as the technique for incorporating burnable poison in the fuel element. Revisions in the design and fuel-element assembly processes are being made to meet new design requirements such as segmented fuel, vibration suppression, and helium backfill.

\section{A. FUEL-ELEMENT MÁTERIALS EVALUATION \\ 1. Cladding Processing}

Work continues on the development of a process for producing integral finned cladding. A hobbing cutter head was purchased to evaluate the feasibility of machining finned tubes by this technique. Hobbing is a special milling process which allows all fins to be machined in one pass. The results obtained from the first two tubes produced by this method are encouraging. Additional tubes are being ordered, with adjustments in the fixturing being made to improve the product. In theory, dimensional repeatability by this process should be quite good, tempered only by the dimensional variance in the starting heavy-walled tubing.

The finned tubes produced by two chem-milling vendors were unsatisfactory, primarily because of the wide (up to $6 \mathrm{mils}$ ) circumferential and axial variations in the tube wall. The bath used by one vendor also resulted in severe intergranular attack.

Approximately 12 finned tubes were machined from 50-mil wall starting tubing by conventional milling, the last six of which met dimensional requirements. While slow and costly this method can be used to produce a limited number of tubes for selected tests and evaluations until a more practical process is developed. 
Initial contact was made with an English firm interested in drawing the finned tubing. In contrast to the American firms which have been contacted, the English feel that their experience and capability will enable them to produce tubing to specification without a development program. This avenue is also being investigated.

Electrical discharge grinding (EDG) and electrical discharge machining (EDM) were also investigated as possible fabrication processes. All vendors contacted indicated that our finned geometry was beyond the current state-ofthe-art of these techniques.

All three new heats of Incoloy-800 have been melted and converted to 4-1/16-in.-diam bar. The ingot chemical analyses are given in Table VII-l. Heat K89338, previously reported, was lost in processing and replaced. The amount of material in lb delivered per heat is as follows: Heat K89339, 1384; K89630, 1222; and K89676, 1385.

Approximately $435 \mathrm{lb}$ of each heat were extruded to 2 -in.-OD by 1-1/4-in.ID draw shells. The draw shells will be reduced to 0.540-in.-ID by 0.050-in.wall tubing, $\sim 500 \mathrm{ft}$ per heat, to be used as starting material for machining finned tubing. The balance of the 4-1/16-in. bar was received at AI at the end of the report period.

Some coating work has been done on finned tubes. It is significant that the finned tubes are remaining straight throughout the oxidation and coating firing cycles. Bowing of straight-walled 15-mil cladding tubes during the se thermal cycles has been a significant and unresolved problem. Apparently, the fins are having a stiffening effect sufficient to resist the stresses resulting from variations in the tube wall and applied SCB-coating thicknesses. Nine coated finned tubes had an average bow of 9 mils (3- to 13-mil range) with no straightening imposed after the oxidation or coating cycles. The bows before coating averaged 9 mils (8- to $10-$ mil range).

A new "standard" SCB frit batch was blended; the previous No. 100C standard had been exhausted. The standard frit is used to make reference flow buttons for comparison with buttons from each batch of frit smelted. The new standard was blended from frit batches No. 221 and 265, and has been designated Standard No. 265. Smelting of about $85 \mathrm{~kg}$ of SCB frit has begun, with about 21 produced to date. 
TABLE VII-1

INGOT CHEMISTRY: THREE NEW HEATS OF INCOLOY-800 DOUBLE VACUUM-MELTED (Units in wt \%)

\begin{tabular}{|c|c|c|c|c|c|}
\hline \multirow{16}{*}{ 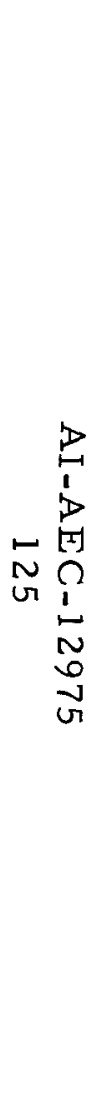 } & Element & $\begin{array}{l}\text { High Ductility } \\
\text { (Heat K89676) }\end{array}$ & $\begin{array}{c}\text { Nominal } \\
\text { (Heat K89339) }\end{array}$ & $\begin{array}{l}\text { High Strength } \\
\text { (Heat K89630) }\end{array}$ & $\begin{array}{c}\text { Normal } \\
\text { Specification } \\
\text { Chemistry }\end{array}$ \\
\hline & Carbon & $0.011(0.03 \mathrm{max})^{*}$ & $0.029(0.02-0.06)^{*}$ & $0.092(0.08-0.12)^{*}$ & $0.08-0.12$ \\
\hline & Titanium & $0.10(0.05-0.15)^{2 k}$ & $0.25(0.2-0.4)^{*}$ & $0.47(0.4-0.6)^{*}$ & $0.4-0.6$ \\
\hline & Aluminum & 0.19 & 0.036 & 0.21 & 0.4 maximum \\
\hline & Chromium & 21.27 & 21.44 & 21.35 & $19-23$ \\
\hline & Nickel & 33.09 & 33.54 & 33.39 & $30-35$ \\
\hline & Manganese & 0.69 & 0.61 & 0.64 & 1.0 maximum \\
\hline & Silicon & 0.32 & 0.29 & 0.27 & 0.50 maximum \\
\hline & Phosphorous & 0.012 & 0.010 & 0.014 & 0.015 maximum \\
\hline & Sulfur & 0.006 & 0.005 & 0.005 & 0.015 maximum \\
\hline & Molybdenum & 0.10 & 0.06 & 0.07 & 0.15 maximum \\
\hline & Copper & 0.02 & 0.04 & 0.03 & 0.35 maximum \\
\hline & Cobalt & 0.02 & 0.04 & 0.04 & 0.20 maximum \\
\hline & Boron & 0.0005 & 0.0005 & 0.0005 & 0.0005 maximum \\
\hline & Nitrogen & 0.025 & 0.016 & Not available & 0.05 maximum \\
\hline & Iron & Balance & Balance & Balance & Balance \\
\hline
\end{tabular}

*Requested 


\section{Fuel Processing \\ a. Burnable Poison}

Necessary modifications of equipment from Autonetics Division were completed for the simultaneous codeposition of two rare-earth oxides and a stable third oxide, each from one of three EB-heated crucibles. Equipment and process characteristics were determined in a series of approximately 15 test runs.

Titanium, zirconium, and yttrium oxides had been selected as candidates to stabilize the rare-earth oxide coatings. Titanium oxide proved difficult to evaporate, reducing to the suboxide and then reacting with the tungsten crucible so that more tungsten than titanium was deposited on the test substrates. Zirconium and yttrium oxides were successfully evaporated. Target test compositions included rare-earth/stabilizer atom ratios of $0.5,1,1.5,2$, and 4 . The rare-earths are to be in the form of oxide compounds or solid solutions, and applied as thin films directly on the fuel or sandwiched between thin layers of the stabilizing oxide. Allowable system temperature, attainable power-level, and cycle-length limitations restricted the attainable rare-earth-oxide/stabilizer. oxide atom ratios to 1.5-4. Accordingly fabrication of the wanted 0.5 and 1.0 ratio (high-stabilizer) vapor-deposited films was deferred, relying on the sandwich approach to keep the glass barrier protected from reaction with the europium/samarium, and the europium/samarium protected from reaction with the zirconium-hydride/fuel.

A total of 30 fuel wafers 0.53 -in.-diam by 0.2 -in.-thick were coated on one face with different rare-earth/stabilizer atom ratios. The same rare-earth/ stabilizer oxide compositions were also prepared by mixing of the raw materials and pressing and sintering the mixtures at 1200 to $1400^{\circ} \mathrm{C}$ in hydrogen, oxygen, or vacuum.

Two preliminary diffusion-couple test-specimen fixtures were assembled. Each contained five SCB-1-coated cladding discs in contact with either stabilized rare-earth oxide pellets or EB-coated (stabilized rare-earth oxide sandwich) fuel specimens. The first assembly was held at $1460^{\circ} \mathrm{F}$ (1165-torr hydrogen pressure) for $1000 \mathrm{hr}$. The second assembly was held at $1500^{\circ} \mathrm{F}(3100$-torr hydrogen pressure) for $1000 \mathrm{hr}$. The yttrium-stabilized (2Y/l-rare-earth atom ratio) and zirconium-stabilized ( $1-\mathrm{Zr} / 1-\mathrm{rare-earth}$ atom ratio) buttons showed 
no detectable reaction with either the fueled-hydride button or the SCB-1 hydrogen-barrier films at either 1460 or $1500^{\circ} \mathrm{F}$. The titanium-stabilized (2-Ti/1-rare-earth atom ratio) button in the $1460^{\circ} \mathrm{F}$ test showed limited but definite reaction with the SCB-1 hydrogen-barrier film. The vapor-deposited sandwich ( $Y$-rare-earth-Y) films appeared to show little or no visible reaction but these conclusions are tentative. The EB-deposited film and the adjacent SCB-l barrier and fuel specimens are now being examined by $\mathrm{X}$-ray fluorescence and diffraction.

A follow-on 37-specimen diffusion-couple test assembly containing both pressed and sintered and vapor-deposited test compositions was fabricated and placed on test at $1430^{\circ} \mathrm{F}$. A second 37 -specimen diffusion-couple test is being assembled for test at $1500^{\circ} \mathrm{F}$.

The Autonetics test fixture was modified to handle 8-in.-long 0.53-in.-diam fueled zirconium-hydride rods. Two such fuel rods were successfully sandwichcoated ( $\mathrm{Y}-\mathrm{Eu}, \mathrm{Y}, \mathrm{Sm}-\mathrm{Y})$, though again with lower than wanted $\mathrm{Y} / \mathrm{rare}-\mathrm{earth}$ atom ratios in the center layer. These rods will be assembled into two fuel elements and placed on test at 1400 and $1500^{\circ} \mathrm{F}$.

Bent-beam $\left(180^{\circ}\right)$ EB-heated evaporators were demonstrated by a vendor in late July. These guns appear to have the necessary evaporating-rate capabilities to achieve the full range of desired $\mathrm{Y}$ (or $\mathrm{Zr}$ )/ rare-earth atom ratios.

3. Fuel-Element Assembly and Test

Installation and checkout of the new induction-heating unit has been completed. The unit is used as the heat source for the fuel-element final assembly fixture. A group of 12 elements was assembled for uniaxial cladding testing.

Seven 15-mil Incoloy-800-clad developmental elements (four double-blindend and three cup-plug type) continued on test and have now accrued 14,000 $\mathrm{hr}$ at $1400^{\circ} \mathrm{F}$ with an average $\mathrm{H}_{2}$ los s of approximately $6 \%$. The four double-blindend elements have lost an average of $5.7 \%$ and the three cup-plug type an average of $6.5 \%$. The seven are currently being subjected to another set of post2000-hr ramp-heat inputs. Curves of the average normalized leakrate and cumulative hydrogen-loss are shown in Figures VII-1 and -2, respectively. 

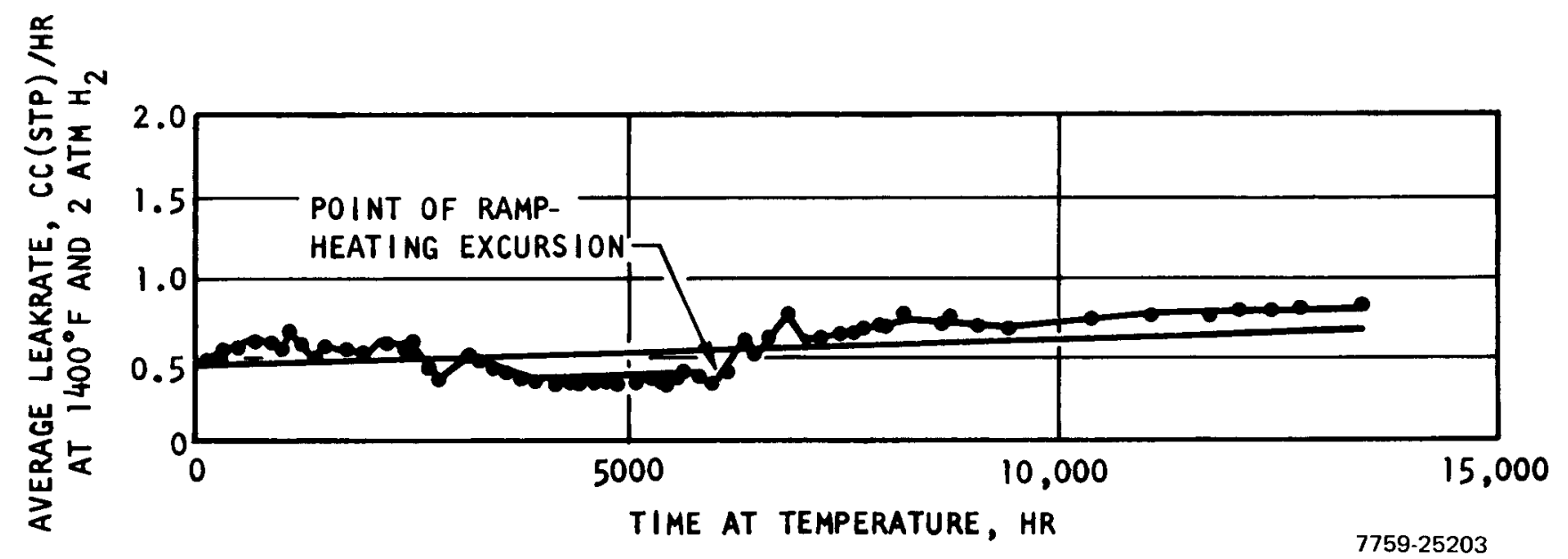

Figure VII-1. Average Normalized Leakrate of the Seven Incoloy800-Clad Developmental Fuel Elements (four double-blind-end type and three cup-plug)

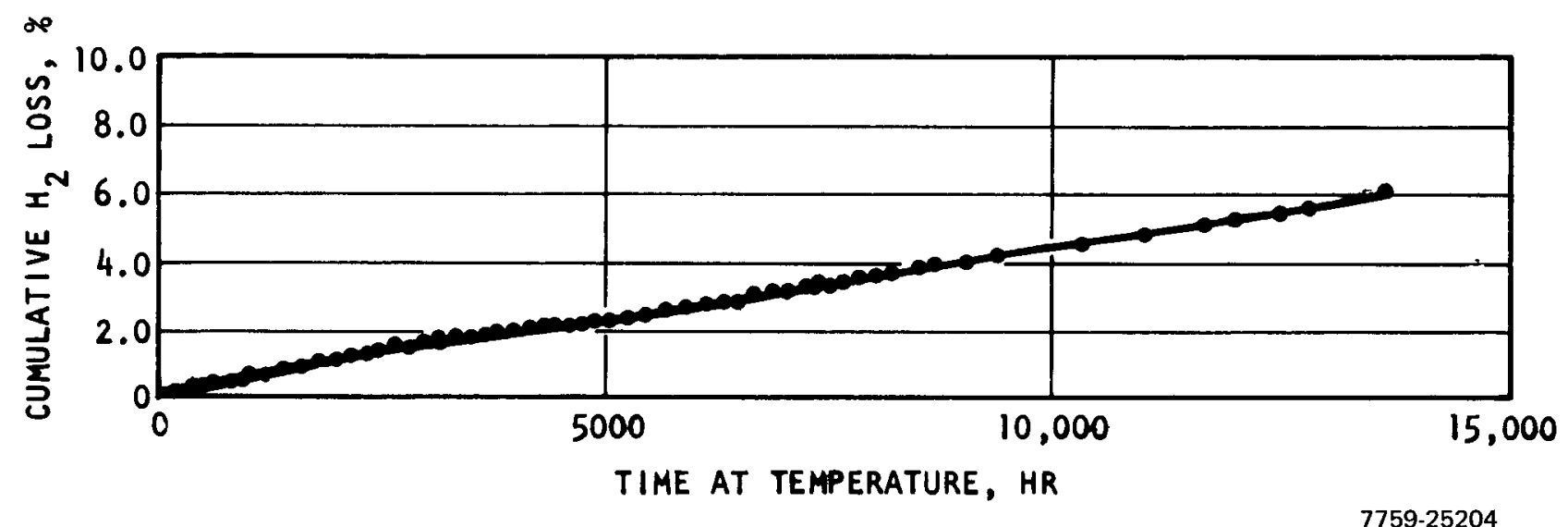

Figure VII-2. Cumulative Average Hydrogen Loss for the Seven Incoloy-800-Clad Developmental Fuel Elements 

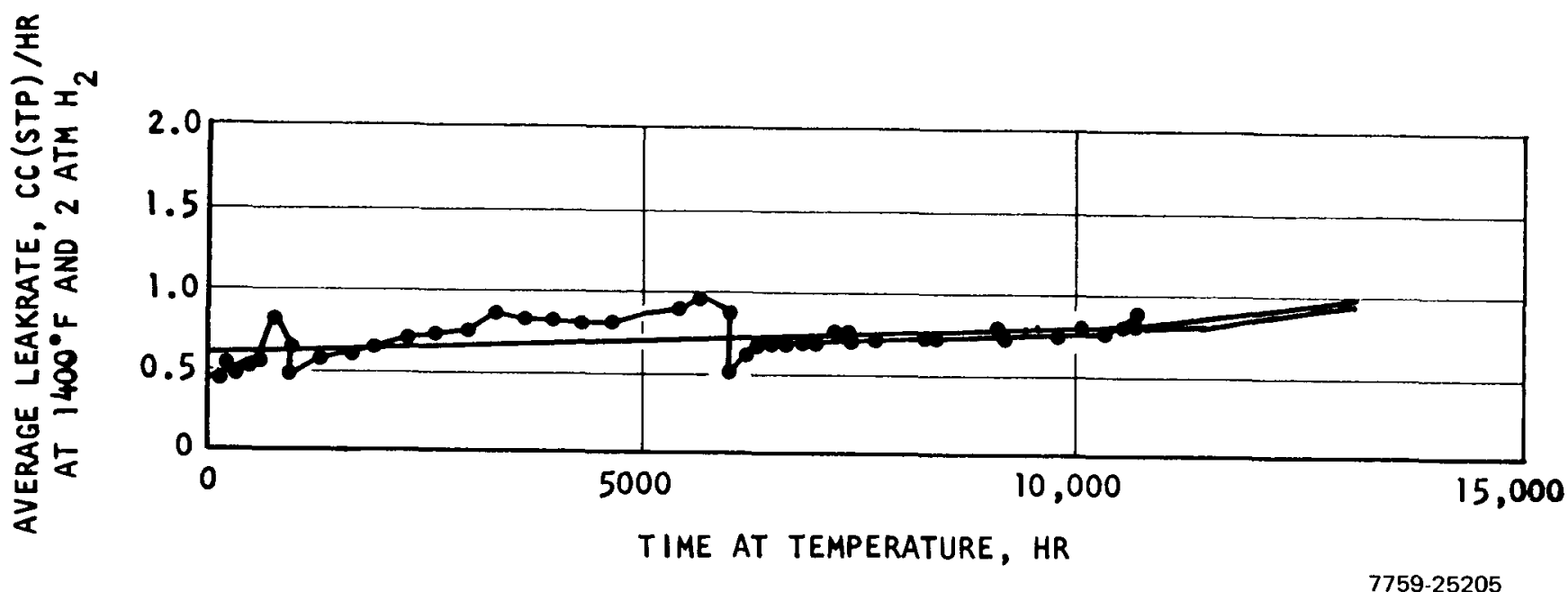

Figure VII-3. Average Normalized Leakrate of the Four Enriched Uranium Double-Blind-End Incoloy-800-Clad

Developmental Elements

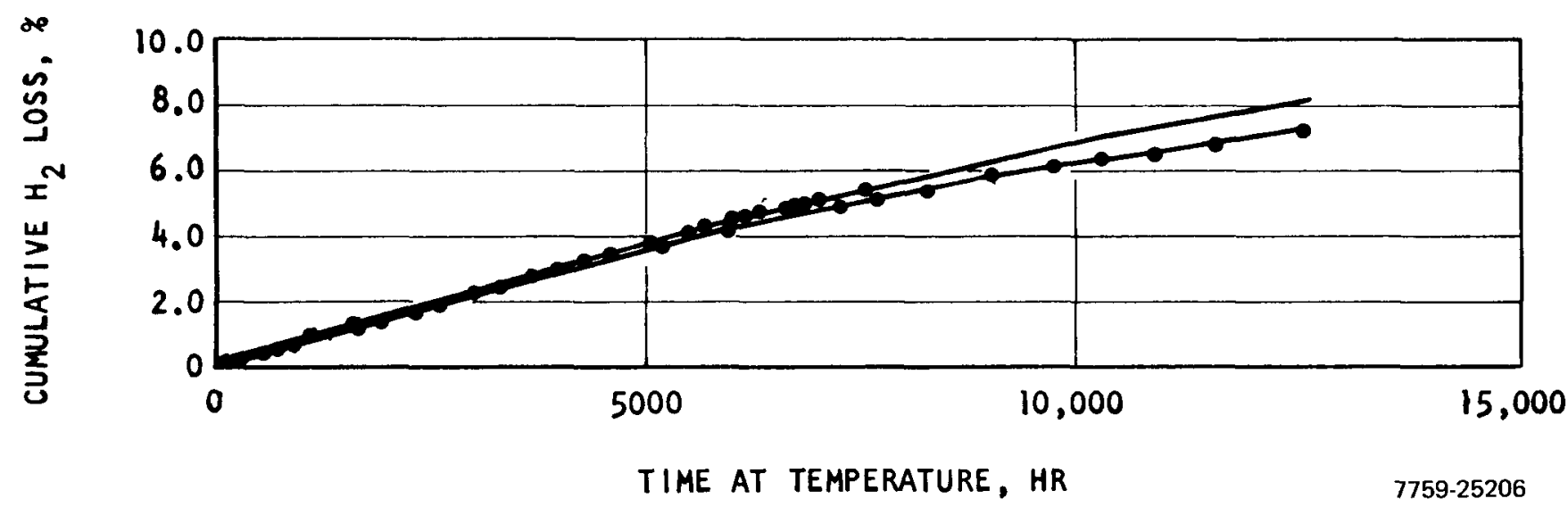

Figure VII-4. Cumulative Average Hydrogen Loss for Four Enriched Uranium Double-Blind-End Incoloy-800-Clad Developmental Elements 
Four double-blind-end Incoloy-clad elements containing enriched uranium rods have now accrued $13,000 \mathrm{hr}$ at $1400^{\circ} \mathrm{F}$. The average normalized leakrate and cumulative hydrogen loss of this group are shown in Figures VII-3 and -4, respectively. The comparatively poor performance when compared to the group of seven normal $U$ elements is primarily due to one high-leaking element. Excluding this element, the remaining three have an average normalized leakrate of $0.60 \mathrm{cc}(\mathrm{STP}) / \mathrm{hr}$ and an average hydrogen loss of $6.1 \%$.

\section{B. IRRADIATION TESTS}

1. $\mathrm{NAR}-120-4$

The topical report on operation, post-irradiation examination, and evaluation (AI-AEC-12963) was published in June 1970.

\section{NAR $-121-1$}

Work was restarted on the post-irradiation examination. Burnup specimens are being prepared for analysis. Selected fuel specimens are being prepared for hydrogen analyses and" metallurgical examination.

\section{3. $\mathrm{NAR}-83$}

a. Incoloy -800

The Incoloy-800 program is being carried out to evaluate the potential of this material as fuel cladding for $\mathrm{ZrH}$ reactors. This is being accomplished by measuring strength and ductility characteristics in simulated reactor environments. The program encompasses: stress-rupture tests in helium of specimens irradiated at different temperatures; in-pile stress-rupture tests both in $\mathrm{He}$ and NaK; out-of-pile stress-rupture tests of controls in both $\mathrm{He}$ and flowing $\mathrm{NaK}$; and tensile tests of unirradiated specimens. A summary of the planned tests was given in a previous quarterly. (7)

The data obtained to date are summarized in Figures VII-5 through - 9. The following conclusions are made regarding these data:

1) A significant degradation in the stress-rupture properties has been identified for samples tested in flowing-NaK loops.

2) The minimum ductility for samples tested biaxially in $\mathrm{NaK}$ at $1400^{\circ} \mathrm{F}$ is $\sim 1 \%$. 


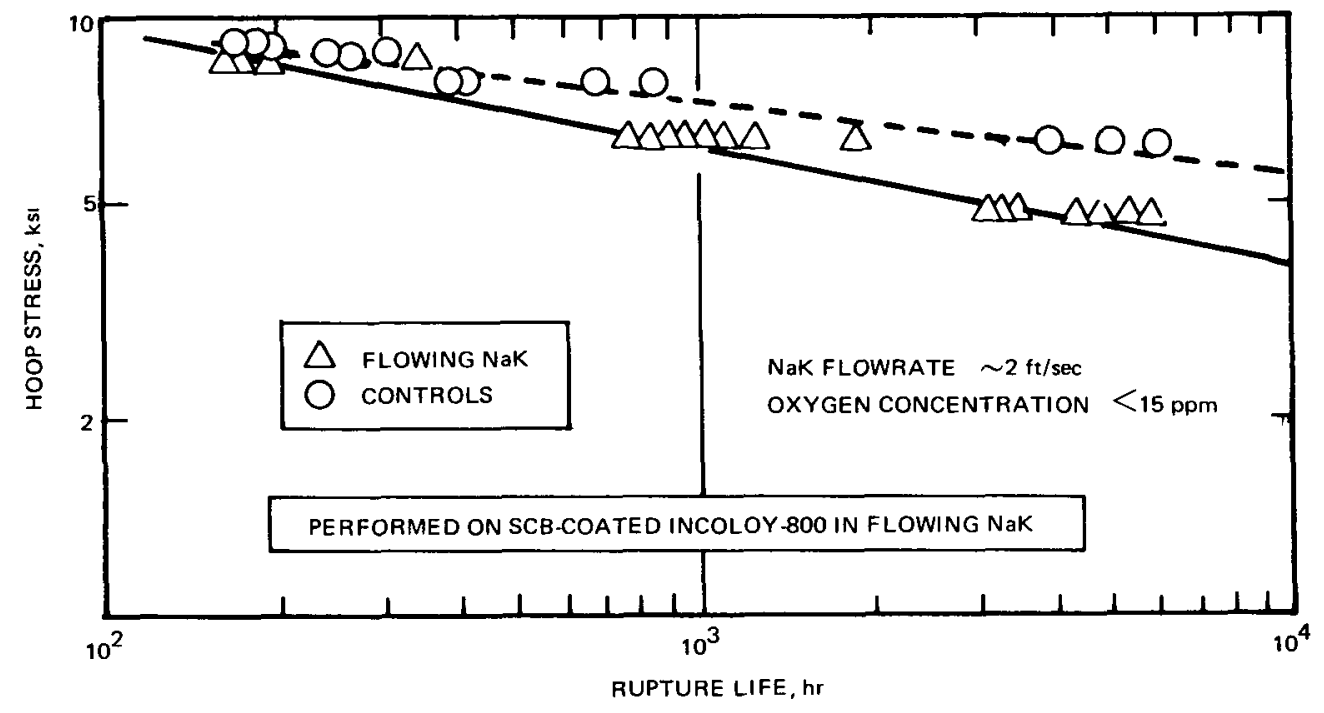

70-MA 15-51-78A

Figure VII-5. $1400^{\circ} \mathrm{F}$ Biaxial Stress-Rupture Tests

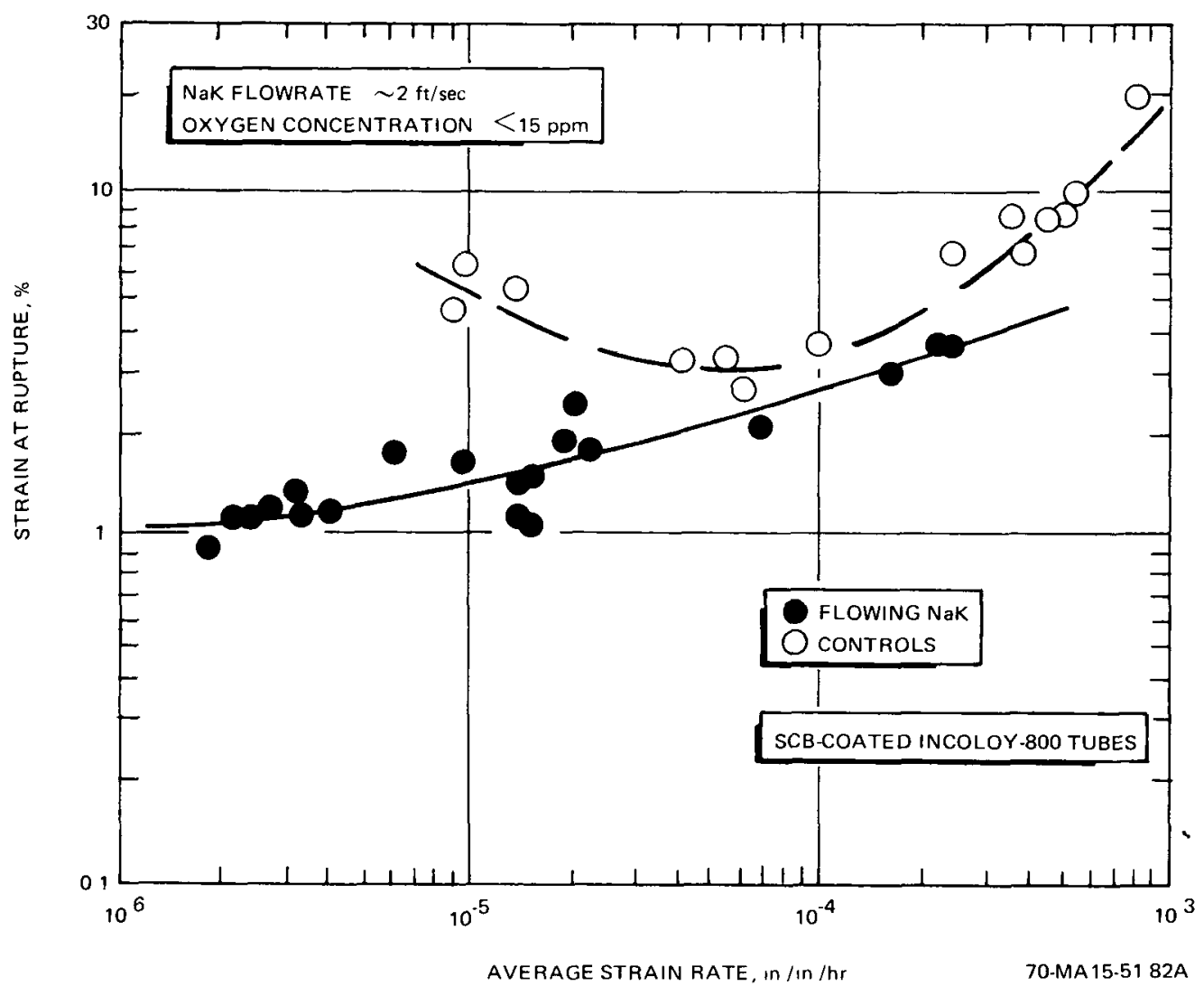

Figure VII-6. $1400^{\circ} \mathrm{F}$ Biaxial Stress-Rupture Data 


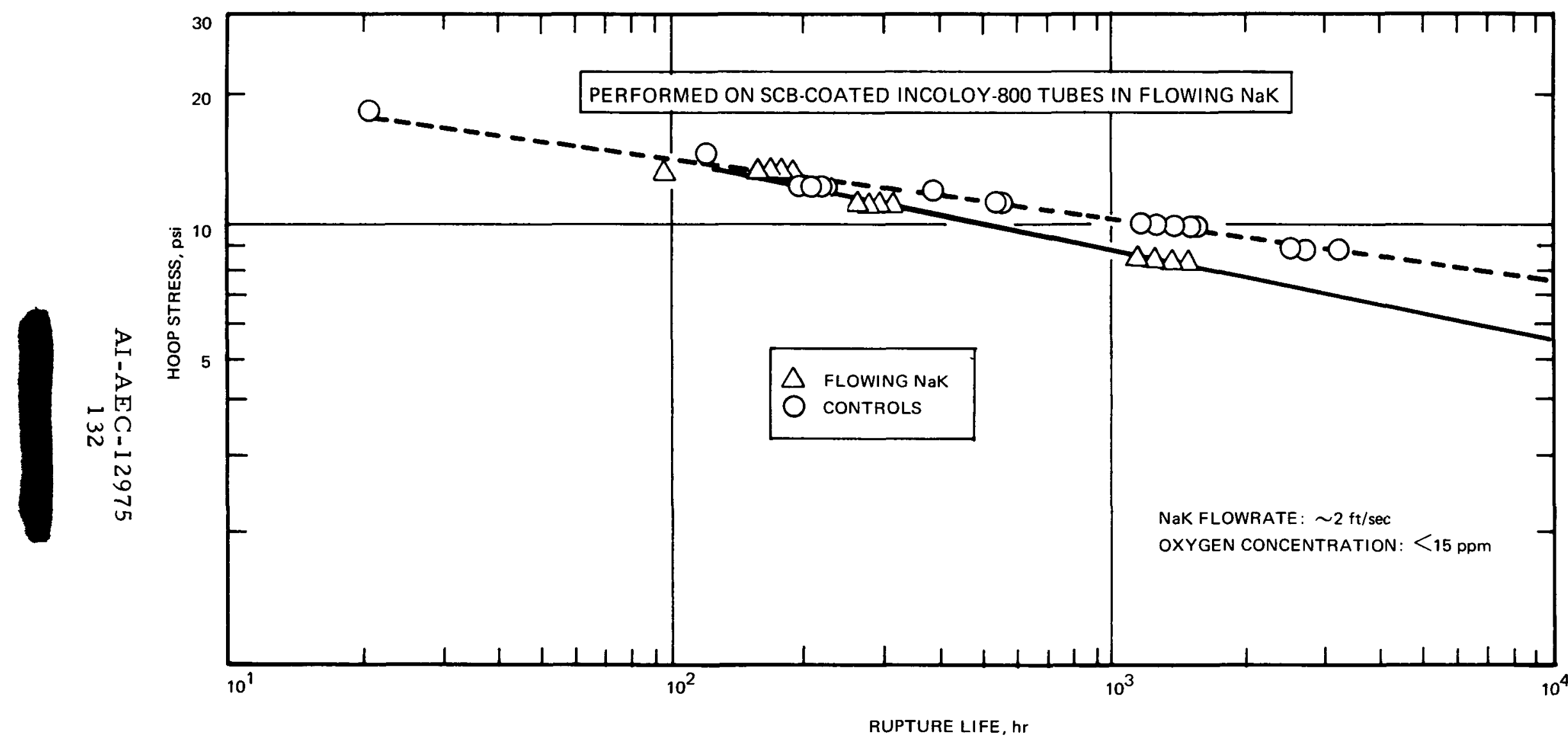

70-MA 15-51-79A

Figure VII-7. $1300^{\circ} \mathrm{F}$ Biaxial Stress-Rupture Tests 


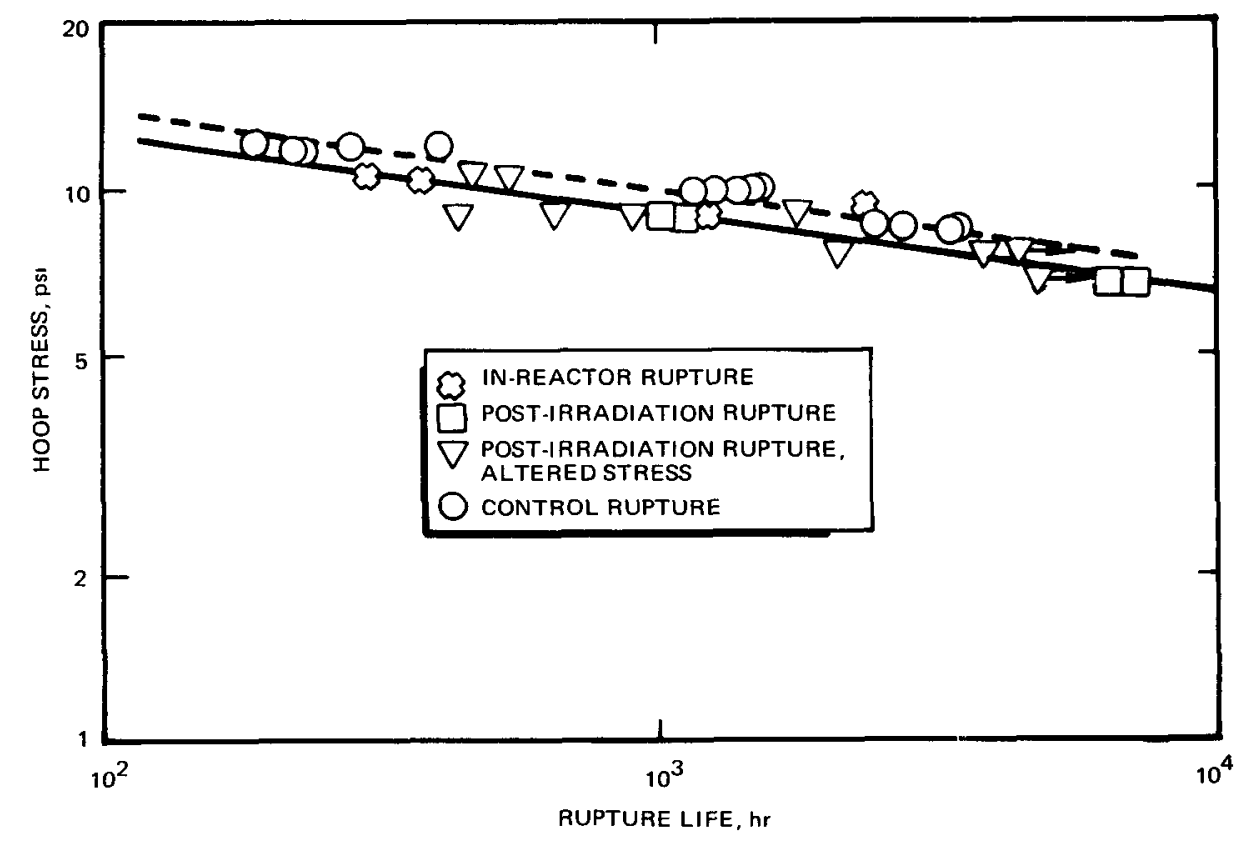

70-JU9-57-19A

Figure VII-8. Biaxial Stress-Rupture of Coated Incoloy -800 at $1300^{\circ} \mathrm{F}$

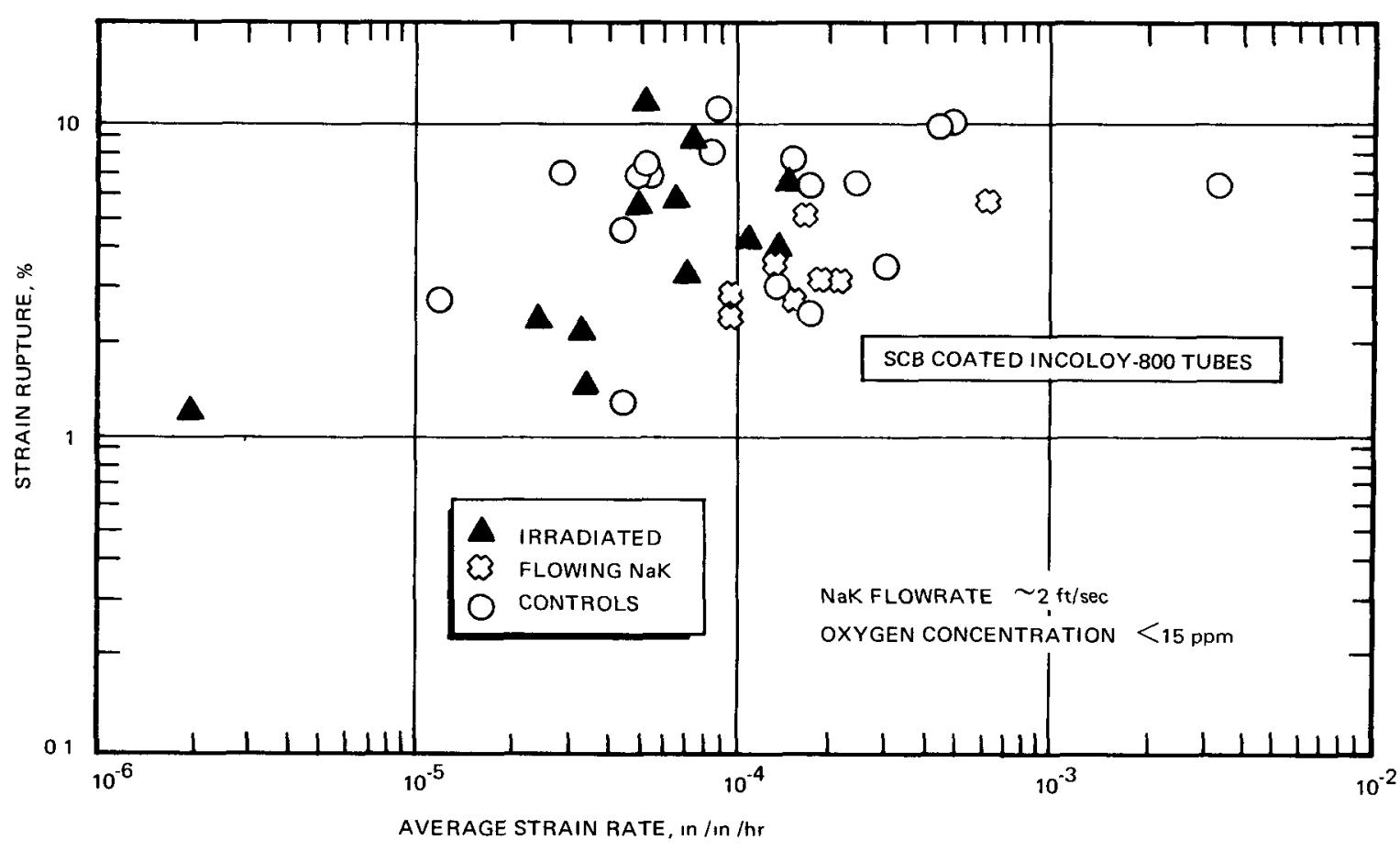

70-MA 15-51-81A

Figure VII-9. $1300^{\circ} \mathrm{F}$ Biaxial Stress-Rupture Data 
3) Only a small offset in the stress rupture-life data for irradiated Incoloy -800 has been observed at $1300^{\circ} \mathrm{F}$.

4) The irradiated samples exhibit ductilities within the scatter of the helium control data.

5) The single long-term data point (Figure VII-9) tends to indicate that $1 \%$ ductility may also be the minimum in 1300 as well as $1400^{\circ} \mathrm{F}$ testing.

6) The data from samples which were restressed to higher values, within about $10 \%$ of the life at the lower stress, ${ }^{(1)}$ are in good agreement with data obtained on samples tested at a single stress value.

A metallographic investigation is being made on samples exposed to flowing $\mathrm{NaK}$ in an effort to determine the nature of the "observed NaK effect." The preliminary results of this investigation indicate that about a $0.3-\mathrm{mil}$ sodium-chromite layer $\left(\mathrm{Na}_{2} \mathrm{O}-\mathrm{Cr}_{2} \mathrm{O}_{3}\right)$ forms on the surface of as-processed and/or solution-annealed samples. This compound also appears to penetrate or form along grain boundaries to a depth of $\sim 0.4$ mil. The existence of this compound at the grain boundaries may in part account for the property degradation. The role of carbon may also be important in this respect but remains to be determined.

The NAR -83-3 $\left(1200^{\circ} \mathrm{F}\right)$ and $-83-4\left(1100^{\circ} \mathrm{F}\right)$ tests have completed $1200 \mathrm{hr}$ of irradiation in the Oak Ridge Reactor. The NAR-83-4 capsule also contained 40 strip specimens for use in fatigue bend-testing.

Two new pumped-NaK loops have been fabricated and installed for testing. These replace the two original loops used in stress-rupture testing.

\section{b. Hastelloy $-\mathrm{N}$}

The status of the stress-rupture tests on SCB-coated Hastelloy-N is shown in Figure VII-10. Only one sample (No. C-3) ruptured during the report period. As can be seen in the figure the rupture life data obtained on the irradiated samples indicate that the curve established in the previous ORR S-2 and S-3 experiments may be conservative. 


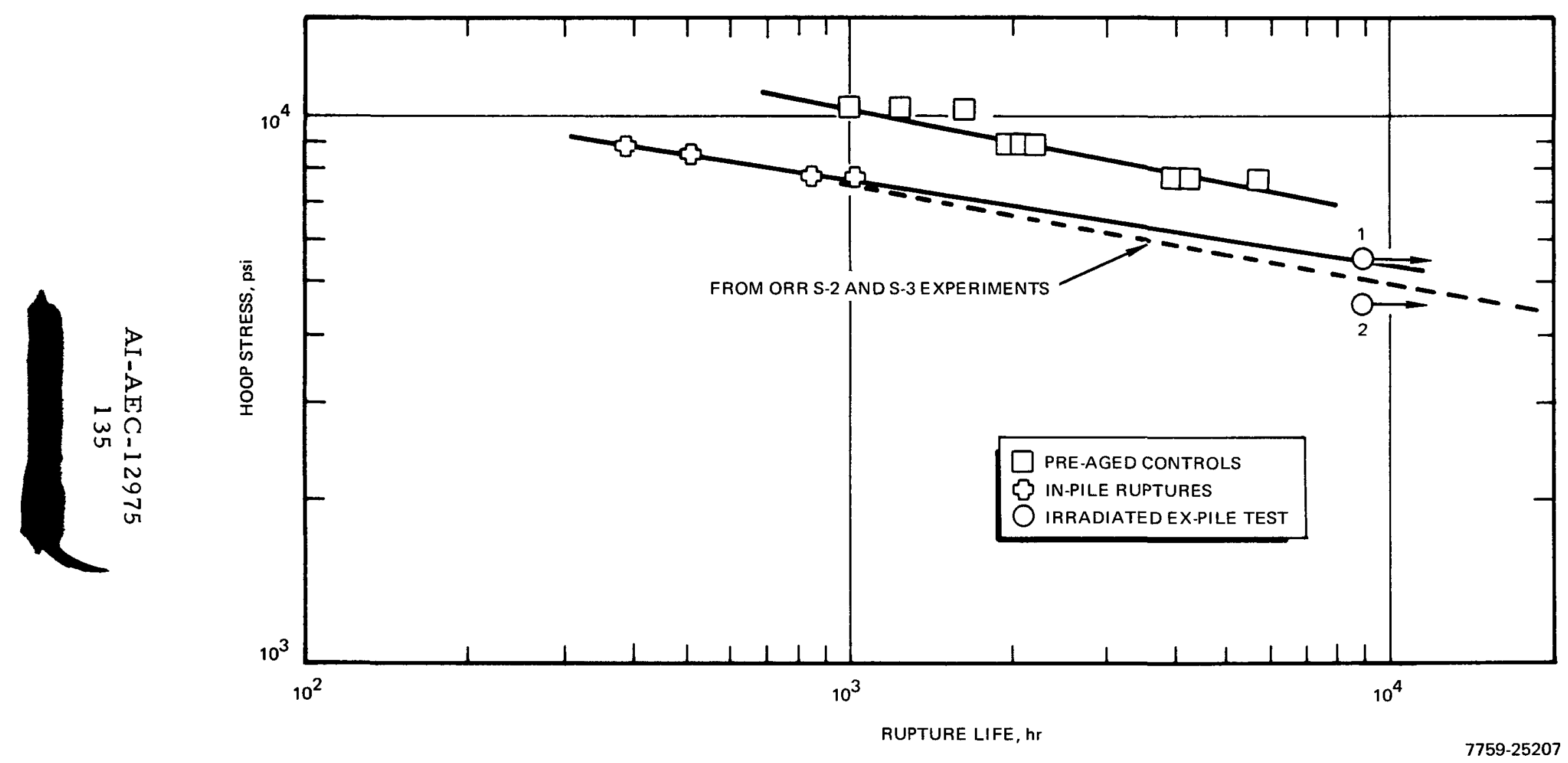

Figure VII-10. Hoop Stress vs Rupture Life for Hastelloy-N at $1400^{\circ} \mathrm{F}$ 



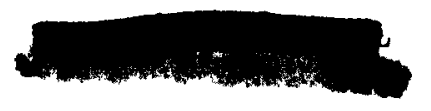

\section{AEROSPACE SAFETY}

\section{A. IMPACT-DISASSEMBLY STUDIES \\ 1. Summary}

A series of impact tests was conducted on 321 -stainless-steel cylindrical shells, lithium-hydride pads, Inconel-800 cylinders, and composite models fabricated from stainless steel and LiH. The objectives of these tests were to (1) determine the feasibility of predicting the post-impact configuration of the reactor system based on the results of scale-model tests, (2) determine the energy-absorbing capacity and failure modes of the reactor materials with geometries and loading conditions similar to the reactor system, and (3) verify the analytical-model approach developed for predicting the reactor post-impact configuration.

The results of this series of tests showed that scale-model testing is a feasible and reliable means for predicting the post-impact deformation of a prototype. The tests also showed that the geometry of the components and their relationship with the other components in a system can affect their energyabsorbing capacity considerably. Finally the analytical model developed for predicting post-impact deformations appears to be a useful tool but should be used with caution in that much of the energy-absorbing capability and resulting deformation depends on the specific design, its geometry, and the interaction of components.

\section{Test Specimens}

The impact tests were made by firing the specimens from the AI gas gun at a granite target. The cylindrical shells tested were fabricated from Type 321 -stainless-steel tubing, with the radius-to-wall-thickness $(R / t)$ and the length-to-diameter (L/D) ratios similar to those of the reactor gamma shield and reactor vessel. Concentrated weights were added to some of the shells.

The LiH tests were done by impacting discs of LiH between the granite target and a steel projectile. This type loading is similar to the loading conditions of the reactor system LiH on earth impact. The composite models tested are shown in Figures VIII-1 and -2 . The models in Figure VIII-1 do not simulate 


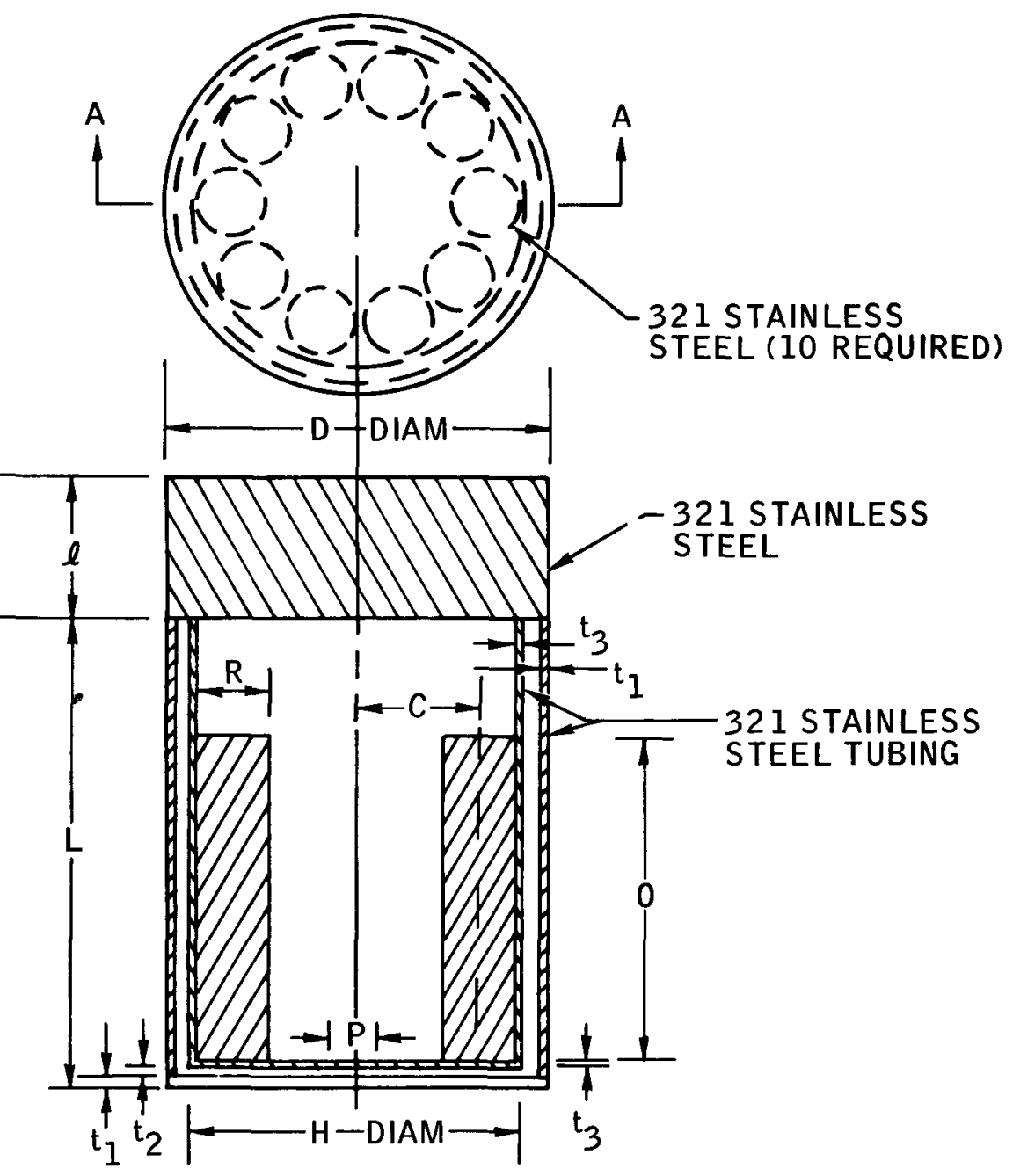

\begin{tabular}{|c|c|c|c|c|c|c|c|c|c|c|c|}
\hline $\begin{array}{l}\text { SPECIMEN } \\
\text { NUMBER }\end{array}$ & $\begin{array}{c}\mathrm{D} \\
\text { (in.) }\end{array}$ & $\stackrel{\ell}{(\text { in.) }}$ & (in.) & $\begin{array}{c}{ }^{t} 1 \\
\text { (in.) }\end{array}$ & $\begin{array}{c}\mathrm{t}_{2} \\
\text { (in.) }\end{array}$ & $\begin{array}{c}t_{3} \\
\text { (in.) }\end{array}$ & $\stackrel{H}{H}$ & $\stackrel{P}{P}$ & $\underset{(i n .)}{R}$ & $\underset{(\text { in. }}{C}$ & $\begin{array}{c}0 \\
\text { (in.) }\end{array}$ \\
\hline 1 & 2.0 & 3.94 & 2.5 & 0.049 & 0.032 & 0.020 & 1.78 & 0.25 & 0.375 & 0.650 & 1.75 \\
\hline 2 & 1.0 & 1.97 & 1.25 & 0.028 & 0.016 & 0.010 & 0.875 & 0.125 & 0.188 & 0.325 & 0.875 \\
\hline
\end{tabular}

70-F13-017-15

Figure VIII-2. Impact-Test Specimens 
any of the reactor components but were used to verify the analytical model and establish the feasibility of scale-model testing. The model in Figure VIII- 2 is an approximate scale model of the reactor gamma shield, reactor vessel, and control drums, all fabricated from Type 321 stainless steel. The shells, LiH pads, and composite models were fabricated in three different sizes, each size a scale model of the other two. In addition, tests were run on cylindrical specimens of Incone1-800 and cylindrical shells filled with LiH.

\section{Scale-Model Laws}

The tests made to verify that scale-model testing was feasible for predicting the post-impact configurations of a prototype were based on the modeling laws described in the previous reporting period. Briefly, these laws state that the percentage deformations of the model and the prototype will be equal if they are geometrically similar, constructed of the same materials, have the same impact velocity, and have the same target material.

\section{Test Results \\ a. Scale-Model Law Verification}

The impact tests made proved that the post-impact deformation of a prototype could be predicted from impact tests of a scaled model and that the modeling laws developed are valid. The percentage deformation of the scaled models was very close and the failure modes identical. For example, Figure VIII-3 compares the post-impact deformations of the scaled cylindrical shells with an $\mathrm{R} / \mathrm{t}$ ratio of 20 , similar to that of the gamma shield. Figure VIII-4 is a plot of the percentage deformations of the three sizes of specimens.

Tests of the LiH pads also verified the modeling laws. The pads were destroyed but the deformation of the impacting weights was very similar as illus trated in Figure VIII-5. The LiH varied in granular structure between specimens and the impact conditions varied some between tests so that the spread of deformations of the $\mathrm{LiH}$ tests is greater than was found on the shell tests.

Figures VIII-6 and -7 show the typical post-impact deformations of Composite Model No.1. The deformation patterns of the scaled models are very similar, though not identical. In every case, the failure modes and the total amount of deformation of the scaled models were in good agreement. The damage to the weight and rods of the destroyed specimens was very similar. 


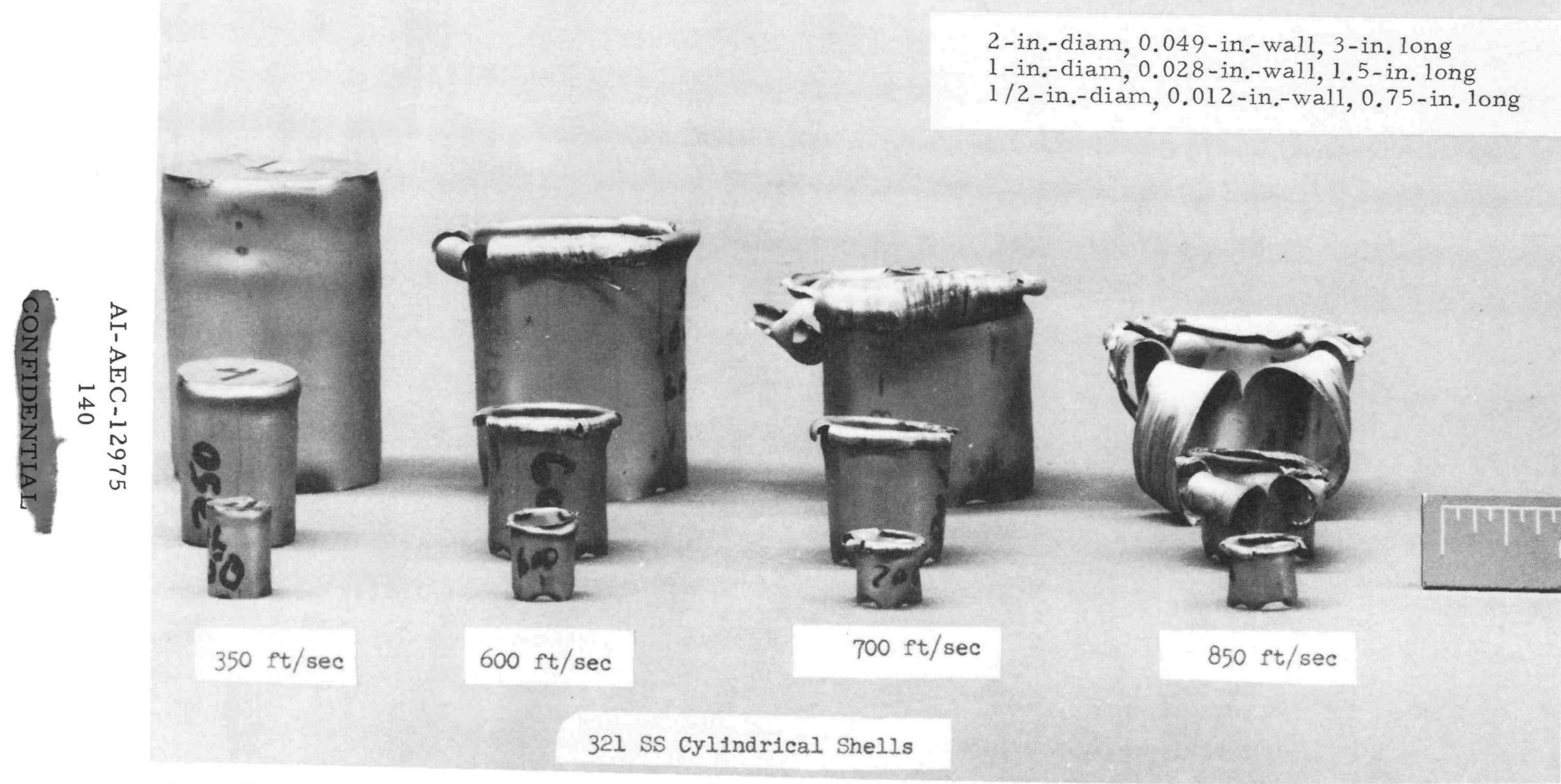

$5-15-70$

Figure VIII-3. Impact-Test Results for Cylindrical Shells with an R/t Ratio of 20

$7700-4041$

○ 


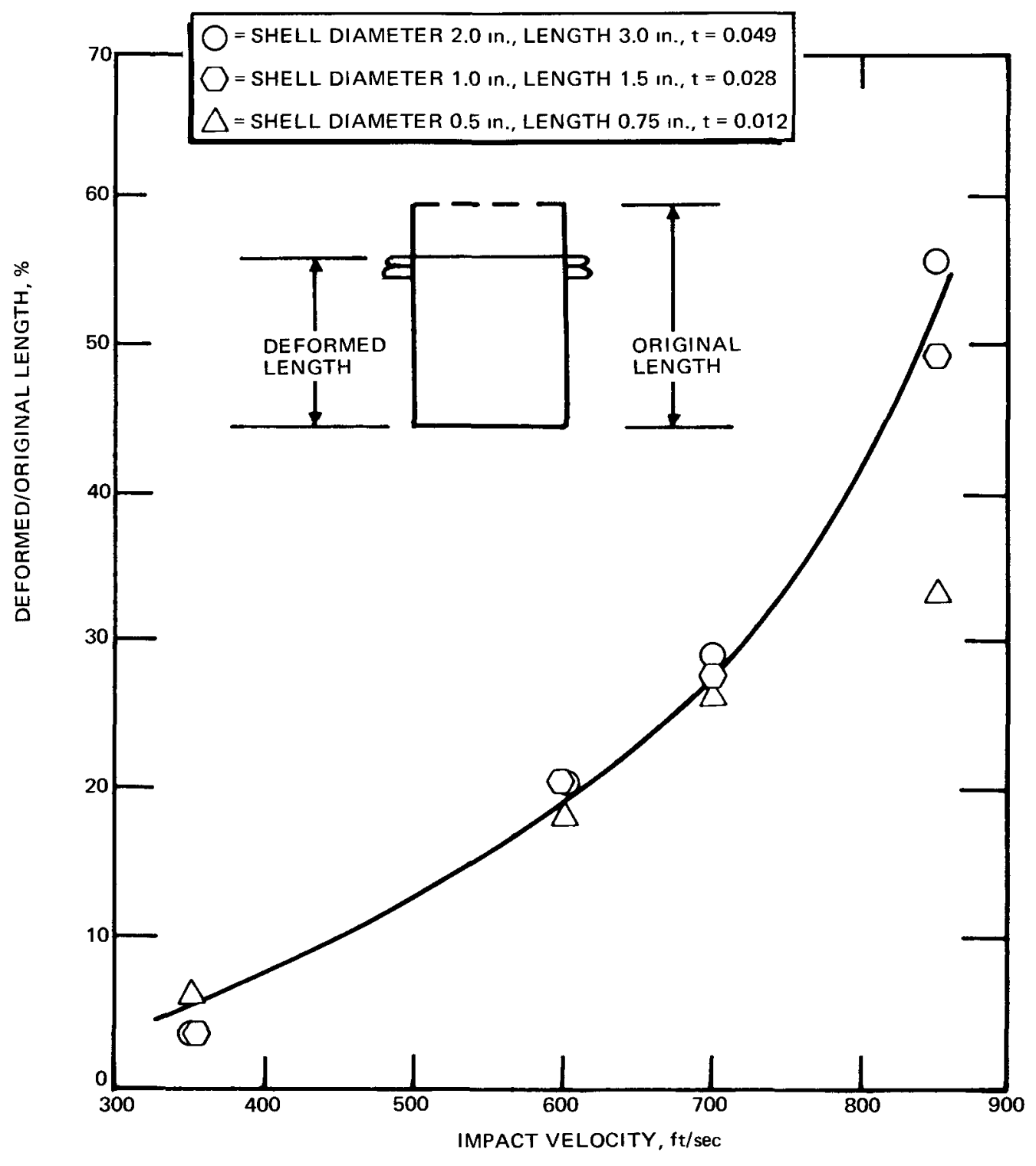

$7759-25200$

Figure VIII-4. Deformation for Cylindrical Shells ( $L / D$ ratio of $1.5, R / t$ ratio of $\approx 20$ ) 


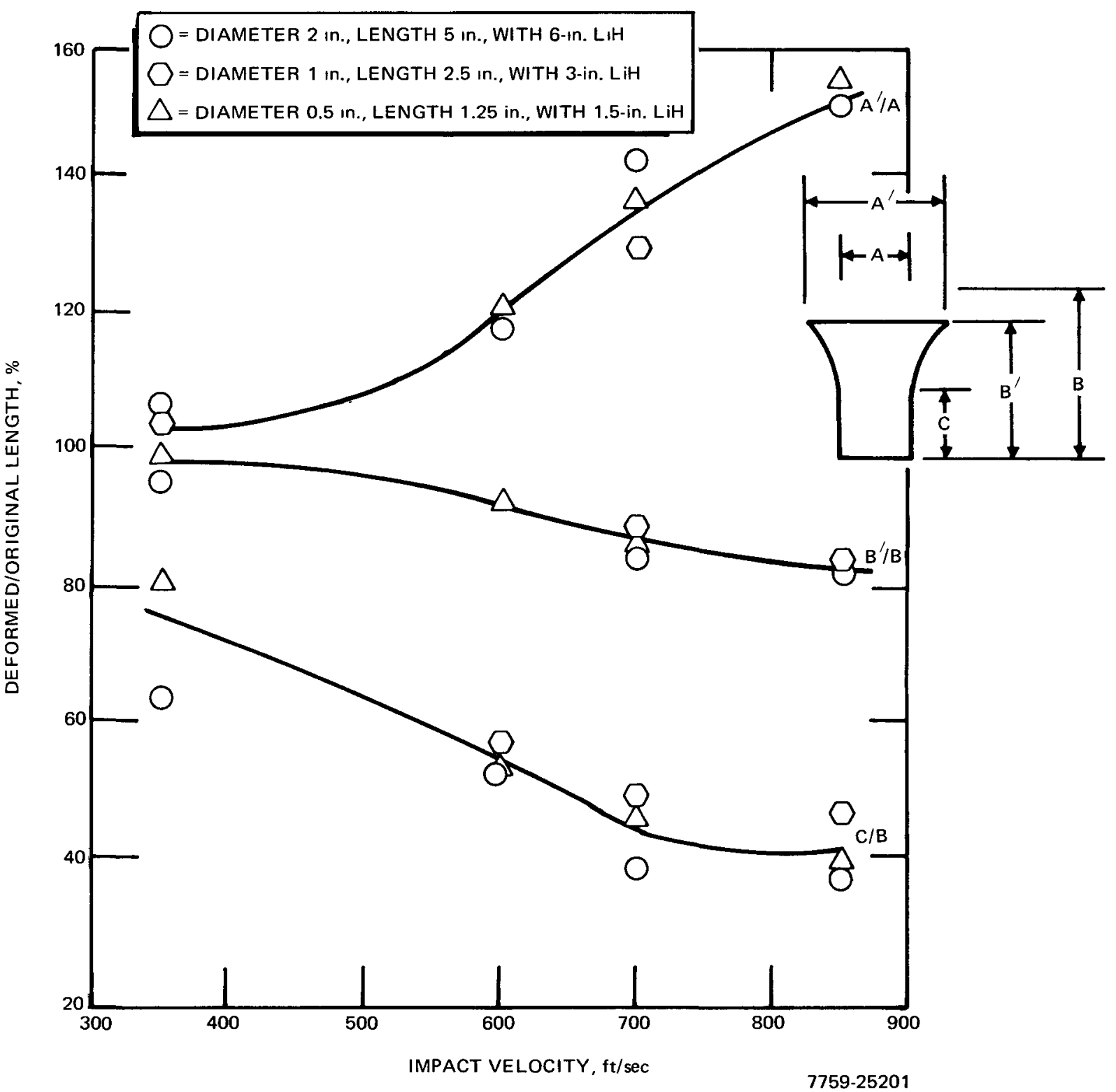

Figure VIII-5. Deformation for 1020 Steel Projectiles with Lithium Hydride Pads 


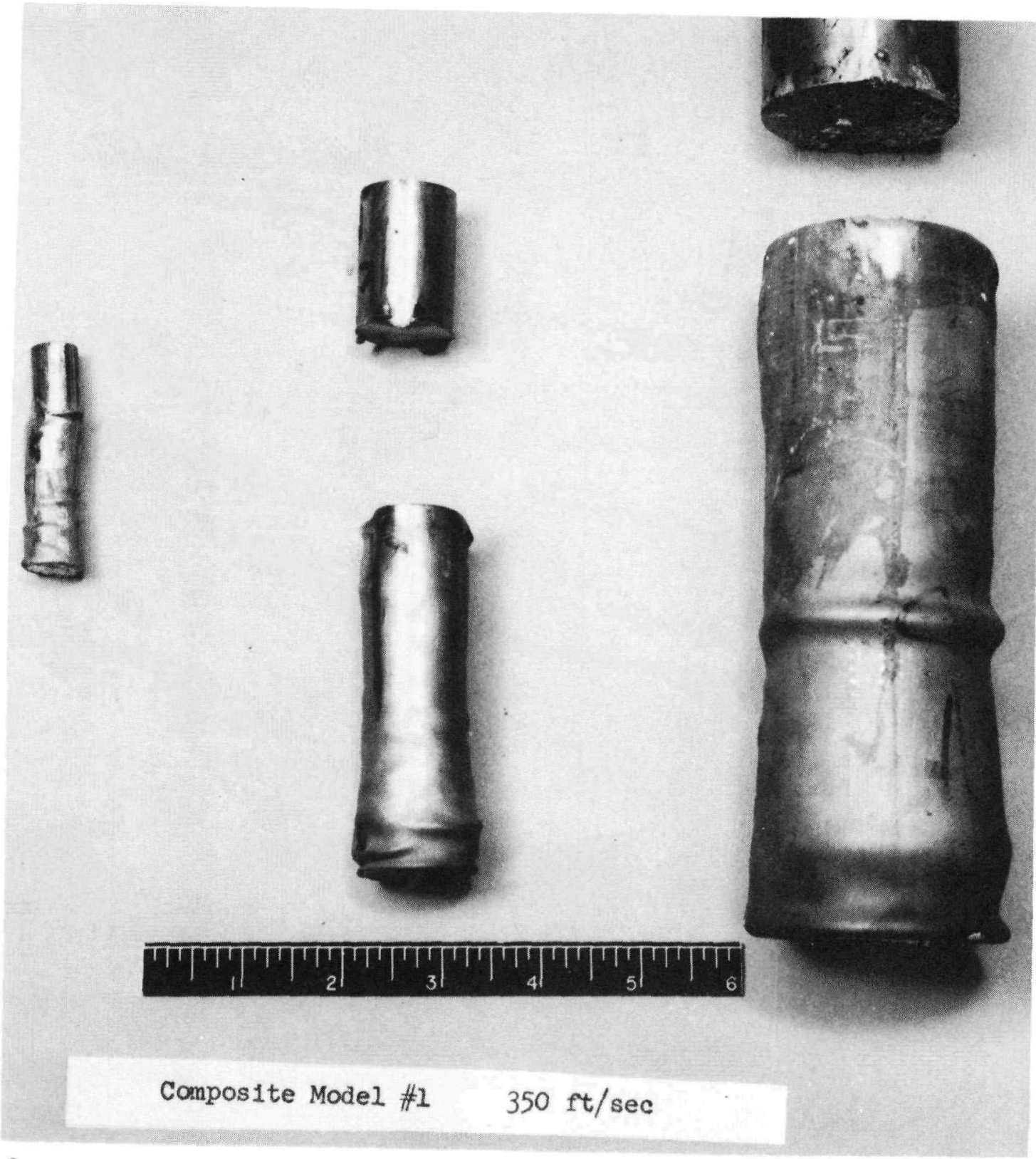

$5-19-70$

$7700-4057$

Figure VIII-6. Post-Impact Configurations for Composite Model No. 1 for Impact at $350 \mathrm{ft} / \mathrm{sec}$ 


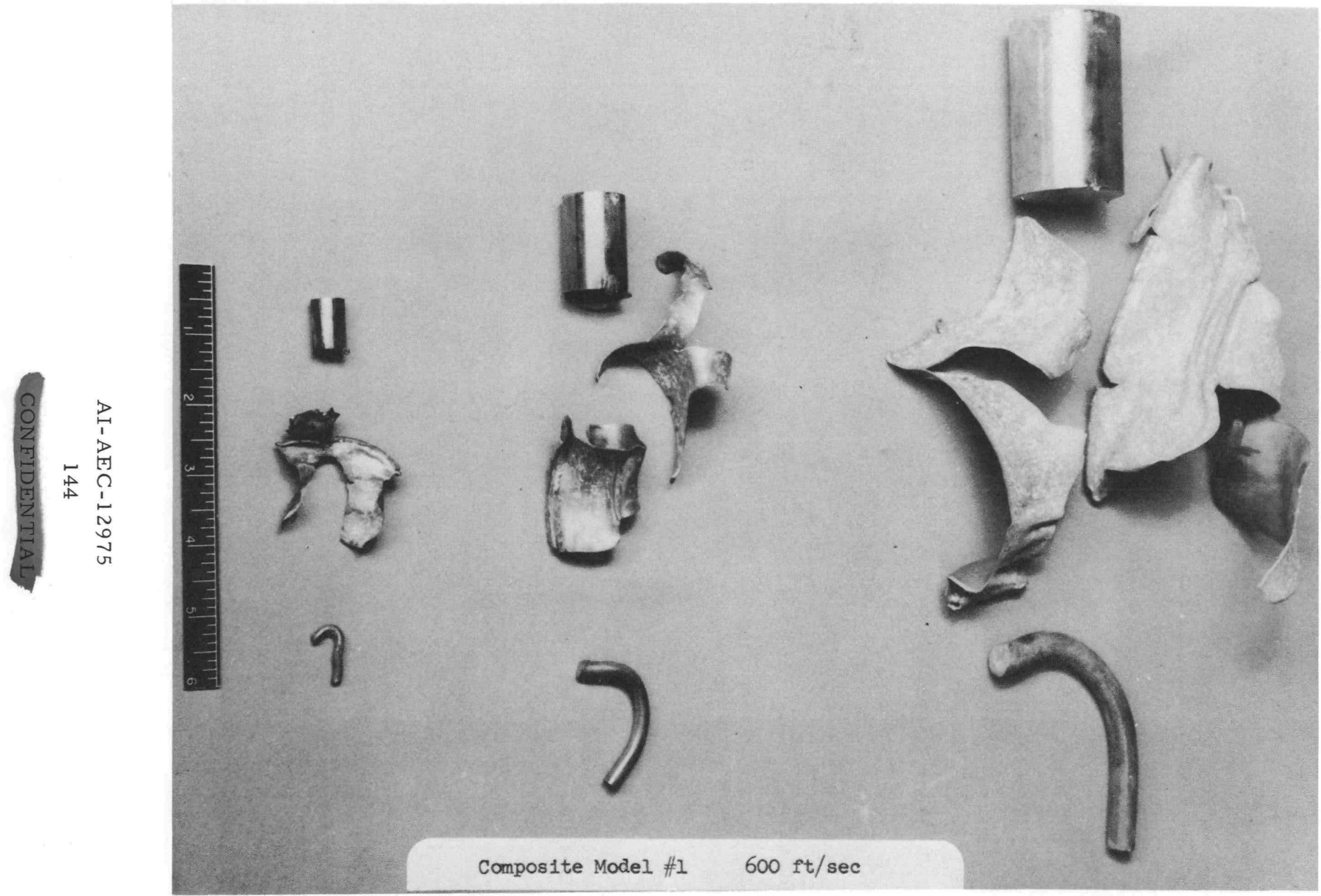

5-19-70

$7700-4061$

Figure VIII-7. Post-Impact Configurations for Composite Model No. 1 for Impact at $600 \mathrm{ft} / \mathrm{sec}$ 
Figures VIII-8 and -9 show typical post-impact deformation of the scaled Composite Model No.2. The post-impact deformation of No. 2 is again very similar, with the failure modes and total deformation between the two sizes of models tested being in very good agreement.

b. Energy-Absorption Capability of Thin-Walled Shells and Lithium Hydride

In addition to verifying the modeling laws, tests were made to determine the energy-absorption capabilities of thin-walled cylinders as found in the reactor system and the energy absorbed in pulverizing LiH. Previous impact tests of LiH showed that it pulverized at very low impact velocities but the energy absorbed by the LiH in pulverizing was not determined. The current test program was designed to determine the energy required to pulverize various thicknesses of LiH pads. The energy-absorption capabilities of thin-walled cylinders and LiH were required for updating the analytical model. Figure VIII-lo shows the effect of $\mathrm{R} / \mathrm{t}$ ratio of the $\mathrm{K}$ factor of cylindrical shells. The $\mathrm{K}$ factor of a material, as defined in the analytical model, is the ratio of the energy absorbed dynamically per pound of material to the energy per pound of material under the normal stress-strain curve. Figure VIII-1l shows the effect of LiH thickness on the $\mathrm{K}$ factors for pulverizing the 2 -in.-diam pads of LiH. The LiH absorbs considerable energy per pound as illustrated in Figure VIII-12, but this energy drops off rapidly as the pad thickness is increased. This is due to the fact that on the thicker pads much of the LiH spreads out to the side at impact and is not effective in absorbing the energy of the projectile.

A series of tests was conducted on 2-in.-diam 0.016-in.-wall Type 321 stainless-steel cylindrical shells filled with LiH. The purpose of these tests was to determine the energy-absorption capacity of the confined LiH. Figures VIII- 13 and -14 show the post-impact configurations of the se specimens. The $\mathrm{LiH}$ remained intact as long as the shell was intact, and did not completely pulverize as did the $\mathrm{LiH}$ when tested alone. Figure VIII-15 is a plot of the $\mathrm{K}$ factors for the composite stainless-steel shell and the LiH. The $\mathrm{K}$ factors for the composite model of from 2 to 9 are much higher than those for either the stainless-steel cylinder or the $\mathrm{LiH}$ by themselves. The $\mathrm{K}$ factors for the shell alone vary from 1.5 to 2.5 (Figure VIII-10), whereas the $K$ values of the LiH alone approach zero as it disintegrates at very low velocities. 


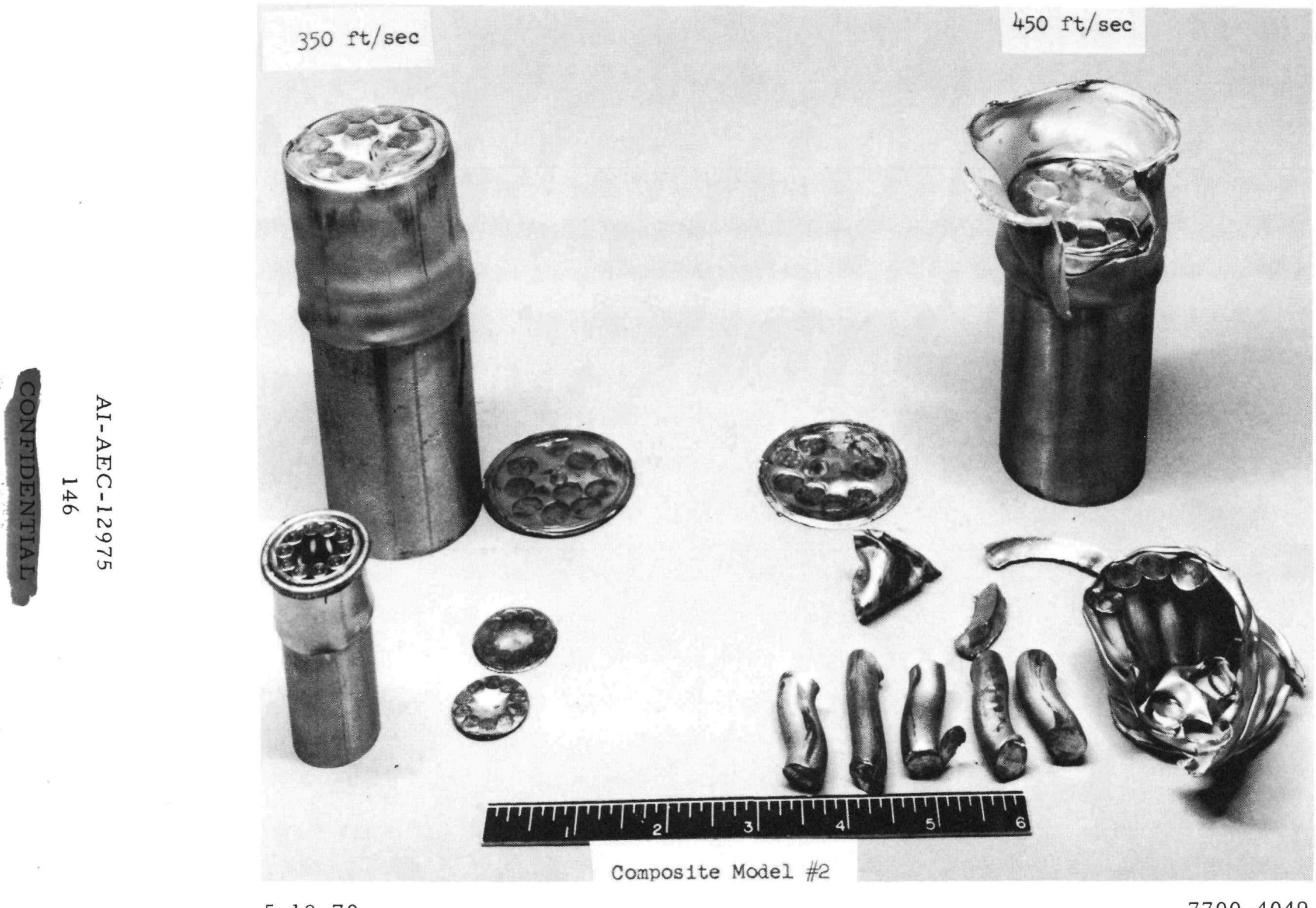

$5-19-70$

$7700-4049$

Figure VIII-8. Post-Impact Configurations for Composite Model No. 2 for Impact at 350 and $450 \mathrm{ft} / \mathrm{sec}$ 



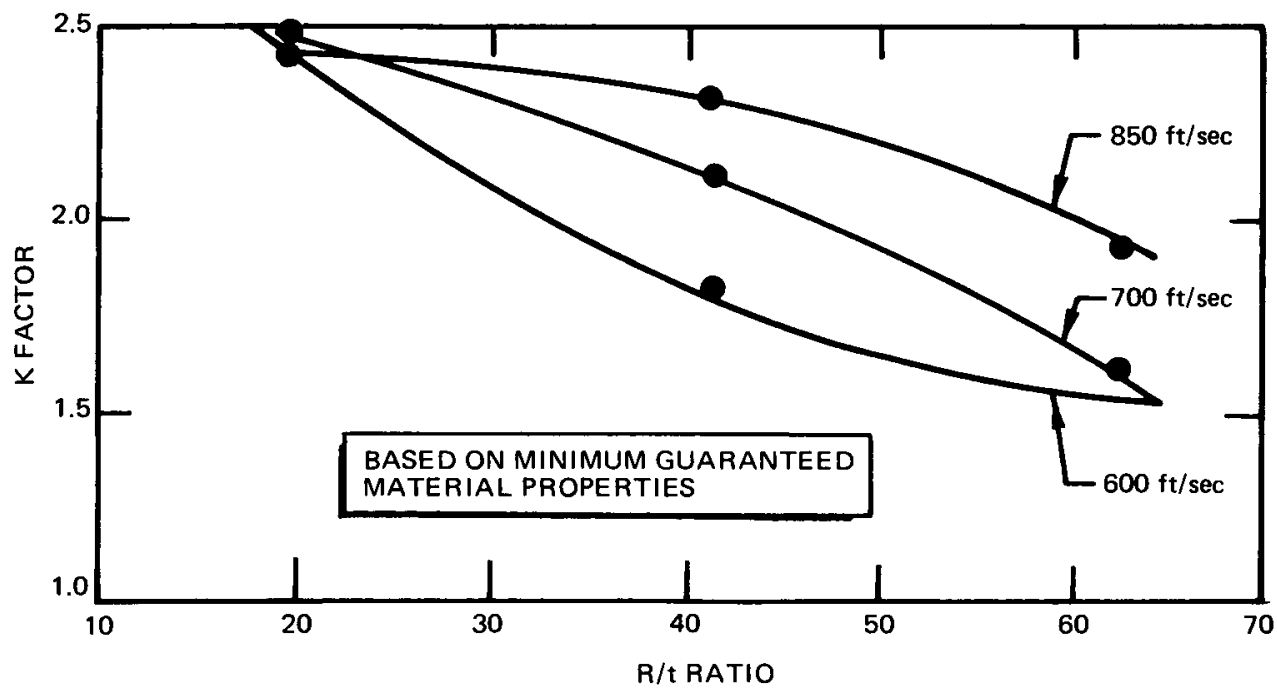

$7759-25208$

Figure VIII-10. Effect of $R / t$ Ratio on the $K$ Factors for Cylindrical Shells with an L/D Ratio of 1.5

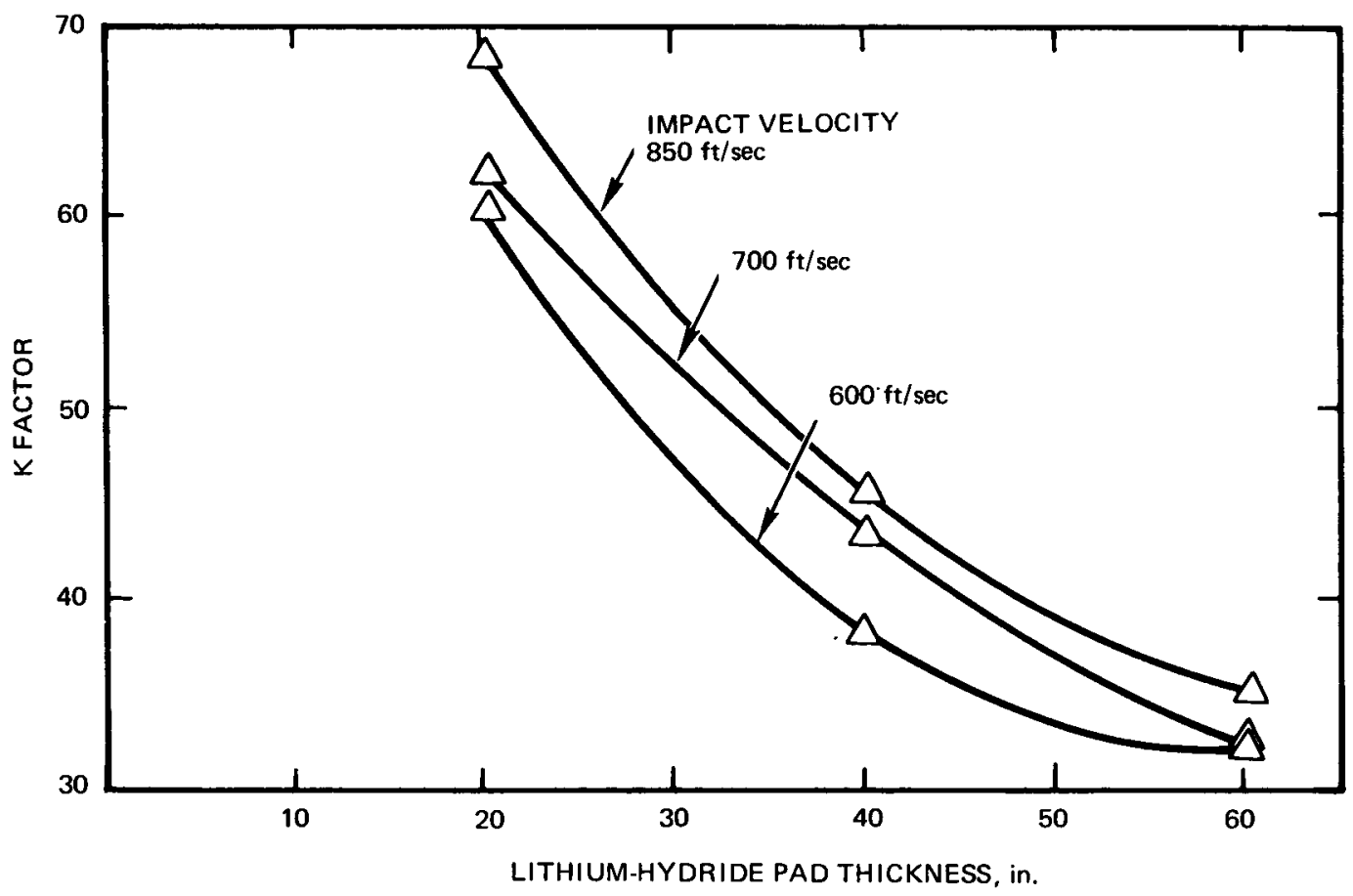

7759-25209

Figure VIII-11. Effect of Thickness on the K Factors for the 2 -in.-diam Lithium-Hydride Pads 


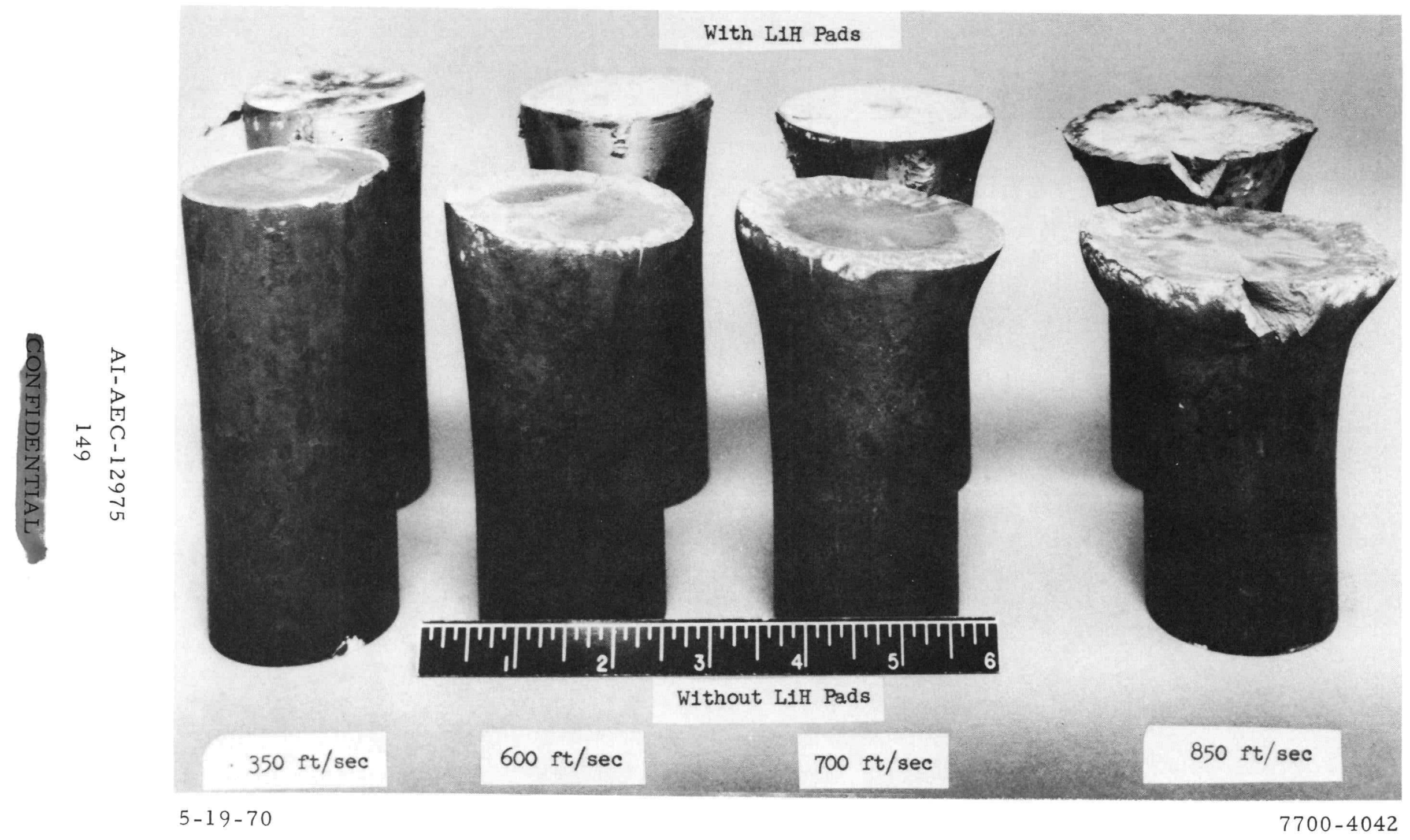

Figure VIII-12. Deformation of 2-in.-diam 1020 Steel Projectiles With and Without Lithium-Hydride Pads 

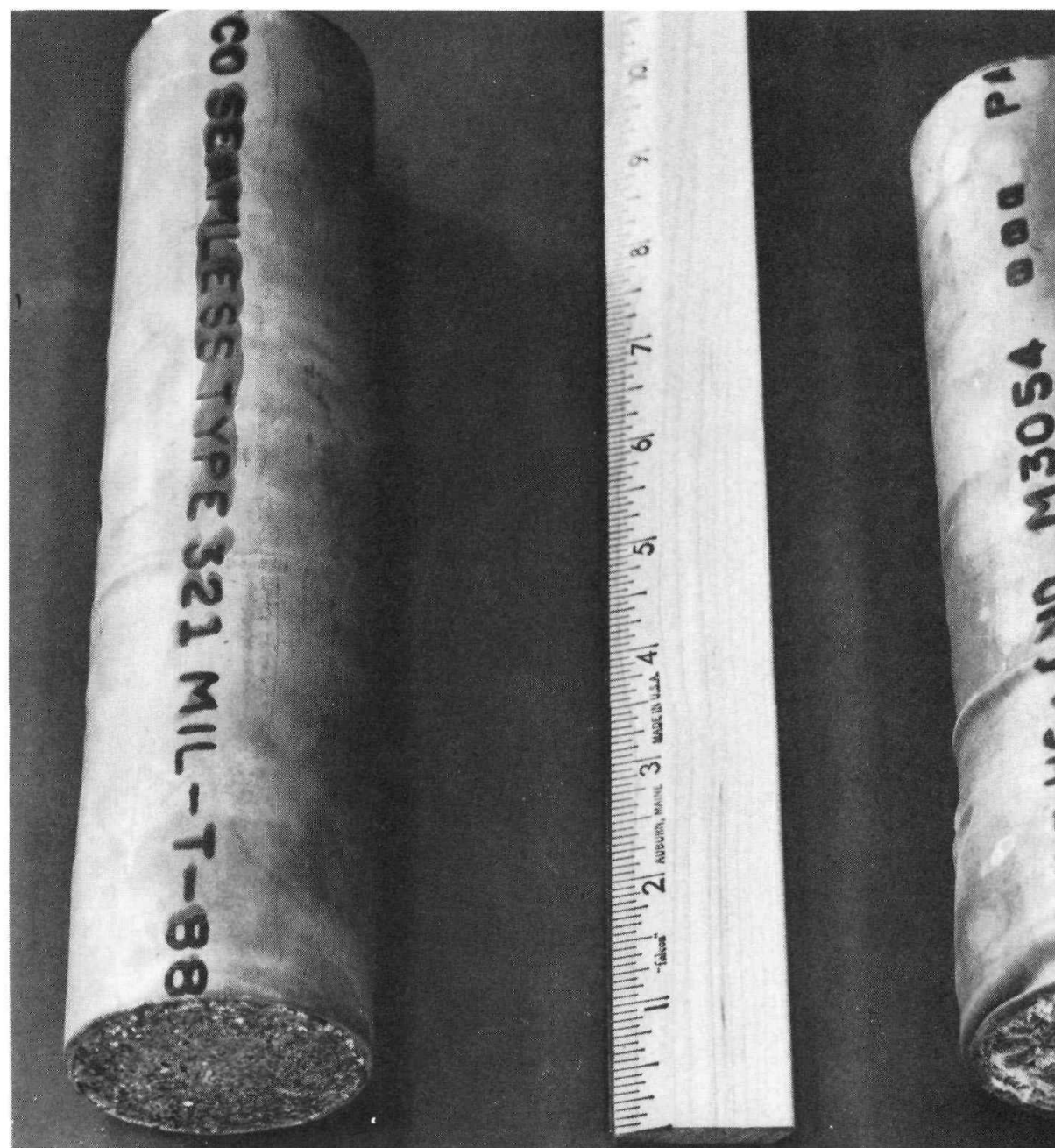

6
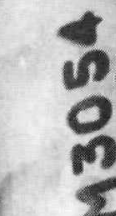

$\frac{1}{2}$
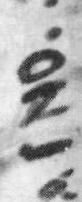

a.

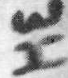

e

G

a

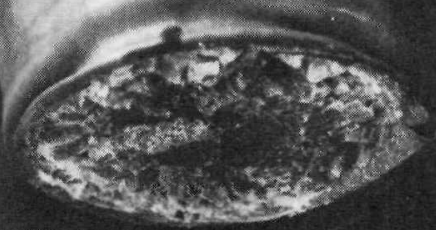

$100 \%$ sec
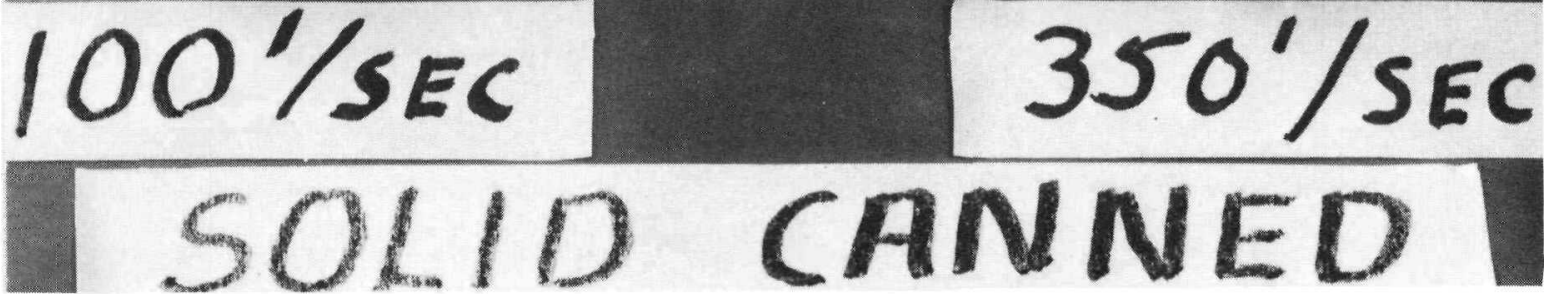

$7700-4019$

$12-3-69$

Figure VIII-13. Post-Impact Configurations of Stainless-Steel

Cylindrical Shell Filled with Lithium Hydride for Impact at 100 and $350 \mathrm{ft} / \mathrm{sec}$

AI-AEC-12975 


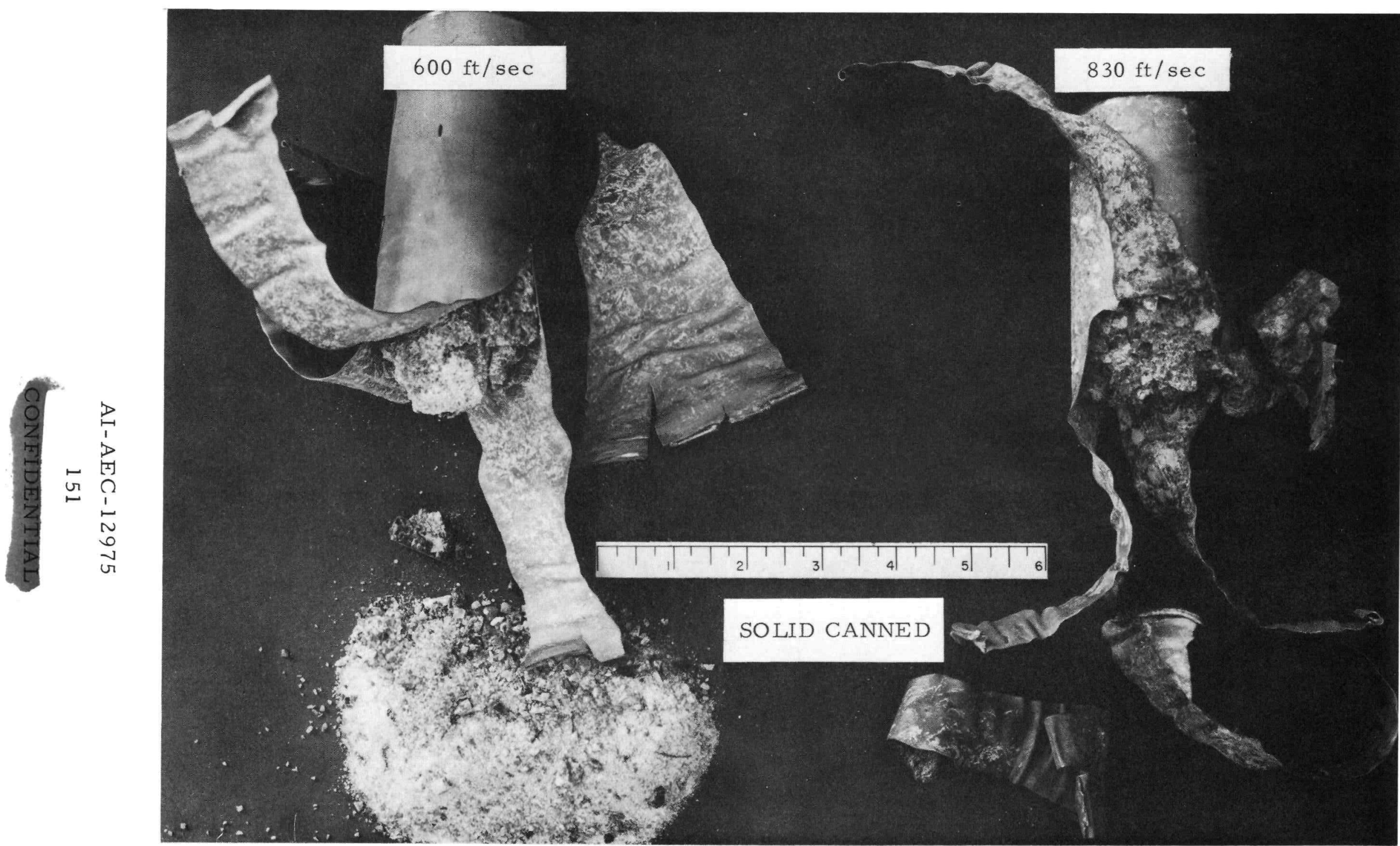

$12-3-69$

$7700-4020$

Figure VIII-14. Post-Impact Configurations of Stainless-Steel Cylindrical Shell Filled with Lithium Hydride for Impact at 600 and $830 \mathrm{ft} / \mathrm{sec}$ 


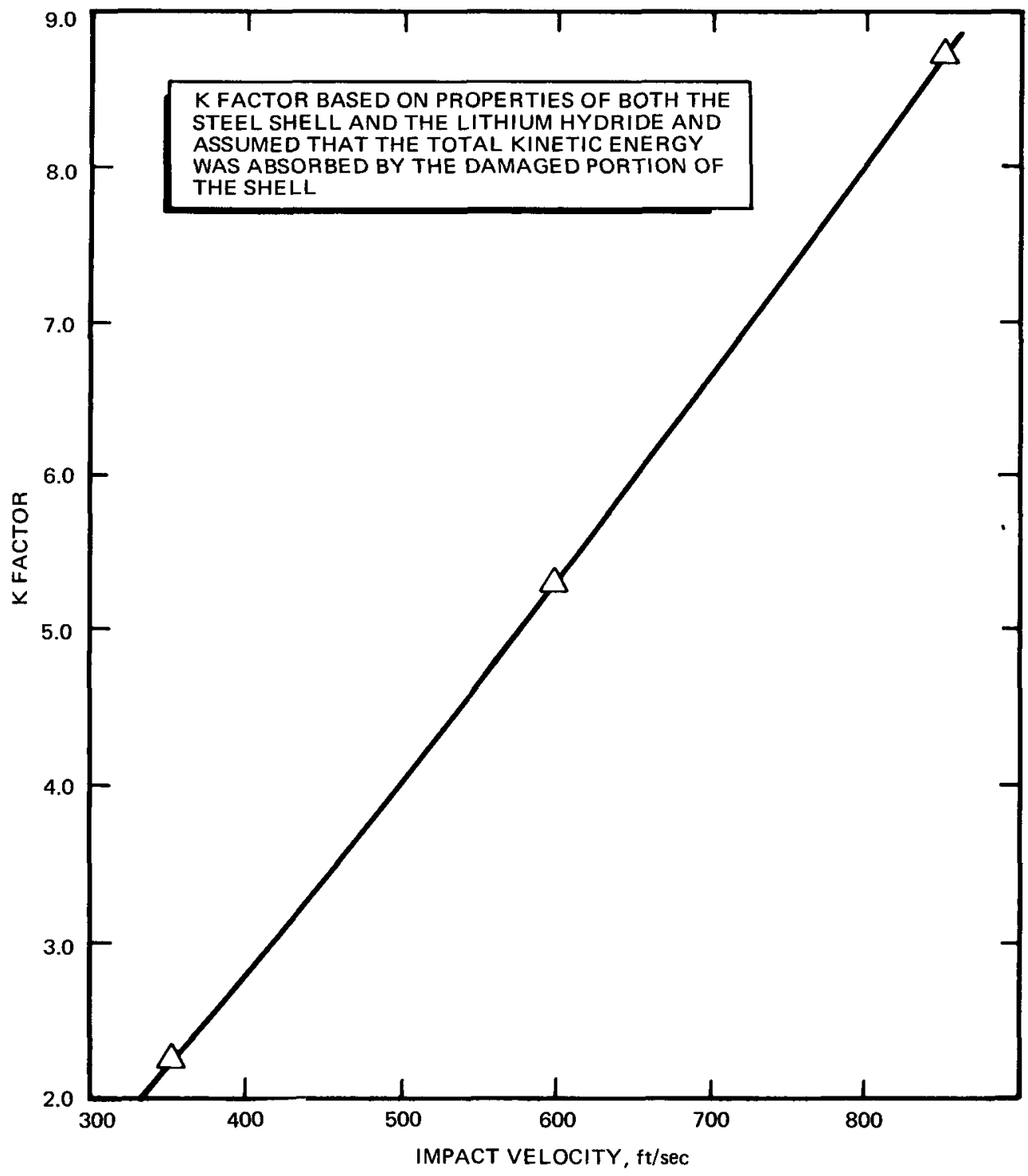

$7759-25210$

Figure VIII-15. K Factor for 2-in.-diam 0.16-in. Wall, 321 Stainless-Steel Cylinder Filled with

Lithium Hydride 


\section{c. Inconel-800}

Impact tests were made on Inconel-800 cylindrical specimens 1/2-in.-diam by 2 -in.-long. The specimens showed no evidence of fracturing at the higher velocities as did the Type 316 stainless-steel specimens impacted in previous tests. At all velocities the specimens tapered in a gradual manner almost the entire length of the cylinder with the taper becoming steeper at the higher impact velocities. Figure VIII-16 shows the post-impact configuration of the Inconel-800 specimens and Figure VIII-17 is a plot of the K values. The K values for the Inconel-800 are less than those for Type 316 stainless-steel but the Inconel-800 apparently can absorb considerably more energy at the higher impact velocities before fracturing.

\section{d. Analytical Model}

The analytical methods developed for determining the post-impact configuration of the reactor system were used on Composite Models No. 1 and 2 to determine how well the analytical approach agrees with the test results. The postimpact analysis of No. 1 indicated that for an impact velocity of $350 \mathrm{ft} / \mathrm{sec}$ the shell would buckle but not rupture. At 600- and 700-ft/sec impact velocities the analysis indicated the shells would rupture but with no damage to the weights, and at an impact velocity of $850 \mathrm{ft} / \mathrm{sec}$ the shells would rupture with a small amount of damage to the weights. For Composite Model No. 1 the analytical prediction of the post-impact configurations agreed very well with the postimpact test results.

The analytical method as applied to Composite Model No. 2 indicated that the models would be completely deformed at all the impact velocities tested. The calculated energy-absorption capacity of the models was approximately $70 \%$ of the impact kinetic energy of the specimens which would indicate that all the components of the models would be completely deformed and the shells ruptured. The test results showed that the shells did not rupture at an impact velocity of $350 \mathrm{ft} / \mathrm{sec}$ and at the higher velocities the shells did rupture but the weights were only $60 \%$ deformed instead of completely deformed as predicted. The reason for the discrepancy between the analytical approach and the test results is most likely that the interaction of the individual components on each other significantly affects the energy-absorption capacity of the system. The close proximity of 


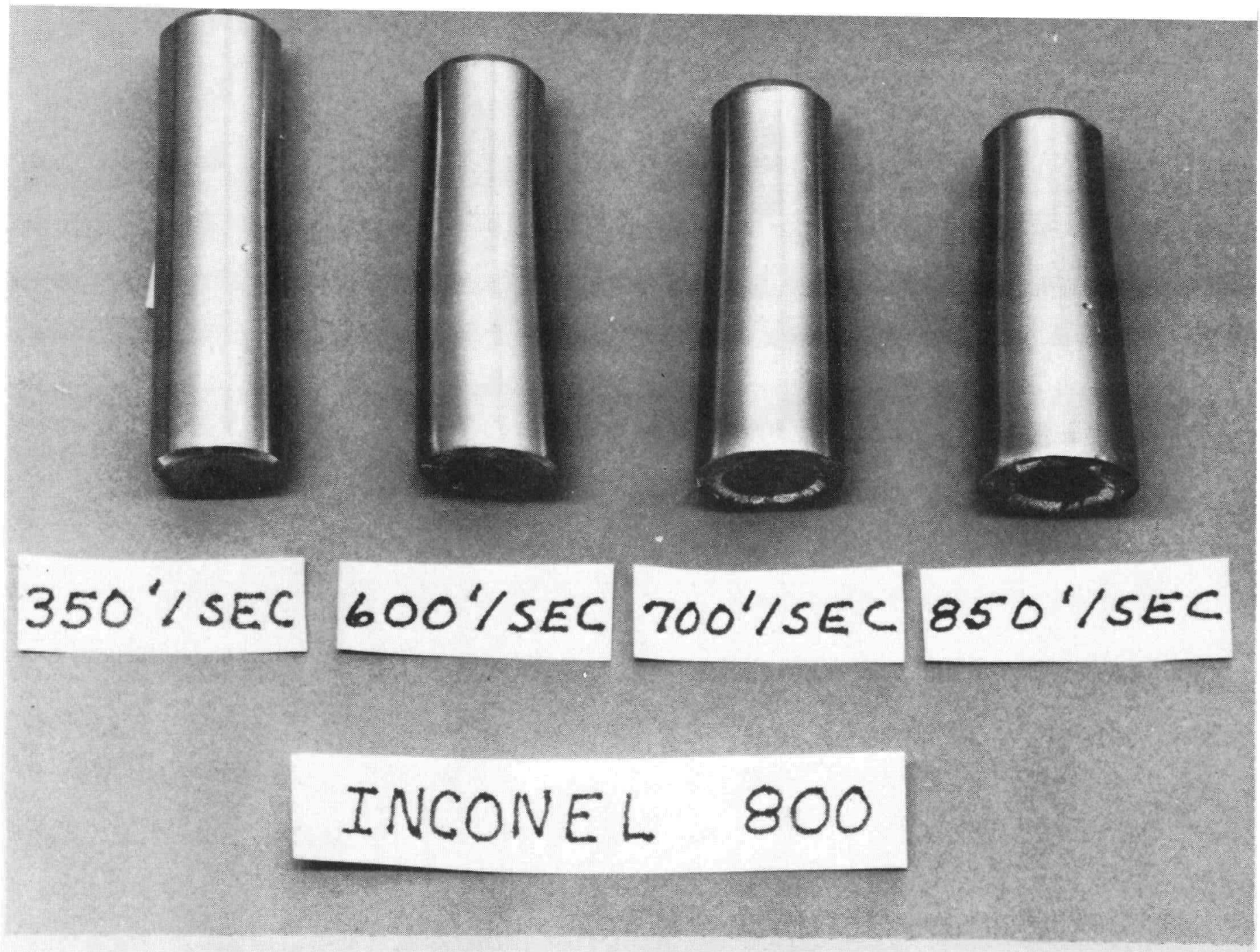




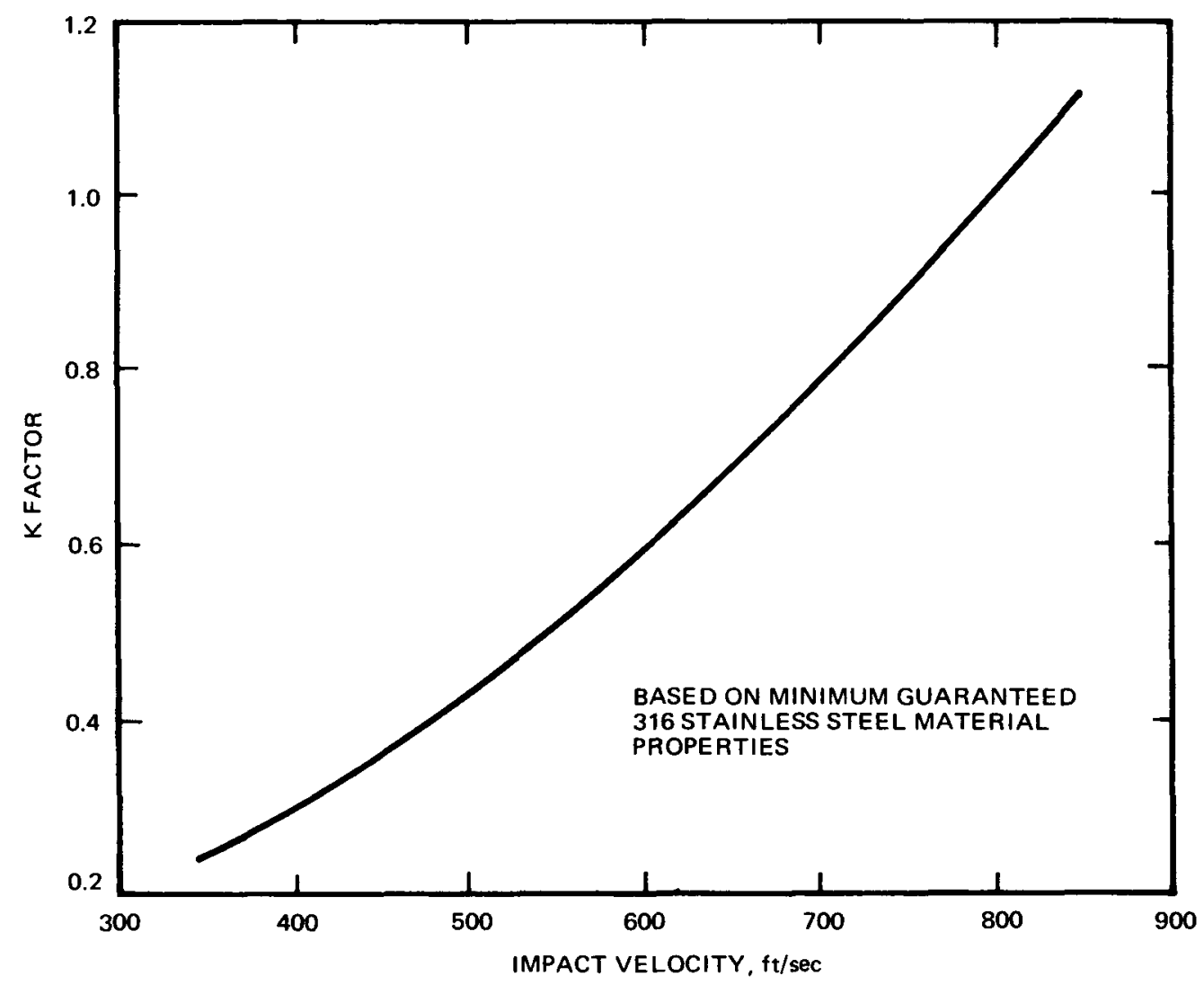

$7759-25211$

Figure VIII-17. K Factors for Inconel-800 Rod

adjoining components can prevent freedom of deformations, change the manner of loading the component, generate friction forces, and change the component effective impact velocity, all of which would affect the $K$ factors.

The analytical model is a useful tool for predicting post-impact deformations and is quite accurate for simple structures, but as the complexity of the structures increases, the uncertainties of the analytical results become greater. With complex structures it appears that scale-model testing is the simplest and most reliable means for predicting the post-impact deformation.

\section{B. INTRINSIC SUBCRITICALITY}

In previous report periods a series of experiments using the SNAPTRAN-1 machine $(8,9)$ to measure prompt-temperature coefficients of reactivity in the presence of burnable poison materials was described. The methodology used for comparing the experimental results with theory was also described. This 
comparison has now been completed. Six configurations were examined. The poison leadings characterized by their cold, measured-reactivity worths were as follows (all with $\mathrm{Ni}$ sleeves):

$\begin{array}{ll}\text { Type 1: } & \$ 0.00 \text { of prepoison } \\ \text { Type 2: } & +\$ 2.71 \text { of } \mathrm{Gd}^{155} \\ \text { Type 3: } & +\$ 5.04 \text { of } \mathrm{Gd}^{155} \\ \text { Type 4: } & +\$ 7.29 \text { of } \mathrm{Gd}^{155} \\ \text { Type S (samarium): } & +\$ 3.22 \text { of } \mathrm{Sm}^{149} \\ \text { Type E (europium): } & +\$ 2.42 \text { of } \mathrm{Eu}^{151}\end{array}$

The configuration with unpoisoned sleeves was analyzed in detail. The prompt-temperature coefficients obtained using APC and APCTC are shown in Figure VIII-18. The two curves labelled "Shaped Calculation (APCTC) 2.05-in. $B e^{\prime \prime}$ and "Flat Calculation (APC) 2.05-in. Be" differ only in that the former includes the correct spatial distribution of transient-energy deposition. It can be seen that the spatial-distribution effect increases the coefficient by about $25 \%$, in agreement with previous estimates. (The "period effect," found to be so significant in the SNAPTRAN experiments, was not an important effect in the se new experiments since reactivity was $\$ 1.30$ or less in all tests.)

For comparison, data using a 3.09-in. Be reflector and only the expansion part of the coefficient are shown. Also displayed are the previous results from the TSN Study. (8) These are of particular interest since those calculations used essentially the same reactor model with a much more cumbersome calculational process and a now-outdated cross-section library. The figure shows excellent agreement between the current "best" calculation (labeled APCTC) and the earlier results, the new data being about $0.01 \not 1^{\circ} \mathrm{F}$ less negative.

The experimental result from the SNAPTRAN-1 and -2 series is also shown (dashed lines). This result was obtained by a bivariant correlation, in the variable temperature and period, of 54 transients run with an unpoisoned core. Although the test conditions varied widely the data correlated with a standard deviation of $\pm 0.015 \mathrm{k} /{ }^{\circ} \mathrm{F}$ as shown in Figure VIII-18. Our new calculations agree with the experiment up to about $600^{\circ} \mathrm{F}$, but above this temperature they fail to reproduce the measured change in coefficient. A cluster of 10 data points was obtained 


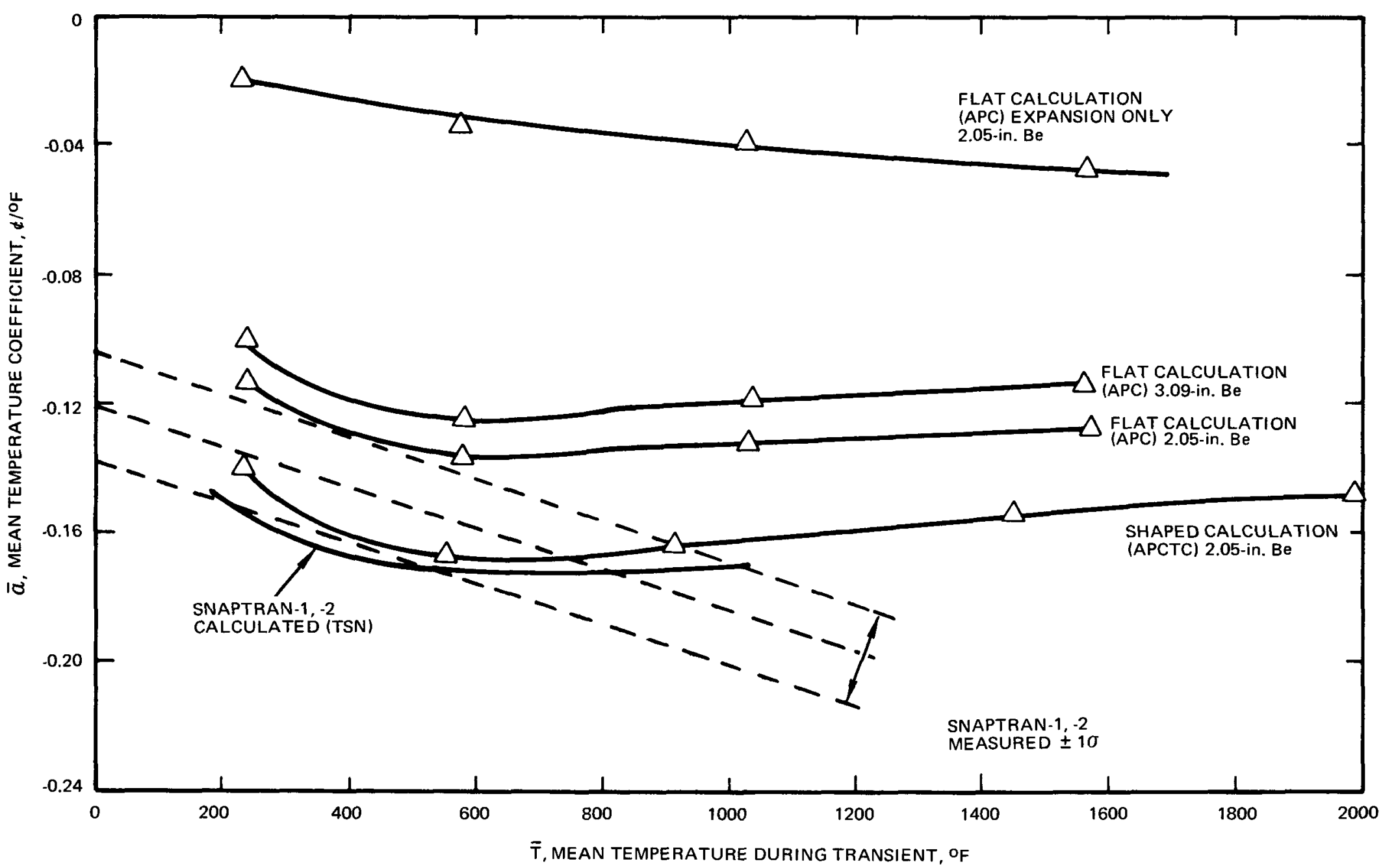

$7759-25212$

Figure VIII-18. Temperature Coefficient of Reactivity, Unpoisoned Reactor with Beryllium Reflector 
in the SNAPTRAN experiments in the range 800 to $1200^{\circ} \mathrm{F}$; hence that portion of the experimental curve is statistically valid.

Figure VIII-19 shows the measured coefficient data for the configurations analyzed. The data points for each type of sleeve are enclosed by a line which indicates the shape of the coefficient-vs-temperature curve which could be inferred from the data. In Figure VIII-20 the unpoisoned and Gd-poisoned data are compared to calculated results. An accuracy analysis indicates that agreement within $0.025 \not /^{\circ} \mathrm{F}$ might be expected, and the agreement in the range 200 to $500^{\circ} \mathrm{F}$ is approximately that. Above $500^{\circ} \mathrm{F}$ the calculated coefficient for the heavily poisoned cases is consistently more positive than the measured data. This is probably indicative of a deficiency in the thermal scattering kernels used in compiling the neutron cross-section data libraries.

Figure VIII-21 shows the same type of comparison with the Sm and Eu poisons. Again, agreement in the range 200 to $500^{\circ} \mathrm{F}$ is acceptable, with the poisoned-coefficient calculation becoming too positive at high temperatures. 


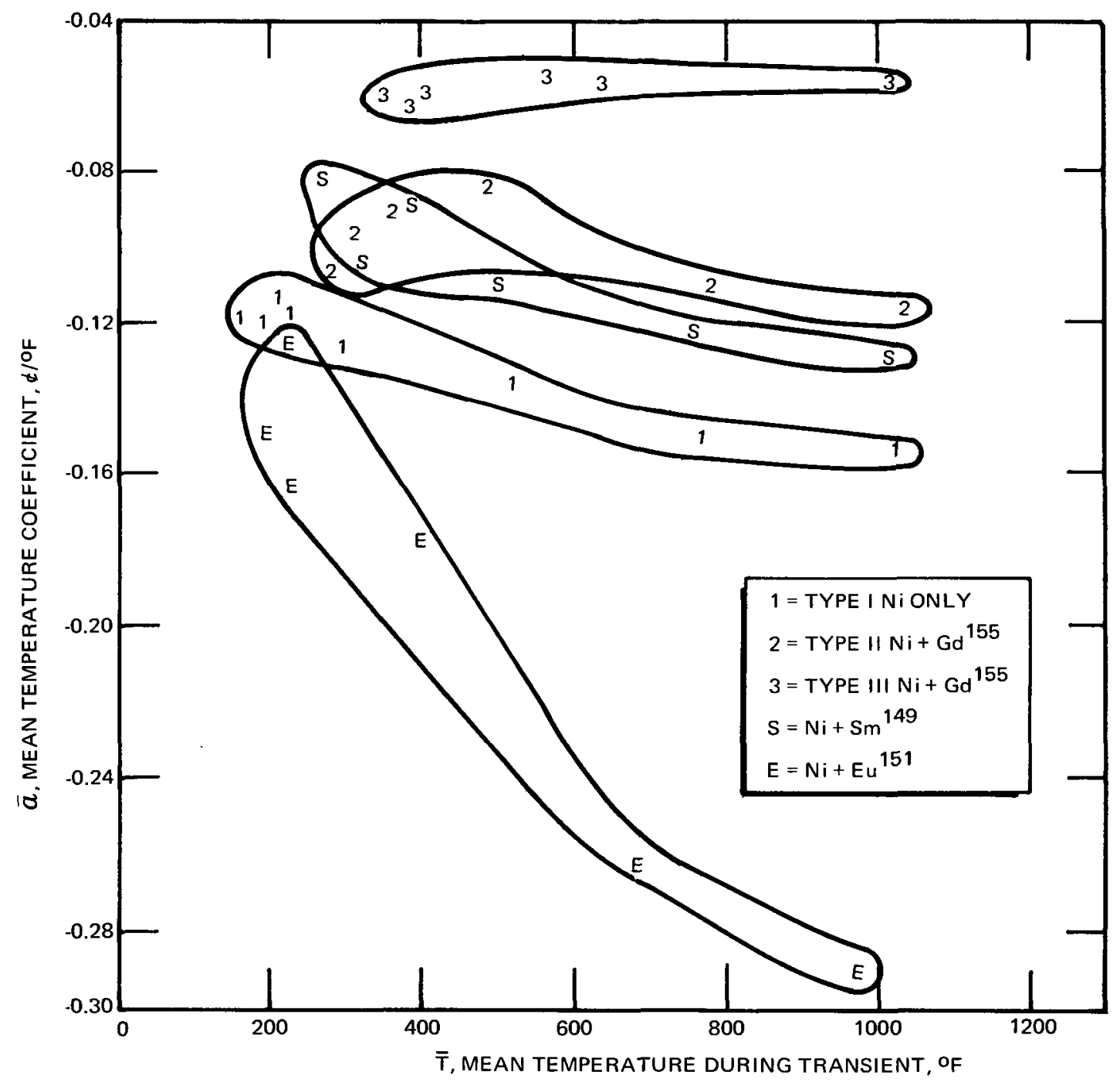

$7759-25213$

Figure VIII-19. Temperature Coefficient of Reactivity Experimental Data 


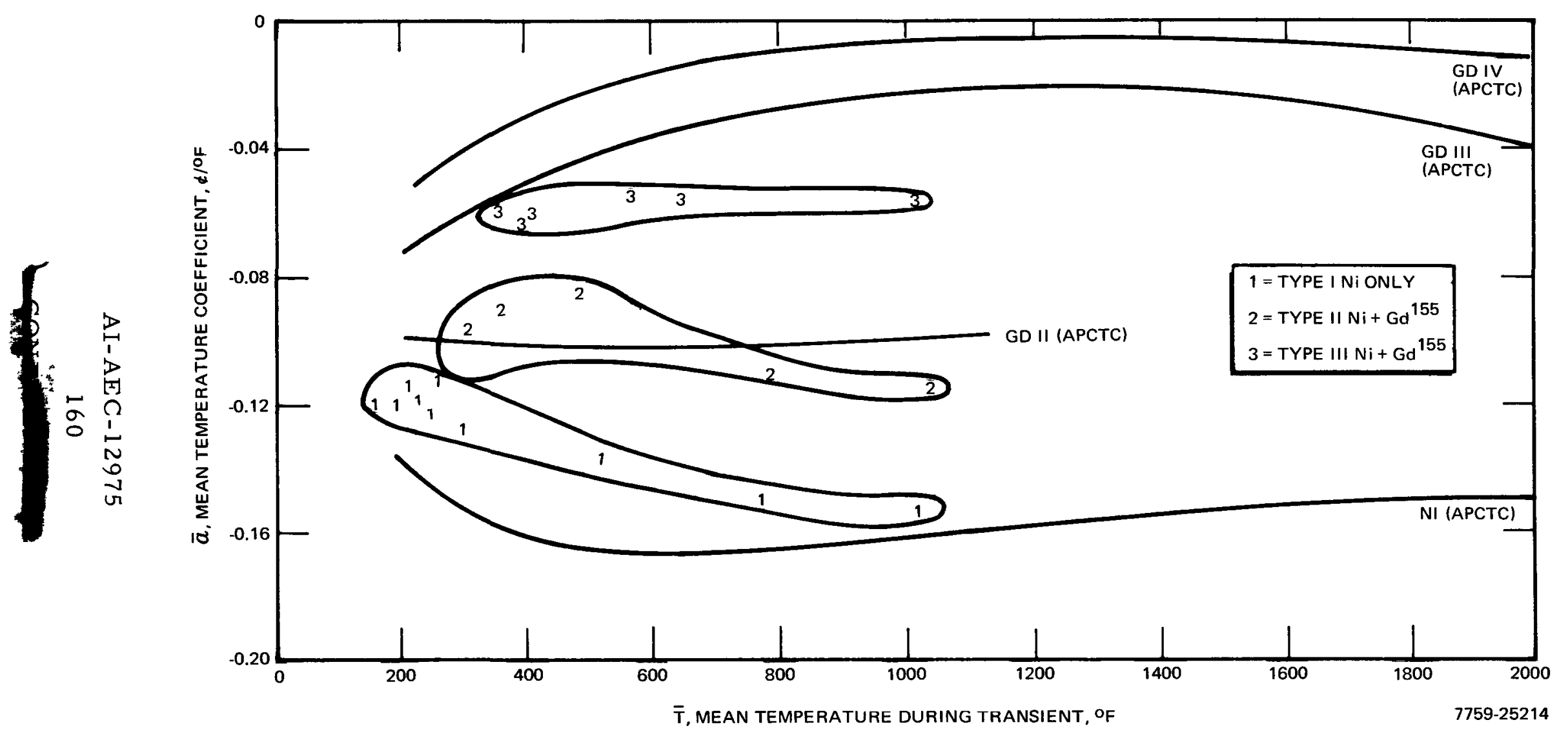

Figure VIII-20. Temperature Coefficient of Reactivity Gadolinium Poison, Theory vs Experiment 


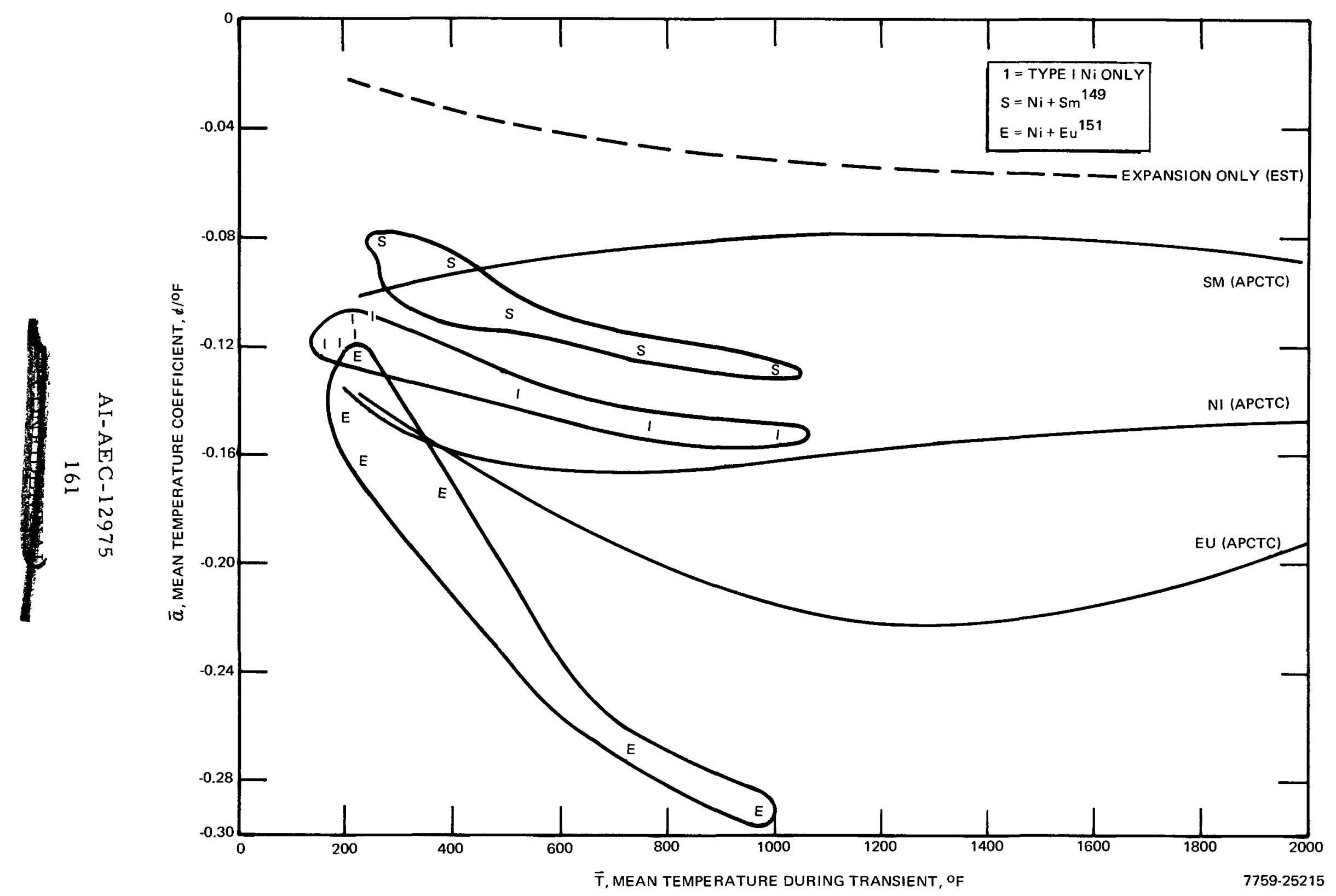

Figure VIII-21. Temperature Coefficient of Reactivity Samarium and Europium Poisons, Theory vs Experiment 


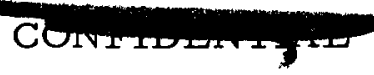

\section{REFERENCES}

1. "SNAP Reactor Programs Progress Report, February-April 1970," AIAEC-12953 (D), July 15, 1970

2. Ibid, $\mathrm{p} 68$

3. "SNAP Reactor Programs Progress Report, August-October 1969," AIAEC-12894 (O), December 30, 1969

4. "SNAP Reactor Programs Progress Report, February-April 1969," AIAEC-12819 (July 25, 1969

5. "SNAP Reactor Programs Progress Report, November 1967 - January 1968," AI-AEC-12641 (March 28, 1968

6. "SNAP Reactor Programs Progress Report, May-July 1969," AI-AEC-12870 September 30, 1969

7. "SNAP Reactor Programs Progress Report, November 1969 - January 1970," AI-AEC-12923 April 1, 1970

8. J. F. Jackson, W. A. Rhoades, and L. I. Moss, "Analysis of SNAPTRAN-1 and -2 Reactor Kinetics Experiments," NAA-SR-11850, North American Aviation, June 26, 1967

9. R. P. Johnson, "SNAPTRAN 10A/2 Kinetics Testing and Destruct Reactor Experiments," NAA-SR-11850, Nor th Ame rican Aviation, July 15, 1966 